University of Louisville

ThinkIR: The University of Louisville's Institutional Repository

Electronic Theses and Dissertations

$12-2018$

\title{
Process-property-microstructure relationships in laser-powder bed fusion of 420 stainless steel.
}

Subrata Deb Nath

University of Louisville

Follow this and additional works at: https://ir.library.louisville.edu/etd

Part of the Biology and Biomimetic Materials Commons, Heat Transfer, Combustion Commons, Manufacturing Commons, and the Metallurgy Commons

\section{Recommended Citation}

Nath, Subrata Deb, "Process-property-microstructure relationships in laser-powder bed fusion of 420 stainless steel." (2018). Electronic Theses and Dissertations. Paper 3074.

https://doi.org/10.18297/etd/3074

This Doctoral Dissertation is brought to you for free and open access by ThinkIR: The University of Louisville's Institutional Repository. It has been accepted for inclusion in Electronic Theses and Dissertations by an authorized administrator of ThinkIR: The University of Louisville's Institutional Repository. This title appears here courtesy of the author, who has retained all other copyrights. For more information, please contact thinkir@louisville.edu. 
PROCESS-PROPERTY-MICROSTRUCTURE RELATIONSHIPS IN LASER-POWDER BED FUSION OF 420 STAINLESS STEEL

\author{
By
}

Subrata Deb Nath

A Dissertation

Submitted to the Faculty of the

J.B. Speed School of Engineering of the University of Louisville in Fulfillment of the Requirements

for the Degree of

\author{
Doctor of Philosophy \\ in Mechanical Engineering \\ Department of Mechanical Engineering \\ University of Louisville \\ Louisville, Kentucky, United States
}

December 2018 


\section{Copyright by Subrata Deb Nath}

November 2018

All rights reserved 

PROCESS-PROPERTY-MICROSTRUCTURE RELATIONSHIPS IN LASER-POWDER BED FUSION OF 420 STAINLESS STEEL

\author{
By \\ Subrata Deb Nath \\ A Dissertation Approved on \\ November 28, 2018 \\ by the following Dissertation Committee
}

Dr. Sundar V. Atre

Dissertation Chairman

Dr. Keng Hsu

Dissertation Member

Dr. Gautam Gupta

Dissertation Member

Dr. Kunal Kate

Dissertation Member 


\section{DEDICATION}

This dissertation is dedicated to my parents

Mrs. Manju Bhowmik

and

Mr. Sunil Chandra Deb Nath

for their endless love, sacrifice and guidance throughout my life 


\section{ACKNOWLEDGEMENT}

First and foremost, I am extremely grateful to my $\mathrm{PhD}$ supervisor, Prof. Sundar V. Atre, Endowed Chair of Manufacturing and Materials, University of Louisville, for his invaluable mentorship and friendship throughout this journey. He constantly motivated me to remain focused on achieving my goal. His in-depth observations and suggestions helped me to establish the overall direction of the research and to move forward in an organized manner. He offered endless patience and support that contributed to my growth as a human being with an exemplary professionalism. I also express my sincerest gratitude to Mrs. Atre, Rachna Malik, for her inspiration and valuable advice.

I greatly acknowledge my PhD committee members, Prof. Keng Hsu, Prof. Gautam Gupta and Prof. Kunal Kate, for their time and valuable feedback in my research, especially in the proposal defense. My sincerest gratitude goes to Prof. Randall M. German, worldrenowned expert in powder metallurgy, who has been an inspiring figure to me. I humbly appreciate Dr. Martin Kearns and Mary Kate Johnson from Sandvik Osprey for providing the raw materials and valuable insights in the manuscripts during my research. I would like to thank Prof. Gilles L'Espérance from Polytechnique Montréal, for his extensive support in the microstructure study. The sabbatical visit of Prof. Ozkan Gulsoy from Marmara University, Turkey, was very helpful to advance my research. I highly appreciate the collaboration with Prof. Ajay Malshe from the University of Arkansas, to implement my research outcomes in biomimetic applications. I would also like to thank Dr. Gerald Grant, 
Professor at the UofL School of Dentistry, for his support in the microCT-3D printing project. I am grateful to Joyce Yeung, Director of Marketing of GE Concept Laser, for giving me the opportunity to work in the surgical tools project.

I am sincerely grateful to the Dept. of Mechanical Engineering, Walmart Foundation and NASA FabLab for their support in my PhD study. I highly appreciate the logistical support from the faculty and staff in Dept. of Mechanical Engineering, School of Interdisciplinary and Graduate Studies, and International Center. I would like to thank James Adams, President of Metal Powders Industries Federation, and his team for the support to participate in several international conferences. I appreciate the opportunity from Moldex3D team in Michigan, US to learn injection molding software to use in my research. My gratitude extends to Prof. Kevin Murphy, Prof. Robert Keynton, Prof. Kevin Walsh, Prof. Thomas Berfield, Prof. Roger Bradshaw and Dr. Jacek Jasinski (University of Louisville), Magnus Ahlfors and Craig Beaumier (Quintus Technologies), Matthew Bulger (NetShape Technologies), Dr. Paul Gangopadhyay (Metal Powder Products), Dr. Samuel Dilip (HP Labs) and Rajendra Kelkar (GE Additive). I also greatly appreciate the support from colleagues Dr. Harish Irrinki, Paramjot Singh, Chang Woo Gal, Anagh Deshpande, Alexander Gupta, Emma Clinning, Abdullah Abdulmogith and Victor Papyshev.

Not but not least, I am deeply thankful to my relatives and friends, my parents, Manju Bhowmik and Sunil Chandra Deb Nath, to my sister, Swapna Nath, and brother, Sudipta Deb Nath for supporting me spiritually throughout my life. This last word of acknowledgment I have saved for my dear wife, Ruponti Nath, who has been with me all these years with great love and joy. 


\begin{abstract}
PROCESS-PROPERTY-MICROSTRUCTURE RELATIONSHIPS IN

LASER-POWDER BED FUSION OF 420 STAINLESS STEEL
\end{abstract}

Subrata Deb Nath

November 18, 2018

Laser-powder bed fusion (L-PBF) is an additive manufacturing technique for fabricating metal components with complex design and customized features. However, only a limited number of materials have been widely studied using L-PBF. AISI 420 stainless steel, an alloy with a useful combination of high strength, hardness, and corrosion resistance, is an example of one such material where few L-PBF investigations have emerged to date. In this dissertation, L-PBF experiments were conducted using 420 stainless steel powders to understand the effects of chemical composition, particle size distribution and processing parameters on ensuing physical, mechanical and corrosion properties and microstructure in comparison to wrought and metal injection molding (MIM). The density of the fabricated specimens increased, and their surface roughness decreased as the layer thickness and median particle size was decreased and energy density was increased. Following heat treatment, the ultimate tensile strength and elongation of L-PBF specimens 
with $\mathrm{Nb}(1.2 \%)$ and $\mathrm{Mo}(0.57 \%)$ improved to $1750 \pm 30 \mathrm{MPa}$ and $9.0 \pm 0.2 \%$, which were higher than the previously reported values in L-PBF, MIM and wrought 420 stainless steel. Tempering of martensite during heat treatment and nanoscale $\mathrm{NbC}$ precipitation were consistent with improvement in properties. L-PBF specimens fabricated with deagglomerated fine powder $\left(\mathrm{D}_{50}: 12 \mu \mathrm{m}\right)$ exhibited similar spreadability, mechanical properties and microstructure to specimens fabricated with coarse powder ( $\left.\mathrm{D}_{50}: 28 \mu \mathrm{m}\right)$. In the presence of $\mathrm{Nb}(1.2 \%)$ and $\mathrm{Mo}(0.57 \%)$, corrosion properties improved over wrought 420 stainless steel. 


\section{TABLE OF CONTENTS}

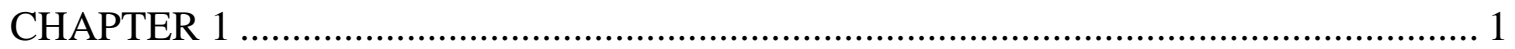

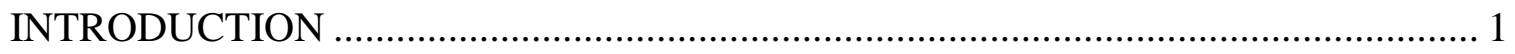

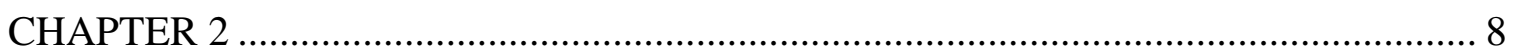

MICROSTRUCTURE-PROPERTY RELATIONSHIPS OF 420 STAINLESS STEEL OF FABRICATED BY LASER-POWDER BED FUSION ........................................... 8

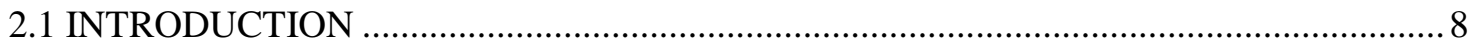

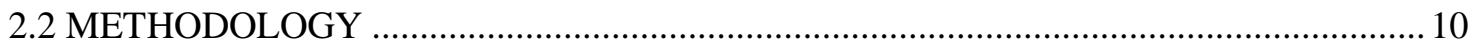

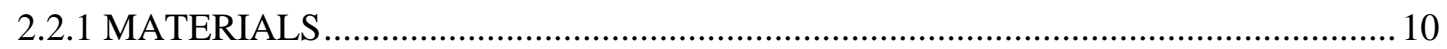

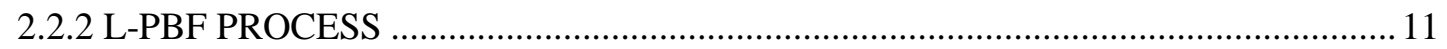

2.2.3 HEAT TREATMENT ........................................................................................ 11

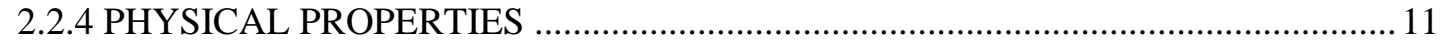

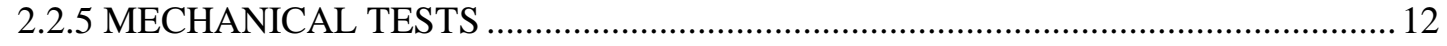

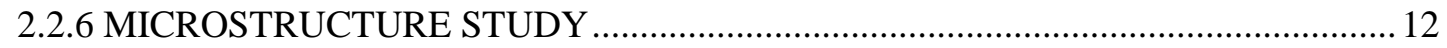

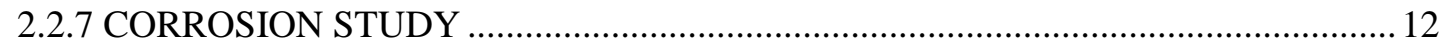

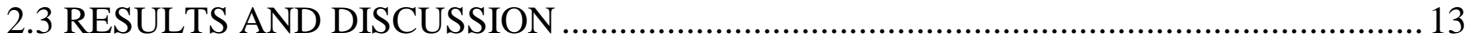

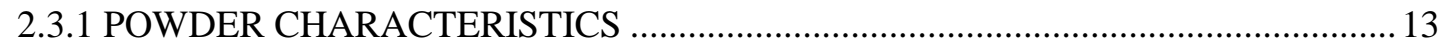

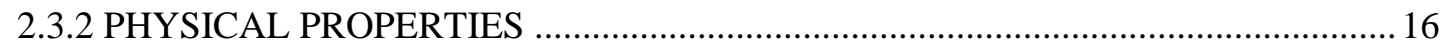

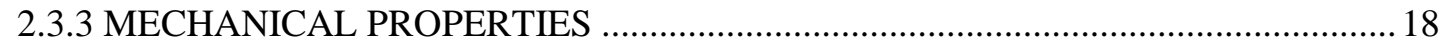

2.3.4 PHASE TRANSFORMATION ……………………………………………........ 19

2.3.5 CORROSION PROPERTIES ………………………………………….... 23

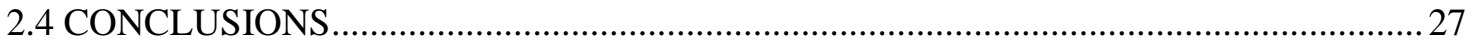

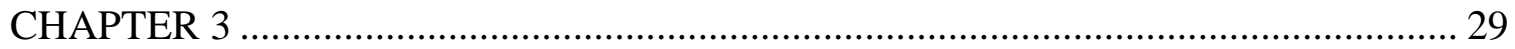

EFFECTS OF LAYER THICKNESS IN LASER-POWDER BED FUSION OF 420

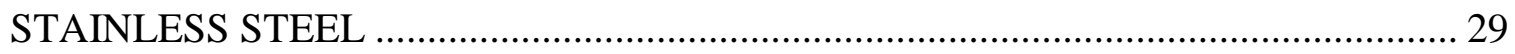

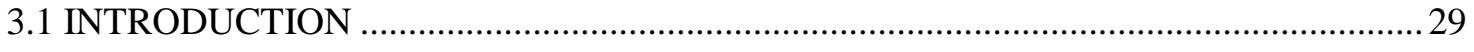

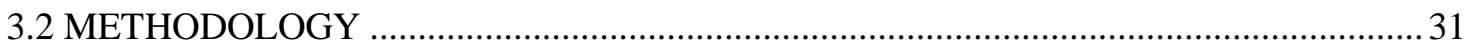

3.2.1 MATERIALS

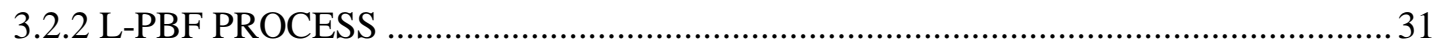

3.2.3 HEAT TREATMENT ................................................................................ 31 


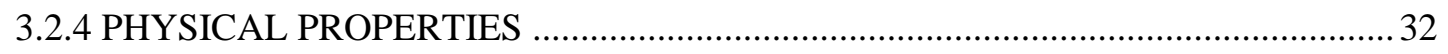

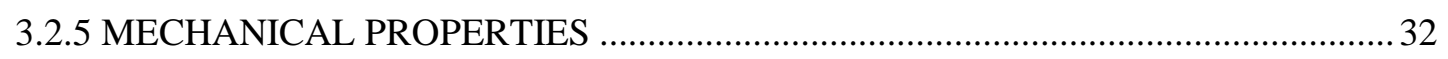

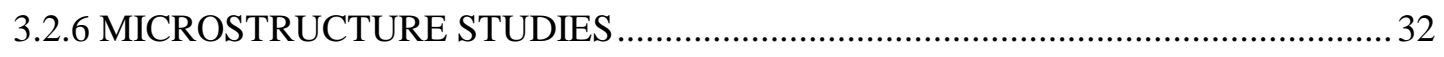

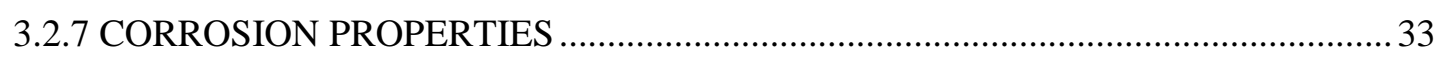

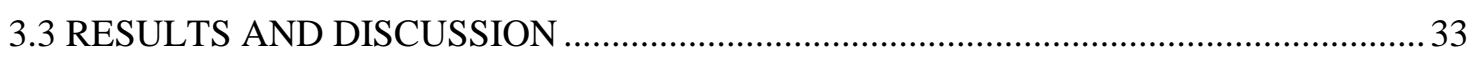

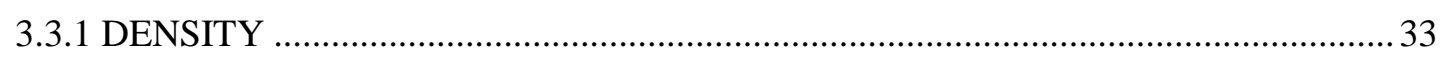

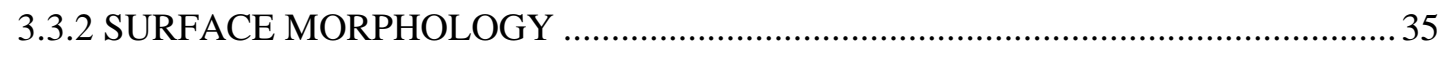

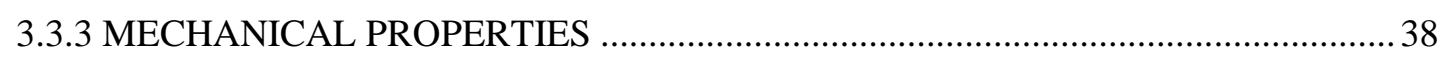

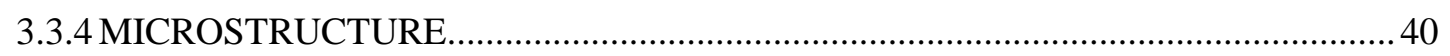

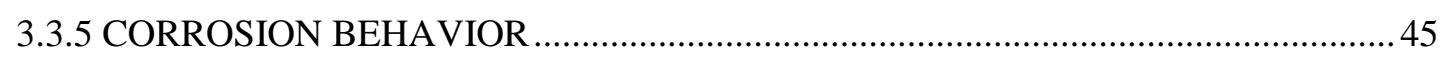

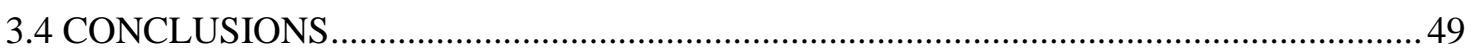

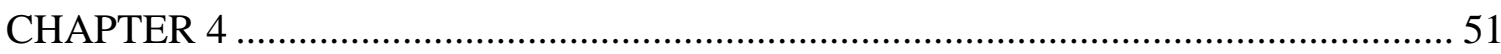

EFFECTS OF NIOBIUM AND MOLYBDENUM ON THE PROPERTIES AND MICROSTRUCTURE OF 420 STAINLESS STEEL PROCESSED BY LASER-

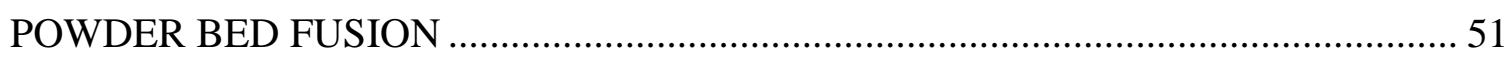

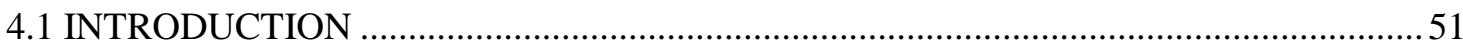

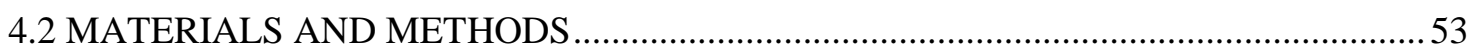

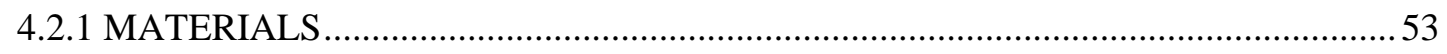

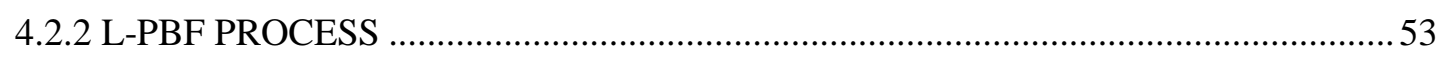

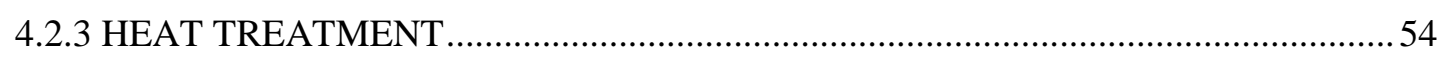

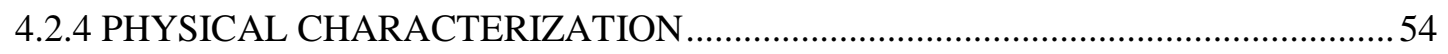

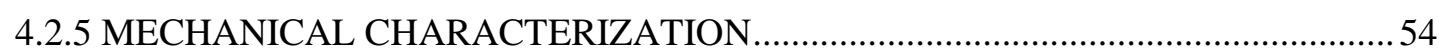

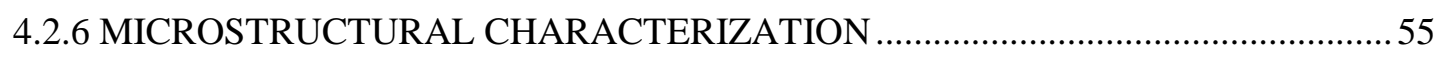

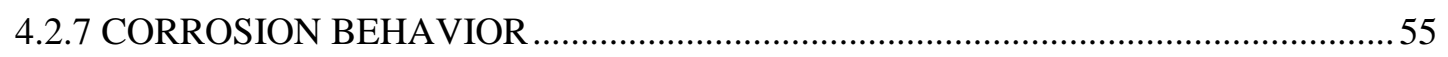

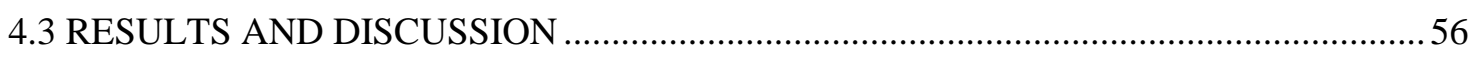

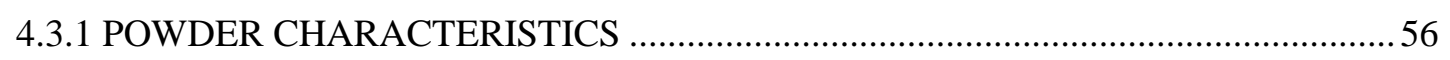

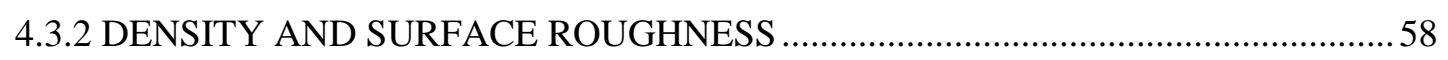

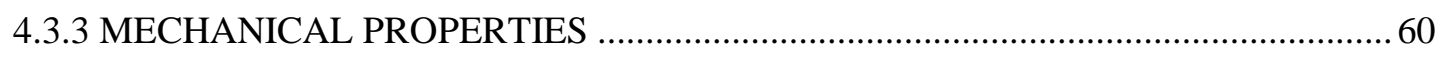

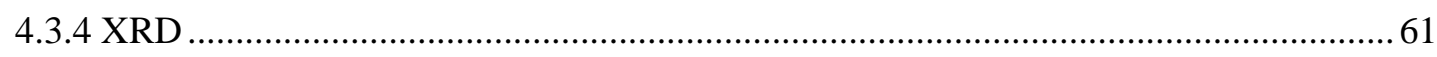

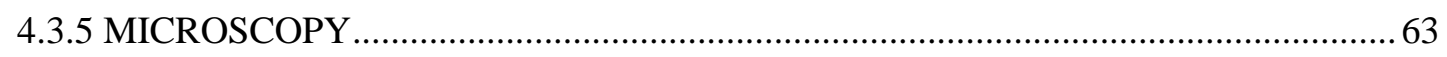

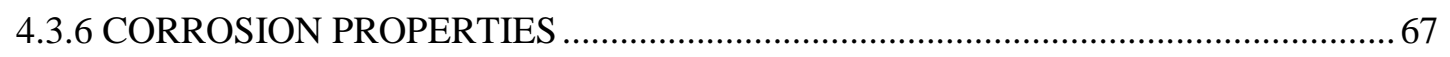

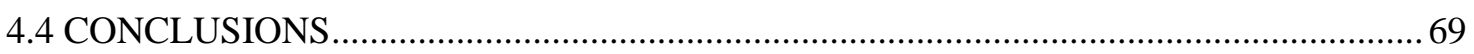

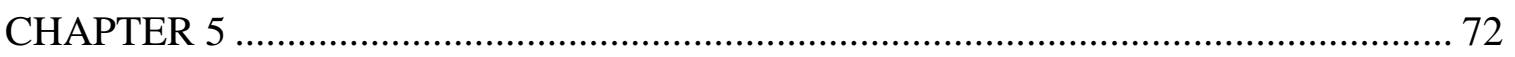

EFFECTS OF PARTICLE SIZE DISTRIBUTION ON THE LASER-POWDER BED

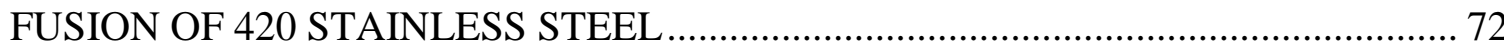




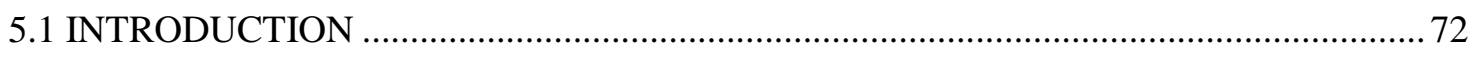

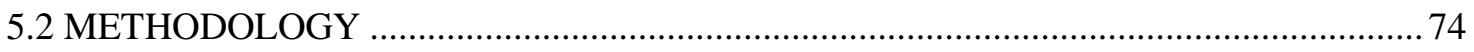

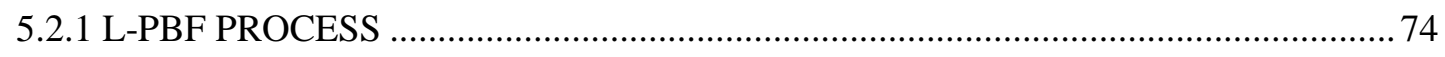

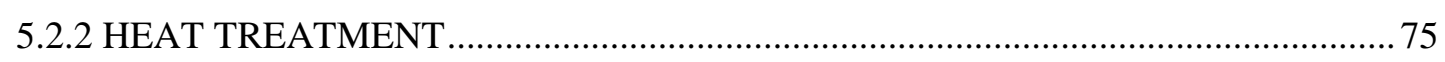

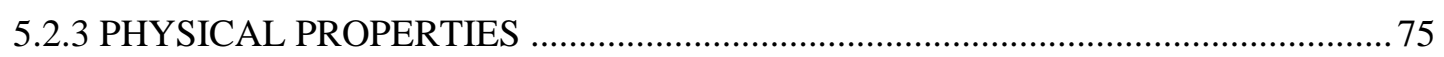

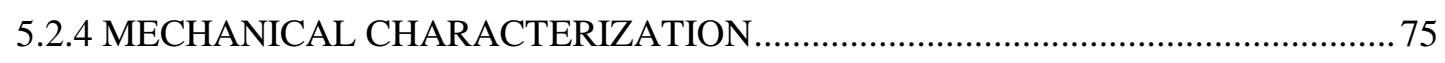

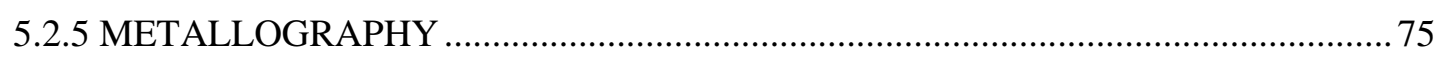

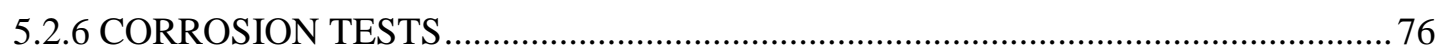

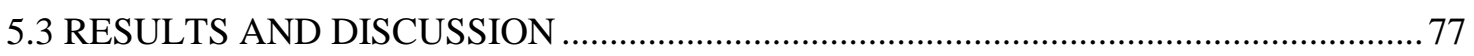

5.3.1 POWDER ATTRIBUTES AND IMPROVEMENT OF SPREADABILITY ............... 77

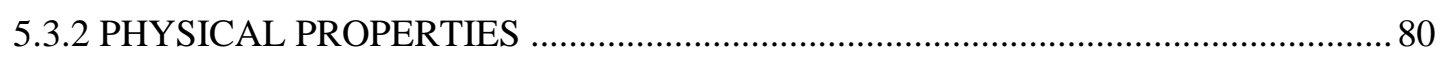

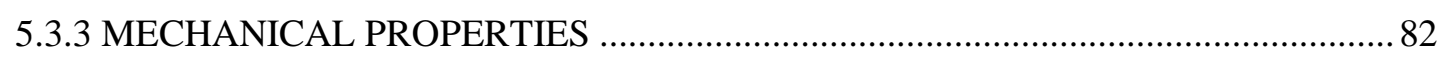

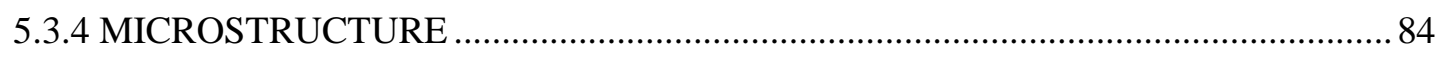

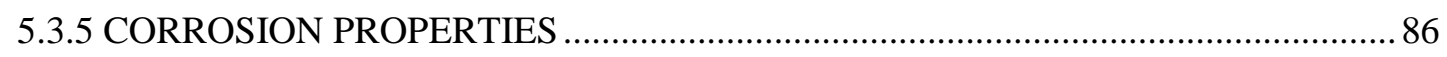

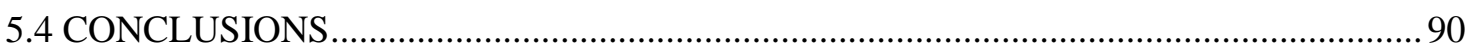

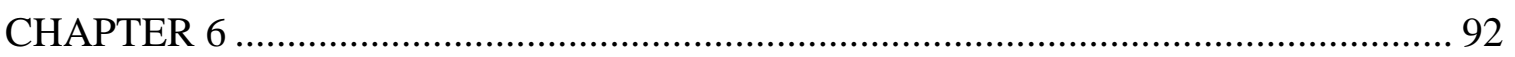

CONCLUSIONS AND FUTURE WORK ............................................................ 92

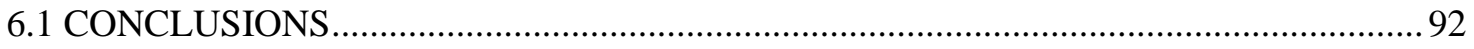

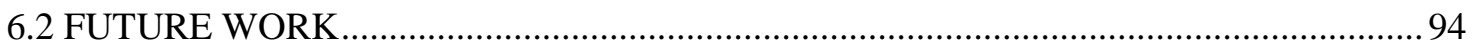

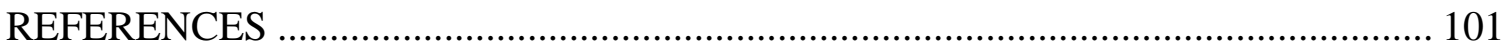

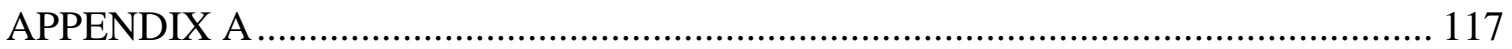

POWDER CHARACTERISTICS OF 420 STAINLESS STEEL .............................. 117

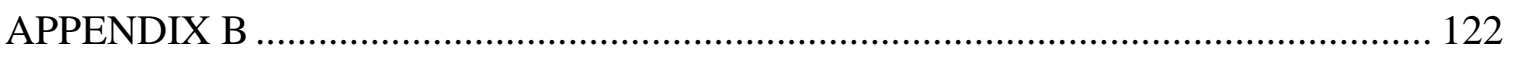

PHYSICAL PROPERTIES OF 420 STAINLESS STEEL FABRICATED BY LASERPOWDER BED FUSION BY VARYING LAYER THICKNESS, CHEMICAL COMPOSITION AND PARTICLE SIZE DISTRIBUTION ................................... 122

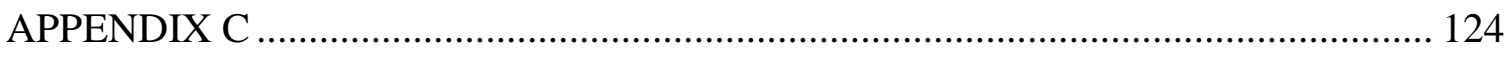

MECHANICAL PROPERTIES OF 420 STAINLESS STEEL FABRICATED USING L-PBF BY VARYING LAYER THICKNESS, CHEMICAL COMPOSITION AND

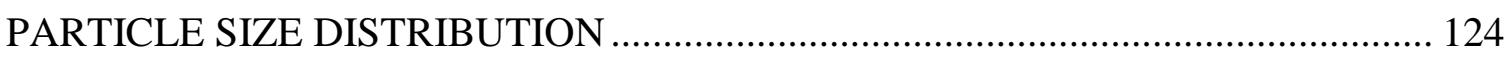

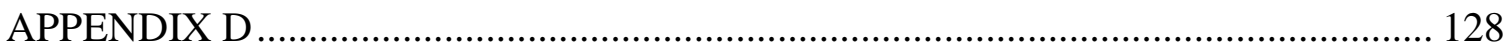

CORROSION PROPERTIES OF 420 STAINLESS STEEL FABRICATED USING LPBF BY VARYING LAYER THICKNESS, CHEMICAL COMPOSITION AND PARTICLE SIZE DISTRIBUTION ................................................................. 128

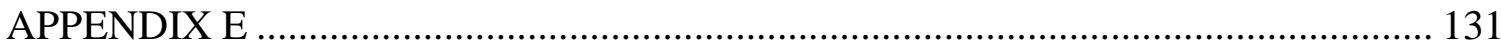


MICROSTRUCTURE OF 420 STAINLESS STEEL FABRICATED BY LASERPOWDER BED FUSION VARYING LAYER THICKNESS, CHEMICAL COMPOSITION AND PARTICLE SIZE DISTRIBUTION …….................................. 131

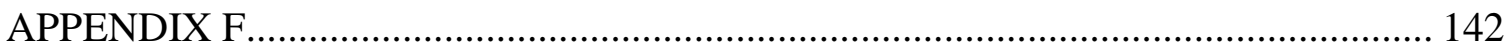

FEASIBILITY STUDIES OF 420 STAINLESS STEEL FABRICATED BY L-PBF .. 142

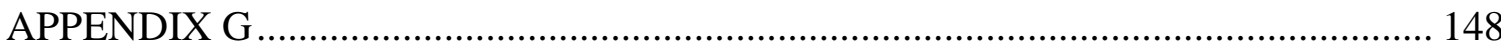

EFFECTS OF ATOMIZATION ATMOSPHERE ON PROPERTIES AND MICROSTRCTURE OF 420 STAINLESS STEEL PROCESSED BY L-PBF.............. 148

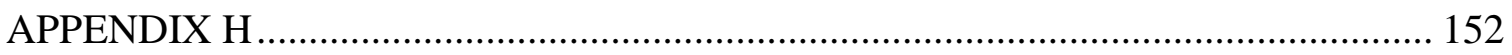

L-PBF OF 420 STAINLESS STEEL INFILTRATED WITH BRONZE ....................... 152

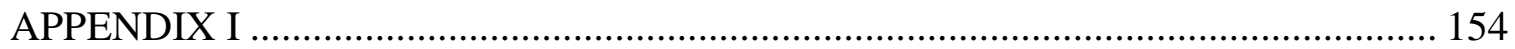

CONFERENCE PAPER ON APPLICATIONS OF L-PBF 420 STAINLESS STEEL PRESENTED AT AMPM 2017 IN LAS VEGAS, NV ............................................. 154

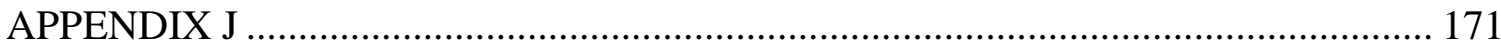

EXLORING SNAKE-SKIN-INSPIRED TEXTURE DESIGNS FOR 3-D PRINTING 171

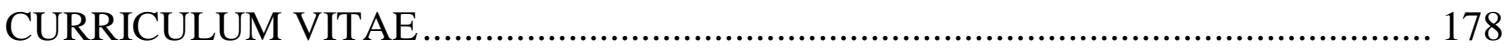




\section{LIST OF TABLES}

Table 1.1 Physical and mechanical properties of 420 stainless steel fabricated by additive manufacturing processes found in literatures. 3

Table 2. 1 Powder characteristics of nitrogen-atomized AISI 420 stainless steel powder 13 Table 2. 2 Chemical composition of nitrogen-atomized AISI 420 stainless steel powder 14 Table 2.3 Mechanical properties of L-PBF 420 stainless steel fabricated at an energy

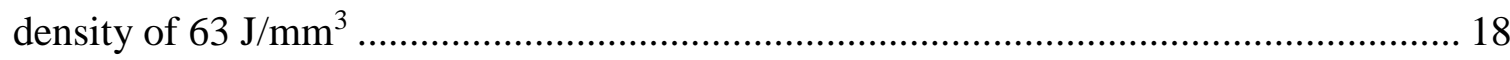

Table 2.4 Corrosion parameters of L-PBF 420 stainless steel in $3.5 \% \mathrm{NaCl}$ solution ..... 25

Table 3.1 L-PBF processing conditions used with AISI 420 stainless steel powder........ 34

Table 3.2 Top surfaces of L-PBF 420 stainless steel parts of varying layer thickness

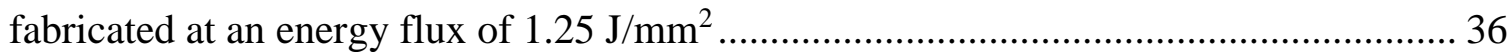

Table 3.3 Mechanical properties of L-PBF 420 stainless steel fabricated by varying layer

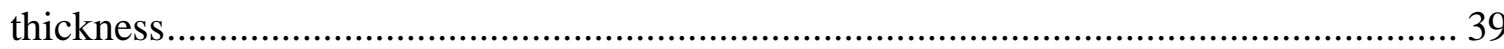

Table 4.1 Chemical composition of AISI 420 stainless steel powders ........................... 56

Table 4.2 Powder characteristics of AISI 420 stainless steel powders used in this study 57

Table 4. 3 Mechanical properties of L-PBF 420 stainless steel containing Nb and Mo... 60

Table 4.4 Corrosion properties of L-PBF 420 stainless steel with and without $\mathrm{Nb}$ and Mo.

Table 5. 1 Chemical composition of the as-received AISI 420 stainless steel powders... 77

Table 5.2 Powder attributes of nitrogen-atomized AISI 420 stainless steel powders ...... 78 
Table 5. 3 Mechanical properties of L-PBF 420 stainless steel using fine powder ( ${ }_{50}: 12$ $\mu \mathrm{m})$ 82

Table 5.4 Corrosion parameters of 420 stainless steel in $3.5 \% \mathrm{NaCl}$ solution fabricated by

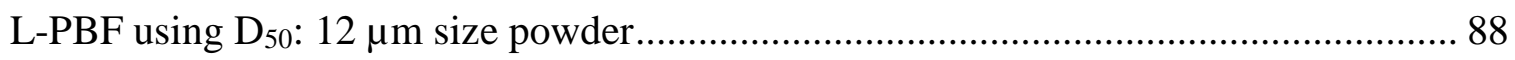




\section{LIST OF FIGURES}

Figure 1.1 Additive manufacturing for tooling offers new possibilities and challenges to

the engineers, researchers and entrepreneurs...................................................... 1

Figure 1.2 An ultimate tensile strength-hardness chart to show mechanical properties of AISI 420 stainless steel in comparison with other tooling materials. Properties can be attributed to the present martensite (body centered tetragonal) and austenite (face centered cubic) phases in microstructure depending on thermal processing.................... 2

Figure 1.3. A schematic representation of L-PBF showing key process parameters. ........ 2

Figure 1.4 Intergranular and pitting corrosion on the as-polished surface of hardened 420 stainless steel obtained by optical microscopy. Electrochemical corrosion test was conducted in $3.5 \%$ of $\mathrm{NaCl}$ solution. Operating condition- reference electrode: $\mathrm{Ag} / \mathrm{AgCl}$; cathode: Pt wire; $\mathrm{pH}=6.0$; scan rate: $0.01 \mathrm{Vs}^{-1}$

Figure 2.1 Particle size distribution and SEM images of nitrogen gas atomized AISI 420

stainless steel powder 13

Figure 2.2 Part density vs energy density chart from L-PBF experiments with nitrogen atomized AISI 420 stainless steel. The wrought density of $7.74 \mathrm{~g} / \mathrm{cc}$ was used to calculate relative density. 15

Figure 2.3 Optical microscopy of L-PBF parts of 420 stainless steel at (a) center of part in the print direction, low magnification, (b) center of part in the print direct, high magnification, and (c) the top of part, in the build direction. The scanning electron microscopy of the top view of parts is also shown (d). 17 
Figure 2.4 XRD pattern of as-printed and heat-treated L-PBF parts printed at an energy density of $63 \mathrm{~J} / \mathrm{mm}^{3}$ with $\mathrm{D}_{50}: 28 \mu \mathrm{m}$ sized 420 stainless steel powders. The XRD data of the initial powder are also shown for comparison. 20

Figure 2.5 Microstructures in the build direction of as-printed (a and b) and heat-treated (c and d) 420 stainless steel tensile bars fabricated by L-PBF. The images were collected after polishing with $1 \mu \mathrm{m}$ diamond paste followed by etching with Kalling reagent II... 21 Figure 2.6 Microstructures in the scan direction of as-printed (a and b) and heat-treated (c and d) 420 stainless steel tensile bars fabricated by L-PBF. 22 Figure 2.7 SEM images in the top row represent the microstructure of as-printed 420 stainless steel at three different magnifications. The microstructure of the heat-treated LPBF parts can be observed in the bottom row. 23 Figure 2.8 Linear sweep voltammetry (LSV) curves for as-printed and heat-treated LPBF 420 stainless steel in aerated aqueous solution containing $3.5 \mathrm{wt} \%$ of $\mathrm{NaCl}$. Operating condition- reference electrode: $\mathrm{Ag} / \mathrm{AgCl}$; cathode: $\mathrm{Pt}$ wire; scan rate: 0.01 ... 24 Figure 2.9 Optical images of as-printed (left column) and heat-treated (right column) 420 stainless steel parts fabricated by L-PBF: (top) initial surface (middle) corroded surface, and (bottom) pits on the corroded surface at higher magnification. 26 Figure 3.1 (a) The variation of part density as a function of energy flux from L-PBF experiments with AISI 420 stainless steel. (b) ANOVA analysis showing the influence of laser power, scan speed, trace width and layer thickness on the density of L-PBF parts. 34 Figure 3.2 Scanning electronic microscopic images of the top surface of L-PBF 420 stainless steel parts varying layer thickness fabricated at an energy flux of $1.25 \mathrm{~J} / \mathrm{mm}^{2} .36$ 
Figure 3.3 Polished cross-sectional images at top and center region where layer thickness was varied during printing of 420 stainless steel. Cross sections were taken parallel to build direction. Images were taken at 100X magnification.

Figure 3.4 XRD patterns of as-printed and heat-treated L-PBF parts printed varying layer thickness of 10, 20 and $30 \mu \mathrm{m}$ with 420 stainless steel powders. The martensite and austenite peaks are labelled as $\alpha$ and $\gamma$, respectively. 40

Figure 3.5 Microstructures in the build direction of as-printed L-PBF 420 stainless steel parts varying layer thickness at 10, 20 and $30 \mu \mathrm{m}$ through optical microscopy. The images were collected after polishing with $1 \mu \mathrm{m}$ diamond paste followed by etching with Kalling II reagent. 41

Figure 3.6 Microstructures through optical microscopy in the build direction of heattreated L-PBF 420 stainless steel parts varying layer thickness of 10, 20 and $30 \mu \mathrm{m}$. The images were collected after etching with Kalling II reagent. 43

Figure 3.7 As-etched microstructures in the build direction of the as-printed and heattreated L-PBF 420 stainless steel fabricated by varying layer thickness.

Figure 3.8 Linear sweep voltammetry (LSV) curves for as-printed and heat-treated LPBF 420 stainless steel varying layer thickness at 10, 20 and $30 \mu \mathrm{m}$ in aerated aqueous solution containing 3.5 wt $\%$ of $\mathrm{NaCl}$. Operating condition- reference electrode: $\mathrm{Ag} / \mathrm{AgCl}$; cathode: $\mathrm{Pt}$ wire; $\mathrm{pH}=6.0$; scan rate: 0.01 . 45 Figure 3.9 Corrosion properties such as a) corrosion current, b) corrosion potential, c) polarization resistance and d) corrosion current of L-PBF 420 stainless steel varying layer thickness at 10, 20 and $30 \mu \mathrm{m}$ in as-printed and heat-treated condition. 46 
Figure 3.10 Optical images of corrosion pits observed after linear sweep voltammetry experiments on the as-printed and heat-treated L-PBF part varying layer thickness at 10,

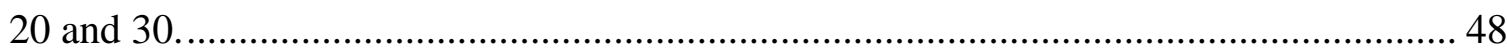

Figure 4.1 Particle size distribution (left) and SEM images (right) of nitrogen atomized AISI 420 stainless steel powders with and without $\mathrm{Nb}$ and Mo................................... 58

Figure 4.2 The variation in relative density (left) and surface roughness (right) as a function of energy density for 420 stainless steel powders with (red) and without (blue)

$\mathrm{Nb}$ and $\mathrm{Mo.}$ 59

Figure 4.3 As polished cross-sectional images at low (50X) and high (1000X) magnifications of L-PBF parts of 420 stainless steels with and without $\mathrm{Nb}$ and Mo. Cross sections were taken parallel to the build direction for samples fabricated at $63 \mathrm{~J} / \mathrm{mm}^{3} \ldots 60$ Figure 4.4 Representative XRDs of 420 stainless steel powder with $\mathrm{Nb}$ and Mo and asprinted and heat-treated L-PBF specimens fabricated at an energy density of $63 \mathrm{~J} / \mathrm{mm} 3$. An ICDD database was used to analyze the observed peaks.

Figure 4.5 Optical micrographs in the build and scan direction of as-printed and heattreated L-PBF 420 stainless steel specimens with $\mathrm{Nb}$ and Mo. All samples were fabricated at an energy density of $63 \mathrm{~J} / \mathrm{mm}^{3}$, polished to $1 \mu \mathrm{m}$, and etched with Kalling II reagent....... 63 Figure 4.6 Optical micrographs in the build and scan direction of the as-printed and heattreated L-PBF 420 stainless steel specimens containing Nb and Mo. All samples were fabricated at $63 \mathrm{~J} / \mathrm{mm}^{3}$, polished to $0.05 \mu \mathrm{m}$, and etched with Fry's reagent. 64 Figure 4.7 SEM images of microstructure in the build direction of as-printed and heattreated L-PBF 420 stainless steel specimens containing $\mathrm{Nb}$ and Mo are shown in the top 
row. All samples were fabricated at $63 \mathrm{~J} / \mathrm{mm}^{3}$ and etched with Fry's reagent. Then EDS analysis show that distribution of $\mathrm{Nb}, \mathrm{Mo}, \mathrm{Mn}, \mathrm{Si}, \mathrm{Cr}$ and $\mathrm{C}$ in the microstructure are homogenous for both the as-printed and heat-treated specimens.

Figure 4.8 Microstructures through optical microscopy in the build direction of as-printed and heat-treated L-PBF 420 stainless steel specimens with $\mathrm{Nb}$ and Mo. 66 Figure 4.9 Plots of current density v/s voltage for as- printed (left) and heat-treated (right) L-PBF 420 stainless steel containing Nb and Mo. Experiments were performed in a 3.5\% $\mathrm{NaCl}$ aqueous solution. Operating condition- reference electrode: $\mathrm{Ag} / \mathrm{AgCl}$; cathode: $\mathrm{Pt}$ wire; $\mathrm{pH}=6.0$; scan rate: $0.01 \mathrm{mV}-\mathrm{s}^{-1}$

Figure 4.10 Microstructures through optical microscopy in the build direction of heattreated L-PBF 420 stainless steel parts specimens with and without $\mathrm{Nb}$ and Mo. 69 Figure 5.1 SEM images of nitrogen gas atomized AISI 420 stainless steel powder of $\mathrm{D}_{50}$ : $12 \mu \mathrm{m}$ are shown in (a) and (b) before and (c) and (d) after sieving and powders with D50: $28 \mu \mathrm{m}$ are shown in (e) and (f). 79

Figure 5.2 (a) Relative density and (b) surface roughness of L-PBF parts using AISI 420 stainless powders of $\mathrm{D}_{50}: 12 \mu \mathrm{m}$ and $\mathrm{D}_{50}: 28 \mu \mathrm{m}$ were plotted against energy density ranged from 28 to $75 \mathrm{~J} / \mathrm{mm}^{3}$. The density of L-PBF parts was measured by the Archimedes method 80 Figure 5.3 Optical images in the build direction of as-printed L-PBF parts of nitrogenatomized 420 stainless steel powders with median particle sizes of $12 \mu \mathrm{m}$ and $28 \mu \mathrm{m} . . .81$ Figure 5.4 XRD data of as- printed and heat-treated L-PBF parts printed at $63 \mathrm{~J} / \mathrm{mm} 3$ with the two 420 stainless steel powders. The XRD data of the initial powders are also shown for comparison. 
Figure 5.5 Microstructures of as-printed tensile bars fabricated by L-PBF using fine (a and c) and coarser (b and d) 420 stainless steel powders. The images are in the build (top) and scan (bottom) directions after polishing with $1 \mu \mathrm{m}$ diamond paste followed by etching with Kalling II reagent. 85 Figure 5.6 Microstructures of heat- treated tensile bars fabricated by L-PBF using fine (a and b) and coarser (c and d) 420 stainless steel powders. The images are in the build (top) and scan (bottom) directions after polishing with $1 \mu \mathrm{m}$ diamond paste followed $\mathrm{b}$ 86 Figure 5.7 Linear sweep voltammetry (LSV) curves for as-printed and heat-treated LPBF 420 stainless steel in aqueous solution containing $3.5 \mathrm{wt} \% \mathrm{NaCl}$. Anode: L-PBF part, reference electrode: $\mathrm{Ag} / \mathrm{AgCl}$; cathode: $\mathrm{Pt}$ wire; $\mathrm{pH}=6.0$; scan rate: 0.01 87 Figure 5.8 Optical images of corroded surfaces showing the formation of pits in asprinted (left) and heat-treated (right) 420 stainless steel parts fabricated by L-PBF. For reference, the initial state before corrosion are shown in Figure 3 89

Figure 6.1 Optical image of etched cross-section in the scan direction of as-printed 420 stainless steel revealing the orientation of martensite needles. 95 Figure 6.2 Microstructure of the as-printed and HIPed 420 stainless steel. 96 Figure 6.3 Optical and scanning electron images of the etched microstructure of the assintered and heat-treated 420 stainless steel. 97 Figure 6.4 Difference in the microstructure of L-PBF 420 stainless steel specimens by varying the nitrogen content of starting powder. 97 Figure 6.5 Microstructure of L-PBF 420 stainless steel-bronze bimetallic alloy 98 Figure 6.6 Injection mold with conformal cooling channels fabricated by L-PBF using 420 stainless steel powder $\left(\mathrm{D}_{50}: 12 \mu \mathrm{m}\right)$ at a layer thickness of $10 \mu \mathrm{m}$. 99 
Figure 6.7 Graspers with varying teeth pattern for laparoscopic surgery.

Figure 6.8 Snake skin-inspired patterns in 420 stainless steel fabricated by L-PBF for potential use in wear resistant moving parts. 


\section{CHAPTER 1}

\section{INTRODUCTION}

Additive manufacturing (AM) facilitates new possibilities in mass customization, shape complexity and design freedom which can be beneficial for the advancement of tooling industry [1]. The global machine tools market is predicted to exceed 120 billion dollars by 2020 [2]. Tooling for a broad range of industries are primarily metals [3]. Fig. 1.1 shows an example of tooling with conformal cooling channels for injection molding (left) and graspers for laparoscopic surgery (right) that have emerged from this dissertation.
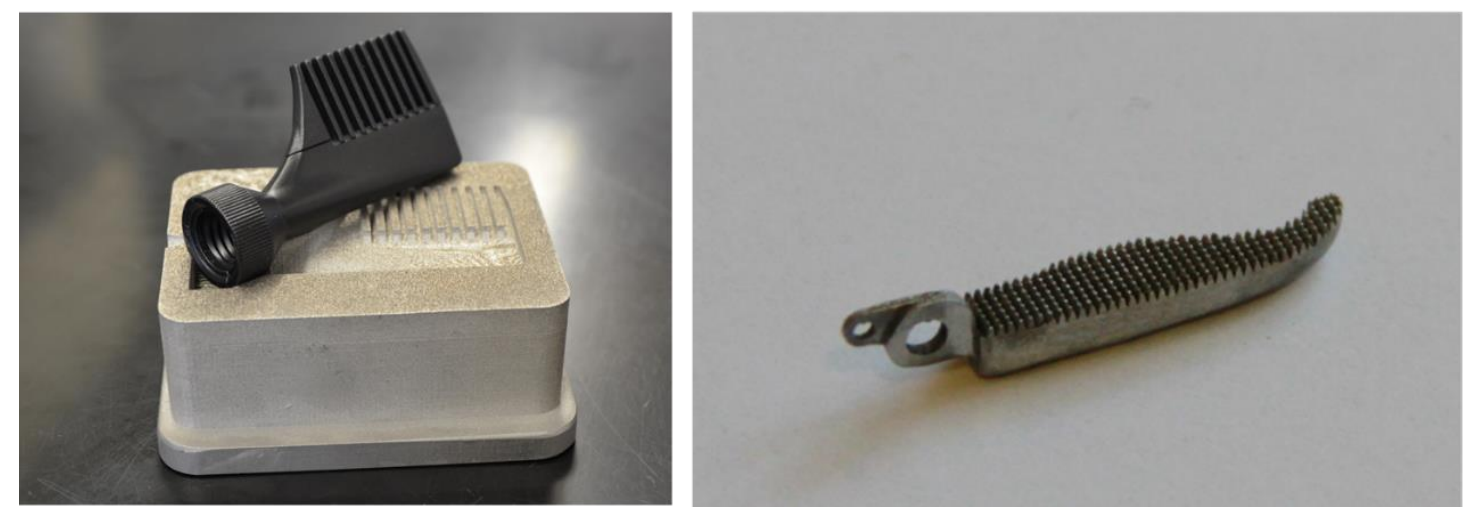

Figure 1.1 Additive manufacturing for tooling offers new possibilities and challenges to the engineers, researchers and entrepreneurs.

Laser-powder bed fusion (L-PBF) is an AM technique that is useful for the manufacturing of metallic parts [4]. This layer-by-layer process uses a focused laser beam to fuse deposited metal powder into a pattern guided by a computer-aided design (CAD) model 
[5]. Metal AM has reportedly seen an annual growth of over $20 \%$ in recent years and is expected to cross $\$ 20$ billion as an industry by 2020 [6].
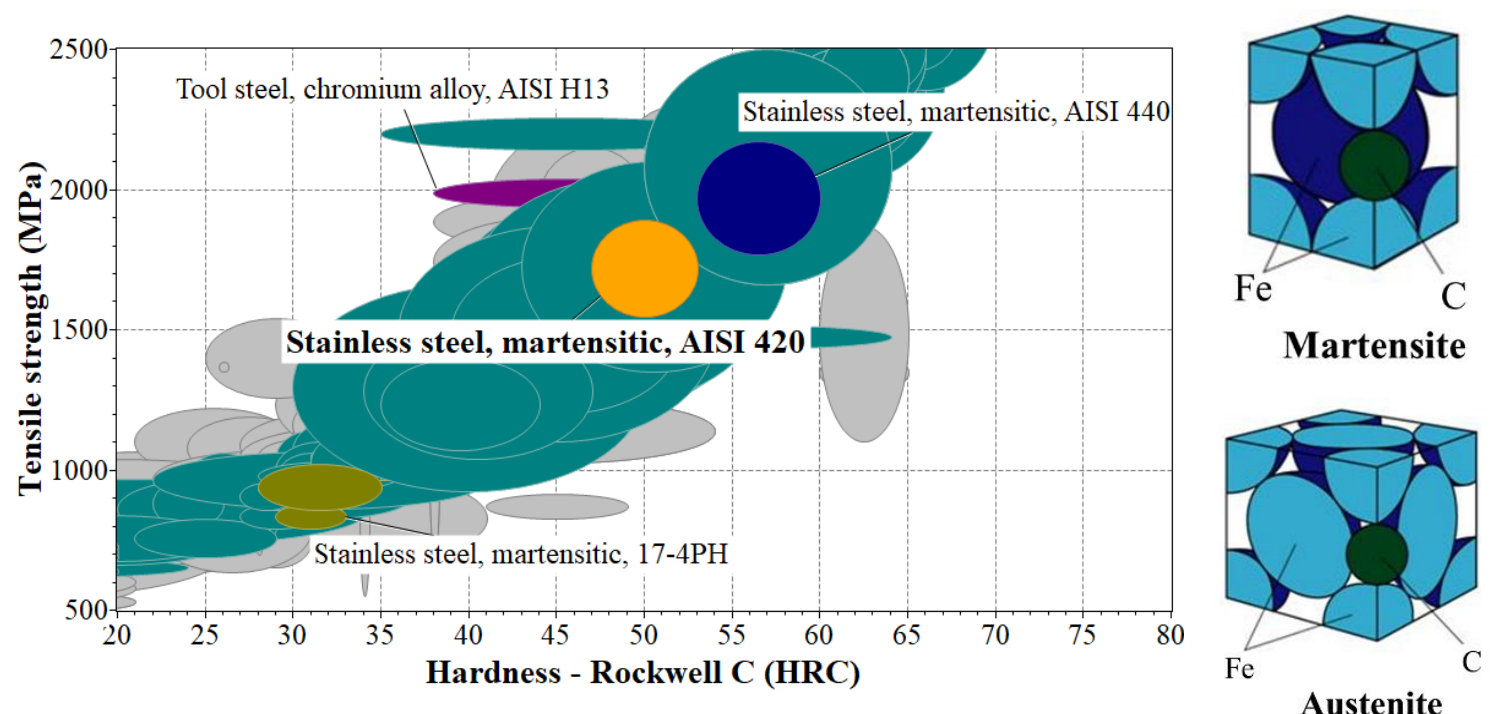

Figure 1.2 An ultimate tensile strength-hardness chart to show mechanical properties of AISI 420 stainless steel in comparison with other tooling materials. Properties can be attributed to the present martensite (body centered tetragonal) and austenite (face centered cubic) phases in microstructure depending on thermal processing.

However, the application of L-PBF have been limited to a few material systems such as austenitic stainless steels, titanium, cobalt-chrome, and superalloys [7-9]. In this regard, very few reports were found to be focused on L-PBF of AISI 420 stainless steel $[10,11]$. This alloy is widely used in surgical and tooling applications because of its high hardness,

- Four basic process parameters-

$t=$ Layer thickness $(\mu \mathrm{m})$

$P=$ Laser power $(\mathrm{W})$

$v=$ Scan speed $(\mathrm{mm} / \mathrm{s})$

$h=$ Trace width $(\mu \mathrm{m})$

Energy density $\left(J / \mathrm{mm}^{3}\right), E=\frac{P}{t * v * h}$

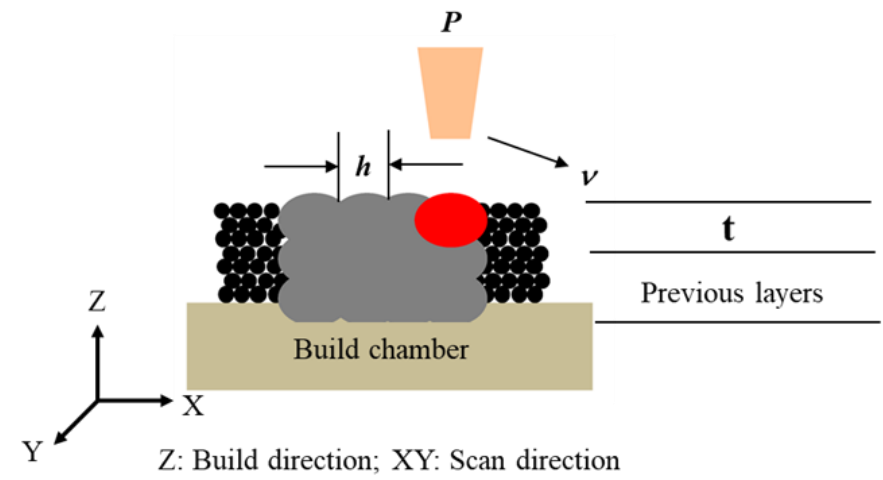

Figure 1.3. A schematic representation of L-PBF showing key process parameters. 
strength and corrosion resistance (Fig. 1.2). It is a martensitic steel and the $\mathrm{Cr}$ and $\mathrm{C}$ content in the chemical composition vary from 12 to $14 \%$ and 0.1 to $0.4 \%$ respectively [12]. It has been reported that the market size of 400 series stainless steel in the US was $\$ 10$ billion in 2017 with a growth rate $5.2 \%$ [13]. Thus, understanding the processing of 420 stainless steel using L-PBF will have significant opportunities in medical, industrial and tooling applications such as surgical scissors, graspers for laparoscopic instruments and molds with cooling channels $[14,15]$.

Table 1.1 Physical and mechanical properties of 420 stainless steel fabricated by additive manufacturing processes found in literatures.

\begin{tabular}{|c|c|c|c|c|c|c|c|c|c|}
\hline Author & PSD & $\begin{array}{c}\text { Fixed } \\
\text { parameter }\end{array}$ & $\begin{array}{l}\text { Energy } \\
\text { density } \\
\left(\mathrm{J} / \mathrm{mm}^{3}\right)\end{array}$ & $\begin{array}{l}\text { Varying } \\
\text { parameter }\end{array}$ & $\begin{array}{l}\text { Physical } \\
\text { properties }\end{array}$ & $\begin{array}{c}\text { Mechanical } \\
\text { properties }\end{array}$ & Hardness & $\begin{array}{l}\text { Micro- } \\
\text { structure }\end{array}$ & Remarks \\
\hline $\begin{array}{c}\text { Nachum } \\
\text { et al, } 2011 \\
{[18]}\end{array}$ & $\begin{array}{l}20-70 \\
\mu \mathrm{m}\end{array}$ & $\begin{array}{l}\mathrm{P}=20 \mathrm{~W} \\
=2 \mathrm{~mm} / \mathrm{s} \\
\mathrm{h}=50 \mu \mathrm{m} \\
\mathrm{t}=40 \mu \mathrm{m}\end{array}$ & 5000 & N/A & $92 \%$ & $\begin{array}{c}\text { Yield } \\
\text { strength } \\
600 \mathrm{MPa}\end{array}$ & No & Yes & $\begin{array}{c}\text { Density was } \\
\text { lower than } \\
\text { wrought value }\end{array}$ \\
\hline $\begin{array}{c}\text { Yadroitsev } \\
\text { et al, } 2014 \\
{[19]}\end{array}$ & $\begin{array}{c}8-39 \\
\mu \mathrm{m} \\
\mathrm{D}_{50}= \\
23 \\
\mu \mathrm{m}\end{array}$ & $\begin{array}{c}\mathrm{P}=70 \mathrm{~W} \\
=120 \\
\mathrm{~mm} / \mathrm{s} \\
\mathrm{h}=120 \\
\mu \mathrm{m} \\
\mathrm{t}=50 \mu \mathrm{m}\end{array}$ & 194 & N/A & $\begin{array}{c}98 \% \text { to } \\
99 \%\end{array}$ & No & No & Yes & $\begin{array}{c}\text { Density was } \\
\text { improved } \\
\text { through } \\
\text { double scan, } \\
\text { but no } \\
\text { mechanical } \\
\text { properties } \\
\text { mentioned }\end{array}$ \\
\hline $\begin{array}{c}\text { Zhao et al, } \\
2015 \\
{[10]}\end{array}$ & $\begin{array}{c}10- \\
53 \\
\\
D_{50}= \\
25 \\
\mu \mathrm{m}\end{array}$ & $\begin{array}{c}=600 \\
\mathrm{~mm} / \mathrm{s} \\
\mathrm{h}=120 \\
\mu \mathrm{m} \\
\mathrm{t}=20 \mu \mathrm{m}\end{array}$ & 111 & $\begin{array}{c}\begin{array}{c}\text { Laser } \\
\text { power }\end{array} \\
120 \mathrm{~W} \text { to } \\
160 \mathrm{~W}\end{array}$ & $\begin{array}{c}96 \% \text { to } \\
99 \%\end{array}$ & No & $\begin{array}{c}\text { HRC } \\
46 \text { to } 51\end{array}$ & No & $\begin{array}{c}\text { Mechanical } \\
\text { properties and } \\
\text { microstructure } \\
\text { were not } \\
\text { analyzed }\end{array}$ \\
\hline $\begin{array}{c}\begin{array}{c}\text { Saeidi et } \\
\text { al, }\end{array} \\
2016 \\
\text { [20] }\end{array}$ & $\begin{array}{c}20- \\
53 \\
\mu \mathrm{m} \\
\\
\mathrm{D}_{50}= \\
34 \\
\mu \mathrm{m}\end{array}$ & $\begin{array}{c}\mathrm{P}=190 \\
\mathrm{~W} \\
=800 \\
\mathrm{~mm} / \mathrm{s} \\
\mathrm{h}=100 \\
\mu \mathrm{m} \\
\mathrm{t}=30 \mu \mathrm{m}\end{array}$ & 79 & $\begin{array}{c}\text { L-PBF } \\
\text { atmosphere: } \\
\text { Ar vs N }\end{array}$ & $99 \%+$ & $\begin{array}{c}\text { UTS } \\
1100 \mathrm{MPa} \\
(\mathrm{Ar}) \\
1400 \mathrm{MPa} \\
(\mathrm{N})\end{array}$ & No & Yes & $\begin{array}{c}\text { Hardness and } \\
\text { elongation } \\
\text { were not } \\
\text { reported }\end{array}$ \\
\hline
\end{tabular}


L-PBF has several challenges that should be addressed methodically to maximize its full potential in terms of part quality and productivity metrics. The variables in this process can be categorized into two sections, powder attributes and processing parameters, that can impact the physical and mechanical properties of an L-PBF component. The powder attributes includes particle size distribution, particle shape, type of atomization and chemical composition of the investigated powder [16]. On the other hand, as seen in Fig. 1.3, there are four fundamental process parameters in the L-PBF such as layer thickness, trace width, laser power and scan speed [17]. These parameters are grouped into a generic parameter named energy density which is a measure of how much energy is provided to a give volume of deposited powder in the build chamber. Both powder attributes and energy density can influence the characteristics of L-PBF specimens such as density, surface morphology, ultimate tensile strength, yield strength, elongation and hardness by altering microstructure.

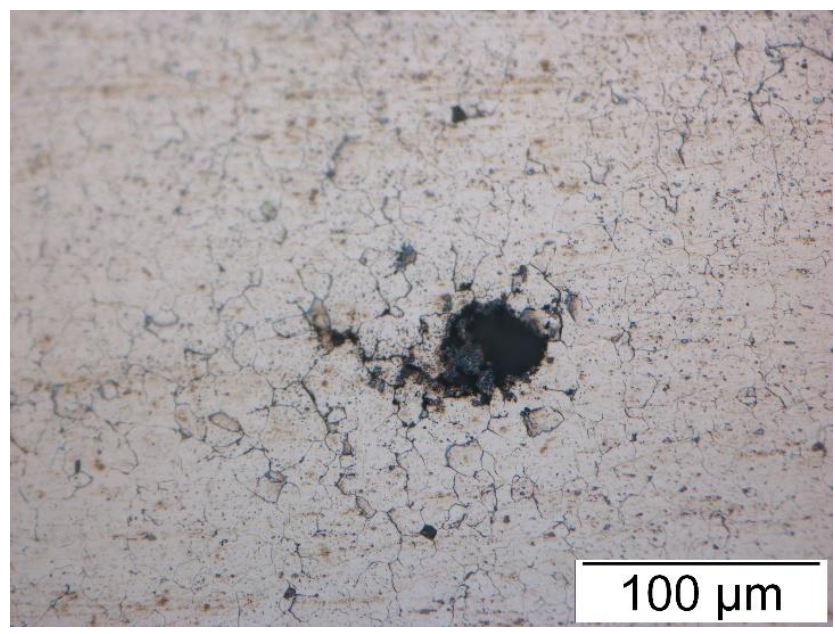

Figure 1.4 Intergranular and pitting corrosion on the as-polished surface of hardened 420 stainless steel obtained by optical microscopy. Electrochemical corrosion test was conducted in $3.5 \%$ of $\mathrm{NaCl}$ solution. Operating condition- reference electrode: $\mathrm{Ag} / \mathrm{AgCl}$; cathode: $\mathrm{Pt}$ wire; $\mathrm{pH}=6.0$; scan rate: $0.01 \mathrm{Vs}^{-1}$. 
From the summary provided in Table 1.1, it is evident that there are no clear correlations established between powder characteristics, processing conditions, mechanical properties and microstructure for 420 stainless steel fabricated by L-PBF [25]. Further, the mechanical properties reported in the literature are considerably lower than wrought 420 stainless steel. Heat treatment is one important way to enhance mechanical properties for 420 stainless steel. However, the post-processing, properties and microstructure of L-PBF 420 stainless steel following heat-treatment has not received any attention. Corrosion resistance is another important property of 420 stainless steel as seen in Fig. 1.4. However, there are no reported studies on the corrosion behavior of 420 stainless steel processed by L-PBF. This dissertation aims to address these gaps in the scientific literature by investigating the influence of powder physical attributes and chemical composition on the L-PBF processing and ensuing properties and microstructures for 420 stainless steel.

Chapter 2 discusses the physical and mechanical properties of the as-printed and heattreated 420 stainless steel using a narrow particle size distribution with a median size of 28 $\mu \mathrm{m}$. Corrosion properties of the as-printed and heat-treated specimens characterized using electrochemical study and Tafel plot was another key part of this study. A correlation of microstructural attributes affecting properties is also presented. The properties are compared to reported values of in the literature for 420 stainless steel processed by L-PBF, wrought and metal injection molding (MIM) [21]. The manuscript based on this chapter was published in Powder Technology journal in 2018.

The effects of layer thickness on microstructure, mechanical, physical and corrosion properties of L-PBF 420 stainless steel are discussed in Chapter 3. The density, surface roughness, ultimate tensile strength, yield strength, elongation, hardness, and corrosion 
properties of these specimens were characterized to establish layer thickness-propertymicrostructure relationships. The manuscript based on this study has been submitted to the International Journal of Powder Metallurgy as an invited paper for a special edition in a metal additive manufacturing.

Chapter 4 presents a novel route to improving mechanical and corrosion properties of LPBF 420 stainless over wrought material by introducing $\mathrm{Nb}$ and Mo. A variation of regular AISI 420 stainless steel powder that was pre-alloyed with $\mathrm{Nb}$ and Mo with the similar particle size distribution as presented in Chapter 2 was investigated in this study. L-PBF experiments were performed to characterize the effects of $\mathrm{Nb}$ and Mo on the physical, mechanical and corrosion properties and correlated with the differences in microstructure in the presence of $\mathrm{Nb}$ and Mo. This paper is ready to be submitted to the Acta Materalia journal.

Chapter 5 focuses on the effects of particle size distribution on the density, mechanical and corrosion properties of L-PBF 420 stainless steel. Conventionally, a narrow particle size distribution of 15 to $45 \mu \mathrm{m}$ is preferred for processing using L-PBF. However, finer particles are not only less expensive but also have a higher surface area and can achieve full density at a lower energy in sintering routes. However, a reduction in particle size tends to have a lower flowability and spreadability for processing using powder bed AM routes. Thus, a method was investigated to improve the flowability of fine 420 stainless steel powders (median particle size of $12 \mu \mathrm{m}$ ) to enable L-PBF processing. The physical, mechanical and corrosion properties of the L-PBF specimens using the finer particle size were measured and compared with the properties and microstructure achieved through the 
processing of the coarser powders reported in Chapter 2. This paper will be submitted to the Journal of Materials Processing Technology.

Appendices A-E provide an extensive compilation of the raw data obtained from the characterization of powders, properties and microstructures used in this dissertation. Appendix F provides a summary of the extensive feasibility studies that enabled the identification of the specific rationale and scope of this dissertation. Appendix G presents preliminary data of the effects of atomization atmosphere on the mechanical and corrosion properties of L-PBF specimens, justifying further work in the future. In Appendix H, initial results from a novel hybrid method combining L-PBF and infiltration is provided using a system of 420 stainless steel and bronze. Appendix I presents a conference paper on the application of the results of this dissertation on fabricating tools for injection molding and laparoscopic surgery using 420 stainless steel. Appendix J presents a novel bio-inspired route to the design and fabrication of wear-resistant surfaces from L-PBF 420 stainless steel using the outcomes of this dissertation resistance and tribological properties. 


\section{CHAPTER 2}

\section{MICROSTRUCTURE-PROPERTY RELATIONSHIPS OF 420 STAINLESS STEEL OF FABRICATED BY LASER-POWDER BED FUSION}

\subsection{INTRODUCTION}

Laser-powder bed fusion (L-PBF) is a layer-by-layer manufacturing process where a laser beam scans the surface of a powder bed and melted powder solidifies to form a three-

dimensional body. This process differs from the traditional casting or sintering in several aspects. For instance, each layer goes through several melting-solidification and re-melting steps [4]. The solidification of the melted powders is a localized phenomenon with a varying cooling rate. Re-melting also occurs in the overlapping zone between adjacent scan tracks. These aspects generally result into distinctive microstructures and mechanical properties of L-PBF parts relative to wrought or sintered structures. Consequently, it is useful to understand the microstructure-property-process inter-relationships in materials processed using L-PBF [22, 23].

One area of interest in our research is to use L-PBF to print industrial and surgical tools with intricate shape and customized attributes [24-27]. AISI 420 stainless steel, a martensitic steel, is a widely used material in tooling applications as it offers high strength, hardness and corrosion properties. It offers good ductility in the annealed state and 
excellent strength and hardness after heat treatment [28]. The microstructure of 420 stainless steel features martensite (body-centered tetragonal), retained austenite (face centered cubic), ferrite (body-centered cubic) phases and dissolved or undissolved carbides [29]. During rapid cooling or quenching , the martensite phase appears through a diffusionless transformation from the austenite phase [30]. This is termed as austenite-martensitic transformation, occurring typically in the temperature range 720 to $400^{\circ} \mathrm{C}$. It has also been reported that the austenite-martensite transformation temperature range can be suppressed down to $300{ }^{\circ} \mathrm{C}$ if the chromium content is increased [31]. If the cooling rate is not fast enough, then austenite phases may remain as retained austenite in the microstructure and the steel then exhibits significantly different properties [32]. The microstructure and properties of AISI 420 stainless steel fabricated using L-PBF have not been investigated widely. A few reports have been published in recent years on the mechanical and physical properties of 420 stainless steel fabricated by L-PBF. For example, Saeidi et al reported an ultimate tensile strength of $1060 \mathrm{MPa}$ with 420 stainless steel fabricated by L-PBF in argon atmosphere [20]. Zhang et al reported a hardness of $50 \mathrm{HRC}$ in 420 stainless steel fabricated by L-PBF but did not include any corresponding tensile properties or microstructure [10]. Overall, to the best of our knowledge, there are no previous reports in the literature on microstructure-property relationships in 420 stainless steel fabricated by L-PBF and subsequent heat treatment $[10,11,33]$.

Corrosion resistance is another significant property of 420 stainless steel besides strength and hardness. The corrosion resistance of stainless steel is attributed to the presence of alloyed chromium (> $11 \mathrm{wt} . \%)$, enabling the formation of a chromium oxide $\left(\mathrm{Cr}_{2} \mathrm{O}_{3}\right)$ based passive film on the metal surface $[34,35]$. In previous studies, linear sweep voltammetry 
(LSV) and cyclic voltammetry (CV) experiments were conducted in $3.5 \% \mathrm{NaCl}$ solution to characterize corrosion behavior of wrought 420 stainless steel [36-38]. However, no reports have been found on the corrosion properties of L-PBF 420 stainless steel. It was also reported in previous studies that wrought 420 stainless steel did not experience any significant change in corrosion properties after heat treatment [39].

In order to address the above gaps in the literature, L-PBF experiments with 420 stainless steel were performed to investigate physical properties, mechanical properties, corrosion behavior and microstructure. Initially, several coupons were printed with different energy densities to identify conditions where the parts reached near full density. Samples of 420 stainless steel fabricated by L-PBF with $99+\%$ density were characterized in both asprinted and heat-treated conditions for their mechanical and corrosion properties as well as microstructure. The present study presents a first comprehensive report on the L-PBF of 420 stainless steel and is expected to enable the evaluation of modern designs and applications of the 3D printed material in the future.

\subsection{METHODOLOGY}

\subsubsection{MATERIALS}

In this study, L-PBF experiments were conducted with nitrogen gas atomized and prealloyed 420 stainless steel powder supplied by Sandvik Osprey Ltd., U.K. The particle size distribution and chemical composition of the powder were provided by the manufacturer. A Carl Zeiss scanning electron microscopy (SEM) machine was used to observe the powder size and shape. 


\subsubsection{L-PBF PROCESS}

A Concept Laser Mlab cusing $\mathrm{R}$ machine equipped with an $\mathrm{Yb}$-fiber laser was used to conduct L-PBF experiments. The machine had a maximum power of $100 \mathrm{~W}$ and a laser beam diameter of $50 \mu \mathrm{m}$. A Y-shaped rubber coater blade was used for spreading the powder on a mild steel baseplate. Argon gas with a setting of 20 percent of maximum ventilation capability was used throughout all experiments. Cube samples $(10 \mathrm{~mm}$ x 10 $\mathrm{mm} \times 10 \mathrm{~mm}$ ) were initially built using energy density ranging from 20 to $180 \mathrm{~J} / \mathrm{mm}^{3}$. A continuous line strategy with alternating layers at $-45^{\circ}$ and $+45^{\circ}$ angle was chosen as the scan pattern. Flat tensile specimens as per the ASTM E8 standard with a gage length of 35 $\mathrm{mm}$, width of $6.2 \mathrm{~mm}$, thickness of $3 \mathrm{~mm}$, and total length of $75 \mathrm{~mm}$ were fabricated at an energy density of $63 \mathrm{~J} / \mathrm{mm}^{3}$ (layer thickness of $20 \mu \mathrm{m}$, laser power of $90 \mathrm{~W}$, scan speed of $600 \mathrm{~mm} / \mathrm{s}$ and trace width of $120 \mu \mathrm{m})$.

\subsubsection{HEAT TREATMENT}

The mechanical behavior of 420 stainless steel is highly dependent on the type of phases and their relative amount present in the microstructure [11]. Low temperature isothermal tempering was implemented by heating the as-printed L-PBF 420 stainless steel parts in a furnace at $315^{\circ} \mathrm{C}$ for 2 hours followed by air cooling. This heating cycle was based on a previous study reported by Marsden et al [12].

\subsubsection{PHYSICAL PROPERTIES}

The measurement of density of as-printed and heat-treated L-PBF parts was based on the Archimedes principle (ASTM 962-17) using a Mettler Toledo XS104 weighing balance equipped with a density measurement kit. Surface roughness of the L-PBF parts was measured with a Mitutoyo Surface Tester SJ-210 by surface profilometry (ISO 4287-1997). 


\subsubsection{MECHANICAL TESTS}

The mechanical properties of as-printed and heat-treated L-PBF 420 stainless steel bars were measured with an MTS Exceed hydraulic dual-column testing system equipped with a $100 \mathrm{kN}$ load cell. The measurements were performed using a strain rate of $0.001 \mathrm{~s}^{-1}$. Four samples were used for reporting each measurement. The hardness of the test specimens was measured using Rockwell ' $\mathrm{C}$ ' scale at $150 \mathrm{~kg}$ load. As the specimens were printed horizontally, hardness was measured on the scan surface. A total of ten measurements was taken for each sample for hardness measurement.

\subsubsection{MICROSTRUCTURE STUDY}

L-PBF samples were sectioned, polished, and etched with Kalling's reagent II for conducting the microstructure study. Etched surfaces were characterized using optical microscopy and SEM (EVO) for examining the porosity and microstructures. Phase analysis of the raw powder and the as-printed and heat treated 420 stainless steel samples was determined using a model Bruker D8 Discover x-ray diffraction (XRD) instrument using $\mathrm{Cu}-\mathrm{K} \alpha$ radiation $\left(\lambda=1.54 \mathrm{~A}^{\circ}\right)$. The phases were identified by comparing the recorded diffraction peaks with the ICDD database.

\subsubsection{CORROSION STUDY}

Four specimens of as-printed and heat-treated parts with a surface area of $1 \mathrm{~cm}^{2}$ were prepared for the linear sweep voltammetry (LSV) measurements. The surfaces were polished using SiC paper with grit size varying from 120 to 1200 . The LSV measurements were conducted in a $3.5 \% \mathrm{NaCl}$ solution at room temperature using a Metrohm Autolab PGSTATION $100 \mathrm{~N}$ system. The specimen, a platinum rod and a saturated $\mathrm{Ag} / \mathrm{AgCl}$, were used as the working, auxiliary and reference electrodes, respectively. For each trial, the 
open circuit potential $\left(\mathrm{E}_{\mathrm{oc}}\right)$ was recorded and the measurements were started from the value of $\mathrm{E}_{\mathrm{oc}}$. A computer controlled Metrohm Autolab PGSTATION 100N was used to measured corrosion current. LSV experiments were carried out in the potential range between -600 $\mathrm{mV}$ and $1000 \mathrm{mV}$ from $\mathrm{E}_{\mathrm{oc}}$ at the forward scan rate of $0.01 \mathrm{mV} \mathrm{s}^{-1}$ with the current density limit of $10 \mathrm{~mA} \cdot \mathrm{cm}^{-2}$ to determine the corrosion potential $\left(\mathrm{E}_{\mathrm{corr}}\right)$, pitting potential $\left(\mathrm{E}_{\mathrm{pitt}}\right)$ and breakdown $\left(\mathrm{E}_{\mathrm{b}}\right)$ potentials. Tafel plots were obtained from the voltage and current measurement to quantify various corrosion parameters. On completion of each corrosion experiment, the samples were washed with deionized water and isopropyl alcohol to perform optical microscopy on the corroded surface.

\subsection{RESULTS AND DISCUSSION}

\subsubsection{POWDER CHARACTERISTICS}
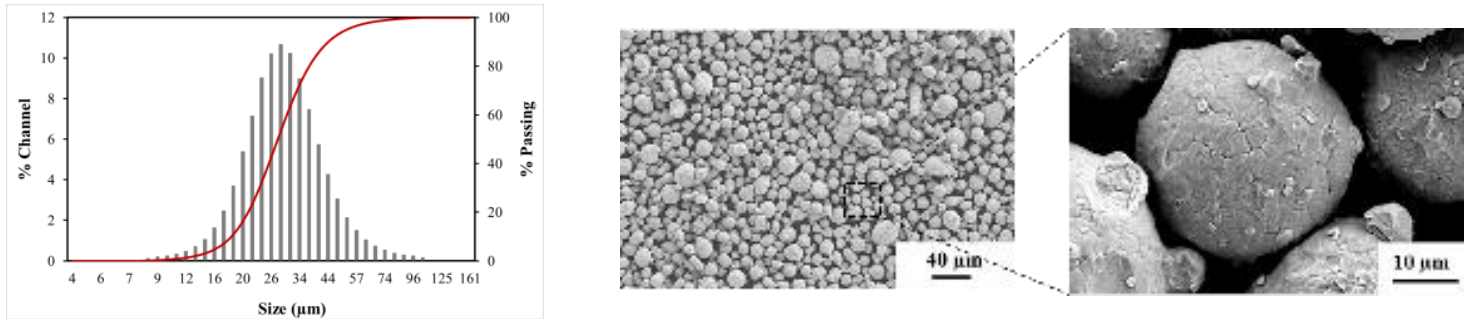

Figure 2.1 Particle size distribution and SEM images of nitrogen gas atomized AISI 420 stainless steel powder.

Table 2.1 Powder characteristics of nitrogen-atomized AISI 420 stainless steel powder

\begin{tabular}{|c|c|c|c|c|c|c|}
\hline Powder & $\begin{array}{l}D_{10} \\
\mu \mathrm{m}\end{array}$ & $\begin{array}{l}\mathrm{D}_{50} \\
\mu \mathrm{m}\end{array}$ & $\begin{array}{l}\mathrm{D}_{90} \\
\mu \mathrm{m}\end{array}$ & $\begin{array}{c}\text { Gas } \\
\text { pycnometer } \\
\text { density } \\
\mathrm{g} / \mathrm{cm}^{3}\end{array}$ & $\begin{array}{c}\text { Apparent } \\
\text { density } \\
\rho_{A} \\
\mathrm{~g} / \mathrm{cm}^{3}\end{array}$ & $\begin{array}{c}\text { Tap density } \\
\rho_{T} \\
\mathrm{~g} / \mathrm{cm}^{3}\end{array}$ \\
\hline $\begin{array}{c}420 \\
\text { stainless } \\
\text { steel }\end{array}$ & 17 & 28 & 47 & $7.68 \pm 0.01$ & $4.0 \pm 0.2$ & $4.7 \pm 0.1$ \\
\hline
\end{tabular}


Table 2.2 Chemical composition of nitrogen-atomized AISI 420 stainless steel powder

\begin{tabular}{|c|c|c|c|c|c|c|c|c|c|}
\hline Powder & $\mathrm{Fe}$ & $\mathrm{Cr}$ & $\mathrm{Mn}$ & $\mathrm{Si}$ & $\mathrm{P}$ & $\mathrm{C}$ & $\mathrm{S}$ & $\mathrm{N}$ & $\mathrm{O}$ \\
\hline $\begin{array}{c}420 \\
\text { stainless } \\
\text { steel }\end{array}$ & Bal. & 12.8 & 0.72 & 0.79 & 0.012 & 0.3 & 0.008 & 0.09 & 0.044 \\
\hline $\begin{array}{c}\text { AISI } \\
\text { standard }\end{array}$ & Bal. & $12-14$ & $<1.0$ & $<1.0$ & $<0.04$ & $>0.15$ & $<0.03$ & - & - \\
\hline
\end{tabular}

From Fig. 2.1, the 420 stainless powder had a monomodal particle size distribution. It was evident that the powders were mostly spherical in shape. There were a few satellite particles attached to the surface of the bigger particles. Some roughness was observed on the surface of the powder which may have occurred during the atomization process. The powder attributes and chemical composition of the powder are listed in Tables 2.1 and 2.2, respectively. The 420 stainless steel powder had a median particle size ( $\left.\mathrm{D}_{50}\right)$ of $28 \mu \mathrm{m}$ and $90 \%$ of the particles $\left(\mathrm{D}_{90}\right)$ were below $47 \mu \mathrm{m}$. The density of the powder was found to be $7.68 \pm 0.01 \mathrm{~g} / \mathrm{cm}^{3}$ based on helium pycnometry. The density of wrought 420 stainless steel, $7.74 \mathrm{~g} / \mathrm{cm}^{3}$, was used to represent the density of L-PBF parts as a percentage of the theoretical value. From Table 2.2, the chromium and carbon content of investigated powder powders were $12.8 \%$ and $0.3 \%$ respectively which was in the range of the corresponding AISI standard. The powder had an apparent density of $4.0 \pm 0.1 \mathrm{~g} / \mathrm{cm}^{3}$ and tap density of $4.7 \pm 0.1 \mathrm{~g} / \mathrm{cm}^{3}$. The Hausner ratio is the ratio of tap density to apparent density and is a measure of powder flowability with lower numbers indicating better flowability [40, 41]. In this study, the Hausner ratio was calculated as $1.18 \pm 0.02$. 
- Current study Literature study

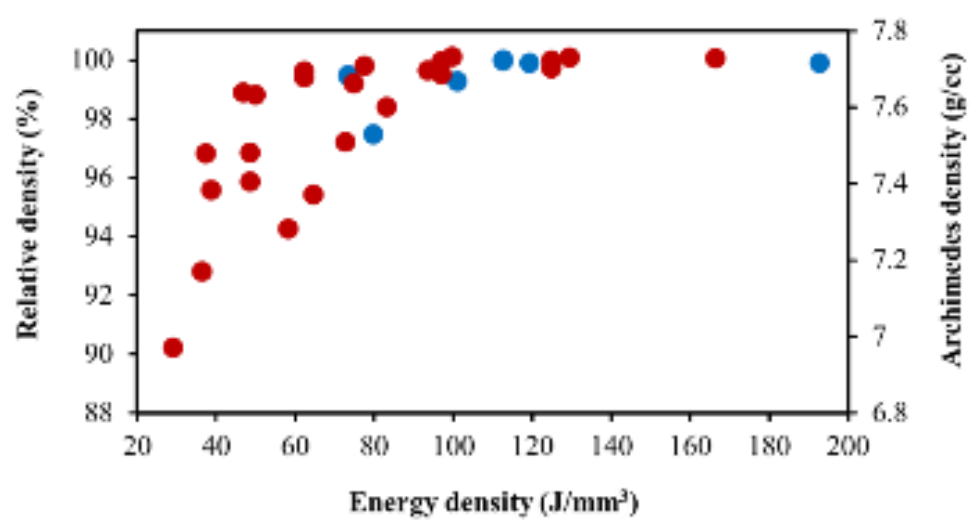

Figure 2.2 Part density vs energy density chart from L-PBF experiments with nitrogen atomized AISI 420 stainless steel. The wrought density of $7.74 \mathrm{~g} / \mathrm{cc}$ was used to calculate relative density.

Energy density (E) combines four basic parameters of L-PBF process based on laser power $(\mathrm{P})$, scan speed (v), trace width (h) and layer thickness (t) using the following equation [22]:

$$
\mathrm{E}=\frac{\mathrm{P}}{\mathrm{h} * \mathrm{v} * \mathrm{t}} \quad \text { Equation } 1
$$

The Archimedes density of the L-PBF coupons was plotted against energy density which is presented in Fig. 2.2. In this processing window, the energy density was varied from 20 to $200 \mathrm{~J} / \mathrm{mm}^{3}$. Below an energy density of $50 \mathrm{~J} / \mathrm{mm}^{3}$, the Archimedes density of L-PBF asprinted parts varied from $6.6 \mathrm{~g} / \mathrm{cc}$ to $7.4 \mathrm{~g} / \mathrm{cm}^{3}$. It can be concluded that the energy density was not enough to fuse all particles together in this region and porous parts were obtained $[42,43]$. Above $50 \mathrm{~J} / \mathrm{mm}^{3}$, several combinations of L-PBF parameters resulted in near fully-dense parts. Above $85 \mathrm{~J} / \mathrm{mm}^{3}$, nearly all combinations of L-PBF parameters experienced $99+\%$ densification. For example, for an energy density of $63 \mathrm{~J} / \mathrm{mm}^{3}$ corresponding to a laser power of $90 \mathrm{~W}$; scan speed of $600 \mathrm{~mm} / \mathrm{s}$; layer thickness of $20 \mu \mathrm{m}$ and trace width of $120 \mu \mathrm{m}$, the Archimedes density was $99.2 \pm 0.3 \%$ theoretical. Prior 
studies have reported the fabrication of 420 stainless steel parts with $98+\%$ density at the energy densities in the range of 75 to $176 \mathrm{~J} / \mathrm{mm}^{3}[10,11,29,33]$. In comparison, in the

present study, 420 stainless steel parts with $99+\%$ density were successfully fabricated at lower energy densities. Densification in L-PBF process is not only influenced by energy density collectively but also by four parameters individually [44]. It is possible that parameters were not optimized to lowest energy density to reach near full density in previous studies. Using of a lower layer thickness and finer beam diameter might also contribute to this achievement.

\subsubsection{PHYSICAL PROPERTIES}

Based on the data presented in Fig. 2.2, an energy density of $63 \mathrm{~J} / \mathrm{mm}^{3}$ was chosen to fabricate ASTM standard tensile test specimens to evaluate physical and mechanical properties of 420 stainless steel. The density and surface morphology of as-printed bars are summarized in Table 2.3. All test specimens were above $99 \%$ dense based on the Archimedes method. Fig. 2.3 shows that polished cross-sectional images at three different regions of the as-printed parts were consistent with the measured density. The images were collected at both top and center section of the printed coupons and each image represented $1.75 \times 1.75 \mathrm{~mm}^{2}$ area. The average size of the pores was below $10 \mu \mathrm{m}$. Regular-shaped pores are considered to be the result of gas entrapment in L-PBF [45]. No irregular pore was found in the cross-sectional structure. As L-PBF is a repetitive melting and re-melting process, and surface tension and heat transfer are associated with this process, it can be said that the combined conditions resulted in near full density parts [46]. For comparison, L-PBF 420 stainless steel was as dense as wrought as-cast 420 stainless steel. Besides, the 
L-PBF offered higher densisification than reported for 420 stainless steel fabricated by metal injection molding (MIM) [47].
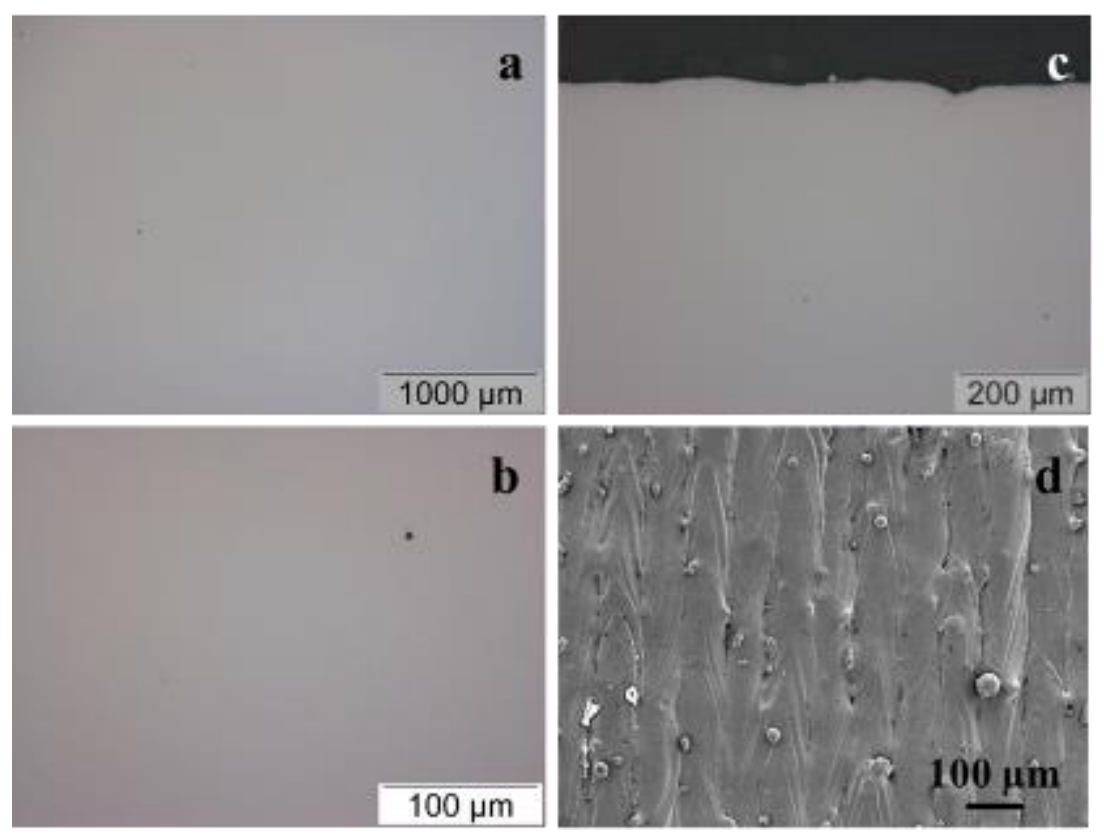

Figure 2.3 Optical microscopy of L-PBF parts of 420 stainless steel at (a) center of part in the print direction, low magnification, (b) center of part in the print direct, high magnification, and (c) the top of part, in the build direction. The scanning electron microscopy of the top view of parts is also shown (d).

Fig. 2.3(d) represents the top surface of the as-printed parts. In addition to a few examples of bead formation, porosity and pore distribution of the top surface was similar to the crosssectional image in Fig. 2.3(c). Laser scan tracks were observed to be continuous and overlapping between the tracks ensured enough fusion both parallel and perpendicular to the scan direction. The surface roughness $\left(\mathrm{R}_{\mathrm{a}}\right)$ was found to be $4.6 \pm 0.4 \mu \mathrm{m}$ through the surface profilometry. Previous L-PBF studies on 420 stainless steel did not discuss surface morphology, however, outcomes in this experiment are comparable to the L-PBF studies with other steel materials [48]. 


\subsubsection{MECHANICAL PROPERTIES}

Table 2.3 summarizes the mechanical properties of 420 stainless steel parts in this L-PBF study. The as-printed L-PBF parts exhibited an ultimate tensile strength of $1050 \pm 25 \mathrm{MPa}$, elongation of $2.5 \pm 0.2 \%$, yield strength $700 \pm 15 \mathrm{MPa}$, and hardness of $55 \pm 1 \mathrm{HRC}$. These results are comparable to previous L-PBF studies on 420 stainless steel using powders with a median particle size of $28 \mu \mathrm{m}$ reported as-printed properties that included an ultimate tensile strength of $1060 \pm 50 \mathrm{MPa}$, elongation of $1.5 \pm 0.3 \%$, and hardness of $50 \pm 2 \mathrm{HRC}$ fabricated at energy density of 79 and $115 \mathrm{~J} / \mathrm{mm}^{3}[10,49]$. Moreover, the findings in the present study were quantitatively superior to MIM as- sintered 420 stainless steel properties (density: $95 \pm 1 \%$, ultimate tensile strength: $775 \pm 30 \mathrm{MPa}$, elongation: $1.2 \pm 0.3 \%$, and hardness: $48 \pm 2$ HRC) [47].

Table 2.3 Mechanical properties of L-PBF 420 stainless steel fabricated at an energy density of $63 \mathrm{~J} / \mathrm{mm}^{3}$

\begin{tabular}{|c|c|c|c|c|c|c|c|}
\hline Process & Condition & $\begin{array}{c}\text { Density } \\
\mathrm{g} / \mathrm{cm}^{3}\end{array}$ & $\begin{array}{c}\text { Ultimate } \\
\text { tensile } \\
\text { strength } \\
\mathrm{MPa}\end{array}$ & $\begin{array}{c}\text { Elongation } \\
\%\end{array}$ & $\begin{array}{c}0.2 \% \text { Yield } \\
\text { Strength } \\
\mathrm{MPa}\end{array}$ & $\begin{array}{c}\text { Young's } \\
\text { modulus } \\
\mathrm{GPa}\end{array}$ & $\begin{array}{c}\text { Hardness } \\
\text { HRC }\end{array}$ \\
\hline \multirow{2}{*}{ L-PBF } & $\begin{array}{c}\text { As- } \\
\text { printed }\end{array}$ & $\begin{array}{c}7.67 \pm \\
0.03\end{array}$ & $\begin{array}{c}1050 \pm \\
25\end{array}$ & $2.5 \pm 0.2$ & $700 \pm 15$ & $190 \pm 7$ & $55 \pm 1$ \\
\cline { 2 - 8 } & $\begin{array}{c}\text { Heat- } \\
\text { treated }\end{array}$ & $\begin{array}{c}7.67 \pm \\
0.03\end{array}$ & $\begin{array}{c}1520 \pm \\
30\end{array}$ & $6.3 \pm 0.2$ & $950 \pm 20$ & $195 \pm 5$ & $53 \pm 1$ \\
\hline
\end{tabular}

After heat treatment at $315^{\circ} \mathrm{C}$, the L-PBF parts were found to have an ultimate strength of $1520 \pm 30 \mathrm{MPa}$, elongation of $6.3 \pm 0.2 \%$, yield strength of $950 \pm 20 \mathrm{MPa}$. and hardness of $53 \pm 1$ HRC. Properties of heat-treated 420 stainless steel parts fabricated using L-PBF have not been previously reported in the literature, to the best of our knowledge. As the as- 
printed and heat-treated parts had no significant porosity, the general increase in mechanical properties after heat-treatment can be attributed to changes in the microstructure and reduction in residual stresses [50]. Also, the increase in elongation of the parts without change in hardness requires further examination of the microstructure. For comparison, according to MPIF 35, MIM parts exhibited a tensile strength of $1350 \pm$ $50 \mathrm{MPa}$ and an elongation of $2.0 \pm 1.0 \%$ and a hardness $48 \pm 2$ after heat treatment [51]. On the other hand, wrought 420 stainless steel is reported to have an ultimate tensile strength of $1625 \pm 40 \mathrm{MPa}$, an elongation of $7 \pm 1.0 \%$ and a hardness of $53 \pm 2 \mathrm{HRC}$ [51, 52]. Thus, mechanical properties of 420 stainless fabricated using L-PBF were higher than MIM and close to the wrought properties.

\subsubsection{PHASE TRANSFORMATION}

In Fig. 2.4, the XRD patterns of 420 stainless steel powder, as-printed and as- heat treated shows a mixture of austenite $(\gamma)$ and martensite/ ferrite $(\alpha)$ phases. The raw powder contained $67 \%$ of austenite in its crystal composition found by Rietveld analysis [53]. The intensity ratio of austenite and martensite phases changed during L-PBF and heat treatment processes. As-printed and heat-treated tensile specimens exhibited a retained austenite phase of $\sim 20 \pm 10 \%$ from Rietveld analysis. L-PBF intrinsically offers localized rapid cooling which contributed to the formation of martensite phases. The proportional change in the phase content however was not significant within experimental error relative to the improvement in mechanical properties after the heat treatment. The nature of melting and re-melting may have led to complete dissolution of carbides together with rapid solidification to inhibit the carbide precipitation which was consistent with the virtual absence of any carbide-associated peak. 


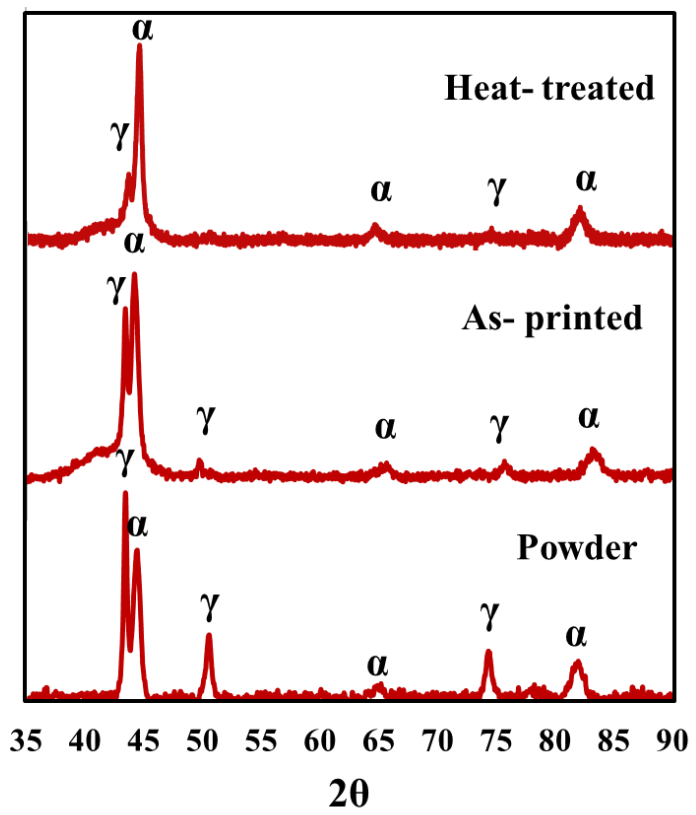

Figure 2.4 XRD pattern of as-printed and heat-treated L-PBF parts printed at an energy density of $63 \mathrm{~J} / \mathrm{mm}^{3}$ with $\mathrm{D}_{50}: 28 \mu \mathrm{m}$ sized 420 stainless steel powders.

The XRD data of the initial powder are also shown for comparison.

\subsubsection{MICROSTRUCTURAL ANALYSIS}

The etched microstructures of the as-printed and heat-treated 420 stainless steel tensile specimens are shown in Figs. 2.5 and 2.6. The austenite phase appears as white cellular structures whereas the martensite phase appears as gray laths or needles [43]. Fig. 2.5 (a and b) represents the microstructure obtained in the build direction of the as-printed L-PBF parts where martensitic laths can be observed being dispersed in the austenite regions. Some martensite appeared on the melt pool boundary where the cooling rate is presumed to be higher during the fusion process. There were some darker laths in the microstructure which may confirm the presence of tempered martensite. Fig. 2.5 (c and d) represent the microstructure of 420 stainless steel samples following L-PBF fabrication and heattreatment. After heat-treatment, the spacing and concentration of needle-shaped phases noticeably increased in the microstructure. The tempering of martensite may be responsible for the improvement in the ultimate tensile strength, yield strength and elongation of the 

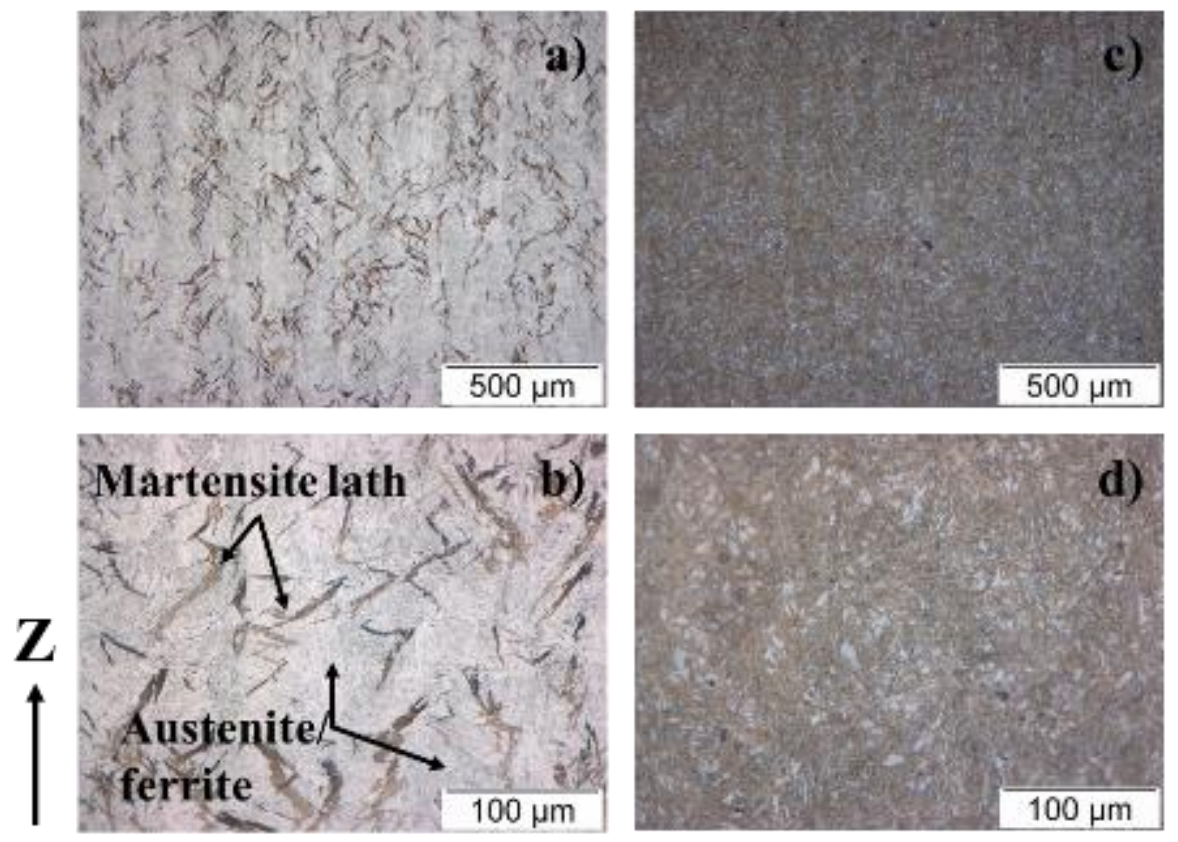

Figure 2.5 Microstructures in the build direction of as-printed ( $\mathrm{a}$ and $\mathrm{b}$ ) and heat-treated (c and d) 420 stainless steel tensile bars fabricated by L-PBF. The images were collected after polishing with $1 \mu \mathrm{m}$ diamond paste followed by etching with Kalling reagent II.

heat-treated 420 stainless steel without increasing the hardness. Besides, residual stresses accumulated during numerous thermal cycles could have been removed from the L-PBF parts during the heat-treatment which may have contributed to the improvement in tensile elongation values.

Striking differences can be observed in the orientation of the needles in the build and scan direction. An increased directionality of the martensite laths was observed in scan direction in Fig. 2.6 ( $\mathrm{a}$ and $\mathrm{b}$ ). The average distance between the laths was found to be $\sim 120 \mu \mathrm{m}$, equal to the trace width or distance between laser scan tracks used in this experiment. Further, the martensite laths were typically located at the edge of the scan tracks, which can be attributed to the faster cooling rates near the edge of the melt pool $[54,55]$. Similar to Fig. 2.5, following heat treatment, in Fig. 2.6 (c and d), the microstructures of the parts appeared to have increased lath content, consistent with the XRD analysis and ultimate 
tensile strength data. These results indicate the potential for a novel tool available to a design engineer for specifically strengthening select regions in a component by changing
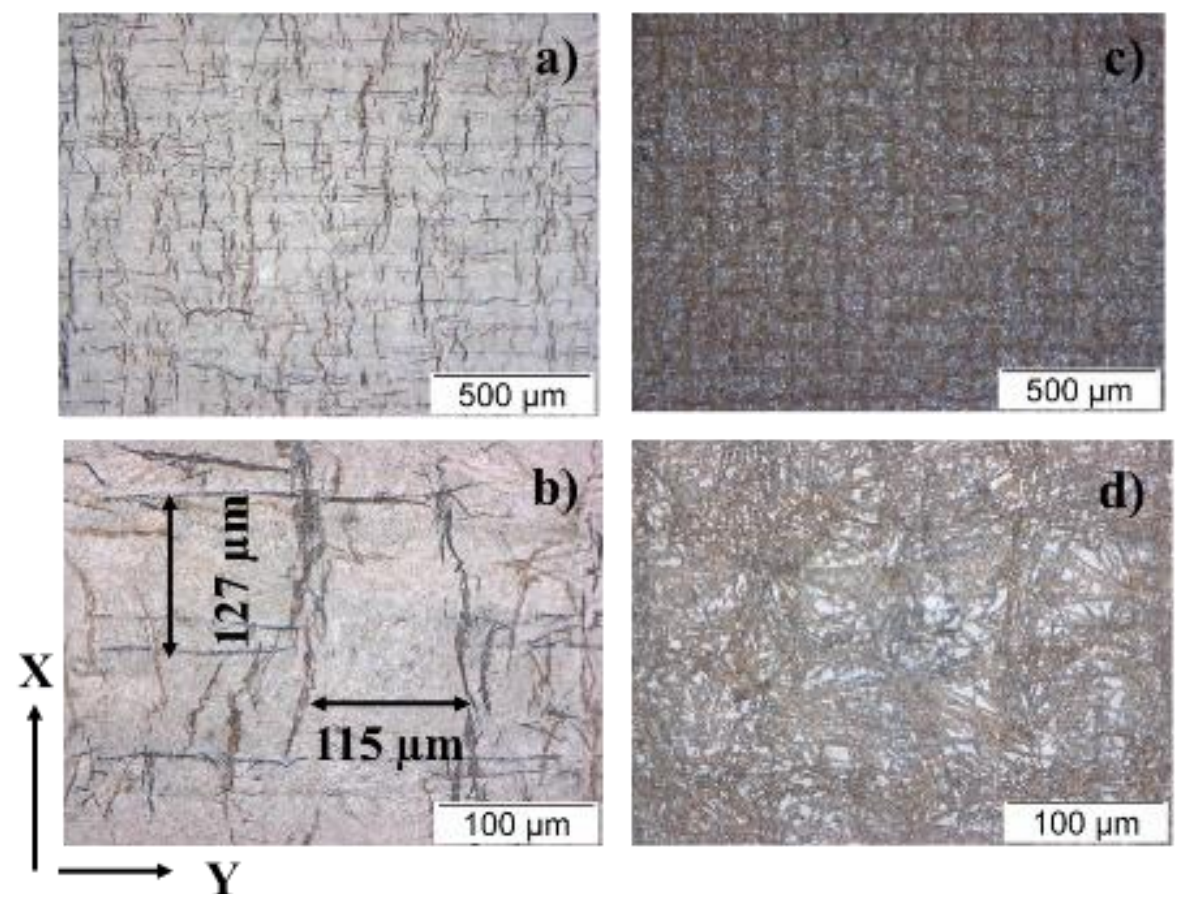

Figure 2.6 Microstructures in the scan direction of as-printed ( $\mathrm{a}$ and $\mathrm{b}$ ) and heat-treated (c and d) 420 stainless steel tensile bars fabricated by L-PBF.

scanning directions in L-PBF instead of adding mass.

For further understanding the microstructure, SEM images of the cross section in the build direction of the as-printed and heat-treated L-PBF parts are presented in Fig. 2.7. Combined with XRD analysis, the data suggests that the as-printed LPBF 420 stainless steel material resulted a microstructure consisting of austenite dendrites partially transformed into fine martensitic needles [56]. In addition, there were columnar dendritic structures at the bottom of the molten pool, cellular microstructures in the middle of the molten pool and coarse equiaxial crystals at the border between the molten pools.

Inside of a solidified melt pool, as seen in Fig. 2.7 (b), colonies of the parental austenitic cells (these cells or grains are the prior austenite cells or grains that have now been partially 
transformed to martensite) and martensite needles were observed. It is possible that the high cooling rates associated with laser consolidation results in a high nucleation rate along with the rapid growth of dendrites with very small spacing between the primary arms. It may also explain the high hardness in as-printed L-PBF parts. Fig. 2.7 (d, e, and f) represent the SEM images of the microstructure in heat-treated condition. No additional phases such as bainite or $\delta$-ferrites were noticed. The tempered microstructure is consistent with the improvement in ultimate tensile strength, yield strength and elongation of 420 stainless steel after heat treatment.
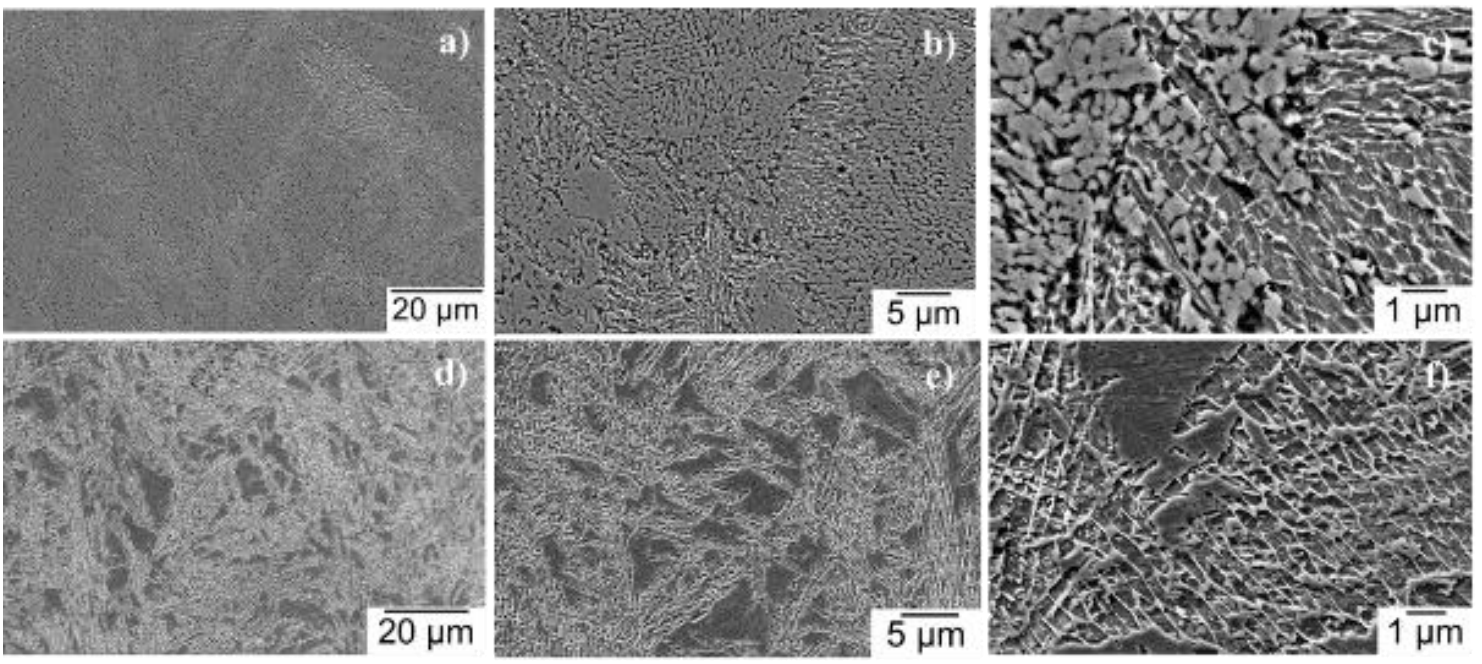

Figure 2.7 SEM images in the top row represent the microstructure of as-printed 420 stainless steel at three different magnifications. The microstructure of the heat-treated L-PBF parts can be observed in the bottom row.

\subsubsection{CORROSION PROPERTIES}

The cathodic and anodic polarization curves obtained from linear sweep voltametry (LSV) experiments on as-printed and heat treated 420 stainless steel fabricated by L-PBF are presented in Fig. 2.8. The trends in the L-PBF data are similar to the corrosion behavior with wrought stainless steels, where the regions of cathode reaction, passivation and the pitting are clearly apparent [39]. The anodic polarization curves suggest an extremely 
active dissolution after the sample reaches the breakdown potential $\left(\mathrm{E}_{\mathrm{b}}\right)$. Pitting corrosion was presumed to be preceded by a uniform thinning of the hydroxide/oxide protective film below the pitting potential. The as-printed and heat-treated L-PBF parts slightly differ in the potential range and potential where the passivation initiated.

The corrosion current $\left(I_{\text {corr }}\right)$, corrosion potential $\left(E_{\text {corr }}\right)$ and cathode and anode slope were measured using a standard extrapolation method to calculate the polarization resistance and corrosion rate $[57,58]$ and tabulated in Table 5 using the equations listed below:

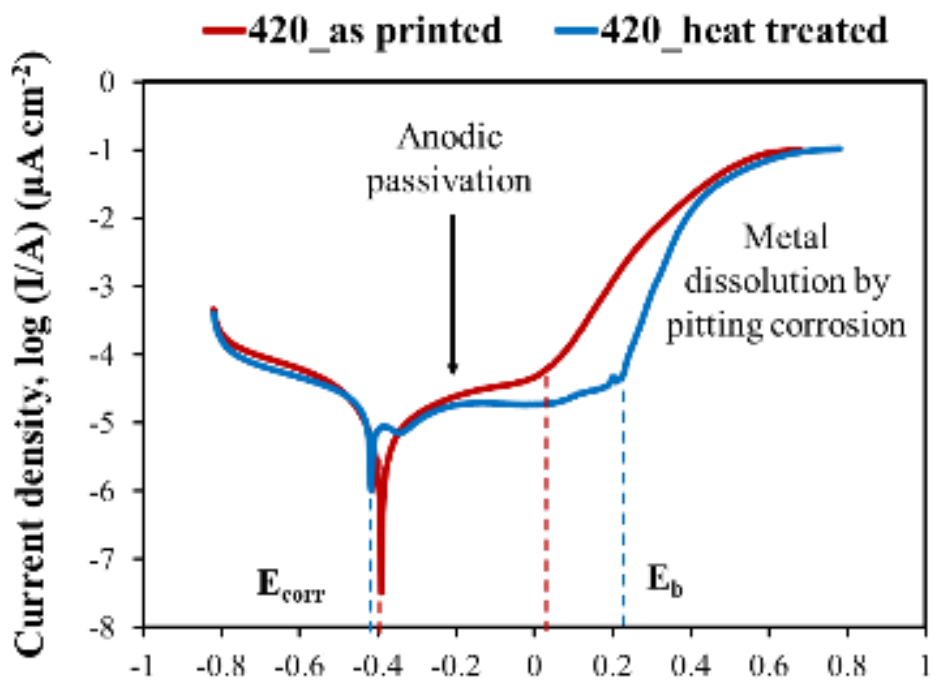

Potential (V)

Figure 2.8 Linear sweep voltammetry (LSV) curves for as-printed and heat-treated LPBF 420 stainless steel in aerated aqueous solution containing $3.5 \mathrm{wt} \%$ of $\mathrm{NaCl}$. Operating condition- reference electrode: $\mathrm{Ag} / \mathrm{AgCl}$; cathode: $\mathrm{Pt}$ wire; scan rate: $0.01 \mathrm{Vs}^{-1}$

$$
\text { Polarization resistance, } R p=\frac{1}{I_{c o r r}}\left(\frac{\beta_{a} \beta_{c}}{\beta_{a}+\beta_{c}}\right) \quad \text { Equation } 2
$$

Where the Tafel constants $\beta_{a}$ and $\beta_{c}$ represent the anodic and cathodic slope respectively.

$$
\text { Corrosion rate, } C R=\frac{I_{\text {corr }}}{\rho A} * k * E W \quad \text { Equation } 3
$$


where, $\rho$ is the Archimedes density of the material, $A$ is the exposed surface area to corrosion, $k$ is a constant ( $3.272 \mathrm{~m} /$ year) and $\mathrm{EW}$ is the equivalent weight of the material.

Table 2.4 Corrosion parameters of L-PBF 420 stainless steel in 3.5\% $\mathrm{NaCl}$ solution

\begin{tabular}{|c|c|c|c|c|c|}
\hline Process & $\begin{array}{c}\text { Corrosion } \\
\text { current } \\
\mathrm{I}_{\text {corr }} \\
\left(\mu \mathrm{A} / \mathrm{cm}^{2}\right)\end{array}$ & $\begin{array}{c}\text { Corrosion } \\
\text { potential } \\
\mathrm{E}_{\text {corr }}\end{array}$ & $\begin{array}{c}\text { Breakdown } \\
\text { potential } \\
\mathrm{E}_{\mathrm{b}}\end{array}$ & $\begin{array}{c}\text { Polarization } \\
\text { resistance } \\
\text { by Tafel plot } \\
\left(\Omega / \mathrm{cm}^{2}\right)\end{array}$ & $\begin{array}{c}\text { Corrosion rate } \\
(\mu \mathrm{m} / \text { year })\end{array}$ \\
\hline $\begin{array}{c}\text { L-PBF_as } \\
\text { printed }\end{array}$ & $2.85 \pm 0.4$ & $-0.39 \pm 0.03$ & $0.05 \pm 0.02$ & $17100 \pm 520$ & $28 \pm 2$ \\
\hline $\begin{array}{c}\text { L-PBF_heat } \\
\text { treated }\end{array}$ & $3.5 \pm 0.1$ & $-0.42 \pm 0.02$ & $0.22 \pm 0.01$ & $16800 \pm 700$ & $35 \pm 1$ \\
\hline
\end{tabular}

From Table 2.4, the as-printed L-PBF 420 stainless steel exhibited an $\mathrm{I}_{\text {corr }}$ of $2.85 \pm 0.4$ $\mu \mathrm{A} . \mathrm{cm}^{-2}$ which was slightly higher than $\mathrm{I}_{\text {corr }}$ of wrought 420 stainless steel $2.1 \pm 0.1 \mu \mathrm{A} . \mathrm{cm}^{-}$

${ }^{2}$. Heat-treated L-PBF parts exhibited a slightly higher current density of $3.5 \pm 0.1 \mu \mathrm{A} . \mathrm{cm}^{-}$

${ }^{2}$. Icorr gives a measure of passivation, the smaller the current, the greater the passivation. From Equation 2, it can be said that the polarization resistance is inversely proportional to the rate of corrosion, $\mathrm{I}_{\mathrm{corr}}$. The as-printed and heat-treated L-PBF 420 stainless steel parts exhibited a polarization resistance of $17,100 \pm 520 \Omega \cdot \mathrm{cm}^{-2}$ and $16,800 \pm 700 \Omega . \mathrm{cm}^{-2}$ respectively which was slightly lower than wrought properties of $18,700 \pm 350 \Omega . \mathrm{cm}^{-2}$. The corrosion rate is linearly proportional to the corrosion current density and calculated using Equation 3. In this study, the L-PBF 420 stainless steel parts showed a corrosion rate $28 \pm 2 \mu \mathrm{m} /$ year in the as-printed condition. A slight higher value, $34 \pm 1 \mu \mathrm{m} /$ year, was observed with the heat-treated parts. In contrast, wrought 420 stainless steel has been reported to have a corrosion rate of $23 \pm 2 \mu \mathrm{m} / \mathrm{year}$ [59]. From the Tafel plots, a corrosion potential $\left(\mathrm{E}_{\text {corr }}\right)$ was calculated to be $-0.39 \pm 0.03 \mathrm{~V}$ for the as-printed 420 stainless steel 
parts. In comparison, the heat-treated L-PBF parts exhibited a corrosion potential of -0.42 $\pm 0.02 \mathrm{~V}$.

As- printed
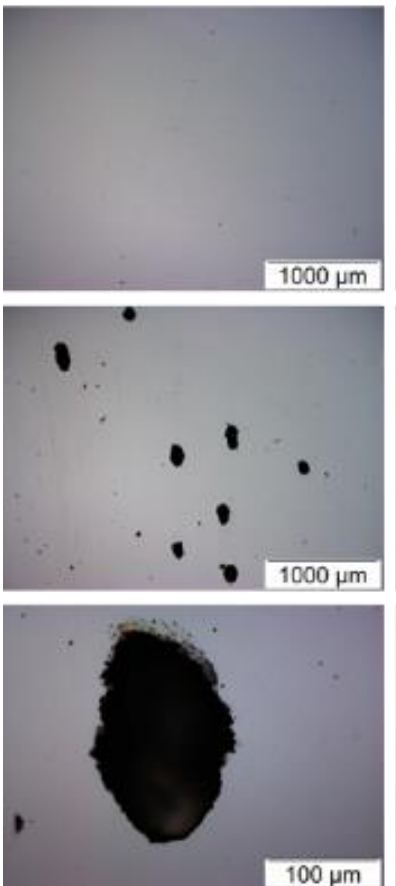

Heat- treated
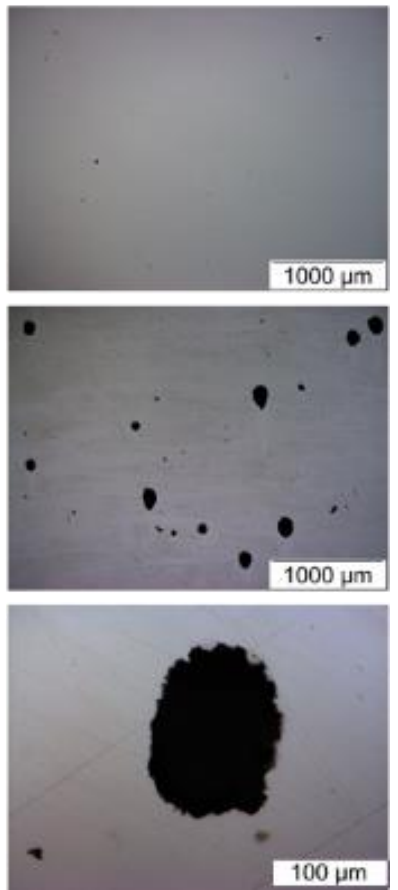

Figure 2.9 Optical images of as-printed (left column) and heat-treated (right column) 420 stainless steel parts fabricated by L-PBF: (top) initial surface (middle) corroded surface, and (bottom) pits on the corroded surface at higher magnification.

The corrosion potential is determined as the potential where the anodic reaction of metal dissolution is equal to the rate of the cathodic reaction. The higher the corrosion potential, the more resistant is the passive layer [37]. The breakdown potential $\left(E_{b}\right)$ is determined at the inflection point. It is an indication of the stability of the passivation layer formed on the metal surface. In this study, the heat-treated 420 stainless steel parts showed the highest $\mathrm{E}_{\mathrm{b}}$ at $0.22 \pm 0.01 \mathrm{~V}$. In comparison, the as-printed 420 stainless steel experienced breakdown of the passive layer at $0.05 \pm 0.02 \mathrm{~V}$.

Fig. 2.9 shows the optical images of the as-printed and heat-treated L-PBF samples taken before and after corrosion tests. It can be observed that regular large pores formed on the 
metal surface following the breakdown potential, indicative of pitting corrosion [60]. No intergranular cracking corrosion was observed in this study. No significant difference was found between as-printed and heat-treated samples. Therefore, it can be concluded that 420 stainless steel fabricated by L-PBF retained its corrosion properties after heat treatment and exhibits improved pitting resistance. The quantitative difference between wrought and L-PBF parts may be explained by differences in the microstructure as austenite phase offer higher corrosion resistance than the martensite phase [61]. Besides, the difference in $E_{b}$ can be caused by the removal of residual stresses through heat-treatment.

\subsection{CONCLUSIONS}

This study reports for the first time, a detailed examination of the mechanical and corrosion properties as well as microstructure of L-PBF 420 stainless steel in the as-printed and heattreated conditions. From the reports it can be concluded that mechanical properties significantly improve following the heat- treatment conditions while corrosion properties remain relatively unchanged. In the as-printed condition, 420 stainless steel tensile bars $(99.2 \pm 0.3 \%)$ exhibited an ultimate tensile strength of $1050 \pm 25 \mathrm{MPa}$, yield strength of $700 \pm 15 \mathrm{MPa}$, and elongation of $2.5 \pm 0.2 \%$. After heat treatment, the ultimate tensile strength improved to $1520 \pm 30 \mathrm{MPa}$, yield strength of $950 \pm 20 \mathrm{MPa}$, and elongation increased to $6.3 \pm 0.2 \%$ respectively. There was no significant change in the hardness of as-printed and heat-treated parts which were found to be HRC $55 \pm 1$ and HRC $53 \pm 1$ respectively. These results were slightly lower than the properties of wrought 420 stainless steel but higher than the properties achieved by MIM.

The above property trends were correlated to microstructure in the following manner. The cross section of the L-PBF parts in the build direction was observed to consist of austenite 
$(\gamma)$ and martensite $(\alpha)$ phases. Fine martensitic needles were dispersed in the austeniticferritic region. The microstructure in the scan direction showed martensite phases formation on the edges of overlapping the scan tracks where rapid cooling occurred. After heat treatment, a tempering of martensite phases was observed which contributed to the improvement in ultimate tensile strength, yield strength and elongation of L-PBF 420 stainless steel without appreciable change in hardness.

The as-printed L- PBF parts showed a corrosion current of $2.85 \pm 0.4 \mu \mathrm{A} . \mathrm{cm}^{-2}$, a polarization resistance of $17100 \pm 520 \Omega . \mathrm{cm}^{-2}$ and a corrosion rate of $28 \pm 2 \mu \mathrm{m} /$ year which are comparable with corrosion properties of wrought 420 stainless steel. Apart from increased pitting resistance, there was no significant difference in corrosion properties after heat- treatment as corrosion current, polarization resistance and corrosion rate. 


\section{CHAPTER 3}

\section{EFFECTS OF LAYER THICKNESS IN LASER-POWDER BED FUSION OF 420 STAINLESS STEEL}

\subsection{INTRODUCTION}

Laser-powder bed fusion (L-PBF) offers the flexibility to fabricate complex threedimensional components by sequentially melting layers of metal powder using a focused laser beam. In L-PBF, the major process parameters influencing part quality include laser power, scan speed, trace width, and layer thickness. The number of cycles involving melting, solidifying and re-melting of the metal powders increases as layer thickness is decreased $[62,63]$. In addition, the part-build time increases as layer thickness is decreased. Further, even previously solidified layers can experience microstructural changes and residual stresses based on the thermal gradients formed during fabrication [56]. Therefore, it is important to understand how microstructures and subsequently properties evolve as a function of layer thickness during L-PBF. The present study addresses this knowledge gap in the context of 420 stainless steel which is being investigated in our group to fabricate industrial and surgical tools $[10,26,27,64,65]$.

AISI 420 stainless steel, a martensitic steel, is a widely used material in tooling applications as it offers high strength, hardness and corrosion properties [28]. The microstructure of 420 
stainless steel can consist of martensite (body-centered tetragonal), retained austenite (facecentered cubic), ferrite (body-centered cubic) phases and dissolved or undissolved carbides depending on the composition and thermal history [29]. During rapid cooling or quenching, the martensite phase appears through a diffusionless transformation from the austenite phase [30]. This is termed as austenite-martensitic transformation, typically occurring in the temperature range from 720 to $400^{\circ} \mathrm{C}$. Depending on the carbon content and cooling rate, 420 stainless steel can also experience tempered martensite [66, 67]. All these metallurgical evolution influence the mechanical properties of the alloy [68]. Previous studies have reported the effects of layer thickness on the density and microstructure of titanium alloys and superalloys but to the best of our knowledge, none on 420 stainless steel [69-71]. This study examined the effects of layer thickness on the densification, microstructure and properties of 420 stainless steel where these attributes are heavily influenced by thermal history during processing $[72,73]$.

Corrosion resistance is another important property of 420 stainless steel and depends on porosity and microstructure. The corrosion resistance of stainless steel is attributed to the presence of alloyed chromium (> 11 wt.\%), enabling the formation of a chromium oxide $\left(\mathrm{Cr}_{2} \mathrm{O}_{3}\right)$ based passive film on the metal surface [34, 35]. In previous studies, linear sweep voltammetry (LSV) experiments were conducted in $3.5 \%$ of $\mathrm{NaCl}$ solution to characterize the corrosion behavior of wrought 420 stainless steel [36-38, 74]. This study also investigated the corrosion performance of 420 stainless steel fabricated by varying the layer thickness during L-PBF [39]. 


\subsection{METHODOLOGY}

\subsubsection{MATERIALS}

Pre-alloyed 420 stainless steel powder (Sandvik Osprey Ltd., U.K) atomized under nitrogen gas was used in L-PBF studies with a particle size distribution: $\mathrm{D}_{10} 17 \mu \mathrm{m}, \mathrm{D}_{50} 28$ $\mu \mathrm{m}$ and $\mathrm{D}_{90} 47 \mu \mathrm{m}$. In ASTM standard tests, the apparent, tap and gas pycnometer densities of this powder were found to be $4.0 \pm 0.2,4.7 \pm 0.1$ and $7.68 \pm 0.01 \mathrm{~g} / \mathrm{cm}^{3}$ respectively. The $\mathrm{Cr}, \mathrm{C}$ and $\mathrm{Mn}$ content of the investigated powder were $12.8 \%, 0.3 \%$ and $0.78 \%$ respectively which was in the range of the corresponding AISI standard. Additional details of the powder characterization results are previously reported [74].

\subsubsection{L-PBF PROCESS}

L-PBF experiments were conducted on Concept Laser Mlab cusing R machine under argon gas. The detailed description of the machine is previously reported [74]. Initial samples (10 $\mathrm{mm} \times 10 \mathrm{~mm} \times 10 \mathrm{~mm}$ ), were built using an energy flux ranging from 0.58 to $1.67 \mathrm{~J} / \mathrm{mm}^{2}$ based on a continuous line scan varying between $-45^{\circ}$ and $+45^{\circ}$ angle in alternate layers. Minitab software (Version 18) was used for the statistical analysis of the variation of density as a function of process parameters listed in Table 3.1. Based on the results, flat tensile specimens as per the ASTM E8 standard with a gage dimensions ( $35 \mathrm{~mm} \times 6.2 \mathrm{~mm}$ x $3 \mathrm{~mm}$ ) were fabricated at an energy flux of $1.25 \mathrm{~J} / \mathrm{mm}^{2}$ (laser power of $90 \mathrm{~W}$, scan speed of $600 \mathrm{~mm} / \mathrm{s}$ and trace width of $120 \mu \mathrm{m}$ ) at layer thicknesses of 10,20 and $30 \mu \mathrm{m}$.

\subsubsection{HEAT TREATMENT}

L-PBF 420 stainless steel parts were heated in a furnace at $315^{\circ} \mathrm{C}$ for 2 hours followed by air cooling. Marsden et al recommended this condition based on the observation that the 
austenite-martensite transformation temperature range can be suppressed down to $300{ }^{\circ} \mathrm{C}$ if the chromium content is increased in 420 stainless steel [31].

\subsubsection{PHYSICAL PROPERTIES}

A Mettler Toledo XS104 weighing balance with a density measurement attachment was used to measure the density of the L-PBF parts according to the procedure outlined in ASTM 962-17. A Mitutoyo Surface Tester SJ-210 was used to measure the surface roughness of the L-PBF parts in accordance with ISO 4287-1997. A minimum of 4 tensile specimens under each condition was used to obtain density and surface roughness data.

\subsubsection{MECHANICAL PROPERTIES}

An MTS Exceed system (100 KN maximum load, $0.001 \mathrm{~s}^{-1}$ strain rate) was used to obtain stress-strain plots of 420 stainless steel fabricated by L-PBF. A minimum of four samples for each L-PBF condition was used to report UTS, YS, and \% elongation data. A Rockwell hardness tester (150 kg load) was used to measure the hardness parallel to the build direction based on a minimum of ten measurements per sample.

\subsubsection{MICROSTRUCTURE STUDIES}

Optical microscopy (Olympus CX21) and scanning electron microscopy (TESCAN Vega3) were used for examining the porosity and microstructure of as-printed and heattreated 420 stainless steel samples in the build and scan orientations. Microstructures were studied following the etching of polished specimens with Kalling reagent II. A Bruker D8 Discover $\mathrm{x}$-ray diffraction (XRD) instrument in conjunction with the ICDD database was used to identify phases in the L-PBF samples. Rietveld analysis was used to quantify the 
relative content of retained austenite and martensite phases. A minimum of 3 samples were used for each condition to report the quantitative data from XRD analysis.

\subsubsection{CORROSION PROPERTIES}

A Metrohm Autolab PGSTATION 100N system was used to conduct linear-sweep voltammetry (LSV) experiments in a medium consisting of 3.5\% $\mathrm{NaCl}$ solution at room temperature. Experimental details have been reported elsewhere [74]. Briefly, a reference potential of $0.543 \mathrm{~V}$, a potential range of $-600 \mathrm{mV}$ to $1000 \mathrm{mV}$, a forward scan rate of 0.01 $\mathrm{mV} \mathrm{s}^{-1}$, and a current density limit of $10 \mathrm{~mA} \cdot \mathrm{cm}^{-2}$ was used. Four specimens with a surface area of $1 \mathrm{~cm}^{2}$ were prepared for each L-PBF condition in the as-printed and heat-treated states for extracting the Tafel constants from the LSV experiments.

\subsection{RESULTS AND DISCUSSION}

\subsubsection{DENSITY}

Fig. 3.1(a) represents the Archimedes density as a function of energy flux for layer thicknesses of 10, 20 and $30 \mu \mathrm{m}$. The energy flux $\left(E_{f}\right)$ is a lumped parameter that combines three L-PBF process variables, viz. laser power $(P)$, scan speed $(v)$ and trace width $(h)$ using the following equation:

$$
E_{f}=\frac{P}{h * v} \quad \text { Equation } 1
$$

Initially test specimens in the form of cubes with $10 \mathrm{~mm}$ sides were fabricated under a range of L-PBF process conditions. For these initial experiments, the laser power was varied at 70 and $90 \mathrm{~W}$, scan speed varied at 600,800 and $1000 \mathrm{~mm} / \mathrm{s}$ and trace width were varied at 90 and $120 \mu \mathrm{m}$. Thus, overall, energy flux was varied from 0.58 to $1.67 \mathrm{~J} / \mathrm{mm}^{2}$ in this processing window for layer thickness of 10,20 and $30 \mu \mathrm{m}$ listed in Table 3.1. 
a)

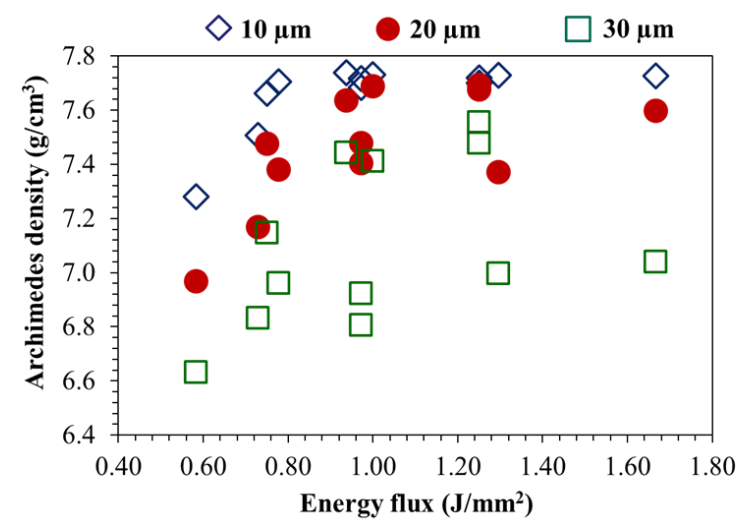

b)

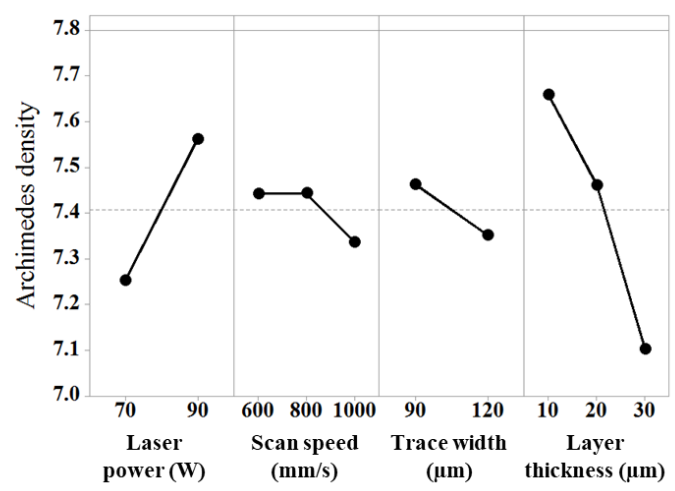

Figure 3.1 (a) The variation of part density as a function of energy flux from L-PBF experiments with AISI 420 stainless steel. (b) ANOVA analysis showing the influence of laser power, scan speed, trace width and layer thickness on the density of L-PBF parts.

Table 3.1 L-PBF processing conditions used with AISI 420 stainless steel powder

\begin{tabular}{|c|c|c|c|c|}
\hline $\begin{array}{l}\text { Processing } \\
\text { parameter }\end{array}$ & $\begin{array}{c}\text { Laser power } \\
P \\
\text { W }\end{array}$ & $\begin{array}{c}\text { Trace width } \\
v \\
\mu \mathrm{m}\end{array}$ & $\begin{array}{c}\text { Scan speed } \\
h \\
\mathrm{~mm} / \mathrm{s}\end{array}$ & $\begin{array}{c}\text { Energy flux } \\
E_{f}=P /\left(v^{*} h\right) \\
\mathrm{J} / \mathrm{mm}^{2}\end{array}$ \\
\hline \multirow{12}{*}{$\begin{array}{l}\text { Layer thickness of } \\
10,20 \text { and } 30 \mu \mathrm{m}\end{array}$} & \multirow{6}{*}{70} & \multirow{3}{*}{90} & 600 & 1.30 \\
\hline & & & 800 & 0.97 \\
\hline & & & 1000 & 0.78 \\
\hline & & \multirow{3}{*}{120} & 600 & 0.97 \\
\hline & & & 800 & 0.73 \\
\hline & & & 1000 & 0.58 \\
\hline & \multirow{6}{*}{90} & \multirow{3}{*}{90} & 600 & 1.67 \\
\hline & & & 800 & 1.25 \\
\hline & & & 1000 & 1.00 \\
\hline & & \multirow{3}{*}{120} & 600 & 1.25 \\
\hline & & & 800 & 0.94 \\
\hline & & & 1000 & 0.75 \\
\hline
\end{tabular}


From Fig 3.1(a), it can be generally seen that the density increased as the energy flux increased. Further, increasing the layer thickness generally resulted in a lower density. For a layer thickness of $10 \mu \mathrm{m}$, a density of $7.68 \pm 0.06 \mathrm{~g} / \mathrm{cm}^{3}$ was achieved using an energy flux above $0.8 \mathrm{~J} / \mathrm{mm}^{2}$. In comparison, for a layer thickness of $20 \mu \mathrm{m}$, a density of $7.41 \pm$ $0.25 \mathrm{~g} / \mathrm{cm}^{3}$ was achieved using an energy flux above $0.8 \mathrm{~J} / \mathrm{mm}^{2}$. On further increasing the layer thickness to $30 \mu \mathrm{m}$, a density of $7.18 \pm 0.26 \mathrm{~g} / \mathrm{cm}^{3}$ was achieved using an energy flux above $0.8 \mathrm{~J} / \mathrm{mm}^{2}$. Thus, the energy flux was not enough to densify the parts fabricated with increasing layer thickness [9].

Fig. 3.1(b) shows the ANOVA analysis of the influence of four L-PBF parameters on density. The data clearly demonstrates that an increase in density with an increase in layer thickness and laser power. However, the effects of scan speed and trace width on density were comparatively less significant within the experimental range. From Fig. 1(b), the layer thickness parameter was the most dominant factor ( $43 \%$ of the total effect) influencing the density of 420 stainless steel parts. Subsequently, further studies were conducted to analyze the evolution of other properties and microstructure by fabricating tensile bars with varying layer thickness, keeping the other three parameters fixed at $90 \mathrm{~W}$ laser power, $600 \mathrm{~mm} / \mathrm{s}$ scan speed, and $120 \mu \mathrm{m}$ trace width. The Archimedes density of these specimens decreased from $7.70 \pm 0.02$ to $7.35 \pm 0.05 \mathrm{~g} / \mathrm{cm}^{3}$ as the layer thickness was increased from 10 to 30 $\mu \mathrm{m}$.

\subsubsection{SURFACE MORPHOLOGY}

The surface roughness of ASTM standard tensile specimens fabricated at layer thicknesses of 10, 20 and $30 \mu \mathrm{m}$ are listed in Table 3.2. It is evident that as the layer thickness was increased from 10 to $30 \mu \mathrm{m}$, the surface roughness $\left(R_{\mathrm{a}}\right)$ increased from $3.0 \pm 0.2$ to $13.6 \pm$ 
$1.2 \mu \mathrm{m}$, which was qualitatively consistent with trends in surface roughness reported for other systems [75].
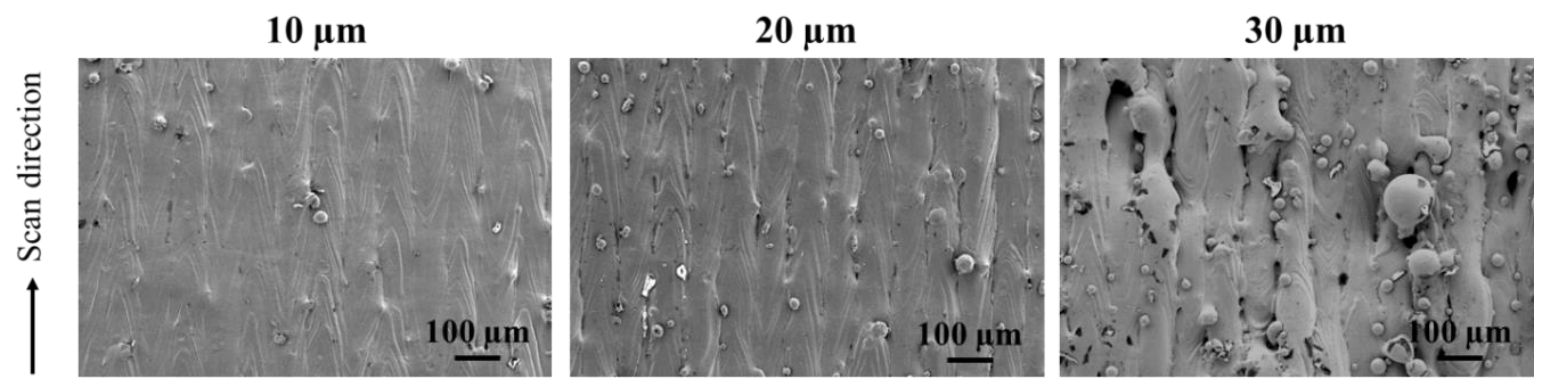

Figure 3.2 Scanning electronic microscopic images of the top surface of L-PBF 420 stainless steel parts varying layer thickness fabricated at an energy flux of $1.25 \mathrm{~J} / \mathrm{mm}^{2}$.

Table 3.2 Top surfaces of L-PBF 420 stainless steel parts of varying layer thickness fabricated at an energy flux of $1.25 \mathrm{~J} / \mathrm{mm}^{2}$

\begin{tabular}{|c|c|c|c|}
\hline Layer thickness $(\mu \mathrm{m})$ & 10 & 20 & 30 \\
\hline Surface roughness, $\mathrm{R}_{\mathrm{a}}(\mu \mathrm{m})$ & $3.0 \pm 0.2$ & $4.6 \pm 0.4$ & $13.6 \pm 1.2$ \\
\hline Density $\left(\mathrm{g} / \mathrm{cm}^{3}\right)$ & $7.70 \pm 0.02$ & $7.67 \pm 0.02$ & $7.35 \pm 0.05$ \\
\hline
\end{tabular}

The SEM images of the top surface for samples fabricated at different values of layer thickness are provided in Fig. 3.2. Laser scan tracks of the solidified melt pool were visible in these SEM images. Qualitatively, the width of scan tracks was close to the trace width $(120 \mu \mathrm{m})$ that was used to print these specimens. However, as the layer thickness was increased, the overlap between adjacent tracks was less visible. Some discontinuities among the tracks were also observed on the top surface of the L-PBF specimens fabricated at a layer thickness of $30 \mu \mathrm{m}$. In contrast, no such discontinuity was found in samples fabricated using layer thicknesses of 10 and $20 \mu \mathrm{m}$. Some beads were observed along the scan tracks. As the layer thickness was increased from 10 to $30 \mu \mathrm{m}$, the concentration of 
beads on top surface were also found to increase. The average size of the bead increased from $15 \pm 4$ to $45 \pm 15 \mu \mathrm{m}$ with an increase of layer thickness from 10 to $30 \mu \mathrm{m}$ The beading phenomenon correlates well with surface roughness changes and has been previously reported in studies involving other materials.[76, 77]

\subsubsection{CROSS-SECTIONAL MORPHOLOGY}

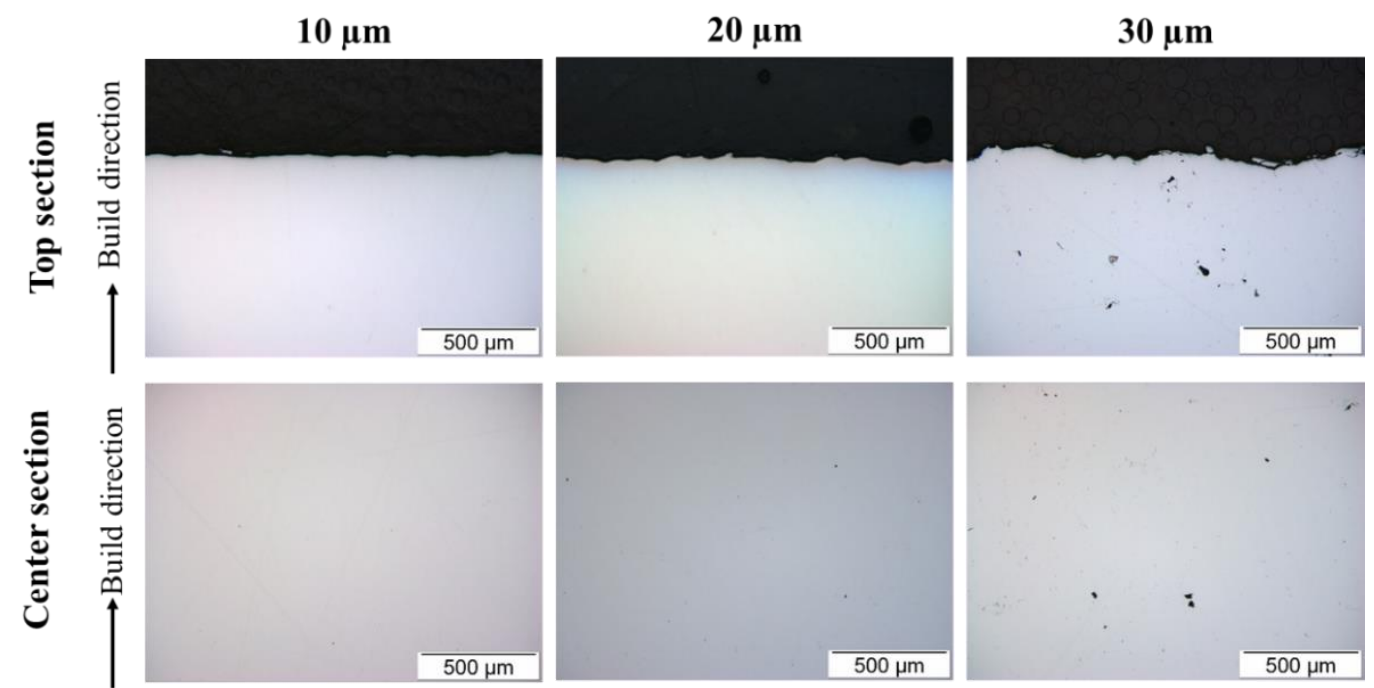

Figure 3.3 Polished cross-sectional images at top and center region where layer thickness was varied during printing of 420 stainless steel. Cross sections were taken parallel to build direction. Images were taken at $100 \mathrm{X}$ magnification.

Fig.3.3 represents the optical images of polished cross-sections of L-PBF specimens in parallel to the build direction. Images were collected at both top and center of the crosssections. These images were taken at a magnification of 50x and each image covered an area of $\sim 1.75 \mathrm{~mm} \times 1.75 \mathrm{~mm}$. It was evident that as the layer thickness was increased from 10 to $30 \mu \mathrm{m}$, porosity in the structure increased. Optical images related to the layer thickness of 10 and $20 \mu \mathrm{m}$ exhibited $0.3 \pm 0.02$ and $0.5 \pm 0.05 \%$ porosity, respectively, in the structure according to the standard ASTM grid method [78]. In contrast, L-PBF parts printed with a layer thickness of $30 \mu \mathrm{m}$ of exhibited $5.3 \pm 0.3 \%$ porosity. These values were qualitatively consistent with the trends in Archimedes density with varying layer 
thickness, as discussed in Table 3.2. The pores were observed to be mostly irregular in shape and dispersed in the structure. The average size of the pores was below $50 \mu \mathrm{m}$. In this study, the median particle size of 420 stainless steel powder was $\sim 28 \mu \mathrm{m}$. It is likely that the pores formed as a result of incomplete melting of powder particles as the overall energy density decreased [73].

\subsubsection{MECHANICAL PROPERTIES}

Table 3.3 indicates that 420 stainless steel specimens fabricated with lower layer thickness exhibited higher ultimate tensile strength and elongation. As the layer thickness was increased from 10 to $30 \mu \mathrm{m}$, the ultimate tensile strength of L-PBF 420 stainless steel decreased from $1130 \pm 35$ to $760 \pm 35 \mathrm{MPa}$ in the as-printed condition. The yield strength also reduced from $1020 \pm 25$ to $670 \pm 20 \mathrm{MPa}$ while the elongation was lowered from 2.8 \pm 0.3 to $1.5 \pm 0.2 \%$ with an increase in layer thickness from 10 to $30 \mu \mathrm{m}$. A significant improvement in mechanical properties were observed after heat treatment for all layer thicknesses, while overall trends in property variation with layer thickness mostly remained the same. Following heat-treatment, the ultimate tensile strength increased to $1540 \pm 20$ $\mathrm{MPa}$ for parts fabricated at a layer thickness of $30 \mu \mathrm{m}$ while it increased to $1020 \pm 30 \mathrm{MPa}$ by increasing the layer thickness to $30 \mu \mathrm{m}$. Similarly, on heat treatment, the yield strength increased to $1140 \pm 30 \mathrm{MPa}$ for parts fabricated at $10 \mu \mathrm{m}$ layer thickness and to $865 \pm 25$ $\mathrm{MPa}$ for parts fabricated at $30 \mu \mathrm{m}$ layer thickness. Also, the elongation increased to $6.2 \pm$ 0.3 and $3.8 \pm 0.3 \%$ for parts fabricated at 10 and 30 respectively, following heat-treatment. For comparison, metal injection molding (MIM) 420 stainless steel parts had an ultimate tensile strength of $1350 \pm 50 \mathrm{MPa}$, yield strength of $1100 \pm 40 \mathrm{MPa}$, and elongation of 2.0 $\pm 1.0 \%$ after heat treatment.[47, 51]. On the other hand, wrought 420 stainless steel is 
reported to have an ultimate strength of $1625 \pm 40 \mathrm{MPa}$, a yield strength of $1350 \pm 50 \mathrm{MPa}$ and an elongation of $7 \pm 1.0 \%[10,64]$. Thus, mechanical properties of 420 stainless steel fabricated using L-PBF were higher than MIM but slightly lesser than wrought properties.

Table 3.3 Mechanical properties of L-PBF 420 stainless steel fabricated by varying layer thickness

\begin{tabular}{|c|c|c|c|c|c|}
\hline $\begin{array}{c}\text { Layer } \\
\text { thickness } \\
\mu \mathrm{m}\end{array}$ & Condition & $\begin{array}{c}\text { Ultimate tensile } \\
\text { strength } \\
\mathrm{MPa}\end{array}$ & $\begin{array}{c}0.2 \% \text { yield } \\
\text { strength } \\
\mathrm{MPa}\end{array}$ & $\begin{array}{c}\text { Elongation } \\
\%\end{array}$ & $\begin{array}{c}\text { Hardness } \\
\text { HRC }\end{array}$ \\
\hline \multirow{2}{*}{10} & As-printed & $1130 \pm 35$ & $1020 \pm 25$ & $2.8 \pm 0.3$ & $57 \pm 1$ \\
\cline { 2 - 6 } & Heat-treated & $1540 \pm 20$ & $1140 \pm 30$ & $6.2 \pm 0.3$ & $55 \pm 1$ \\
\hline \multirow{2}{*}{20} & As-printed & $1050 \pm 25$ & $850 \pm 15$ & $2.5 \pm 0.2$ & $55 \pm 1$ \\
\cline { 2 - 6 } & Heat-treated & $1520 \pm 30$ & $1080 \pm 20$ & $6.3 \pm 0.2$ & $53 \pm 1$ \\
\hline \multirow{2}{*}{30} & As-printed & $760 \pm 35$ & $670 \pm 20$ & $1.5 \pm 0.2$ & $51 \pm 1$ \\
\cline { 2 - 6 } & Heat-treated & $1020 \pm 30$ & $865 \pm 25$ & $3.8 \pm 0.3$ & $49 \pm 1$ \\
\hline
\end{tabular}

Hardness is another important property of martensitic stainless steel, especially in the tooling industry. In this study, the hardness of L-PBF parts was also found to be influenced by the layer thickness. The hardness of L-PBF 420 stainless steel decreased from $57 \pm 1$ to $51 \pm 1 \mathrm{HRC}$ upon increasing the layer thickness from 10 to $30 \mu \mathrm{m}$ in the as-printed condition. Following heat-treatment, no significant change in hardness values or trends were observed, as hardness remained at $55 \pm 1$ and $49 \pm 1 \mathrm{HRC}$ with the layer thickness of 10 and $30 \mu \mathrm{m}$ respectively. For comparison, the hardness of wrought and MIM 420 stainless steel were mentioned as $53 \pm 2$ and $49 \pm 2 \mathrm{HRC}$ respectively [47, 51]. 


\subsubsection{MICROSTRUCTURE}
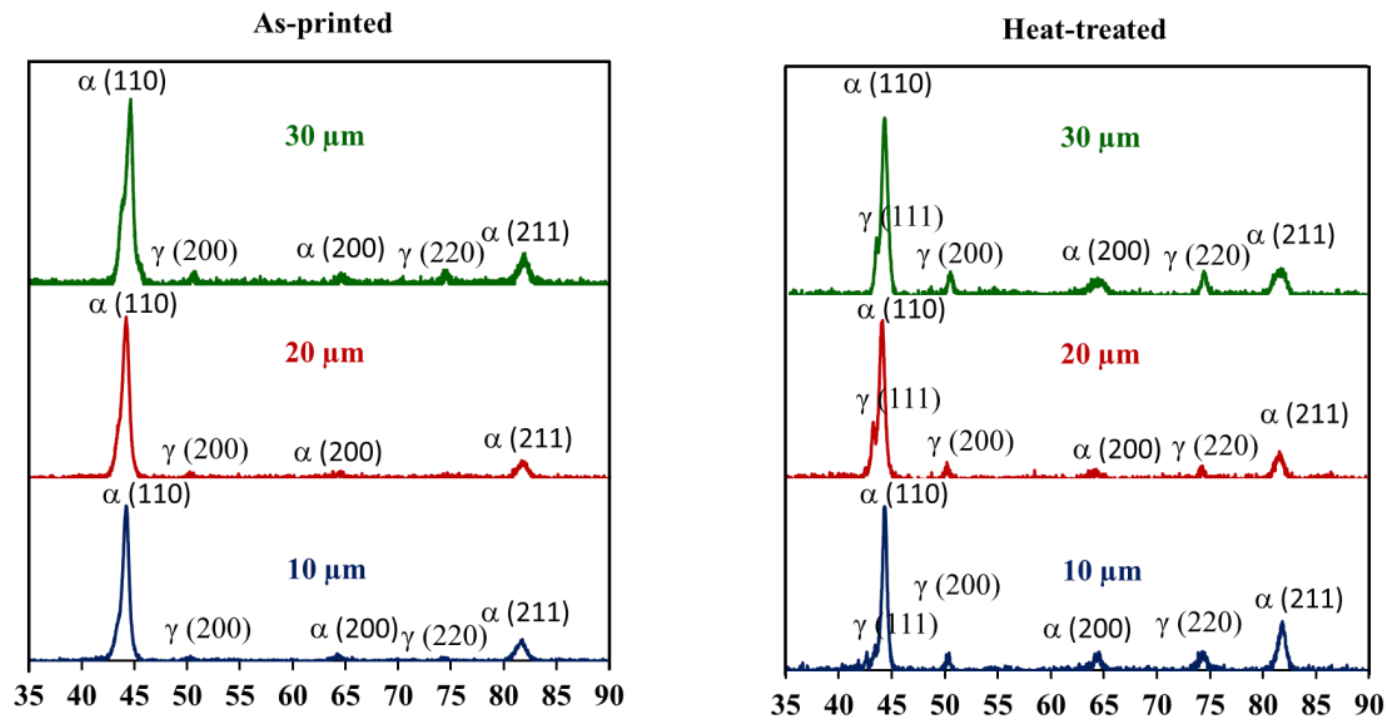

Figure 3.4 XRD patterns of as-printed and heat-treated L-PBF parts 2 printed varying layer thickness of 10, 20 and $30 \mu \mathrm{m}$ with 420 stainless steel powders. The martensite and austenite peaks are labelled as $\alpha$ and $\gamma$, respectively.

Fig. 3.4 shows the XRD patterns of 420 stainless steel as a function of layer thickness in the as-printed and heat-treated conditions. The starting 420 stainless steel powder was found to contain $\sim 67 \%$ austenite based on Rietveld analysis in our recent study [74]. Compared to the starting powder, the XRD patterns of as-printed L-PBF parts for all three layer thickness showed a dominance of martensite peaks such as $\alpha$ (110), $\alpha$ (200) and $\alpha$ (211). Austenite peaks, $\gamma(200)$ and $\gamma$ (220), were also observed but with relatively lower intensities. In the as-printed condition, the retained austenite content was found to be $15 \pm$ $10,15 \pm 12$, and $21 \pm 17 \%$ respectively for L-PBF specimens fabricated at layer thicknesses of 10, 20 and $30 \mu \mathrm{m}$. Following heat treatment, the retained austenite content was found to be $11 \pm 1,16 \pm 5$ and $25 \pm 3 \%$ respectively for L-PBF parts fabricated at layer thickness of 10,20 and $30 \mu \mathrm{m}$. It can be seen that the overall trends in austenite content variation with increased layer thickness remained the same. However, the standard 
deviation of retained austenite content was lower for heat-treated specimens compared to as-printed specimens in case of all layer thicknesses, suggesting a greater uniformity of microstructures following heat treatment. The martensite phase is formed in carbon steels by the rapid cooling of the austenite that carbon atoms do not have time to diffuse out of the crystal structure [79]. As a result, the face-centered cubic austenite transforms to a highly strained body-centered tetragonal martensite that is supersaturated with carbon. The shear deformations that result tend to increase dislocations which consequently influence strength and hardness. L-PBF intrinsically offers localized rapid cooling which is likely to contribute to the formation of martensite phases [46]. A high martensite content in the microstructure of L-PBF 420 stainless steel is consistent with the trends in high hardness and ultimate tensile strength as well as low elongation. The reduction in mechanical properties for samples fabricated at a layer thickness of $30 \mu \mathrm{m}$ appears to result from a reduction in density as well as martensite content.
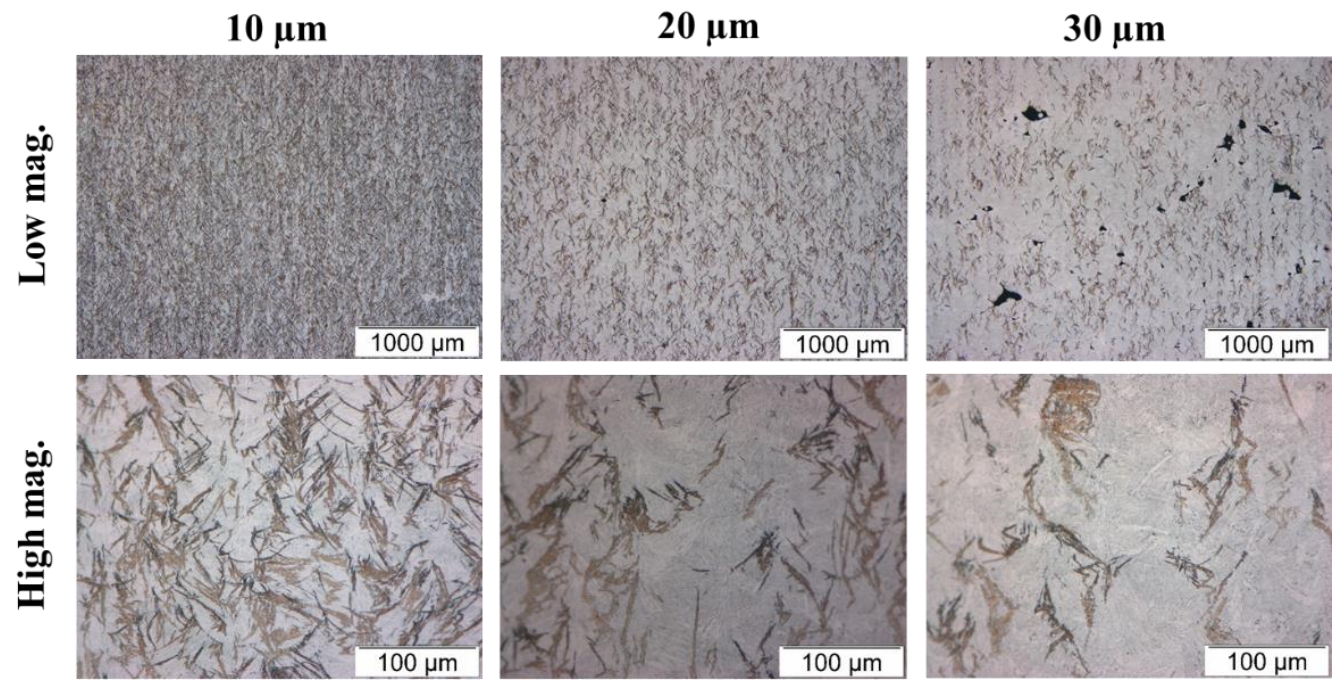

Figure 3.5 Microstructures in the build direction of as-printed L-PBF 420 stainless steel parts varying layer thickness at 10,20 and $30 \mu \mathrm{m}$ through optical microscopy. The images were collected after polishing with $1 \mu \mathrm{m}$ diamond paste followed by etching with Kalling II reagent. 
Etched cross-sectional microstructures at two different magnifications, for varying layer thickness, in as-printed specimens, along the build direction are shown in Fig. 3.5. In consistence with XRD data, the microstructure of L-PBF parts had a significant presence of martensitic phases. The gray or black lath phases can be associated with re-melting or tempering of martensite. As the parts with a layer thickness of 10 and $20 \mu \mathrm{m}$ experienced more thermal cycles, the density of gray and black lath was higher in these specimens compared to the microstructure obtained with a layer thickness of $30 \mu \mathrm{m}$. In this study, the higher content of martensite relative to retained austenite with 10 and $20 \mu \mathrm{m}$ of layer thickness can explain the higher strength and hardness in mechanical tests compared to the strength and hardness with $30 \mu \mathrm{m}$. Austenite is known to be associated with higher elongation. However, in this study, the relatively higher porosity content at a layer thickness of $30 \mu \mathrm{m}$ appears to have reduced the elongation despite an increase in austenite.

Etched cross-sectional microstructures at two different magnifications, for varying layer thickness, along the build direction, in heat-treated specimens are shown in Fig. 3.6. The microstructure of heat-treated L-PBF specimens consisted of gray color lath-like structure (tempered martensite) and plain white regions (austenite). As the layer thickness was increased from 10 to $30 \mu \mathrm{m}$, the density of austenite (white regions) seem to increase, consistent with XRD data. Melt pool boundaries were more clearly evident in the microstructure of specimens fabricated with a layer thickness of $10 \mu \mathrm{m}$, probably contributing to grain size effects on microstructure. The proportional change in the phase content also correlated to the improvement in mechanical properties after the heat treatment. 


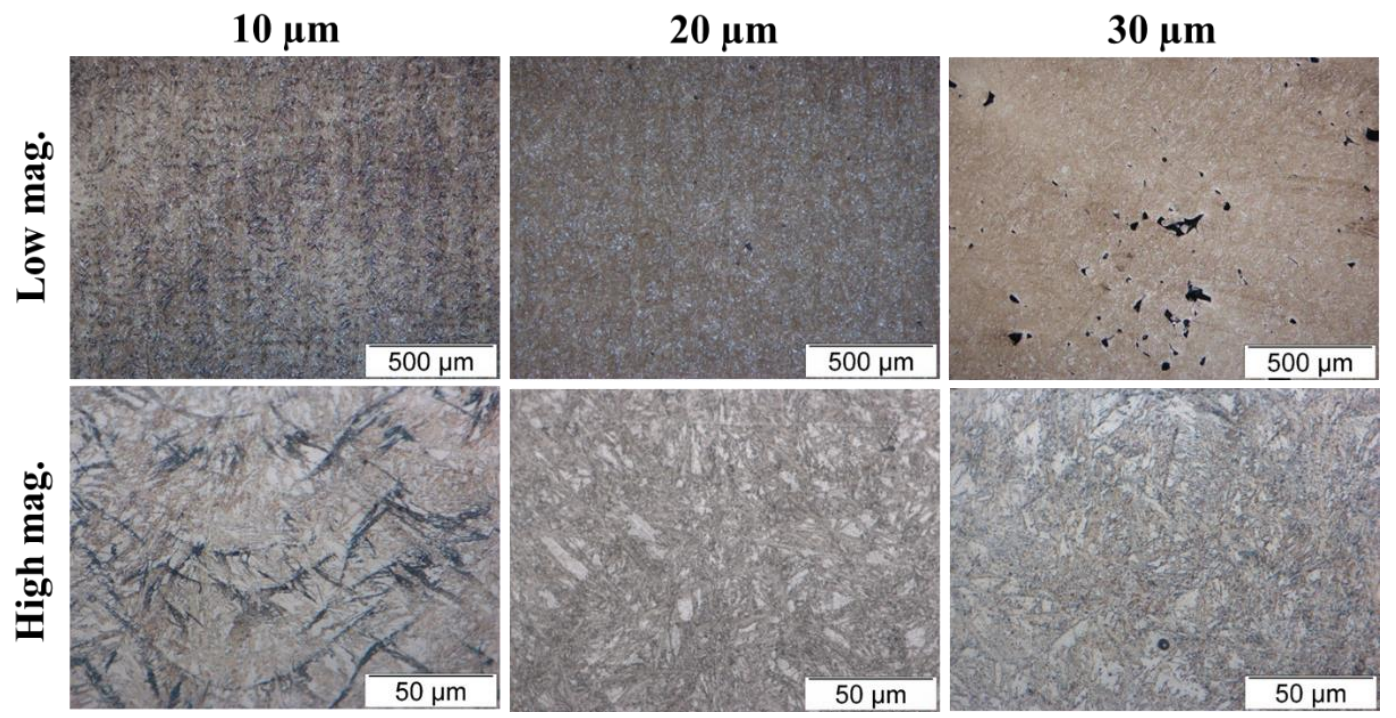

Figure 3.6 Microstructures through optical microscopy in the build direction of heattreated L-PBF 420 stainless steel parts varying layer thickness of 10, 20 and $30 \mu \mathrm{m}$. The images were collected after etching with Kalling II reagent.

Generally, porosity decreases thermal conductivity and solidification rate and influences the austenite formation [80]. The higher content of austenite in L-PBF parts with a layer thickness of $30 \mu \mathrm{m}$ may thus be explained by the higher amount of porosity in the microstructure. The higher martensite content in L-PBF parts fabricated with the layer thickness of 10 and $20 \mu \mathrm{m}$ specimens may also be as a result of the parts undergoing more thermal cycles compared to the specimens fabricated at a layer thickness of $30 \mu \mathrm{m}$. The higher amount of martensite and tempered martensite were also in agreement with the higher strength and elongation observed with the parts printed with lower layer thicknesses.

Fig 3.7 represents the SEM images of etched microstructures of L-PBF specimens fabricated at varying layer thickness, in the as-printed and heat-treated conditions. In the as-printed and heat-treated conditions, the specimens fabricated at a layer thickness of 10 $\mu \mathrm{m}$ showed finer martensite features compared to specimens fabricated using a layer thickness of $30 \mu \mathrm{m}$. The heat-treated microstructures were finer than as-printed 

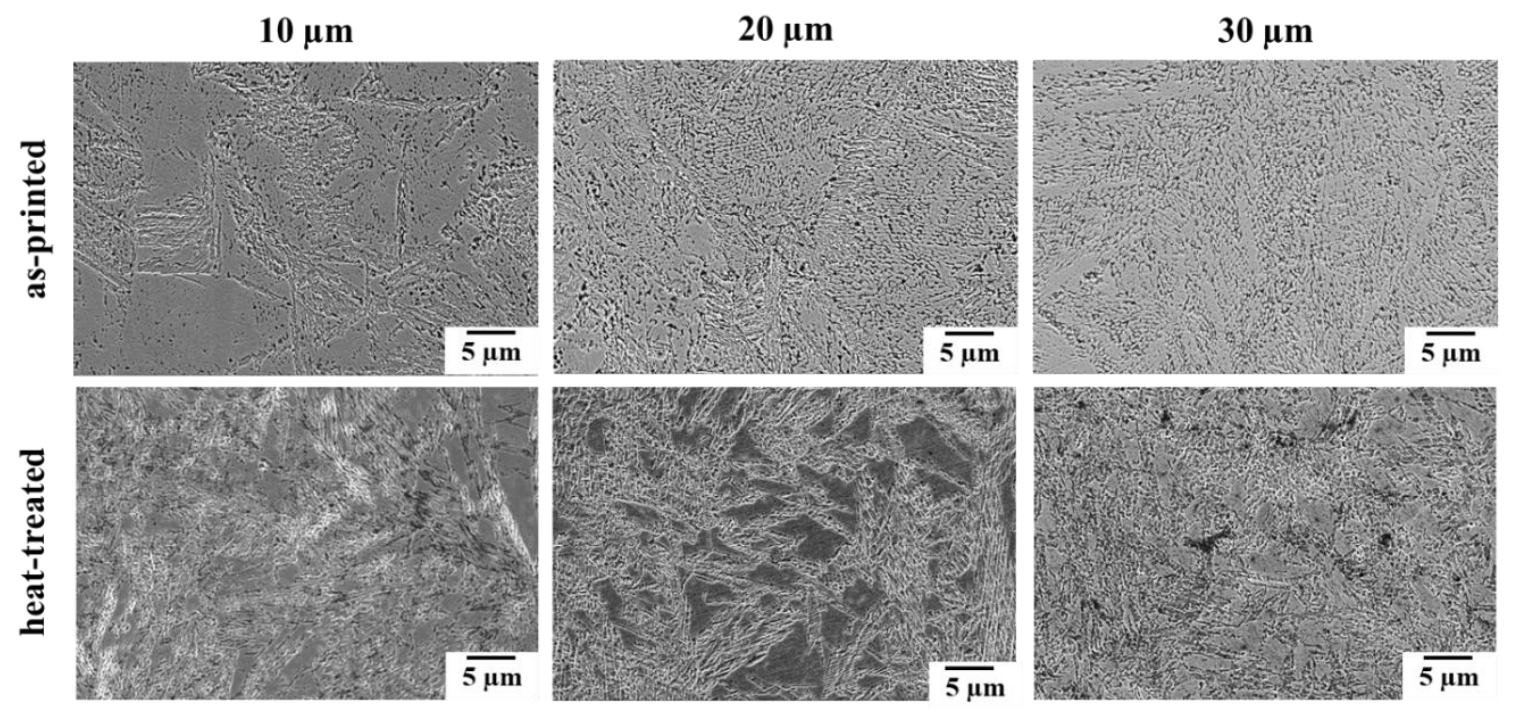

Figure 3.7 As-etched microstructures in the build direction of the as-printed and heattreated L-PBF 420 stainless steel fabricated by varying layer thickness.

microstructures indicating tempering. The microstructure of L-PBF specimens were significantly different from the microstructures reported for wrought 420 stainless steel [81]. For example, there was no distinguishable grain size or boundary in the microstructure which is a common feature of wrought 420 stainless steel. Further, no carbide precipitates were observed in the L-PBF microstructure irrespective of the layer thickness. The nature of melting and re-melting in L-PBF process could hve led to complete dissolution of carbides. In addition, the rapid solidification during L-PBF may have inhibited the carbide precipitation in as-printed condition and thus no noticeable carbide associated peak was found as has been previously reported for other systems [82]. 


\subsubsection{CORROSION BEHAVIOR}
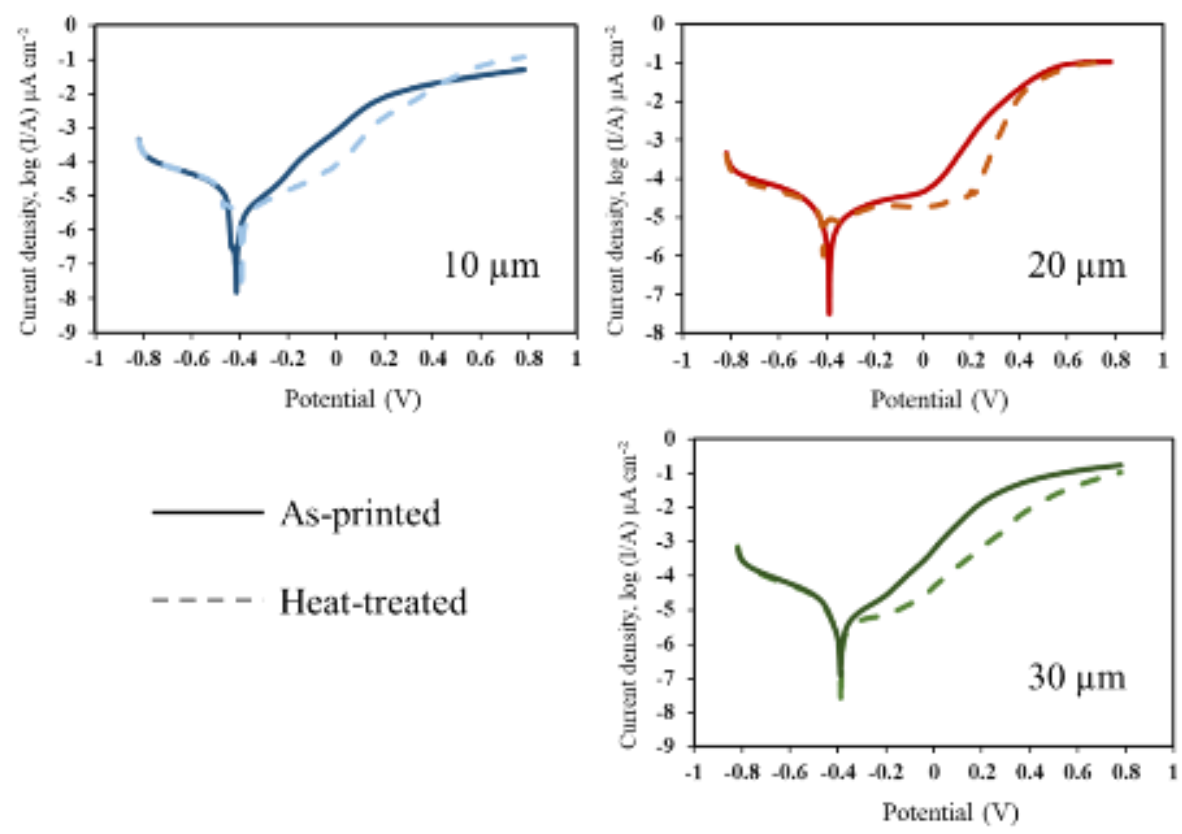

Figure 3.8 Linear sweep voltammetry (LSV) curves for as-printed and heat-treated LPBF 420 stainless steel varying layer thickness at 10, 20 and $30 \mu \mathrm{m}$ in aerated aqueous solution containing $3.5 \mathrm{wt} \%$ of $\mathrm{NaCl}$. Operating condition- reference electrode: $\mathrm{Ag} / \mathrm{AgCl}$; cathode: $\mathrm{Pt}$ wire; $\mathrm{pH}=6.0$; scan rate: $0.01 \mathrm{Vs}^{-1}$.

Outcomes of linear sweep voltammetry (LSV) experiments on the as-printed and heattreated 420 stainless steel with varying layer thickness are demonstrated in Fig. 3.8 by plotting potentiodynamic polarization curves [39]. The curve was used to determine the corrosion current $\left(I_{c o r r}\right)$, corrosion potential $\left(E_{c o r r}\right)$ and cathode and anode slope by the Tafel method. Then, the polarization resistance and corrosion rate can be calculated based on previously reported methods $[57,58]$. The equations used are listed below

$$
\text { Polarization resistance, } R p=\frac{1}{I_{\text {corr }}}\left(\frac{\beta_{a} \beta_{c}}{\beta_{a}+\beta_{c}}\right) \quad \text { Equation } 2
$$

Where the Tafel constants $\beta_{a}$ and $\beta_{c}$ represent the anodic and cathodic slope respectively.

$$
\text { Corrosion rate, } C R=\frac{I_{\text {corr }}}{\rho A} * k * E W \quad \text { Equation } 3
$$


where, $\rho$ is the Archimedes density of the material, $A$ is the exposed surface area to corrosion, $k$ is a constant ( $3.272 \mathrm{~m} / \mathrm{year})$ and $\mathrm{EW}$ is the equivalent weight of the material.
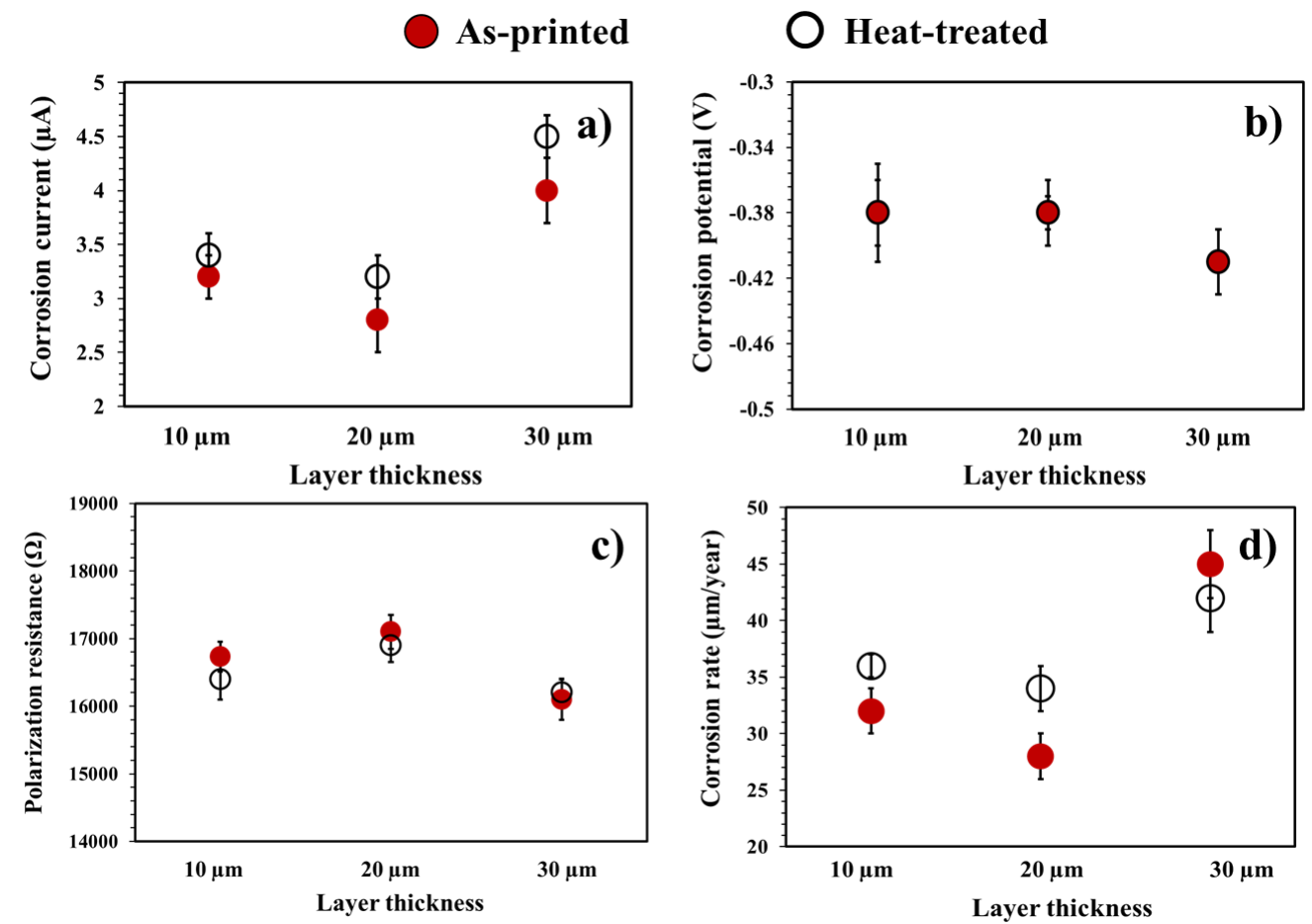

Figure 3.9 Corrosion properties such as a) corrosion current, b) corrosion potential, c) polarization resistance and d) corrosion current of L-PBF 420 stainless steel varying layer thickness at 10,20 and $30 \mu \mathrm{m}$ in as-printed and heat-treated condition.

Fig. 3.9 demonstrates the corrosion properties of L-PBF 420 stainless steel fabricated at layer thickness of 10,20 and $30 \mu \mathrm{m}$ characterized by Tafel plot. The corrosion current ( $\mathrm{I}_{\text {corr }}$ ) corelates to the ease of protective oxide layer formation during the corrosion experiment. From Fig. 9(a), it can be seen that in the as-printed condition, the corrosion current increased from $3.05 \pm 0.2$ to $4.10 \pm 0.3 \mu \mathrm{A} . \mathrm{cm}^{-2}$ when the layer thickness was increased from 10 to $30 \mu \mathrm{m}$. After heat-treatment, no significant change was seen as the corrosion current was $3.4 \pm 0.2$ and $4.5 \pm 0.3 \mu \mathrm{A} . \mathrm{cm}^{-2}$ for the layer thickness of 10 and 30 $\mu \mathrm{m}$ respectively. 
The corrosion potential is determined as the potential where the anodic reaction of metal dissolution is equal to the rate of the cathodic reaction [37]. Comparatively, layer thickness was found to be less influential on corrosion potential of L-PBF parts. From Fig. 3.9(b), in as-printed condition, as the layer thickness was changed from 10 to $30 \mu \mathrm{m}$, the corrosion potential decreased from $-0.38 \pm 0.2$ to $-0.4 \pm 0.2 \mathrm{~V}$. There was no significant change in corrosion potential after heat treatment as the equilibrium of anodic and cathodic regions occurred at the same position irrespective of the layer thickness.

Polarization resistance is defined as the resistance of a specimen to oxidation in presence of an external potential. This parameter is used to calculate corrosion rate by Equation 3 and presented in Fig. 3.9(c). A superior corrosion performance can be inferred from higher values of polarization resistance. In this study, as the layer thickness was increased from 10 to $30 \mu \mathrm{m}$, polarization resistance decreased from $16,800 \pm 250$ to $16,100 \pm 350 \Omega . \mathrm{cm}^{-2}$ respectively in the as-printed condition. After heat-treatment, polarization resistance varied from $16,600 \pm 300$ to $16,300 \pm 250 \Omega . \mathrm{cm}^{-2}$ by varying layer thickness from 10 to $30 \mu \mathrm{m}$.

The corrosion rate parameter can be used to describe the rate of material loss during an electrochemical corrosion test. As the layer thickness was varied from 10 to $30 \mu \mathrm{m}$, the corrosion rate of L-PBF parts increased from $31 \pm 2$ to $42 \pm 3 \mu \mathrm{m} /$ year in the as-printed condition. After heat treatment, the corrosion rate values were similar to the as-printed condition, being $34 \pm 2$ and $46 \pm 3 \mu \mathrm{m} /$ year by varying the layer thickness from 10 to 30 $\mu \mathrm{m}$. Overall, lower corrosion rates were observed for specimens fabricated at lower thicknesses. It is possible that for the layer thickness of 10 and $20 \mu \mathrm{m}$, a high density and 
a higher amount of martensite may have contributed to improved corrosion properties compared to specimens fabricated with a layer thickness of $30 \mu \mathrm{m}$.
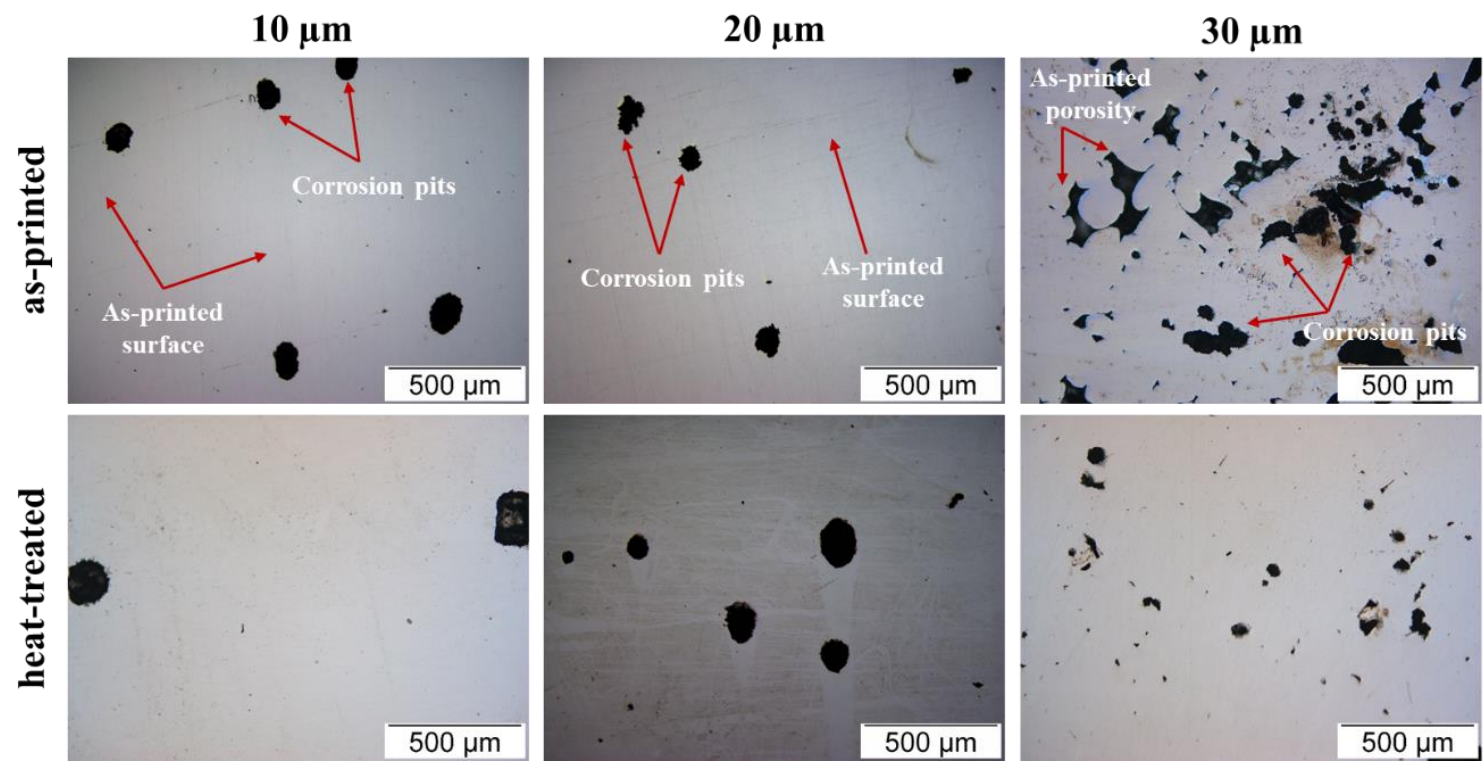

Figure 3.10 Optical images of corrosion pits observed after linear sweep voltammetry experiments on the as-printed and heat-treated L-PBF part varying layer thickness at 10,20 and 30.

Fig. 3.10 shows optical images of the as-printed and heat-treated L-PBF specimens. It can be observed that regular large pores evolved on the metal surface following the breakdown potential, indicative of pitting corrosion [60]. The density of corrosion pits increased as the layer thickness was increased from 10 to $30 \mu \mathrm{m}$. Besides, several corrosion pits were found to be originated from the as-printed pores in case of a layer thickness of $30 \mu \mathrm{m}$. In this study, L-PBF specimens did not appear to exhibit any intergranular cracking corrosion. The data from optical microscopy appeared to be consistent with improved corrosion resistance of specimens fabricated with a lower layer thickness. 


\subsection{CONCLUSIONS}

This study successfully demonstrated that density, surface morphology, mechanical and corrosion properties and microstructure were influenced as a function of layer thickness in L-PBF of 420 stainless steel. The following conclusions emerged from the study:

1) Parts printed with the layer thickness of 10 and $20 \mu \mathrm{m}$ were denser than the parts printed with a layer thickness of $30 \mu \mathrm{m}$. Above an energy flux of $0.8 \mathrm{~J} / \mathrm{mm}^{2}$, density decreased from $7.68 \pm 0.06 \mathrm{~g} / \mathrm{cm}^{3}$ to $7.18 \pm 0.26 \mathrm{~g} / \mathrm{cm}^{3}$ when the layer thickness was increased from 10 to $30 \mu \mathrm{m}$. Cross-sectional images of the L-PBF specimens with varying layer thickness correlated to the Archimedes densities.

2) Parts printed with a lower layer thickness exhibited lower surface roughness. With the increase of layer thickness from 10 to $30 \mu \mathrm{m}$, the surface roughness $\left(\mathrm{R}_{\mathrm{a}}\right)$ increased from $3.0 \pm 0.2$ to $13.6 \pm 1.2 \mu \mathrm{m}$.

3) Parts printed with lower a layer thickness exhibited better mechanical properties. In the as-printed condition, as the layer thickness was increased from 10 to $30 \mu \mathrm{m}$, the ultimate tensile strength decreased from $1130 \pm 35$ to $760 \pm 35 \mathrm{MPa}$, the yield strength decreased from $1020 \pm 25$ to $670 \pm 35 \mathrm{MPa}$ and the elongation decreased from $2.8 \pm 0.3$ to $1.5 \pm 0.2$ $\%$. Rockwell hardness was influenced by the layer thickness and decreased from $57 \pm 1$ to $51 \pm 1 \mathrm{HRC}$ with as increase layer thickness from 10 to $30 \mu \mathrm{m}$. After heat treatment, the ultimate strength, yield strength, elongation and hardness increased from $1020 \pm 30$ to 1540 $\pm 20 \mathrm{MPa}, 860 \pm 30$ to $1140 \pm 30 \mathrm{MPa}, 3.8 \pm 0.3$ to $6.2 \pm 0.3 \%$ and $50 \pm 1$ to $55 \pm 1 \mathrm{HRC}$ respectively when the layer thickness was decreased from 30 to $10 \mu \mathrm{m}$. 
4) The microstructure of the L-PBF parts in the build direction was observed to consist of martensite $(\alpha)$ rich phases relative to the starting powders. Parts printed using lower layer thickness were observed to be richer in martensite content. A higher martensite content was also observed in parts printed with 10 and $20 \mu \mathrm{m}$ of layer thickness as these parts went through more thermal cycles compared to parts printed with $30 \mu \mathrm{m}$. After heat treatment, tempering of the existing martensite contributed to the improvement in mechanical properties of L-PBF 420 stainless steel.

5) Corrosion properties determined by measuring the corrosion current, corrosion potential, polarization resistance and corrosion rate were found to be influenced by layer thickness. Corrosion properties reduced with increased layer thickness but remained relatively unaffected following heat treatment. 


\section{CHAPTER 4}

\section{EFFECTS OF NIOBIUM AND MOLYBDENUM ON THE PROPERTIES AND MICROSTRUCTURE OF 420 STAINLESS STEEL PROCESSED BY LASER- POWDER BED FUSION}

\subsection{INTRODUCTION}

Laser-powder bed fusion (L-PBF) process has been gaining significant interest in a broad range of applications as a result of the possibility to design and custom fabricate metallic components with highly intricate geometries [83-85]. The processing and properties of LPBF components depend on the chemical composition as well as particle characteristics $[22,86,87]$. In L-PBF, the specimen goes through a large number of thermal cycles potentially resulting in very different microstructures compared to wrought or other powder net-shaping processes such as powder metallurgy (PM) and metal injection molding (MIM) $[72,88]$.

AISI 420 stainless steel has high chromium (12 to 14\%) and medium carbon content (> $0.15 \%$ ) in its chemical composition [12]. Following heat treatment, the material has useful properties including high hardness, strength and corrosion resistance, making it a suitable choice for surgical tools and mold making.[24, 27, 64]. However, the L-PBF of 420 stainless steel has not been well investigated $[11,20]$. Our recent work on the L-PBF of 420 stainless steel reported a UTS of $1050 \pm 25 \mathrm{MPa}$, yield strength of $700 \pm 25 \mathrm{MPa}$, and an elongation of $2.5 \pm 0.2 \%$ in the as-printed condition which were lower than the 
properties of wrought 420 stainless steel (UTS $1625 \pm 40 \mathrm{MPa}$, a yield strength $1350 \pm 50$ $\mathrm{MPa}$, and elongation $7 \pm 1.0 \%$ ) [74]. Thus, the exploration of ways to improve L-PBF properties of 420 stainless steel would expand the range of applications.

$\mathrm{Nb}$ and Mo have a higher affinity to $\mathrm{C}$ than $\mathrm{Cr}$. In low $\mathrm{C}$ alloy steels, the addition of $\mathrm{Nb}$ has been reported to improve the mechanical properties [89]. $\mathrm{Nb}$ can also decrease the hardenability of steel because it forms very stable carbides, thereby reducing the amount of $\mathrm{C}$ dissolved into the austenite during heat treatment $[90,91]$. Another role of $\mathrm{Nb}$ in cast and wrought stainless steels is as a stabilizing agent to reduce the tendency to undergo intergranular corrosion [92]. Mo has also been found to improve corrosion resistance in martensitic stainless steels $[93,94]$. Though 420 stainless steel possessed good corrosion resistance in the heat-treated condition, during annealing it can undergo carbide formation which reduces its corrosion resistivity significantly.

To the best of our knowledge, there has been no previous L-PBF study in the literature that has focused on understanding the effects of $\mathrm{Nb}$ and Mo on the processing, properties and microstructure of 420 stainless steel. The present study aims to address the knowledge gap concerning the effects of $\mathrm{Nb}(1.2 \mathrm{wt} . \%)$ and Mo $(0.57 \mathrm{wt} . \%)$ addition on the L-PBF processing, microstructure, physical, mechanical and corrosion properties of 420 stainless steel in the as-printed and heat-treated conditions. A comparison of these attributes is also made to data presented in our recent publication on the L-PBF of 420 stainless steel without the addition of $\mathrm{Nb}$ and $\mathrm{Mo}$ in order to understand and highlight the differences between the two compositions [74]. 


\subsection{MATERIALS AND METHODS}

\subsubsection{MATERIALS}

Nitrogen gas-atomized and pre-alloyed 420 stainless steel powders (with and without $\mathrm{Nb}$ and Mo) were supplied by Sandvik Osprey Ltd., U.K. and used to conduct L-PBF experiments. The corresponding chemical compositions were also obtained from the manufacturer. Powders with 1.2 wt. $\% \mathrm{Nb}$ and 0.57 wt.\% Mo were used in the present study. The particle size distribution, including $\mathrm{D}_{10}, \mathrm{D}_{50}$ and $\mathrm{D}_{90}$, of powders was characterized using a Microtrac laser diffraction system. Powder attributes such as helium pycnometer, apparent and tap densities were recorded using ASTM standards B923, B212 and B527, respectively.

\subsubsection{L-PBF PROCESS}

L-PBF experiments were conducted in a Concept Laser Mlab cusing $\mathrm{R}$ machine. The machine was equipped with a $1050 \mathrm{~nm}$ wavelength, Yb-fiber laser capable of providing a maximum power of $100 \mathrm{~W}$ by using a beam diameter was $50 \mu \mathrm{m}$. The 420 stainless steel powders were spread on a mild steel build plate using a Y-shaped rubber coater blade. The building chamber was first evacuated and then filled with argon gas. This resulted in an atmosphere with a low oxygen content during printing. The layer thickness was chosen as $20 \mu \mathrm{m}$ as an optimization of physical and mechanical properties, as discussed in a previous study [74]. The energy density was initially varied from 25 to $80 \mathrm{~J} / \mathrm{mm}^{3}$ to fabricate NIST standard density cubes of $10 \mathrm{~mm} \times 10 \mathrm{~mm}$ x $10 \mathrm{~mm}$. Based on the results of density

measurements, an energy density of $63 \mathrm{~J} / \mathrm{mm}^{3}$ (a laser power of $90 \mathrm{~W}$, a scan speed of 600 $\mathrm{mm} / \mathrm{s}$ and a trace width of $120 \mu \mathrm{m}$ ) was chosen to fabricate ASTM E8 standard tensile specimens of a gage length of $35 \mathrm{~mm}$, a width of $6.2 \mathrm{~mm}$, a thickness of $3 \mathrm{~mm}$, and a total 
length of $75 \mathrm{~mm}$. In this study, a constant scan strategy used was based on a line pattern with alternating layers at $-45^{\circ}$ and $+45^{\circ}$ angle for all specimens. SolidWorks and AutoFab software were used to design and slice the print coupons and control print parameters.

\subsubsection{HEAT TREATMENT}

As-printed L-PBF 420 stainless steel tensile specimens were heat treated in an air furnace at $315^{\circ} \mathrm{C}$ for 2 hours followed by air cooling. The ramp up rate was $15^{\circ} \mathrm{C} / \mathrm{min}$. This heating cycle was based on a previous study reported by Marsden et al [31]. The temperature was selected based on a report that the austenite-martensite transformation temperature range can be suppressed down to $300{ }^{\circ} \mathrm{C}$ when the chromium content is increased [32].

\subsubsection{PHYSICAL CHARACTERIZATION}

ASTM and ISO standard procedures were followed to report the physical properties of LPBF specimens. At first, the Archimedes density of the as-printed and heat-treated L-PBF parts was measured using a Mettler Toledo XS104 weighing balance according to the ASTM standard, 962-17. The surface roughness $\left(\mathrm{R}_{\mathrm{a}}\right)$ of the L-PBF parts was characterized with a Mitutoyo SJ-210 surface profilometer according to the ISO 4287-1997 standard. L-PBF specimens built from 420 stainless steel with and without $\mathrm{Nb}$ and Mo were cross sectioned and polishing using standard metallography to observe internal structure.

\subsubsection{MECHANICAL CHARACTERIZATION}

Mechanical tests of L-PBF 420 stainless steels with and without $\mathrm{Nb}$ and Mo were conducted in an MTS Exceed hydraulic dual-column testing system in the as-printed and heat-treated conditions. A minimum four samples of each type were tested using a load cell of $50 \mathrm{kN}$ and a strain rate of $0.001 \mathrm{~s}^{-1}$. The macro hardness of the test specimens was 
measured using the Rockwell ' $\mathrm{C}$ ' scale using a $150 \mathrm{~kg}$ load prior to conducting tensile tests. A total of ten measurements were recorded to determine the hardness.

\subsubsection{MICROSTRUCTURAL CHARACTERIZATION}

The microstructure of 420 stainless steels in the as-printed and heat-treated conditions were examined with a Brucker X-ray diffractometer. The bulk specimen was ground into powder and pressed into a disc. The working voltage of the diffractometer was $30 \mathrm{kV}$, and the operating current was $20 \mathrm{~mA}$. The scanning region ranged from $35^{\circ}$ to $90^{\circ}$, and the scanning rate was $2 \%$ min. An ICDD database was used assign peak positions to specific phases.

Metallographic samples were initially mechanically polished using SiC paper from 120 to 1200 grit, followed by a slurry of $1 \mu \mathrm{m}$ diamond particles. Etching was performed for $20 \mathrm{~s}$ with Kalling reagent II and Fry's reagent. After etching, the specimens were cleaned with ethanol and dried in air. Finally, the specimens were examined using an Olympus CX21 optical microscope, a TESCAN Vega3 scanning electron microscope (SEM) and corresponding energy-dispersive X-ray spectroscopy (EDS).

\subsubsection{CORROSION BEHAVIOR}

Test solutions were prepared from reagent grade $\mathrm{NaCl}$ dissolved in distilled water at a concentration of $3.5 \mathrm{wt} . \%$. This concentration has been previously used in corrosion studies of stainless steels in several research studies [95, 96]. Using metallographic techniques reported in the previous section, four specimens of as-printed and heat-treated L-PBF 420 stainless steel for each composition exposing a surface area of $1 \mathrm{~cm}^{2}$ were prepared. Linear sweep voltammetry (LSV) experiments were conducted in the $3.5 \mathrm{wt} . \% \mathrm{NaCl}$ solution at 
room temperature using a Metrohm Autolab PGSTATION 100N system. For polarization experiments, a three-electrode cell was used consisting of the sample as the working electrode, $\mathrm{Ag} / \mathrm{AgCl}$ as the reference electrode, and a smooth $\mathrm{Pt}$ wire as the counter electrode. For each trial, the open circuit potential $\left(E_{o c}\right)$ was recorded and the measurements were started from the value of $\mathrm{E}_{\mathrm{oc}}$. The potential was controlled, and the current was measured, using a potentiostat/galvanostat (Metrohm Autolab PGSTATION 100N) with a computer-controlled electrochemical interface, allowing continuous monitoring of the potential (E), total current (I), and time (t). Experiments were conducted at a scan rate of $0.01 \mathrm{mV} / \mathrm{s}$ and automatically terminated when the anodic current $\left(\mathrm{I}_{\mathrm{a}}\right)$ reached $100 \mathrm{~mA}$. The pitting potential $\left(\mathrm{E}_{\mathrm{pit}}\right)$ or breakdown potential $\left(\mathrm{E}_{\mathrm{b}}\right)$ was determined by noting the potential at which a continuous increase in anodic current occurred, indicating sustained localized breakdown of the passive film. To determine the reproducibility, tests were repeated three times for each type of L-PBF 420 stainless steel. Tafel plots were created from the LSV data and five parameters (corrosion current, corrosion potential, breakdown potential, polarization resistance, and corrosion rate) were extracted to quantitatively describe the corrosion behavior. Following the LSV experiments, the samples were removed from the $\mathrm{NaCl}$ solution, rinsed with distilled water, and examined using optical microscopy.

\subsection{RESULTS AND DISCUSSION}

\subsubsection{POWDER CHARACTERISTICS}

The chemical compositions of the two 420 stainless steel powders used in this study are provided Table 4.1. The content of $\mathrm{Nb}$ and Mo was 1.2 and $0.57 \%$ respectively. There was no significant difference in content of other elements between the two 420 stainless steel 
powders. Additionally, all amounts of the other elements besides $\mathrm{Nb}$ and Mo were within AISI standards.

From Fig. 4.1(a) the particle size distribution of 420 stainless steel powders with and without $\mathrm{Nb}$ and Mo were very similar, with a median particle size distribution of $\sim 28 \mu \mathrm{m}$. Both powders had particle size distributions ranging from 17 to $48 \mu \mathrm{m}$. SEM images in Fig. 4.1(b) showed that the particles of 420 stainless steel powders were predominantly spherical. No noticeable agglomeration was observed in SEM images.

Table 4.1 Chemical composition of AISI 420 stainless steel powders

\begin{tabular}{|c|c|c|c|c|c|c|c|c|c|c|c|}
\hline Element & $\mathrm{Fe}$ & $\mathrm{Nb}$ & $\mathrm{Mo}$ & $\mathrm{Cr}$ & $\mathrm{Mn}$ & $\mathrm{Si}$ & $\mathrm{P}$ & $\mathrm{C}$ & $\mathrm{S}$ & $\mathrm{O}$ & $\mathrm{N}$ \\
\hline $\begin{array}{c}420 \\
\text { stainless + } \\
\mathrm{Nb}+\mathrm{Mo}\end{array}$ & Bal. & 1.2 & 0.57 & 12.9 & 0.9 & 1.0 & 0.01 & 0.35 & 0.01 & 0.04 & 0.12 \\
\hline $\begin{array}{c}420 \\
\text { stainless } \\
\text { steel }\end{array}$ & Bal. & N/A & N/A & 12.8 & 0.72 & 0.79 & 0.012 & 0.3 & 0.01 & 0.04 & 0.09 \\
\hline $\begin{array}{c}\text { AISI } \\
\text { standard }\end{array}$ & Bal. & - & - & $\begin{array}{c}12- \\
14\end{array}$ & $\begin{array}{c}< \\
1.0\end{array}$ & $\begin{array}{c}< \\
1.0\end{array}$ & $\begin{array}{c}< \\
0.04\end{array}$ & $\begin{array}{c}> \\
0.15\end{array}$ & 0.03 & - & - \\
\hline
\end{tabular}

Table 4.2 Powder characteristics of AISI 420 stainless steel powders used in this study

\begin{tabular}{|c|c|c|c|c|c|c|c|}
\hline Powder & $\begin{array}{c}\mathrm{D}_{10} \\
\mu \mathrm{m}\end{array}$ & $\begin{array}{c}\mathrm{D}_{50} \\
\mu \mathrm{m}\end{array}$ & $\begin{array}{c}\mathrm{D}_{90} \\
\mu \mathrm{m}\end{array}$ & $\begin{array}{c}\text { True } \\
\text { density } \\
\mathrm{g} / \mathrm{cm}^{3}\end{array}$ & $\begin{array}{c}\text { Tap } \\
\text { density } \\
\mathrm{g} / \mathrm{cm}^{3}\end{array}$ & $\begin{array}{c}\text { Apparent } \\
\text { density } \\
\mathrm{g} / \mathrm{cm}^{3}\end{array}$ & $\begin{array}{c}\text { Hausner } \\
\text { ratio }\end{array}$ \\
\hline $\begin{array}{c}420 \mathrm{SS} \\
+\mathrm{Nb}+ \\
\mathrm{Mo}\end{array}$ & 17 & 28 & 49 & $7.71 \pm 0.01$ & $4.9 \pm 0.1$ & $4.2 \pm 0.1$ & $\begin{array}{c}1.16 \pm \\
0.02\end{array}$ \\
\hline $420 \mathrm{SS}$ & 17 & 28 & 48 & $7.68 \pm 0.01$ & $4.7 \pm 0.1$ & $4.0 \pm 0.1$ & $\begin{array}{c}1.21 \pm \\
0.03\end{array}$ \\
\hline
\end{tabular}


(a)

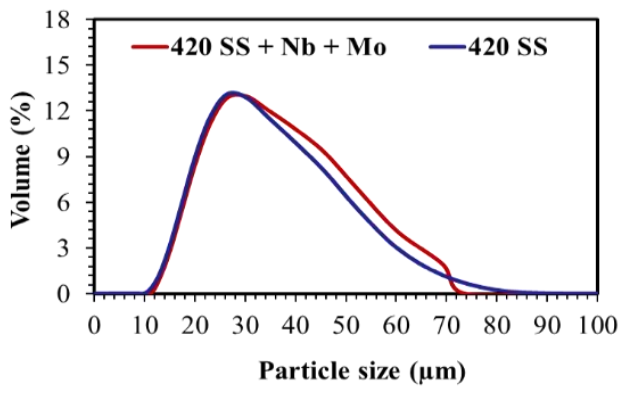

(b)

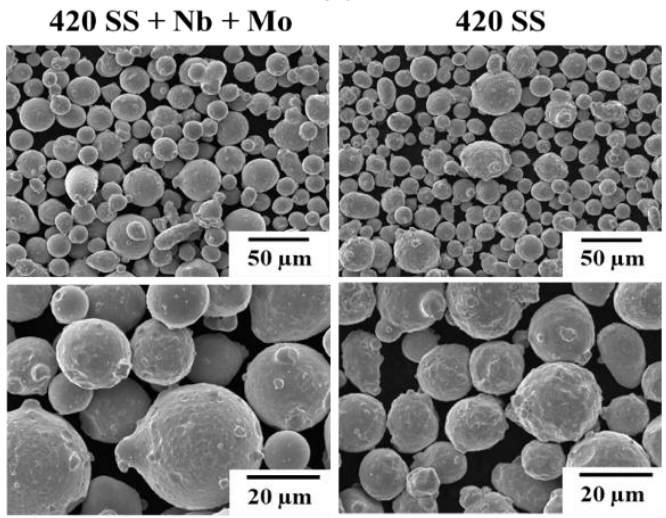

Figure 4.1 Particle size distribution (left) and SEM images (right) of nitrogen atomized AISI 420 stainless steel powders with and without $\mathrm{Nb}$ and Mo.

The key powder attributes are listed in Table 2. Both pre-alloyed powders had $\mathrm{D}_{10}, \mathrm{D}_{50}$ and $\mathrm{D}_{90}$ of 17,28 and $48 \mu \mathrm{m}$. The helium pycnometer density of 420 stainless steel powder with and without $\mathrm{Nb}$ and Mo was found to be $7.71 \pm 0.01$ and $7.68 \pm 0.01 \mathrm{~g} / \mathrm{cm}^{3}$ respectively. In addition, there was no significant difference in the tap and apparent densities. The Hausner ratio is a measure of flowability of bulk powder, was calculated using tap and apparent densities. In this study, 420 stainless steel powders with and without $\mathrm{Nb}$ and Mo exhibited a Hausner ratio of $1.16 \pm 0.02$ and $1.21 \pm 0.03$ respectively. A Hausner ratio below 1.25 is typically considered as an indicator of good flowability [40].

\subsubsection{DENSITY AND SURFACE ROUGHNESS}

Fig. 4.2 shows the variation in relative density and surface roughness of the two 420 stainless steel as a function of energy density ranging from 28 to $75 \mathrm{~J} / \mathrm{mm}^{3}$. It can be seen that both the powders displayed a similar densification behavior. For example, at an energy density of $28 \mathrm{~J} / \mathrm{mm}^{3}$, the relative density of L-PBF parts was $91 \pm 0.05 \%$. As the energy density was increased, the density of the parts of 420 stainless steel with and without $\mathrm{Nb}$ and Mo increased. At an energy density of 63 and $75 \mathrm{~J} / \mathrm{mm}^{3}$, all L-PBF specimens exhibited 


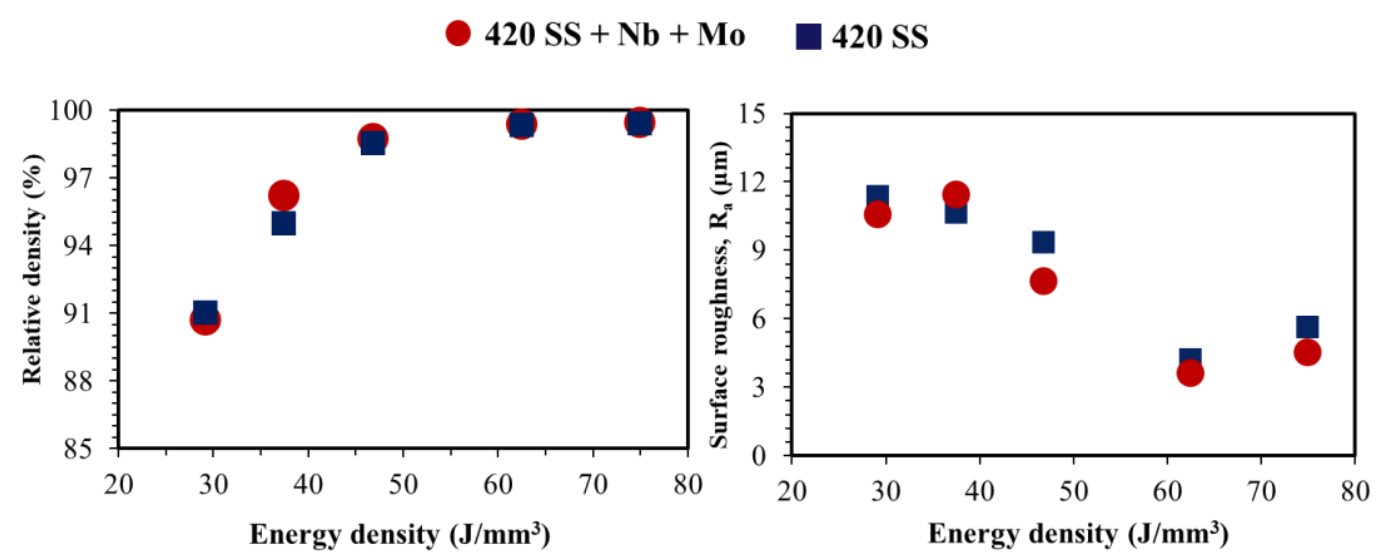

Figure 4.2 The variation in relative density (left) and surface roughness (right) as a function of energy density for 420 stainless steel powders with (red) and without (blue) $\mathrm{Nb}$ and Mo.

physical density of above $99 \%$. The optical images of polished cross sections of L-PBF specimens in the build direction also correlated well with the relative density. As seen in Fig. 4.3, the specimens fabricated at $63 \mathrm{~J} / \mathrm{mm}^{3}$ had a relative density of $99.3 \pm 0.02$ based on the ASTM grid method.

From Fig. 4.2, it can also be seen that the surface roughness of the two 420 stainless steels fabricated by L-PBF were comparable. For example, at an energy density of $29 \mathrm{~J} / \mathrm{mm}^{3}$, the surface roughness $\left(\mathrm{R}_{\mathrm{a}}\right)$ of 420 stainless steels parts containing $\mathrm{Nb}$ and Mo was found to be $10.7 \pm 0.3 \mu \mathrm{m}$. In comparison, the surface roughness of 420 stainless steels parts without $\mathrm{Nb}$ and Mo was found to be $11.4 \pm 0.2 \mu \mathrm{m}$. For both materials, the surface roughness $\left(\mathrm{R}_{\mathrm{a}}\right)$ of L-PBF specimens decreased as the energy density was increased. At an energy density of $75 \mathrm{~J} / \mathrm{mm}^{3}$, the surface roughness of 420 stainless steels parts containing $\mathrm{Nb}$ and Mo was found to be $4.8 \pm 0.1 \mu \mathrm{m}$. In comparison, 420 stainless steels parts without $\mathrm{Nb}$ and Mo was found to have a surface roughness of $5.3 \pm 0.2 \mu \mathrm{m}$. In this study, the minimum $\mathrm{R}_{\mathrm{a}}$ of $\mathrm{L}$ PBF specimen with $(3.1 \pm 0.6 \mu \mathrm{m})$ and without $(3.4 \pm 0.1 \mu \mathrm{m}) \mathrm{Nb}$ and Mo was observed at an energy density of $63 \mathrm{~J} / \mathrm{mm}^{3}$. Consequently, this L-PBF process conditions (layer 
thickness $20 \mu \mathrm{m}$, laser power $90 \mathrm{~W}$, scan speed $600 \mathrm{~mm} / \mathrm{s}$ and trace width $120 \mu \mathrm{m}$ ) were chosen to fabricate ASTM standard tensile bars to evaluate the effects of $\mathrm{Nb}$ and $\mathrm{Mo}$ addition on the mechanical properties, microstructure and corrosion behavior of 420 stainless steel.

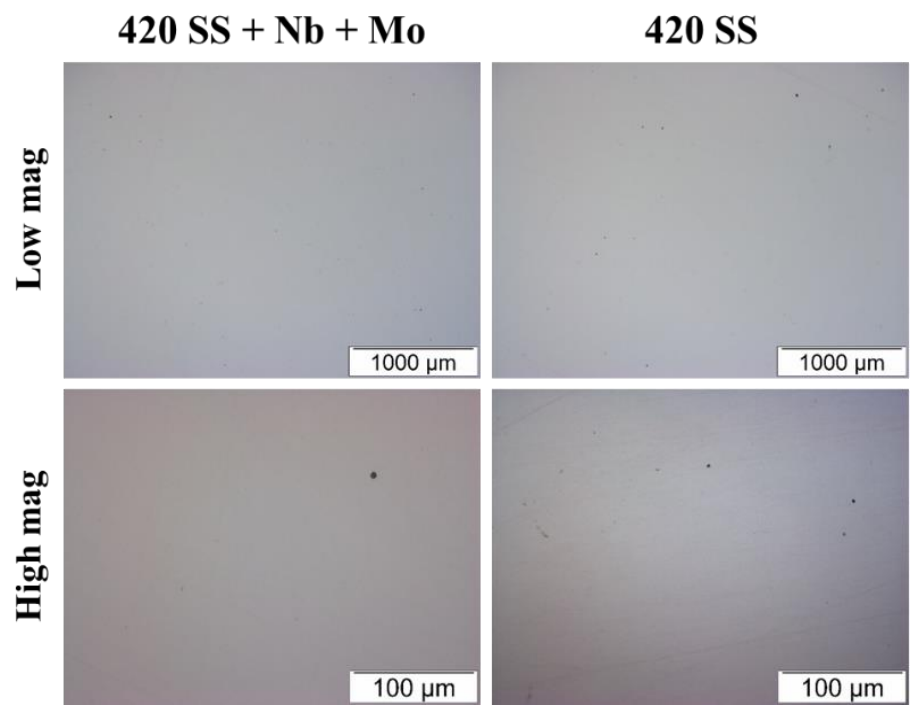

Figure 4.3 As polished cross-sectional images at low (50X) and high (1000X) magnifications of L-PBF parts of 420 stainless steels with and without $\mathrm{Nb}$ and Mo. Cross sections were taken parallel to the build direction for samples fabricated at $63 \mathrm{~J} / \mathrm{mm}^{3}$.

\subsubsection{MECHANICAL PROPERTIES}

Table 4.3 Mechanical properties of L-PBF 420 stainless steel containing Nb and Mo

\begin{tabular}{|c|c|c|c|c|c|c|}
\hline Material & Condition & $\begin{array}{l}\text { Density } \\
(\mathrm{g} / \mathrm{cc})\end{array}$ & $\begin{array}{l}\text { UTS } \\
(\mathrm{MPa})\end{array}$ & $\begin{array}{l}\text { Yield Strength } \\
(\mathrm{MPa})\end{array}$ & $\begin{array}{c}\text { Elongatio } \\
\text { n } \\
(\%)\end{array}$ & $\begin{array}{c}\text { Hardness } \\
\text { (HRC) }\end{array}$ \\
\hline \multirow{2}{*}{$\begin{array}{c}420 \\
\text { stainless } \\
\text { steel } \\
\text { with } \mathrm{Nb} \\
\text { and Mo }\end{array}$} & As-printed & $\begin{array}{c}7.69 \pm \\
0.03\end{array}$ & $1320 \pm 25$ & $1065 \pm 20$ & $3.5 \pm 0.2$ & $52 \pm 1$ \\
\hline & $\begin{array}{l}\text { Heat- } \\
\text { treated }\end{array}$ & $\begin{array}{c}7.69 \pm \\
0.03\end{array}$ & $1760 \pm 35$ & $1280 \pm 35$ & $9.0 \pm 0.3$ & $51 \pm 1$ \\
\hline
\end{tabular}

In mechanical tests, L-PBF specimens containing $\mathrm{Nb}$ and Mo exhibited better mechanical properties compared to L-PBF specimens without $\mathrm{Nb}$ and Mo. In the as-printed condition, 
a UTS of $1320 \pm 25 \mathrm{MPa}$, yield strength of $1065 \pm 20 \mathrm{MPa}$, and elongation of $3.5 \pm 0.2 \%$ were observed with L-PBF 420 stainless steel with $\mathrm{Nb}$ and Mo. In comparison, L-PBF 420 stainless steel without $\mathrm{Nb}$ and Mo exhibited a UTS of $1050 \pm 25 \mathrm{MPa}$, yield strength of $700 \pm 20 \mathrm{MPa}$, and elongation of $2.5 \pm 0.2 \%$ [74]. The mechanical properties of LPBF 420 stainless steel containing $\mathrm{Nb}$ and Mo significantly improved following heat treatment. The heat-treated L-PBF 420 stainless steel containing Nb and Mo exhibited a UTS of $1760 \pm$ $35 \mathrm{MPa}$, yield strength of $1280 \pm 35 \mathrm{MPa}$, and elongation of $9.0 \pm 0.3 \%$. The properties of 420 stainless steel containing $\mathrm{Nb}$ and Mo exceeded the reported values of heat-treated wrought 420 stainless steel (UTS $1625 \pm 40 \mathrm{MPa}$, elongation $7 \pm 1 \%$ ) [28, 97]. Following heat treatment, the properties of LPBF 420 stainless steel with the addition of $\mathrm{Nb}$ and Mo were also superior to metal injection molded (MIM) 420 stainless steel parts (UTS $1350 \pm$ $50 \mathrm{MPa}$, yield strength $1100 \pm 40 \mathrm{MPa}$, and elongation $2 \pm 1 \%$ ) after heat treatment [47, 51]. The properties of heat-treated L-PBF 420 stainless steel containing $\mathrm{Nb}$ and Mo were also better than heat-treated L-PBF 420 stainless steel without $\mathrm{Nb}$ and Mo (UTS $1520 \pm 25$ $\mathrm{MPa}$, yield strength $950 \pm 20 \mathrm{MPa}$, and elongation of $6.3 \pm 0.2 \%$ ) reported in our recent study.

\subsubsection{XRD}

The addition of $\mathrm{Nb}$ and $\mathrm{Mo}$ in 420 stainless steel did not have an appreciable influence on the hardness of as-printed and heat-treated L-PBF specimens. As shown in Table 4.3, LPBF 420 stainless steel containing $\mathrm{Nb}$ and Mo exhibited a hardness of $52 \pm 1$ and $51 \pm 1$ $\mathrm{HRC}$ in as-printed and heat-treated conditions, respectively. These results were comparable to the L-PBF 420 stainless steel without the addition of $\mathrm{Nb}$ and Mo $(55 \pm 1 \mathrm{HRC}$, as-printed and $53 \pm 1$ HRC, heat-treated) that were reported in our recent study [74]. For comparison, 
wrought and MIM 420 stainless steel exhibited a hardness of HRC $53 \pm 2$ and HRC $49 \pm$ 2 in the heat-treated condition $[47,51,97]$.

$\alpha:$ martensite; $\gamma:$ austenite

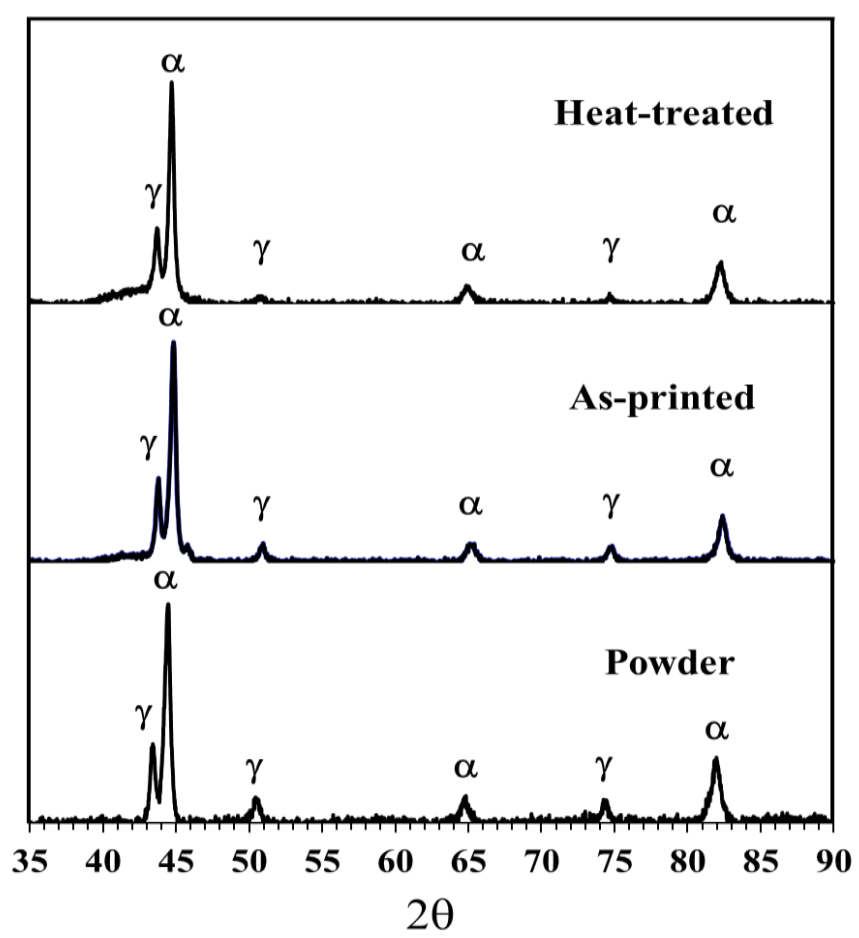

Figure 4.4 Representative XRDs of 420 stainless steel powder with $\mathrm{Nb}$ and Mo and asprinted and heat-treated L-PBF specimens fabricated at an energy density of $63 \mathrm{~J} / \mathrm{mm}^{3}$.

An ICDD database was used to analyze the observed peaks.

In Fig. 4.4, the XRD patterns of 420 stainless steel powders and as-printed and heat-treated specimens with $\mathrm{Nb}$ and Mo exhibited presence of austenite $(\gamma)$ and martensite $(\alpha)$ phases. The presence of $\mathrm{Nb}$ and Mo reduced the austenite content from $67 \%$ to $31 \%$ in the gasatomized raw powder based on comparison with our recent study on 420 stainless steel without the addition of $\mathrm{Nb}$ and $\mathrm{Mo}$ [74]. The intensity ratio of austenite and martensite phases were altered after the parts were printed and heat-treated. The as-printed and heattreated tensile specimens of L-PBF 420 stainless steel containing $\mathrm{Nb}$ and Mo exhibited a retained austenite phase of $\sim 14 \pm 7 \%$ and $15 \pm 5 \%$ respectively from Rietveld analysis. The presence of $\mathrm{Nb}$ and Mo did not measurably change the retained austenite content 
compared to our recently published XRD data on L-PBF 420 stainless steel without the addition of $\mathrm{Nb}$ and $\mathrm{Mo}(15 \pm 12 \%$ - as printed, $16 \pm 5 \%$ - heat-treated $)$ [74]. L-PBF intrinsically offers localized rapid cooling which is consistent with the formation of martensite dominant structure as evidenced in Fig. 4.4. However, the proportional change in the retained austenite content was not significant within experimental error relative to the enhancement in mechanical properties after the heat treatment or with change in composition.

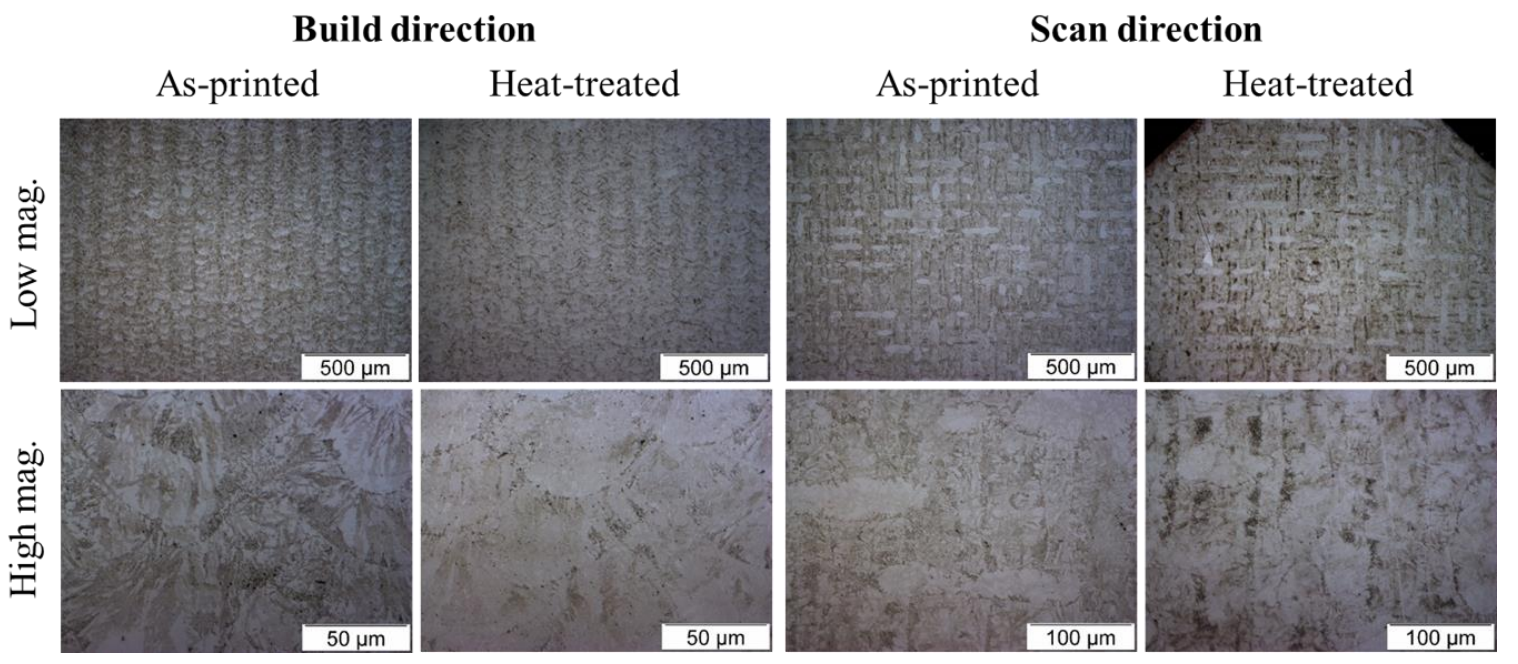

Figure 4.5 Optical micrographs in the build and scan direction of as-printed and heattreated L-PBF 420 stainless steel specimens with $\mathrm{Nb}$ and Mo. All samples were fabricated at an energy density of $63 \mathrm{~J} / \mathrm{mm}^{3}$, polished to $1 \mu \mathrm{m}$, and etched with Kalling II reagent.

\subsubsection{MICROSCOPY}

Fig. 4.5 shows the optical micrographs of L-PBF 420 stainless steel following the addition of $\mathrm{Nb}$ and Mo using Kaling II reagent for etching. The microstructure showed needle-liked structures that were dispersed throughout the etched microstructure representing a predominantly martensitic (body centered tetragonal) structure in the as-printed and heattreated conditions, consistent with XRD results. These cross-sectional optical images in the build direction were qualitatively different from the scan direction, suggesting potential 
anisotropy that persisted after heat treatment. Martensite forms through austenitemartensite transformation in the range from 700 to $300^{\circ} \mathrm{C}$ when the cooling is rapid. In Fig. 4.5, the heat-treated microstructure of L-PBF 420 stainless steel specimens containing $\mathrm{Nb}$ and Mo showed tempering of the martensite that is consistent with the enhancement in mechanical properties. The reduction in the diameter and spacing of martensitic needles following heat treatment was more discernible using Fry's agent for etching, as seen in Fig. 4.6. The trends in microstructural changes strongly correlated with the enhancement of mechanical properties following heat treatment and are also consistent with our recent report by for L-PBF 420 stainless steel specimens without Nb and Mo [74].

SEM images in conjunction with elemental analysis using energy dispersive spectroscopy

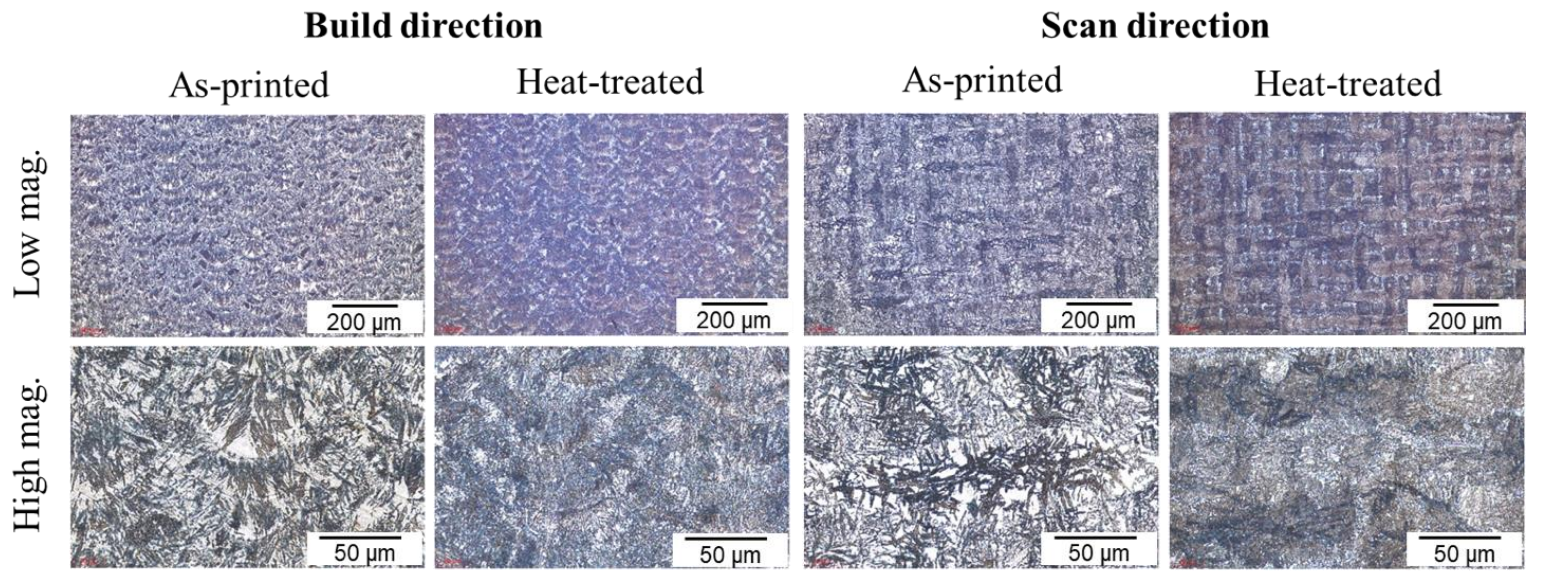

Figure 4.6 Optical micrographs in the build and scan direction of the as-printed and heattreated L-PBF 420 stainless steel specimens containing Nb and Mo. All samples were fabricated at $63 \mathrm{~J} / \mathrm{mm}^{3}$, polished to $0.05 \mu \mathrm{m}$, and etched with Fry's reagent.

(EDS) are shown in Fig. 4.7. The analysis revealed a homogeneous microstructure at high magnification before and after heat treatment. Dendritic features formed according to the direction of cooling or solidification [98]. Comparatively more tempering was observed in these microstructures than those without $\mathrm{Nb}$ and Mo. Interestingly, grain boundaries were not seen in this metallographic study. In this regard, the microstructures of L-PBF 420 
stainless steel with and without $\mathrm{Nb}$ and Mo were significantly different compared to wrought and MIM specimens [99, 100]. Further, laves phases of $\mathrm{Fe}_{2} \mathrm{Nb}$ were absent, unlike in wrought stainless steel with $\mathrm{Nb}$ and $\mathrm{Ti}[89,101]$.

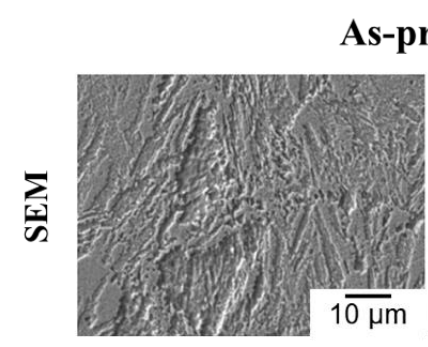

$\mathrm{Nb}$ L series
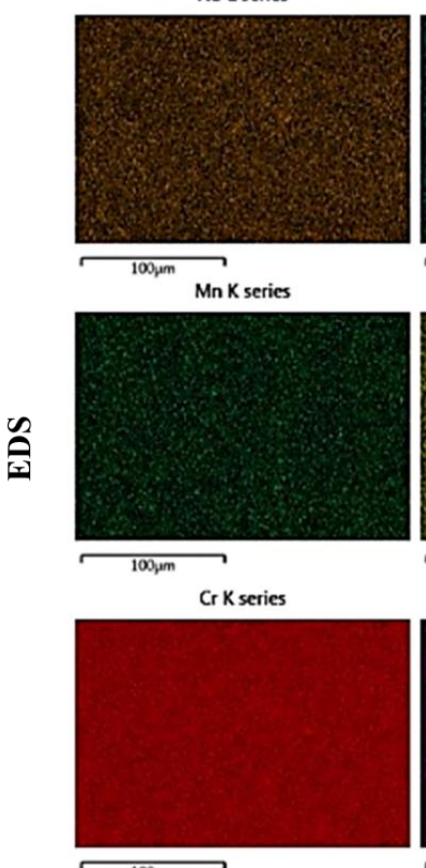

$100, \mathrm{~m}$
As-printed

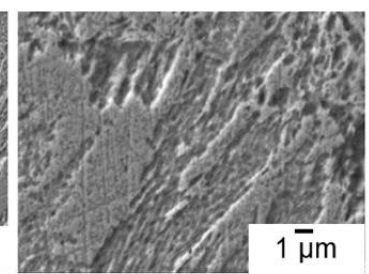

MoL series

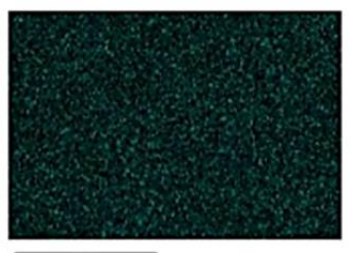

Si K series

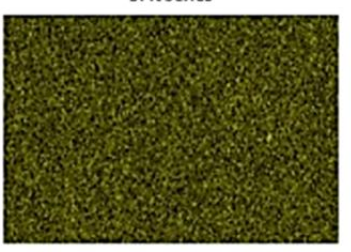

C K series

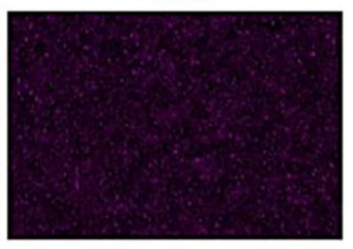

$100, \mathrm{~mm}$
Heat-treated

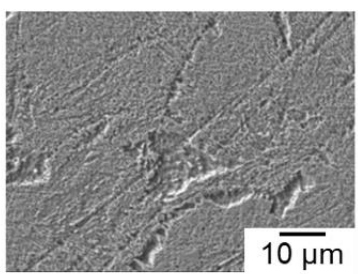

$\mathrm{Nb} L$ series
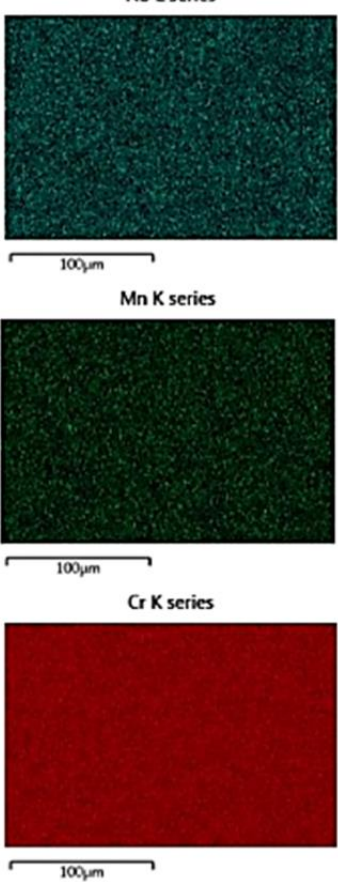

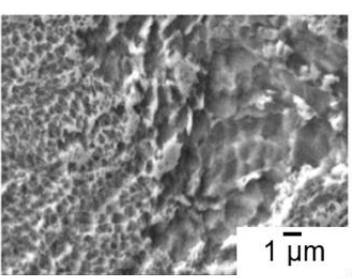

Mo L series

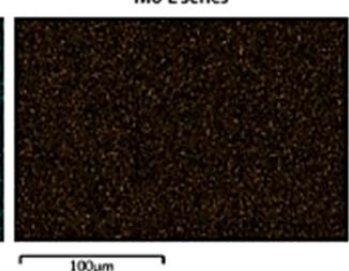

Si K series

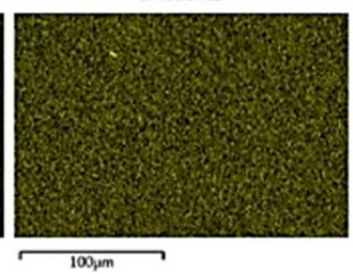

$\mathrm{CK}$ series

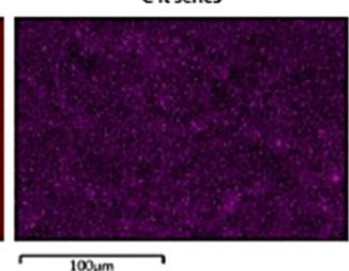

Figure 4.7 SEM images of microstructure in the build direction of as-printed and heattreated L-PBF 420 stainless steel specimens containing $\mathrm{Nb}$ and Mo are shown in the top row. All samples were fabricated at $63 \mathrm{~J} / \mathrm{mm}^{3}$ and etched with Fry's reagent. Then EDS analysis show that distribution of $\mathrm{Nb}, \mathrm{Mo}, \mathrm{Mn}, \mathrm{Si}, \mathrm{Cr}$ and $\mathrm{C}$ in the microstructure are homogenous for both the as-printed and heat-treated specimens. 

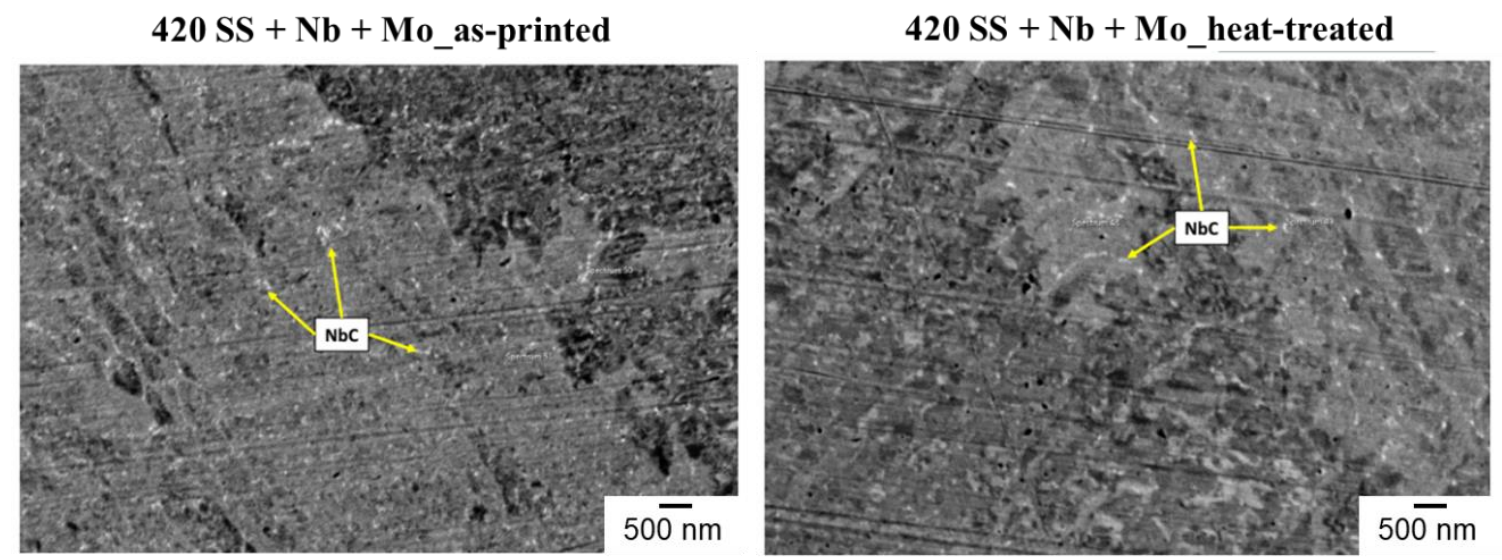

Figure 4.8 Microstructures through optical microscopy in the build direction of asprinted and heat-treated L-PBF 420 stainless steel specimens with $\mathrm{Nb}$ and Mo.

Fig. 4.8 shows SEM images at a higher resolution than in Fig. 4.7. The presence of nanoscale features of $\mathrm{NbC}$ could be observed in the as-printed and heat-treated conditions for L-PBF 420 stainless steel containing $\mathrm{Nb}$ and Mo. In contrast, no $\mathrm{NbC}$ formation was observed in the microstructure of L-PBF 420 stainless steel without $\mathrm{Nb}$ and Mo. In combination, the nanoscale $\mathrm{NbC}$ precipitation along with tempered martensite appears to contribute to the enhanced mechanical properties of L-PBF stainless steel containing $\mathrm{Nb}$ and Mo relative to wrought, MIM or LPBF 420 stainless steel samples without $\mathrm{Nb}$ and Mo [102]. Tempering of martensite and the nanoscale carbide precipitation is also consistent with the increase in both strength and elongation after heat treatment [103]. $\mathrm{NbC}$ has been reported to be precipitated at the temperature range of 900 to $950{ }^{\circ} \mathrm{C}$.[104] The size and amount of NbC could not be determined by SEM and transmission electron microscopy (TEM) experiments are planned in the future. 


\subsubsection{CORROSION PROPERTIES}
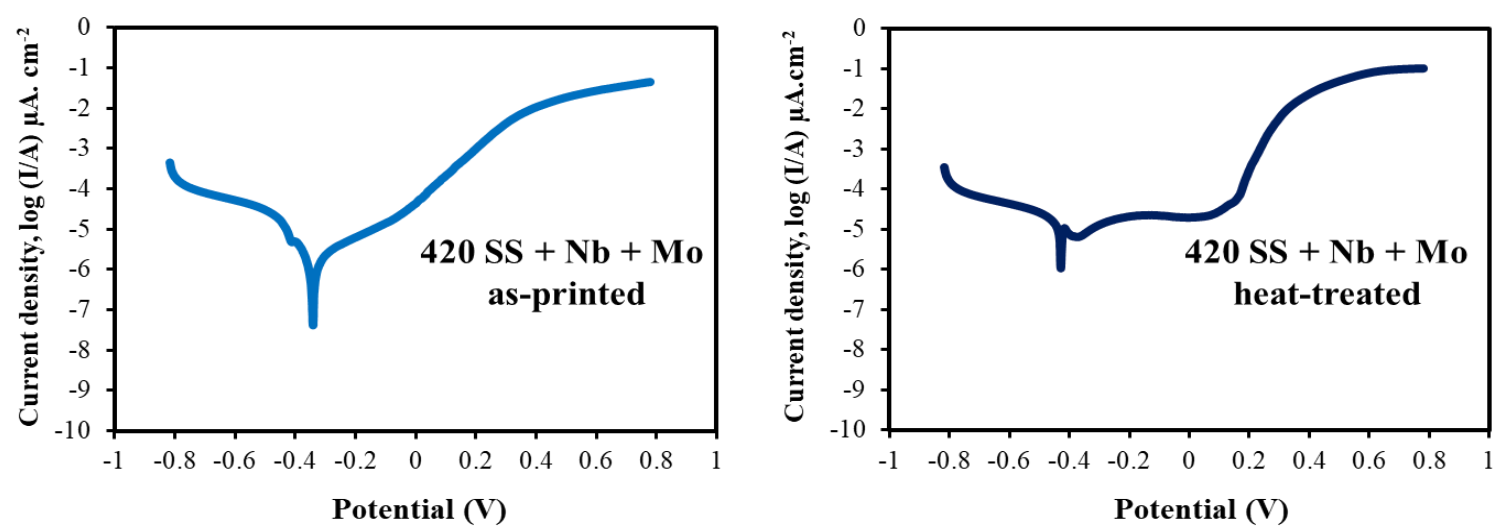

Figure 4.9 Plots of current density v/s voltage for as- printed (left) and heat-treated (right) L-PBF 420 stainless steel containing $\mathrm{Nb}$ and Mo. Experiments were performed in a 3.5\% $\mathrm{NaCl}$ aqueous solution. Operating condition- reference electrode: $\mathrm{Ag} / \mathrm{AgCl}$; cathode: $\mathrm{Pt}$ wire; $\mathrm{pH}=6.0$; scan rate: $0.01 \mathrm{Vs}^{-1}$.

Linear sweep voltammetry (LSV) experimental data on the as-printed and heat-treated 420 stainless steel containing $\mathrm{Nb}$ and Mo are shown in Fig. 4.8 [39]. The results of these experiments were compared to corrosion properties on 420 stainless steel without $\mathrm{Nb}$ and Mo that were previously reported by our group [74]. The data was used to find the corrosion current $\left(I_{\text {corr }}\right)$ and corrosion potential $\left(E_{c o r r}\right)$ by a standard extrapolation method known as the Tafel plot. The Tafel constants $\beta_{a}$ and $\beta_{c}$, representing the anodic and cathodic slopes were used to calculate the polarization resistance and corrosion rate using previously reported equations $[57,58]$.

Lower values of corrosion current represent an increased resistance of an alloy surface to oxidation. In the as-printed condition, 420 stainless steel containing $\mathrm{Nb}$ and Mo exhibited a corrosion current of $1.5 \pm 0.2 \mu \mathrm{A} / \mathrm{cm}^{2}$. In comparison, the corrosion current was reported to be $2.8 \pm 0.4 \mu \mathrm{A} / \mathrm{cm}^{2}$ for L-PBF 420 stainless steel without $\mathrm{Nb}$ and Mo [74] and $2.1 \pm$ $0.1 \mu \mathrm{A} / \mathrm{cm}^{2}$ for wrought 420 stainless steel [59]. Following heat treatment, 420 stainless steel showed a slightly higher corrosion current. 
Table 4.4 Corrosion properties of L-PBF 420 stainless steel with and without $\mathrm{Nb}$ and Mo.

\begin{tabular}{|c|c|c|c|c|c|}
\hline Specimen & $\begin{array}{c}\text { Corrosion } \\
\text { current } \\
\mathrm{I}_{\text {corr }} \\
\left(\mu \mathrm{A} / \mathrm{cm}^{2}\right)\end{array}$ & $\begin{array}{c}\text { Corrosion } \\
\text { potential } \\
\mathrm{E}_{\text {corr }} \\
(\mathrm{V})\end{array}$ & $\begin{array}{c}\text { Breakdown } \\
\text { potential } \\
\mathrm{E}_{\mathrm{b}} \\
(\mathrm{V})\end{array}$ & $\begin{array}{c}\text { Polarization } \\
\text { resistance } \\
\left(\Omega / \mathrm{cm}^{2}\right)\end{array}$ & $\begin{array}{c}\text { Corrosion } \\
\text { rate } \\
(\mu \mathrm{m} / \text { year })\end{array}$ \\
\hline $\begin{array}{c}420+ \\
\mathrm{Nb}+\mathrm{Mo}_{-} \\
\text {as-printed }\end{array}$ & $1.5 \pm 0.2$ & $-0.42 \pm 0.03$ & $0.03 \pm 0.05$ & $24,200 \pm 550$ & $16 \pm 1$ \\
\hline $\begin{array}{c}420+ \\
\text { Nb+Mo_} \\
\text { heat-treated }\end{array}$ & $1.8 \pm 0.2$ & $-0.32 \pm 0.02$ & $0.2 \pm 0.01$ & $23,800 \pm 450$ & $18 \pm 2$ \\
\hline Wrought & $2.1 \pm 0.1$ & $-0.4 \pm 0.02$ & $0.15 \pm 0.01$ & $18,700 \pm 350$ & $23 \pm 2$ \\
\hline
\end{tabular}

Higher values of polarization resistance represent an enhanced ability of the oxide layer to withstand a corrosive environment. In this study, in the as-printed and heat-treated conditions, 420 stainless steel exhibited a higher polarization resistance following the addition of $\mathrm{Nb}$ and Mo. From Table 4.4, L-PBF 420 stainless steel specimens containing $\mathrm{Nb}$ and Mo exhibited a polarization resistance of $24,200 \pm 550 \Omega / \mathrm{cm}^{2}$. In comparison, the as-printed L-PBF 420 stainless steel specimens without $\mathrm{Nb}$ and Mo were reported to have a lower polarization resistance of $17,100 \pm 520 \Omega / \mathrm{cm}^{2}$. A lower polarization resistance of $18,700 \pm 350 \Omega / \mathrm{cm}^{2}$ has also been reported for wrought 420 stainless steel. Following heattreatment, the polarization resistance of L-PBF 420 stainless steel specimens containing $\mathrm{Nb}$ and Mo was found to be relatively unchanged. The addition of $\mathrm{Nb}$ and $\mathrm{Mo}$ to 420 stainless steel also lowered the corrosion rate of L-PBF specimens. The as-printed and heattreated L-PBF 420 stainless steel exhibited a corrosion rate of $16 \pm 1$ and $18 \pm 2 \mu \mathrm{m} /$ year respectively in the presence of $\mathrm{Nb}$ and Mo. Therefore, it can be concluded that 420 stainless steel fabricated by L-PBF retained its corrosion properties after heat treatment. The corrosion rate was comparatively lower than that of L-PBF 420 stainless steel without $\mathrm{Nb}$ 
and Mo (28 $\pm 2 \mu \mathrm{m} /$ year) and comparable to the reported values of wrought 420 stainless steel (23 $\pm 2 \mu \mathrm{m} /$ year) [59]. Further x-ray diffraction and x-ray photoelectron spectroscopy will be conducted on the corroded surfaces to understand the changes in chemical composition and determine if there are any mechanistic changes in the corrosion process of L-PBF parts.
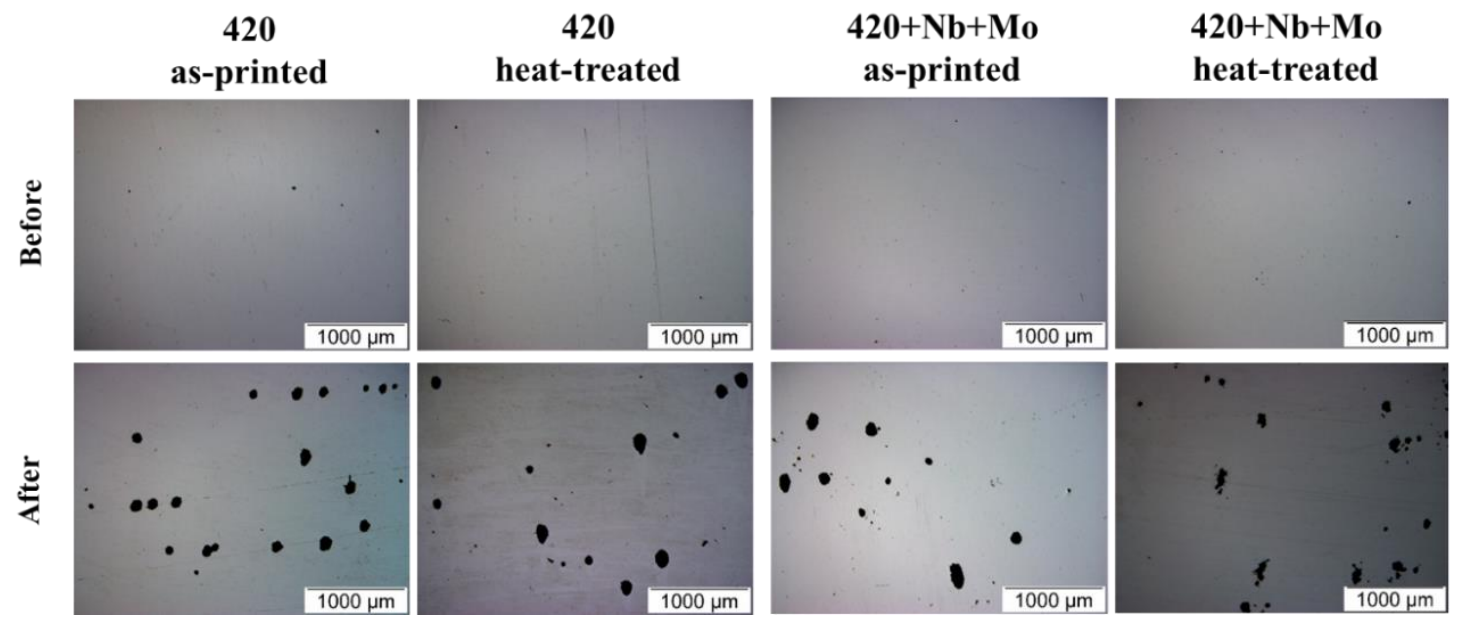

Figure 4.10 Microstructures through optical microscopy in the build direction of heattreated L-PBF 420 stainless steel parts specimens with and without $\mathrm{Nb}$ and Mo.

Fig. 4.10 shows the corroded surface of L-PBF specimens following electrochemical tests.

Formation of pits are evident for as-printed and heat-treated specimens. There was no quantitative difference in pits between 420 stainless steel with and without $\mathrm{Nb}$ and $\mathrm{Mo}$. Qualitatively, irregular pores were formed in case with $\mathrm{Nb}$ specimen. Future studies are planned to characterize the oxide layer and understand the mechanistic origins of the differences in corrosion behavior.

\subsection{CONCLUSIONS}

This study concluded that the pre-alloying with 1.2 wt. $\% \mathrm{Nb}$ and 0.57 wt. \% Mo significantly affected the properties and microstructure L-PBF 420 stainless steel in the as- 
printed and heat-treated conditions without altering its processability. The specific conclusions are:

1) In a processing window ranging from 28 to $75 \mathrm{~J} / \mathrm{mm}^{3}$, no difference in densification behavior was observed between 420 stainless steel powders with and without $\mathrm{Nb}$ and Mo. At $63 \mathrm{~J} / \mathrm{mm}^{3}$, L-PBF specimens with both compositions exhibited a density $99.3 \pm 0.02 \%$.

2) The addition of $\mathrm{Nb}$ and Mo contributed in improved mechanical properties of L-PBF specimens in the as-printed condition. The UTS of the as-printed L-PBF 420 stainless steel improved from $1050 \pm 25$ to $1340 \pm 30 \mathrm{MPa}$, yield strength from $900 \pm 20 \mathrm{MPa}$ to $1050 \pm$ $20 \mathrm{MPa}$, and elongation from $2.5 \pm 0.2$ to $3.0 \pm 0.2 \%$ respectively in the as-printed condition in presence of $\mathrm{Nb}$ and $\mathrm{Mo}$. In the as-printed condition, the hardness of 420 stainless steel with and without $\mathrm{Nb}$ and Mo was characterized to be $52 \pm 1$ and $55 \pm 1 \mathrm{HRC}$ in the as-printed condition respectively.

3) In heat-treated specimens, the addition of $\mathrm{Nb}$ and Mo further improved properties, with UTS increasing from $1520 \pm 30$ to $1750 \pm 30 \mathrm{MPa}$, yield strength to $1280 \pm 35 \mathrm{MPa}$ from $950 \pm 20 \mathrm{MPa}$, and elongation from from $6.3 \pm 0.2$ to $9.0 \pm 0.3 \%$. No significant change was found in hardness following heat treatment as hardness stayed at $53 \pm 1$ and $51 \pm 1$, respectively.

4) Heat-treated L-PBF 420 stainless steel containing $\mathrm{Nb}$ and Mo had properties superior to heat-treated wrought (UTS $1625 \pm 40 \mathrm{MPa}$, elongation $7 \pm 1 \%$ and hardness $53 \pm 2 \mathrm{HRC}$ ) and MIM (UTS $1350 \pm 50 \mathrm{MPa}$, elongation $2 \pm 1 \%$, hardness $49 \pm 2 \mathrm{HRC}$ ) 420 stainless steel. 
5) Martensite-dominant microstructures were observed in L-PBF specimens in the asprinted condition. In addition, nanoscale NbC was observed in L-PBF 420 stainless steel containing $\mathrm{Nb}$ and Mo. However, no carbide was found in L-PBF 420 stainless steel without $\mathrm{Nb}$ and Mo. After heat treatment, tempering of martensite was evident in both compositions. The precipitation of nanoscale $\mathrm{NbC}$ and tempering of martensite correlated well with the improvement of mechanical properties of heat-treated L-PBF specimens.

6) The addition of $\mathrm{Nb}$ and Mo also improved the corrosion properties of L-PBF 420 stainless steel With the addition of $\mathrm{Nb}$ and $\mathrm{M}$ to L-PBF 420 stainless steel specimens, the corrosion current was found to reduce from $2.85 \pm 0.4$ to $1.5 \pm 0.2 \mathrm{~mA} . \mathrm{cm}^{-2}$, the polarization resistance increased from $17,200 \pm 520$ to $24,200 \pm 550 \Omega / \mathrm{cm}^{2}$ and corrosion rate reduced from $28 \pm 2$ to $16 \pm 1 \mu \mathrm{m}$ /year in the as-printed condition. There was no significant difference in the corrosion properties after heat treatment of both with and without $\mathrm{Nb}$ and Mo specimens. The corroded surfaces also revealed pitting corrosion rather than intergranular corrosion. 


\section{CHAPTER 5}

\section{EFFECTS OF PARTICLE SIZE DISTRIBUTION ON THE LASER-POWDER BED FUSION OF 420 STAINLESS STEEL}

\subsection{INTRODUCTION}

Additive manufacturing (AM) processes are used to create intricate components with improved design freedom, faster design-to-build time, reduction in fabrication and assembly steps, and mass customization $[4,105]$. One of the primary AM processes to fabricate metallic parts is laser-powder bed fusion (L-PBF). In L-PBF, a laser beam scans the surface of a powder bed to selectively melt regions in a layer-by-layer method to create a three-dimensional geometry [5]. The energy density parameter is a measure of thermal energy that is supplied to a given volume of powder in the build chamber [22]. The energy density parameter is useful to evaluate the sensitivity of properties and microstructure to variation in L-PBF process parameters such as layer thickness, laser power, scanning speed and trace width. However, there are very few studies on how powder attributes influence the energy density parameter used in L-PBF.

Although metal powders can vary widely in size and shape, spherical powders with a particle size distribution of $15-45 \mu \mathrm{m}$ have been most commonly used in L-PBF [106, 107]. However, finer powders with a median particle size in the range of 5-25 $\mu \mathrm{m}$ powder are commonly used for other processes such as metal injection molding (MIM) [21]. However, while the sinterability of powders improves with finer particle size [21], the spreadability 
of such fine powder has been reported to be unsuitable for L-PBF [108, 109]. Lee et al showed through physical modelling that better densification can be achieved with fine size particles in L-PBF [110]. However, the influence of particle attributes on the ensuing surface roughness, hardness, tensile strength, yield strength and elongation in L-PBF parts are less understood.

The present study focuses on L-PBF of 420 stainless steel. 420 stainless steel offers high hardness, strength and corrosion resistance [28]. The applications of 420 stainless steel include surgical instruments, knives, bearings, and tooling. AISI 420 stainless steel is primarily a $\mathrm{Fe}-\mathrm{Cr}-\mathrm{C}$ ternary system which typically contain $12 \sim 14 \% \mathrm{Cr}$ and $>0.15 \% \mathrm{C}$, with minor additions of several other alloying elements. The microstructure of 420 stainless steel consists of martensite (body-centered tetragonal), retained austenite (face-centered cubic) and dissolved or undissolved carbides [111]. Depending on the carbon content and heat treatment, the strength of this martensitic stainless steel can reach to $1800 \mathrm{MPa}$ and elongation to $8 \%$.

There are only a limited number of studies reported in the literature on the L-PBF of powders with fine particle size distribution $[86,112]$. Further, there are also very few studies in the literature on L-PBF of 420 stainless steel $[10,20]$. In this study, L-PBF experiments were performed with fine $\left(\mathrm{D}_{50}: 12 \mu \mathrm{m}\right) 420$ stainless steel powders to understand the effect of particle size on the densification, mechanical and corrosion properties and microstructure of L-PBF 420 parts. The results were compared to our recent L-PBF study using coarse ( $\left.\mathrm{D}_{50}: 28 \mu \mathrm{m}\right) 420$ stainless steel powders [74]. It is expected that the results and analysis from these experiments will further enhance the knowledge on the 
densification, properties and microstructure of L-PBF parts fabricated with 420 stainless steel.

\subsection{METHODOLOGY}

Nitrogen gas-atomized 420 stainless steel pre-alloyed powders of two median particle sizes, $12 \mu \mathrm{m}$ and $28 \mu \mathrm{m}$ (Sandvik Osprey Ltd., U.K.), were used. The powder morphology was examined in Carl Zeiss Supra 35 scanning electron microscope (SEM) after platinum coating. A Retsch AS 200 vibratory sieve-shaker with a vibration amplitude of $1.5 \mathrm{~mm}$ (50 $\%)$ and a $40 \mu \mathrm{m}$ mesh opening was used for sieving the powders. The $\mathrm{D}_{50}: 12 \mu \mathrm{m}$ powder were sieved for 6 cycles prior to L-PBF processing.

\subsubsection{L-PBF PROCESS}

In this study, all L-PBF experiments were conducted in a Concept Laser M Lab cusing R machine equipped with $100 \mathrm{~W}$ Yb-fiber laser with a spot size of $50 \mu \mathrm{m}$ under argon gas using previously reported scanning strategies [74]. All CAD (computer aided design) models were prepared in SolidWorks (Dassault System) and Autofab (Materialise) software. ASTM standard cube samples $(10 \mathrm{~mm}$ x $10 \mathrm{~mm}$ x $10 \mathrm{~mm})$ were initially built using energy density ranging from $20-80 \mathrm{~J} / \mathrm{mm}^{3}$. After optimization of process parameters, flat tensile specimens were also fabricated as per the ASTM E8 standard with a gage length of $35 \mathrm{~mm}$, width of $6.2 \mathrm{~mm}$, thickness of $3 \mathrm{~mm}$, and total length of $75 \mathrm{~mm}$. The samples were fabricated in a horizontal orientation at an energy density of $63 \mathrm{~J} / \mathrm{mm}^{3}$ (layer thickness of $20 \mu \mathrm{m}$, laser power of $90 \mathrm{~W}$, scan speed of $600 \mathrm{~mm} / \mathrm{s}$ and trace width of $120 \mu \mathrm{m}$ ) to facilitate comparison with recently reported data using coarse ( $\left.\mathrm{D}_{50}: 28 \mu \mathrm{m}\right)$ powders [74]. 


\subsubsection{HEAT TREATMENT}

The mechanical behavior of 420 stainless steel is highly dependent on the microstructure [113]. Low temperature isothermal tempering was implemented by heating the as- printed L-PBF 420 stainless steel parts in a furnace at $315^{\circ} \mathrm{C}$ for 2 hours followed by air cooling. This heating cycle was based on a study conducted by Marsden et al [31].

\subsubsection{PHYSICAL PROPERTIES}

The physical density of the as-printed and heat-treated L-PBF parts was measured based on the Archimedes principle using a Mettler Toledo XS104 weighing balance equipped with a custom-fabricated density measurement kit. Surface roughness was measured with Mitutoyo Surface Tester.

\subsubsection{MECHANICAL CHARACTERIZATION}

The tensile tests of as-printed and heat-treated L-PBF 420 stainless steel specimens were conducted in an MTS Exceed hydraulic dual column testing system equipped with a $90 \mathrm{kN}$ load cell at a strain rate of $0.001 \mathrm{~s}$. The strain-stress curves were obtained to calculate ultimate tensile strength (UTS), elongation and yield strength. Four samples were used for reporting each measurement. The hardness of the test specimens was measured using a Rockwell ' $\mathrm{C}$ ' hardness scale at $150 \mathrm{~kg}$ load. The hardness values reported in this article were an average \pm standard deviation from ten measurements for each sample.

\subsubsection{METALLOGRAPHY}

L-PBF samples were sectioned, polished, and etched with Kalling's reagent II for conducting the microstructure study. Etched surfaces were characterized using optical microscopy and an EVO scanning electron microscopy (SEM) for examining the porosity 
and microstructures. Phase analysis of the raw powder, as- printed and heat treated 420 stainless steel samples were characterized on a model Bruker D8 Discover X-ray diffraction (XRD) instrument using $\mathrm{Cu}-\mathrm{K} \alpha$ radiation $\left(\lambda=1.54 \mathrm{~A}^{\circ}\right)$. The phases were identified by comparing the recorded diffraction peaks with the ICDD database.

\subsubsection{CORROSION TESTS}

Electrochemical corrosion properties of L-PBF specimens were characterized by linear sweep voltammetry (LSV) measurements where the specimen, a platinum rod and a saturated $\mathrm{Ag} / \mathrm{AgCl}$, were used as the working, auxiliary and reference electrodes, respectively.[58] Four specimens of the as-printed and heat-treated parts with a surface area of $1 \mathrm{~cm}^{2}$ were prepared using SiC paper grit size varying from 120 to 1200 . All corrosion experiments were conducted in $3.5 \% \mathrm{NaCl}$ solution at room temperature. A computer controlled Metrohm Autolab PGSTATION 100N was used to measured corrosion current. LSV experiments were carried out in the potential range between -600 $\mathrm{mV}$ and $1000 \mathrm{mV}$ from the open circuit potential $\left(\mathrm{E}_{\mathrm{oc}}\right)$ at the forward scan rate of 0.01 $\mathrm{mV} . \mathrm{s}^{-1}$ with the current density limit of $10 \mathrm{~mA} \cdot \mathrm{cm}^{-2}$ to determine the corrosion potential $\left(\mathrm{E}_{\mathrm{corr}}\right)$, pitting potential $\left(\mathrm{E}_{\mathrm{pitt}}\right)$ and breakdown $\left(\mathrm{E}_{\mathrm{b}}\right)$ potentials. Tafel plots were obtained from the voltage and current measurement to quantify various corrosion parameters. Further, Tafel constants, polarization resistance and corrosion rate were calculated using established equations [114]. On completion of each corrosion experiment, the samples were washed with deionized water and isopropyl alcohol to perform optical microscopy on the corroded surface. 


\subsection{RESULTS AND DISCUSSION}

\subsubsection{POWDER ATTRIBUTES AND IMPROVEMENT OF SPREADABILITY}

The chemical composition of fine and coarse 420 stainless steel powders are presented in Table 5.1. All elemental compositions were in the limit of AISI standard. The content of $\mathrm{Cr}$ and $\mathrm{C}$ in the fine powder was $12.9 \%$ and $0.3 \%$ respectively. There was no significant difference observed in the elemental composition of the fine and coarse powders.

Table 5.1 Chemical composition of the as-received AISI 420 stainless steel powders

\begin{tabular}{|c|c|c|c|c|c|c|c|c|c|}
\hline Powder & Atomization & $\mathrm{Fe}$ & $\mathrm{Cr}$ & $\mathrm{Mn}$ & $\mathrm{Si}$ & $\mathrm{P}$ & $\mathrm{C}$ & $\mathrm{S}$ & $\mathrm{O}$ \\
\hline $\begin{array}{c}\mathrm{D}_{50}: 12 \\
\mu \mathrm{m}\end{array}$ & $\mathrm{N}$ & Bal. & 12.9 & 0.73 & 0.79 & 0.012 & 0.35 & 0.008 & 0.044 \\
\hline $\begin{array}{c}\mathrm{D}_{50}: 28 \\
\mu \mathrm{m}\end{array}$ & $\mathrm{N}$ & Bal. & 12.8 & 0.72 & 0.79 & 0.012 & 0.3 & 0.008 & 0.04 \\
\hline $\begin{array}{c}\text { AISI } \\
\text { standard }\end{array}$ & - & Bal. & $\begin{array}{r}12- \\
14\end{array}$ & $\begin{array}{c}< \\
1.0\end{array}$ & $\begin{array}{c}< \\
1.0\end{array}$ & $\begin{array}{c}< \\
0.04\end{array}$ & $\begin{array}{c}> \\
0.15\end{array}$ & $\begin{array}{c}< \\
0.03\end{array}$ & - \\
\hline
\end{tabular}

The chemical composition and particle characteristics of the powder are listed in Tables

5.1 and 5.2, respectively. The as-received fine 420 stainless steel powder had a median particle size $\left(D_{50}\right)$ of $12 \mu \mathrm{m}$ and $90 \%$ of the particles $\left(D_{90}\right)$ were below $27 \mu \mathrm{m}$. The coarse 420 stainless steel powder had a median particle size $\left(D_{50}\right)$ of $28 \mu \mathrm{m}$ and $90 \%$ of the particles $\left(D_{90}\right)$ were below $47 \mu \mathrm{m}$. Both powders possessed the same density of $7.68 \mathrm{~g} / \mathrm{cm}^{3}$ based on gas pycnometry. The pycnometer density of wrought 420 stainless steel was found to be $7.74 \mathrm{~g} / \mathrm{cm}^{3}$ and was used to represent the density of L-PBF parts as a $\%$ of the theoretical value. 
The as-received fine 420 stainless steel powder had an apparent density of $3.8 \pm 0.3 \mathrm{~g} / \mathrm{cm}^{3}$ which improved to $4.1 \pm 0.2 \mathrm{~g} / \mathrm{cm}^{3}$ after sieving. The as-received coarse powder has an apparent density of $4.0 \pm 0.1 \mathrm{~g} / \mathrm{cm}^{3}$. Additionally, the as-received fine stainless steel powder had an initial tap density of $4.7 \pm 0.1 \mathrm{~g} / \mathrm{cm}^{3}$ before sieving which improved to 5.0 $\pm 1 \mathrm{~g} / \mathrm{cm}^{3}$. The coarse powder had a tap density of $4.7 \pm 0.1 \mathrm{~g} / \mathrm{cm}^{3}$.

Table 5.2 Powder attributes of nitrogen-atomized AISI 420 stainless steel powders

\begin{tabular}{|c|c|c|c|c|}
\hline Powder & $\begin{array}{c}\text { Gas } \\
\text { pycnometer } \\
\text { density } \\
\mathrm{g} / \mathrm{cm}^{3}\end{array}$ & $\begin{array}{c}\text { Apparent } \\
\text { density } \\
\rho_{\mathrm{A}} \\
\mathrm{g} / \mathrm{cm}^{3}\end{array}$ & $\begin{array}{c}\text { Tap density } \\
\rho_{\mathrm{T}} \\
\mathrm{g} / \mathrm{cm}^{3}\end{array}$ & $\begin{array}{c}\text { Hausner ratio } \\
\rho_{\mathrm{A}} / \rho_{\mathrm{T}}\end{array}$ \\
\hline $\begin{array}{c}\text { D50: } 12 \mu \mathrm{m} \\
\text { (sieved) }\end{array}$ & 7.68 & $4.1 \pm 0.2$ & $5.0 \pm 0.1$ & $1.2 \pm 0.02$ \\
\hline D50: $28 \mu \mathrm{m}$ & 7.68 & $4.0 \pm 0.2$ & $4.7 \pm 0.1$ & $1.18 \pm 0.02$ \\
\hline
\end{tabular}

The Hausner ratio is the ratio of tap density to apparent density and is a measure of powder spreadability with lower numbers indicating better spreadability [40]. The fine 420 stainless steel powder had an initial Hausner ratio of $1.3 \pm 0.05$ which reduced to $1.2 \pm 0.02$ after sieving. The coarse powder had a Hausner ratio of $1.18 \pm 0.02$. The improved values of apparent density, tap density and Hausner ratio for the fine powder after sieving were consistent with the subsequent observation that their spreadability and 3D printing performance were qualitatively improved. 

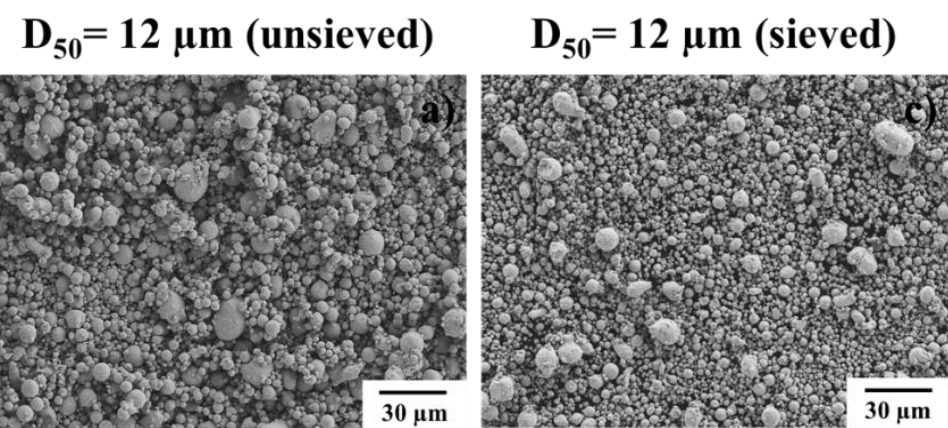

$$
D_{50}=28 \mu \mathrm{m} \text { (unsieved) }
$$
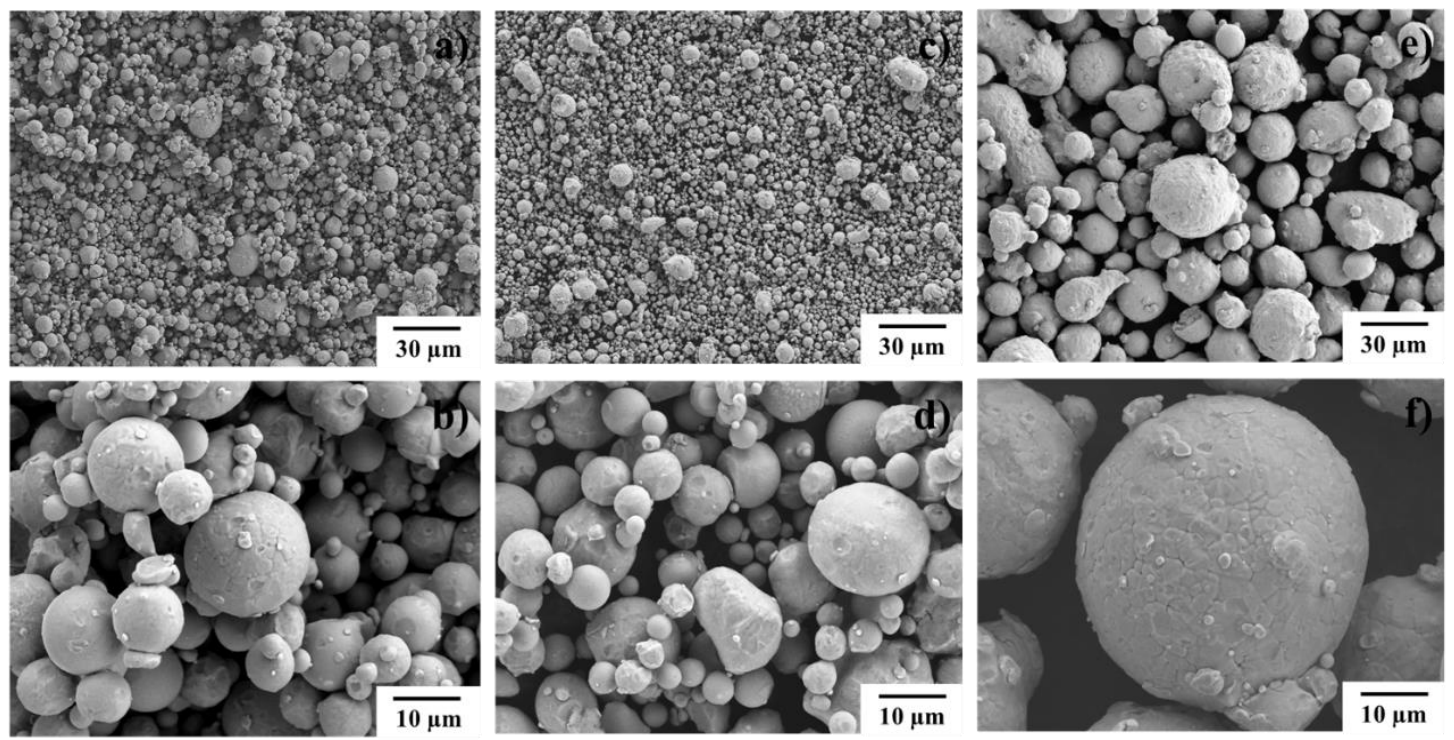

Figure 5.1 SEM images of nitrogen gas atomized AISI 420 stainless steel powder of $\mathrm{D}_{50}: 12 \mu \mathrm{m}$ are shown in (a) and (b) before and (c) and (d) after sieving and powders with D50: $28 \mu \mathrm{m}$ are shown in (e) and (f).

Fig. 5.1 shows the SEM of the as-received and sieved fine and as-received coarse 420 stainless steel powders. It is evident from the images that the powders were predominantly spherical in shape. There were some satellite particles attached to surface of bigger particles in the powders. Some roughness was observed on the surfaces of particle which may have occurred during the atomization process. The initial fine powder appeared to have more agglomeration which was not as apparent in the coarse powder. This observation is consistent with similar observations reported in the literature [115]. The increased presence of agglomerates is consistent with the lower tap and apparent densities in the asreceived fine powder relative to the coarse powder. The improvement in apparent and tap densities are consistent with deagglomeration because of vibratory impact during sieving. The lower values of Hausner ratio for the coarse powder as well as the sieved fine powder are qualitatively consistent with improved spreadability following deagglomeration. 
Qualitative L-PBF assessments of powder spreadability and printability using the sieved fine powder and the coarse powder relative to the as-received fine powder were consistent with the respective particle characteristics described above. The rest of the study compares the processing, properties and microstructures of sieved fine powder to the coarse powder.

\subsubsection{PHYSICAL PROPERTIES}
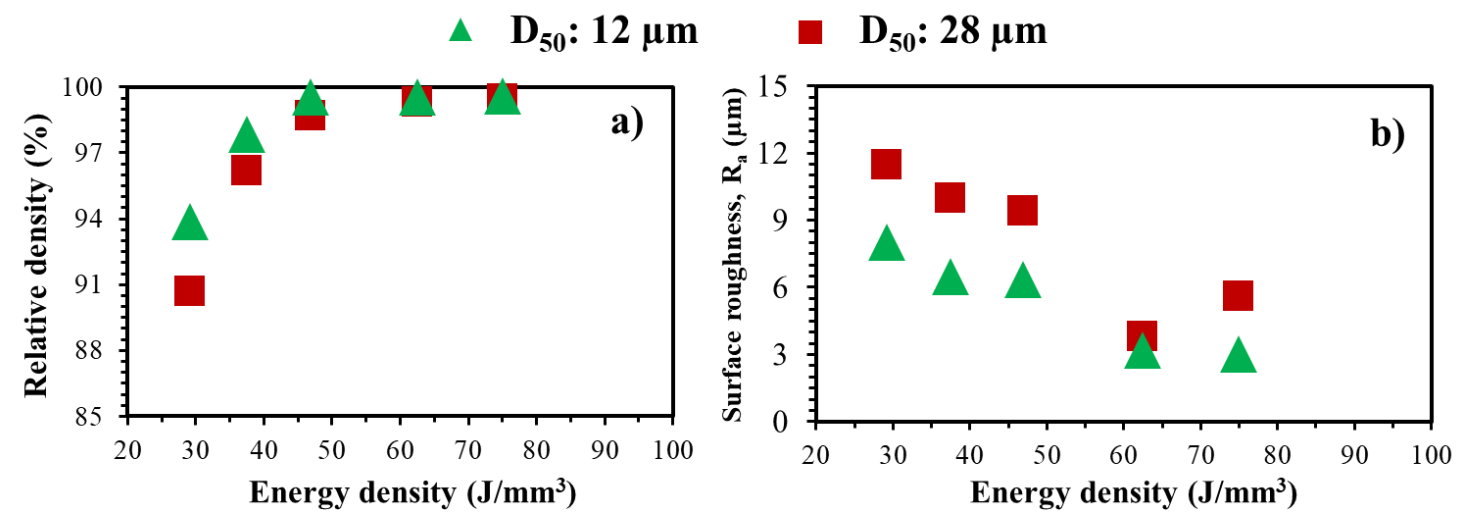

Figure 5.2 (a) Relative density and (b) surface roughness of L-PBF parts using AISI 420 stainless powders of $\mathrm{D}_{50}: 12 \mu \mathrm{m}$ and $\mathrm{D}_{50}: 28 \mu \mathrm{m}$ were plotted against energy density ranged from 28 to $75 \mathrm{~J} / \mathrm{mm}^{3}$. The density of L-PBF parts was measured by the Archimedes method

Fig. 5.2(a) represents the densification behavior of 420 stainless steel when varying the energy density during L-PBF from $29 \mathrm{~J} / \mathrm{mm}^{3}$ to $75 \mathrm{~J} / \mathrm{mm}^{3}$. At $29 \mathrm{~J} / \mathrm{mm}^{3}$, the fine powder resulted in a relative density of $93.9 \%$. In contrast, L-PBF parts were $89.5 \%$ dense with the coarse powder. As the energy density was increased, the difference in relative density between L-PBF parts with the fine and coarse powders started to decrease. For example, at an energy density of $47 \mathrm{~J} / \mathrm{mm}^{3}$, the density of parts fabricated using the fine powder was $99.6 \%$, slightly above the density of $98.7 \%$ for the part using the coarse powder. As the energy density increased above $63 \mathrm{~J} / \mathrm{mm}^{3}$, densification with both powders remained above 99.5\% and no significant difference was found. Prior literature studies on the L-PBF of 
420 stainless steel have reported 96 - $99 \%$ density being achieved at $\sim 80-120 \mathrm{~J} / \mathrm{mm}^{3}$ using powders with a median particle size of over $~ 30 \mu \mathrm{m}[10,11,20]$. Further experimental and simulation studies are needed to better understand the differences in densification behavior as a function of particle size in L-PBF.

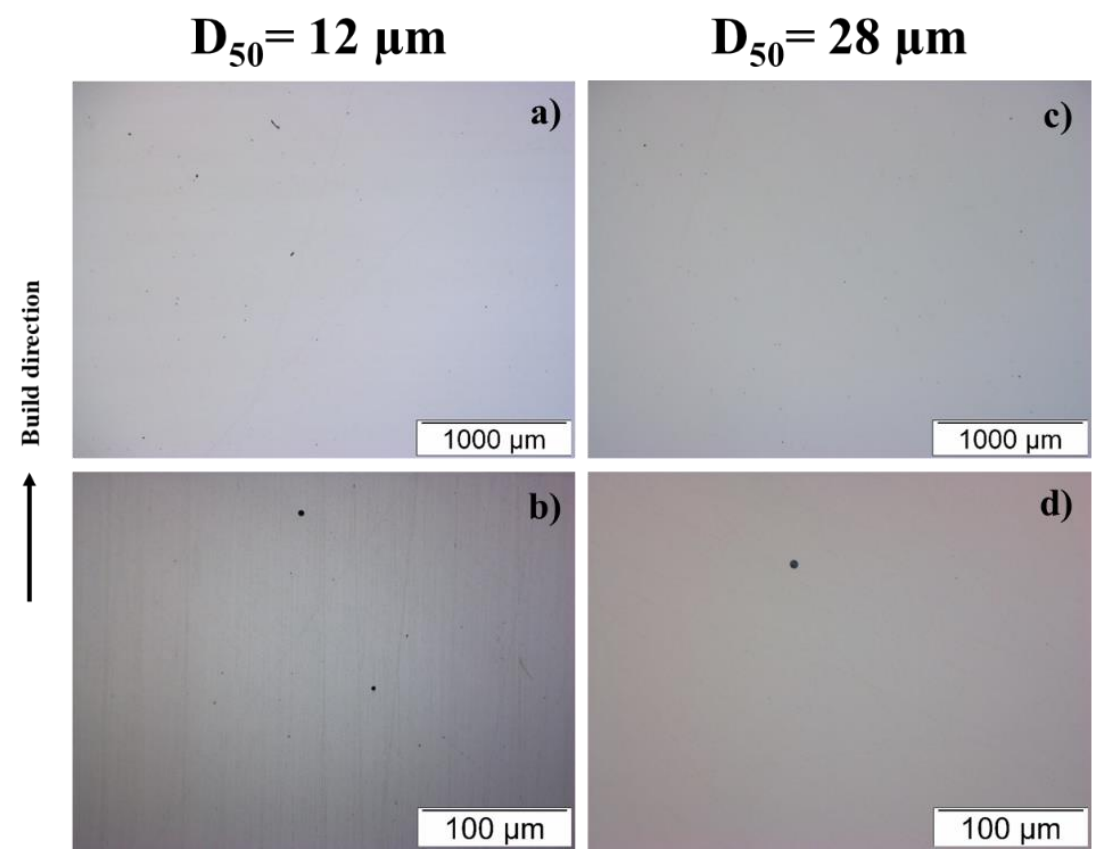

Figure 5.3 Optical images in the build direction of as-printed L-PBF parts of nitrogenatomized 420 stainless steel powders with median particle sizes of $12 \mu \mathrm{m}$ and $28 \mu \mathrm{m}$.

The surface roughness of the top surface of L-PBF specimens correlated to particle size and energy density. As seen in Fig 5.2(b), the surface roughness $\left(\mathrm{R}_{\mathrm{a}}\right)$ of L-PBF specimens decreased with the median particle size of the powder. For instance, at an energy density of $29 \mathrm{~J} / \mathrm{mm}^{3}$, the $\mathrm{R}_{\mathrm{a}}$ decreased from $11.6 \pm 0.6$ to $8.3 \pm 0.1 \mu \mathrm{m}$ as the median particle size (D 50 ) was changed from 28 to $12 \mu \mathrm{m}$. At an energy density of $63 \mathrm{~J} / \mathrm{mm}^{3}, \mathrm{~L}-\mathrm{PBF}$ specimens fabricated with fine and coarse powders exhibited an $R_{a}$ of $3.1 \pm 0.1$ and $4.6 \pm 0.4 \mu \mathrm{m}$ respectively. At this energy density, the difference in surface roughness was found to be minimum. Thus, an energy density of $63 \mathrm{~J} / \mathrm{mm}^{3}$ was chosen to fabricate ASTM standard 
tensile specimens for mechanical characterization. For investigating the effects of particle size on mechanical properties, ASTM standard tensile bars were printed $63 \mathrm{~J} / \mathrm{mm}^{3}$ of energy density with the sieved fine and the coarse 420 stainless steel powders. Crosssectional images in the build direction of L-PBF tensile bars are shown in Fig. 5.3. Very few pores are observed in the structure in the as- printed parts, consistent with the Archimedes density values.

\subsubsection{MECHANICAL PROPERTIES}

Table 5. 3 Mechanical properties of L-PBF 420 stainless steel using fine powder (D50: 12 $\mu \mathrm{m})$

\begin{tabular}{|c|c|c|c|c|c|c|}
\hline Powder & Condition & $\begin{array}{l}\text { Density } \\
\mathrm{g} / \mathrm{cm}^{3}\end{array}$ & $\begin{array}{l}\text { Ultimate } \\
\text { tensile } \\
\text { strength } \\
\mathrm{MPa}\end{array}$ & $\begin{array}{c}\text { Elongation } \\
\%\end{array}$ & $\begin{array}{c}0.2 \% \text { Yield } \\
\text { Strength } \\
\mathrm{MPa}\end{array}$ & $\begin{array}{c}\text { Hardness } \\
\text { HRC }\end{array}$ \\
\hline \multirow{2}{*}{$\begin{array}{c}\mathrm{D}_{50}: 12 \\
\mu \mathrm{m}\end{array}$} & $\begin{array}{l}\text { As- } \\
\text { printed }\end{array}$ & $\begin{array}{c}7.65 \pm \\
0.02\end{array}$ & $\begin{array}{c}1040 \pm \\
30\end{array}$ & $2.4 \pm 0.2$ & $720 \pm 20$ & $56 \pm 1$ \\
\hline & $\begin{array}{l}\text { Heat- } \\
\text { treated }\end{array}$ & $\begin{array}{c}7.65 \pm \\
0.02\end{array}$ & $\begin{array}{c}1515 \pm \\
35\end{array}$ & $6.1 \pm 0.3$ & $960 \pm 35$ & $54 \pm 1$ \\
\hline
\end{tabular}

The as-printed and heat-treated mechanical properties of L-PBF parts obtained from the fine 420 stainless steel powder are summarized in Table 5.3. L-PBF parts in the as-printed condition with the fine 420 stainless steel powder exhibited a UTS of $1040 \pm 30 \mathrm{MPa}$, yield 
strength of $720 \pm 20 \mathrm{MPa}$, elongation of $2.4 \pm 0.2 \%$, and hardness of $56 \pm 1 \mathrm{HRC}$. After heat treatment, the UTS of L-PBF parts fabricated with the fine 420 stainless steel powder increased to $1515 \pm 35 \mathrm{MPa}$, the yield strength increased to $960 \pm 35 \mathrm{MPa}$, the elongation increased to $6.1 \pm 0.3 \%$, and the hardness remained similar at $54 \pm 1 \mathrm{HRC}$. In comparison, our previous L-PBF study on 420 stainless steel using powders with a median particle size of $28 \mu \mathrm{m}$ reported as-printed properties that included a UTS of $1050 \pm 50 \mathrm{MPa}$, yield strength of $700 \pm 20 \mathrm{MPa}$, elongation of $2.5 \pm 0.2 \%$, and hardness of $55 \pm 1 \mathrm{HRC}$ [74]. In addition, that study also reported heat-treated properties that included a UTS of $1520 \pm 30$ $\mathrm{MPa}$, yield strength of $950 \pm 20 \mathrm{MPa}$, elongation of $6.3 \pm 0.2 \%$, and hardness of $53 \pm 1$ HRC [74]. These properties were slightly lower to the properties compiled for heat-treated wrought 420 stainless steel (UTS $1625 \pm 40 \mathrm{MPa}$, yield strength $1350 \pm 50 \mathrm{MPa}$, elongation $7 \pm 1.0 \%$ and hardness of $53 \pm 2 \mathrm{HRC}$ ) [47]. For further comparison, heat-treated metal injection molded (MIM) parts exhibited lower mechanical properties than L-PBF properties of comparable median particle size to the present study: UTS of $1350 \pm 50 \mathrm{MPa}$, elongation of $2 \pm 1 \%$, and hardness of $48 \pm 2$ HRC [51]. Taken together, it can be concluded that there was no significant difference in mechanical properties between the sieved fine powders used in this study and the as-received coarse 420 stainless steel powders. Further the properties were slightly better than MIM and a bit lower than wrought values. 


\subsubsection{MICROSTRUCTURE}

The XRD analysis for as-printed and heat-treated L-PBF parts of the two powders is presented in Fig. 5.4. Also included are the XRD data for the two starting powders,
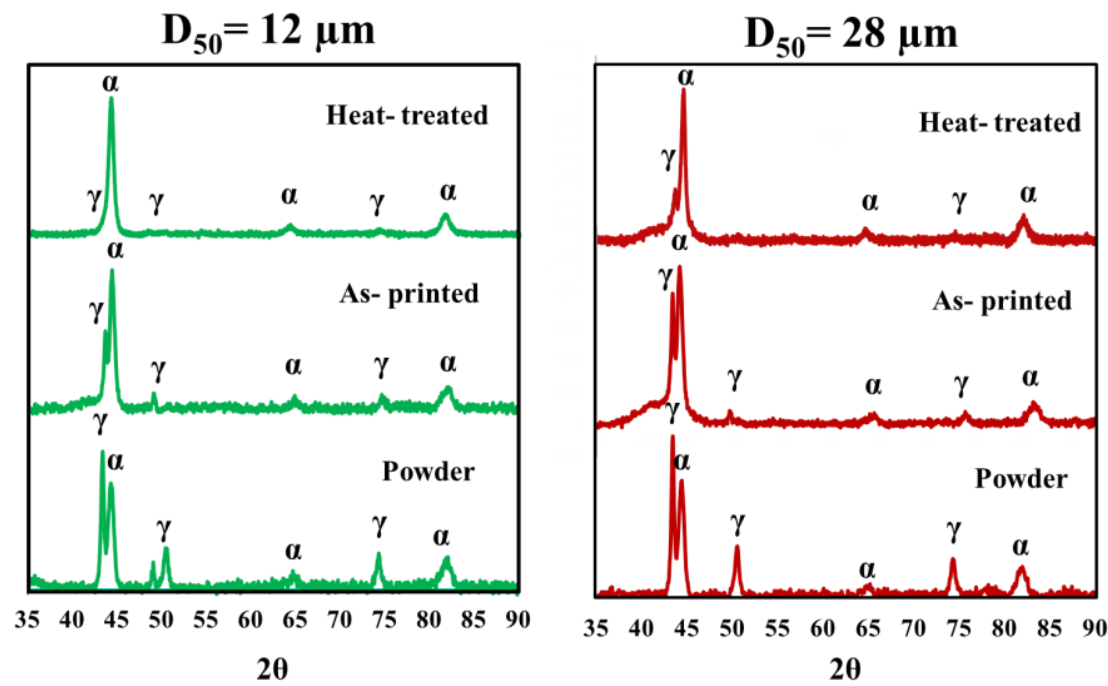

Figure 5.4 XRD data of as- printed and heat-treated L-PBF parts printed at $63 \mathrm{~J} / \mathrm{mm}^{3}$ with the two 420 stainless steel powders. The XRD data of the initial powders are also shown for comparison.

indicating the presence of $\alpha$ (martensite) and $\gamma$ (austenite) peaks. From Reitveld analysis, the retained austenite in the starting powders were similar and estimated to be $\sim 67 \%$. Following L-PBF, the XRD data of as-printed parts from both the powders showed that the $\alpha$ phase increased. Reitveld analysis indicated that the L-PBF parts obtained from the finer powder contained $\sim 17 \pm 10 \%$ retained austenite, compared to reported values for L-PBF parts using the coarse powder, $15 \pm 12 \%$ [74]. The increased martensitic content can be attributed to the intrinsically rapid cooling rates during the L-PBF process [116]. Following heat-treatment, the XRD data of the L-PBF parts from both the powders showed that there was no notable change. Reitveld analysis indicated that the heat- treated L-PBF parts using 
the fine powder contained $\sim 20 \pm 10 \%$ retained austenite, in comparison to $16 \pm 5 \%$ for the L-PBF parts using the coarse powder.[74]

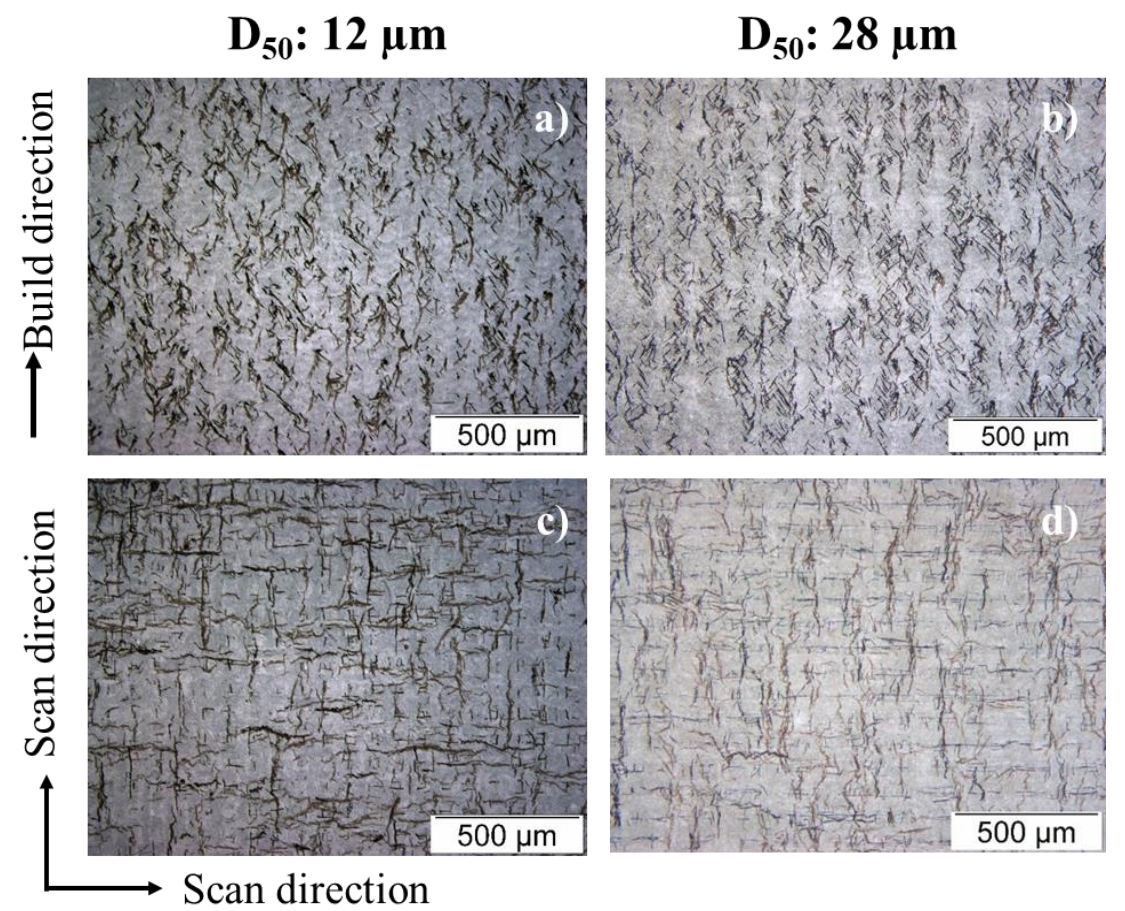

Figure 5.5 Microstructures of as-printed tensile bars fabricated by L-PBF using fine ( $a$ and $c$ ) and coarser ( $b$ and d) 420 stainless steel powders. The images are in the build (top) and scan (bottom) directions after polishing with $1 \mu \mathrm{m}$ diamond paste followed by etching with Kalling II reagent.

The etched microstructures of as-printed tensile bars fabricated by L-PBF using the two powders are shown in Fig. 5.5. Consistent with the trends in mechanical properties, the change in particle size did not appear to have any major influence in the microstructure when parts were printed at the same energy density. Both microstructure were martensite rich in the as-printed condition [43]. Striking differences could also be observed in the orientation of the needles in the build and scan direction. An increased directionality of the martensite laths was observed in scan direction. Similar to the microstructure achieved in the experiments with the coarse powder, the average distance between the laths were found to be $120 \mu \mathrm{m}$, equal to the trace width or distance between laser scan tracks used in this 


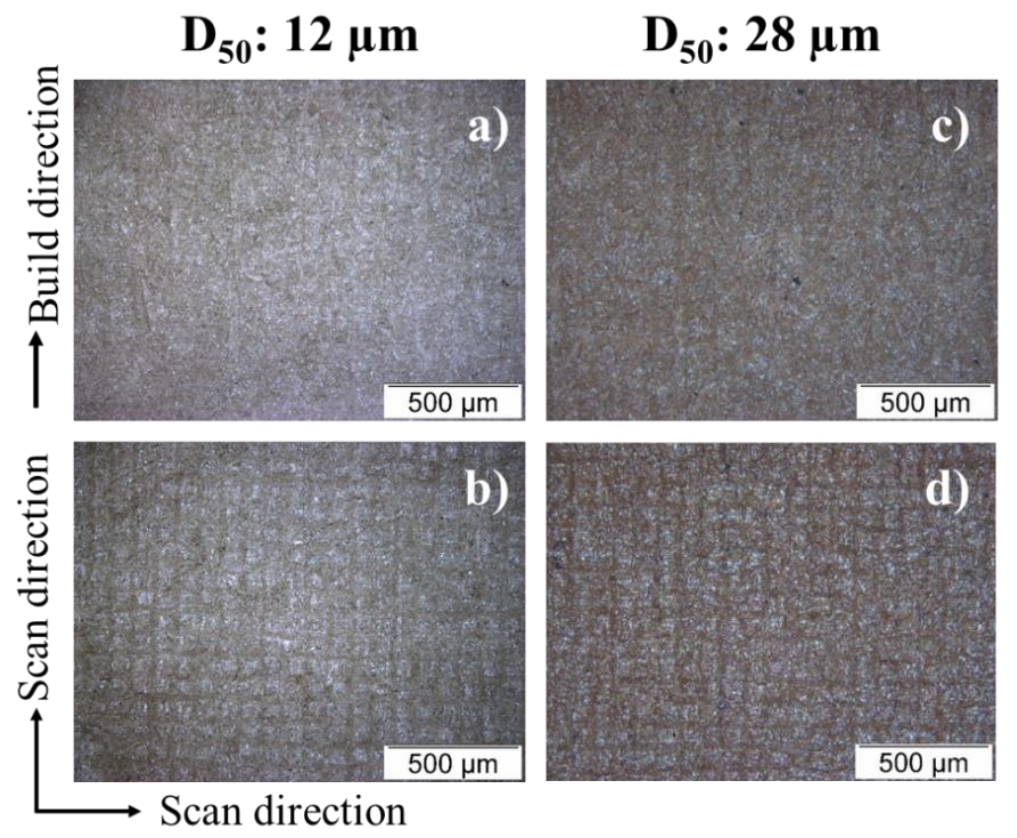

Figure 5.6 Microstructures of heat- treated tensile bars fabricated by L-PBF using fine ( $a$ and b) and coarser ( $c$ and d) 420 stainless steel powders. The images are in the build (top) and scan (bottom) directions after polishing with $1 \mu \mathrm{m}$ diamond paste followed $b$.

experiment. Further, the martensite laths were typically located at the edge of the scan tracks, which can be attributed to the faster cooling rates near the edge of the melt pool. Following heat treatment (Fig. 5.6), the microstructures of the parts appeared to have a tempered martensite microstructure, consistent with the UTS, yield strength, elongation and hardness data. Further experiments are underway to characterize the tempered structures at higher resolutions.

\subsubsection{CORROSION PROPERTIES}

The corrosion current $\left(\mathrm{I}_{\mathrm{corr}}\right)$, corrosion potential $\left(\mathrm{E}_{\mathrm{corr}}\right)$ and cathode and anode slope were measured using a standard extrapolation method to calculate the polarization resistance and corrosion rate $[57,58]$ and tabulated in Table 5.4 using the equations listed below:

$$
\text { Polarization resistance, } \operatorname{Rp}=\frac{1}{I_{\text {corr }}}\left(\frac{\beta_{\mathrm{a}} \beta_{\mathrm{c}}}{\beta_{\mathrm{a}}+\beta_{\mathrm{c}}}\right) \quad \text { Equation } 1
$$




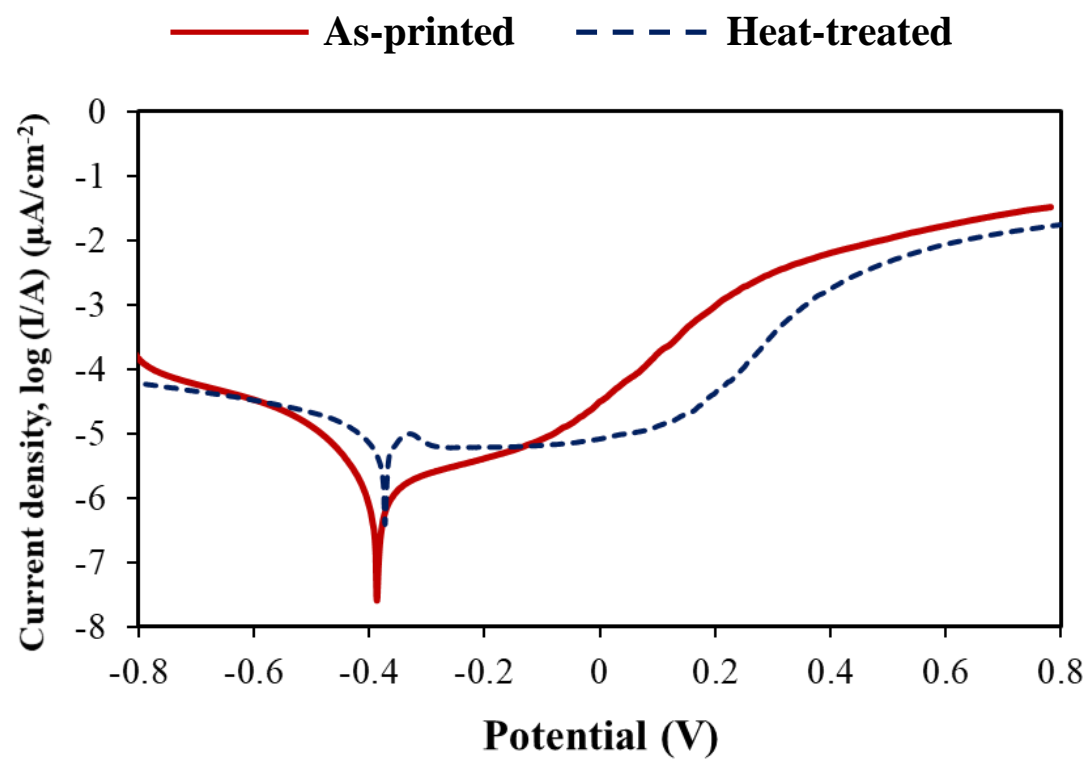

Figure 5.7 Linear sweep voltammetry (LSV) curves for as-printed and heat-treated LPBF specimens fabricated with 420 stainless steel powder of $\mathrm{D}_{50}: 12 \mu \mathrm{m}$ in aqueous solution containing $3.5 \mathrm{wt} \% \mathrm{NaCl}$. Anode: L-PBF part, reference electrode: $\mathrm{Ag} / \mathrm{AgCl}$; cathode: Pt wire; $\mathrm{pH}=6.0$; scan rate: $0.01 \mathrm{Vs}^{-1}$.

Where the Tafel constants $\beta_{\mathrm{a}}$ and $\beta_{\mathrm{c}}$ represent the anodic and cathodic slope respectively.

$$
\text { Corrosion rate, } \mathrm{CR}=\frac{\mathrm{I}_{\mathrm{corr}}}{\rho \mathrm{A}} * \mathrm{k} * \mathrm{EW} \quad \text { Equation } 2
$$

where, $\rho$ is the Archimedes density of the material, $A$ is the exposed surface area to corrosion, $\mathrm{k}$ is a constant $(3.272 \mathrm{~m} /$ year) and $\mathrm{EW}$ is the equivalent weight of the material.

From Table 5.4, the as-printed L-PBF 420 stainless steel fabricated with fine powder exhibited an $\mathrm{I}_{\text {corr }}$ of $2.80 \pm 0.1 \mu \mathrm{A} . \mathrm{cm}^{-2}$. Heat-treated L-PBF parts exhibited a slightly higher current density of $3.3 \pm 0.21 \mu \mathrm{A} . \mathrm{cm}^{-2}$. As-printed and heat-treated L-PBF 420 stainless steel specimens using the coarse powder were reported by us to have a similar corrosion current of $2.85 \pm 0.4 \mathrm{~mA} \cdot \mathrm{cm}^{-2}$ and $3.5 \pm 0.1 \mu \mathrm{A} . \mathrm{cm}^{-2}$, respectively [74]. These values were relatively higher than the reported value of $2.1 \pm 0.1 \mu \mathrm{A} / \mathrm{cm}^{2}$ for heat-treated wrought 420 stainless steel. ${ }^{27}$ 
Table 5.4 Corrosion parameters of 420 stainless steel in $3.5 \% \mathrm{NaCl}$ solution fabricated by L-PBF using $\mathrm{D}_{50}: 12 \mu \mathrm{m}$ size powder

\begin{tabular}{|c|c|c|c|c|c|}
\hline & Corrosion & Corrosion & Breakdown & Polarization & \\
Process & current & potential & potential & resistance & Corrosion rate \\
& $\mathrm{I}_{\text {corr }}$ & $\mathrm{E}_{\text {corr }}$ & $\mathrm{E}_{\mathrm{b}}$ & by Tafel plot & $(\Omega \mathrm{m} / \mathrm{year})$ \\
\hline printed & 0.1 & 0.01 & 0.01 & $\left.(\mathrm{~cm})^{2}\right)$ & $26 \pm 1$ \\
\hline L-PBF_as & $2.80 \pm$ & $-0.38 \pm$ & $0.25 \pm$ & & \\
PBF_heat & $3.3 \pm 0.1$ & $-0.35 \pm$ & $0.20 \pm$ & & $32 \pm 1$ \\
treated & & 0.01 & 0.02 & & \\
\hline
\end{tabular}

The as-printed and heat-treated L-PBF 420 stainless steel parts using the fine powder exhibited a polarization resistance of $17,420 \pm 290 \Omega . \mathrm{cm}^{-2}$ and 17,070 $\pm 320 \Omega . \mathrm{cm}^{-2}$. Asprinted and heat-treated L-PBF 420 stainless steel specimens using the coarse powder were reported to have a similar polarization resistance of $17,100 \pm 520 \Omega . \mathrm{cm}^{-2}$ [74]. A slightly higher polarization resistance of $18,700 \pm 350 \Omega . \mathrm{cm}^{-2}$ has also been reported for heattreated wrought 420 stainless steel [59].

The corrosion rate is linearly proportional to the corrosion current density and calculated using Equation 2. In this study, the L-PBF 420 stainless steel parts showed a corrosion rate $26 \pm 1 \mu \mathrm{m} /$ year in the as-printed condition. A slight higher value, $32 \pm 1 \mu \mathrm{m} / \mathrm{year}$, was observed with the heat-treated parts. In contrast, heat-treated wrought 420 stainless steel has been reported to have a corrosion rate of $23 \pm 2 \mu \mathrm{m} /$ year [59]. 

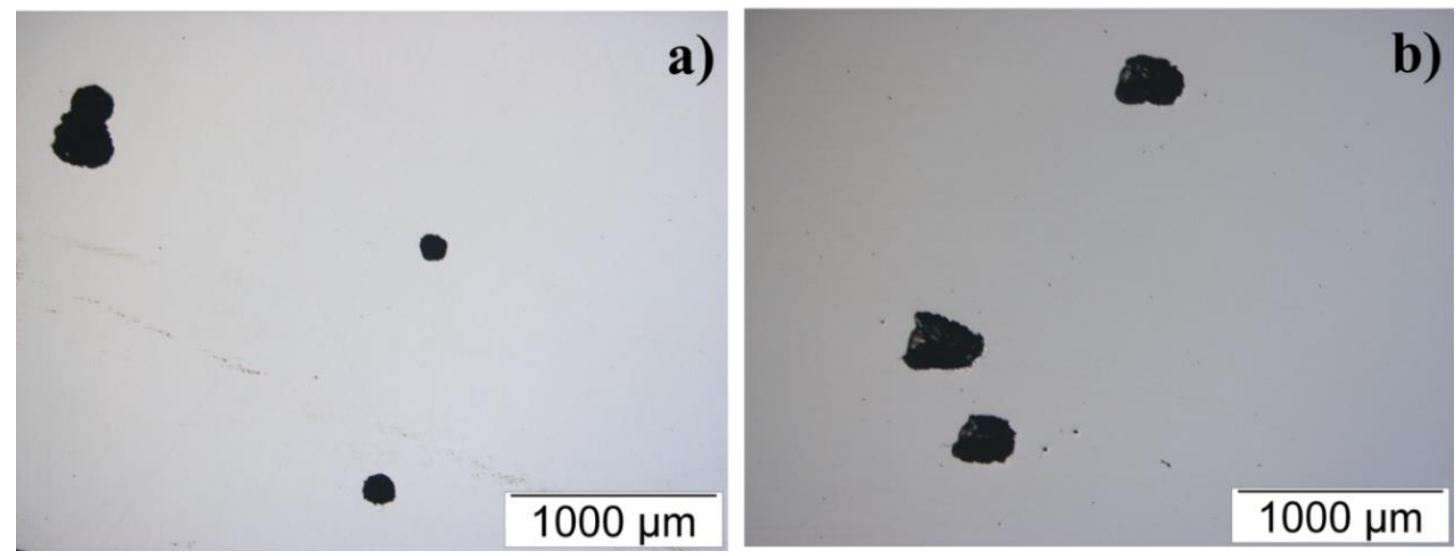

Figure 5.8 Optical images of corroded surfaces showing the formation of pits in asprinted (left) and heat-treated (right) 420 stainless steel parts fabricated by L-PBF. For reference, the initial state before corrosion are shown in Figure 3.

From the Tafel plots, a corrosion potential $\left(E_{\text {corr }}\right)$ was calculated to be $-0.38 \pm 0.01 \mathrm{~V}$ for the as-printed 420 stainless steel parts. In comparison, the heat-treated L-PBF parts exhibited a corrosion potential of $-0.35 \pm 0.01 \mathrm{~V}$. A higher corrosion potential is indicative of a more stable passivation layer [37]. The breakdown potential $\left(\mathrm{E}_{\mathrm{b}}\right)$ is determined at the inflection point. It is an indication of the stability of the passivation layer formed on the metal surface. In this study, the heat-treated 420 stainless steel parts showed the highest $\mathrm{E}_{\mathrm{b}}$ at $0.20 \pm 0.02 \mathrm{~V}$. In comparison, the as-printed 420 stainless steel experienced breakdown of the passive layer at $0.25 \pm 0.01 \mathrm{~V}$.

Fig. 5.8 shows the optical images of the as-printed and heat-treated L-PBF samples taken before and after corrosion tests. Regular large pores were observed on the metal surface following the breakdown potential, indicative of pitting corrosion [60]. No intergranular cracking corrosion was observed in this study. No significant difference was found between as-printed and heat-treated samples. Therefore, it can be concluded that 420 stainless steel fabricated by L-PBF retained its corrosion properties after heat treatment and exhibits improved pitting resistance. 


\subsection{CONCLUSIONS}

This study convincingly demonstrated that fine 420 stainless steel powder can be used in L-PBF to successfully fabricate parts with comparable mechanical and corrosion properties. The conclusions emerging from this study are listed below:

1. Vibratory sieving process improved the spreadability and printability of as-received fine $\left(\mathrm{D}_{50}: 12 \mu \mathrm{m}\right)$ powder by breaking up agglomerates. The apparent density of fine 420 stainless steel powder improved from $3.8 \pm 0.3$ to $4.1 \pm 0.2 \mathrm{~g} / \mathrm{cm}^{3}$ after sieving. Additionally, the tap density of fine powder, $4.7 \pm 0.1 \mathrm{~g} / \mathrm{cm}^{3}$, improved to $5.0 \pm 1 \mathrm{~g} / \mathrm{cm}^{3}$.

2. L-PBF parts fabricated using the fine powder experienced higher densification and lower surface roughness compared to the parts fabricated with coarse powder. As the energy density was increased from $29 \mathrm{~J} / \mathrm{mm}^{3}$ to $63 \mathrm{~J} / \mathrm{mm}^{3}$ to, the difference in density of L-PBF parts printed with fine and coarse powder decreased.

3. Parts fabricated using the sieved fine powder also quantitatively exhibited a lower surface roughness than the coarse powder at all energy densities.

4. In mechanical tests, $99.5 \%$ dense parts printed with the fine powder exhibited similar tensile behavior to $99.5 \%$ dense parts printed with the coarse powder. The L-PBF specimens using the sieved fine powder and coarse powders showed an ultimate strength of $1040 \pm 30 \mathrm{MPa}$, a yield strength $700 \pm 15 \mathrm{MPa}$ and an elongation of $2.5 \pm$ $0.5 \%$. The hardness was measured to be $55 \pm 1 \mathrm{HRC}$ in the as- printed condition. After heat- treatment at $315^{\circ} \mathrm{C}$, the L-PBF parts exhibited an ultimate tensile strength of 1515 $\pm 35 \mathrm{MPa}$, a yield strength of $960 \pm 35 \mathrm{MPa}$ and an elongation $6.0 \pm 0.3 \%$, while the hardness remained at $53 \pm 1 \mathrm{HRC}$. These properties were slightly better than 420 
stainless steel properties reported for MIM using a similar particle size but slightly lower than heat-treated wrought 420 stainless steel.

5. The as-printed L- PBF parts using the fine 420 stainless steel powder showed a corrosion current of $2.80 \pm 0.1 \mu \mathrm{A} . \mathrm{cm}^{-2}$, a polarization resistance of $17420 \pm 290 \Omega . \mathrm{cm}^{-}$ 2 and a corrosion rate of $26 \pm 1 \mu \mathrm{m} / \mathrm{year}$. These properties were comparable to the corrosion properties observed with L-PBF parts print with the coarse powder. Following heat treatment, there was a slight decrease in corrosion current, polarization resistance and corrosion rate and an increase in breakdown potential.

6. L-PBF specimens printed at same energy density using fine and coarse powders showed no significant difference in the microstructure. Martensite dominant microstructure was observed in the as-printed condiction, consistent with high mechanical properties. Similar to the parts fabricated with coarse powder, orientation of martensite phase in the scan direction was observed in the microstructure of L-PBF parts printed with fine powder. The tempering of martensite was consistent with improvement in mechanical properties. 


\section{CHAPTER 6}

\section{CONCLUSIONS AND FUTURE WORK}

\subsection{CONCLUSIONS}

This dissertation successfully addressed key gaps in the scientific literature on the fabrication of 420 stainless steel using L-PBF by establishing powder-processing-propertymicrostructure relationships. The conclusions from this dissertation are summarized below.

- L-PBF parts with density greater than $99.5 \%$ were fabricated at an energy density of $63 \mathrm{~J} / \mathrm{mm}^{3}$. This energy density was lower than previously reported energy densities that achieved $99+\%$ density. The part density increased with the decreasing layer thickness used during L-PBF. Variation in chemical composition by the addition of $\mathrm{Nb}(1.2$ wt.\%) and Mo (0.57 wt.\%) while keeping the particle size distribution same did not show any influence the densification behavior. L-PBF specimens with a lower particle size ( $D_{50}: 12 \mu \mathrm{m}$ ) achieved a part density above $99.5 \%$ at lower energy densities than a coarser particle size $\left(\mathrm{D}_{50}: 28 \mu \mathrm{m}\right)$. No significant change was found in the density of heat-treated specimens irrespective of layer thickness of the process, chemical composition or particle size distribution of the powder.

- L-PBF parts with surface roughness of $3.1 \pm 0.1 \mu \mathrm{m}$ were fabricated at an energy density of $63 \mathrm{~J} / \mathrm{mm}^{3}$. The surface roughness increased with the decreasing layer thickness and particle size used during L-PBF. Variation in chemical composition by the addition of $\mathrm{Nb}(1.2 \mathrm{wt} . \%)$ and $\mathrm{Mo}(0.57 \mathrm{wt} . \%)$ while keeping the particle size 
distribution same did not show any influence the surface roughness. No significant change was found in the surface roughness of heat-treated specimens irrespective of layer thickness of the process, chemical composition or particle size distribution of the powder.

- In presence of $\mathrm{Nb}(1.2$ wt. \%) and Mo (0.57 wt. \%), heat-treated L-PBF specimens of 420 stainless steel exhibited an ultimate tensile strength of $1750 \pm 30 \mathrm{MPa}$ and elongation of $9.0 \pm 0.3 \%$; exceeding previously reported literature values of 420 stainless steel fabricated by L-PBF as well as heat -treated MIM and wrought materials. Mechanical properties were found to increase by reducing the layer thickness, adding $\mathrm{Nb}$ and $\mathrm{Mo}$, and following heat treatment. Once rendered spreadable and printable using a novel vibratory sieving method, comparable mechanical properties were achieved using fine powder $\left(\mathrm{D}_{50}: 12 \mu \mathrm{m}\right)$ and coarse powder $\left(\mathrm{D}_{50}: 28 \mu \mathrm{m}\right)$.

- L-PBF 420 stainless steel with $\mathrm{Nb}(1.2$ wt.\%) and Mo (0.57 wt. \%) exhibited a corrosion current of $1.5 \pm 0.2 \mu \mathrm{A} . \mathrm{cm}^{-2}$, a polarization resistance of $24,200 \pm 550 \Omega / \mathrm{cm}^{2}$ and a corrosion rate $16 \pm 1 \mu \mathrm{m} / \mathrm{year}$; improving on previously reported literature values on the corrosion performance of 420 stainless steel fabricated by L-PBF as well as heattreated MIM and wrought materials.

- The microstructure of L-PBF 420 stainless steel was pre-dominantly martensitic in the as-printed condition which contributed to high mechanical properties of the specimens. Striking difference was found in the microstructure between scan and build directions. Orientation of martensitic laths were observed in the scan direction which opened the opportunity for tailoring the properties in a certain direction. Martensite content in the microstructure increased as the layer thickness was decreased. In the presence of $\mathrm{Nb}$ 
(1.2 wt.\%) and Mo (0.57 wt. \%), L-PBF 420 stainless steel showed nanoscale NbC in the as-printed microstructure which played a key role to achieve significantly better mechanical properties. There was no difference in the microstructure between parts printed with fine $\left(\mathrm{D}_{50}: 12 \mu \mathrm{m}\right)$ and coarse $\left(\mathrm{D}_{50}: 28 \mu \mathrm{m}\right) 420$ stainless steel powders processed at the same energy density. Tempering of martensite correlated with the improvement of both mechanical strength and elongation after heat treatment, as well as the retained corrosion properties in the heat-treated condition. Grain boundaries were not observed in any L-PBF 420 stainless steel specimens in the as-printed and heattreated conditions, consistent with the absence of intergranular corrosion in LSV study and high corrosion properties. The microstructures of 420 stainless steel processed by L-PBF were significantly different from those found in powder metallurgy and wrought samples.

\subsection{FUTURE WORK}

In addition to generating the above scientific contributions, the work undertaken during the preparation of this dissertation also identified new scientific areas for further investigation on the L-PBF of 420 stainless steel. They are listed below:

- Martensite is known to be the strengthening phase in austenitic and martensitic stainless steels. This dissertation reported the observation of directionally aligned martensitic needles in the as-printed L-PBF specimens as shown in Fig. 6.1. The diameter and spacing of the directionally martensite needles further correlated with the laser trace 


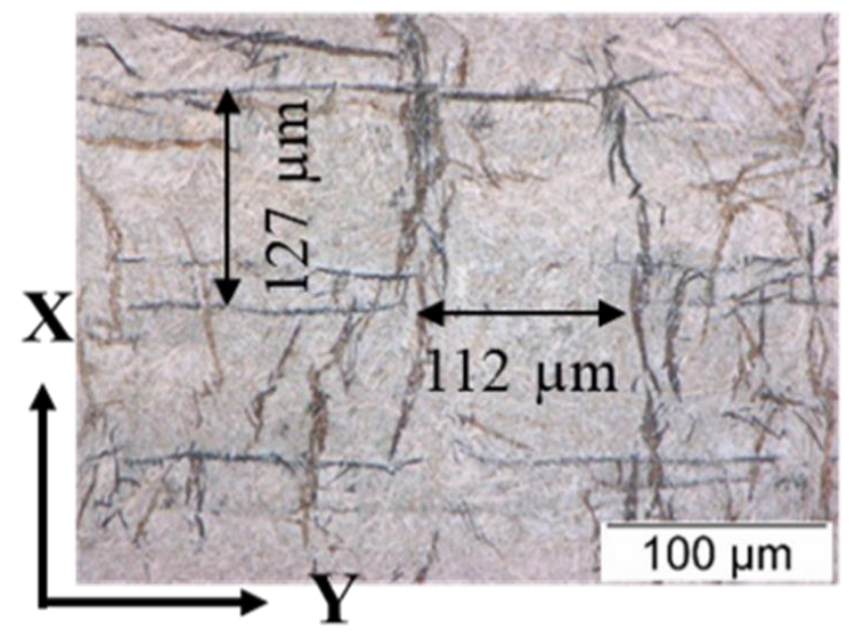

Figure 6.1 Optical image of etched cross-section in the scan direction of asprinted 420 stainless steel revealing the orientation of martensite needles.

width. Future studies can be undertaken to use this approach to selectively fabricate cross-sections with increased strength without adding additional mass to the design.

- In L-PBF, a part goes through repetitive thermal cycles. The thermal cycle in one layer can influence the microstructure achieved in the previous layers. Rapid changes in microstructure can induce thermal stain in the part which can ultimately result in distortion, cracking, or brittleness. Therefore, future work on characterizing the thermal strain distributions in parts and establishing relationships between microstructure, processing and the coefficient of thermal expansion for L-PBF 420 stainless steel will provide valuable information on defining suitable printing and annealing conditions for eliminating thermal strains and associated defects. 

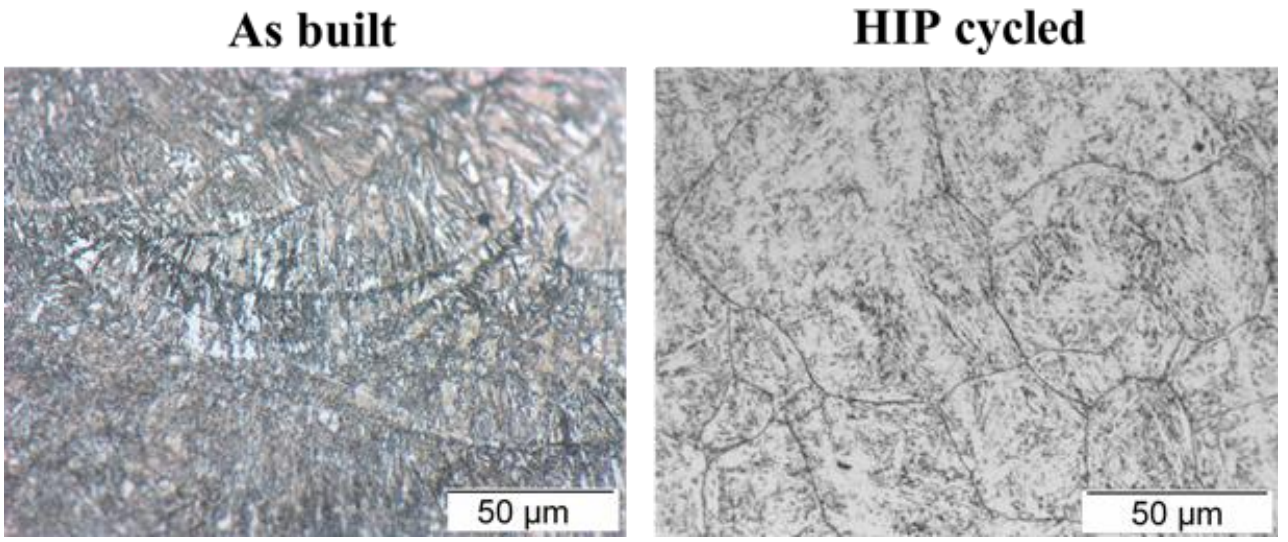

Figure 6.2 Microstructure of the as-printed and HIPed 420 stainless steel.

- Optimizing process parameters to achieve high density and mechanical properties currently involves time-consuming and expensive iterations. A pragmatic solution of this problem could be to use post processing using hot isostatic pressing (HIP), a wellestablished approach in PM and MIM industries. Application of pressure and temperature during a HIP cycle can improve the density by removing internal pores in the fabricated specimens. In HIP, the temperature is simultaneously raised to a point where recrystallization of material occurs a change in the microstructure and mechanical properties is expected, as shown in Fig 6.2. Some feasibility studies are also presented in APPENDIX F. 

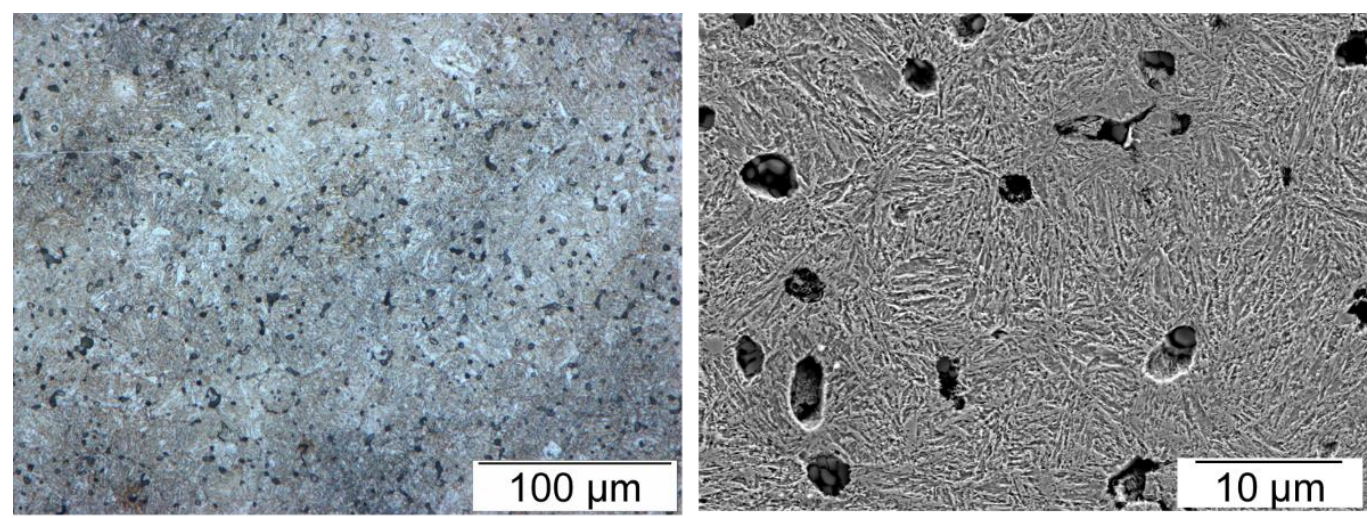

Figure 6.3 Optical and scanning electron images of the etched microstructure of the as-sintered and heat-treated 420 stainless steel.

- In this dissertation, heat treatment was conducted at a $315^{\circ} \mathrm{C}$ followed by air cooling. As shown in Fig. 6.3, the martensite undergoes tempering accompanied by an enhancement of mechanical properties despite the continued retention of $\sim 15 \%$ austenite. However, oil quenching from much higher temperatures, e.g. $800{ }^{\circ} \mathrm{C}$, is routinely used in the heat-treatment of for wrought 420 stainless steel to achieve full martensitic microstructure. Quenching of L-PBF specimens have not been well investigated yet and could be the focus of future work.

Ar-atomized

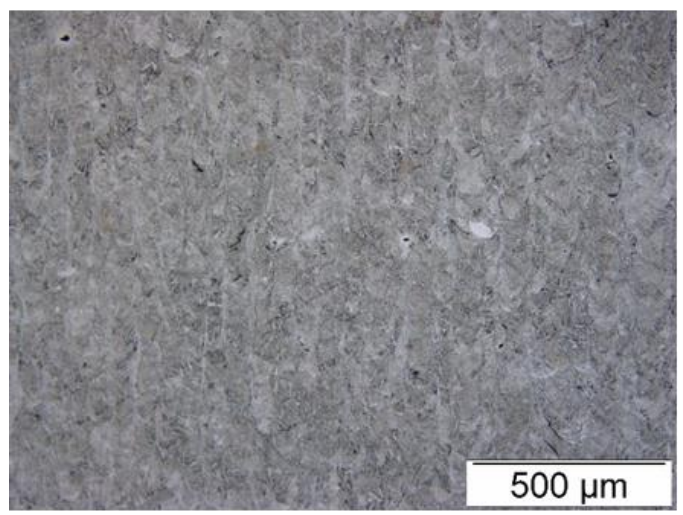

N-atomized

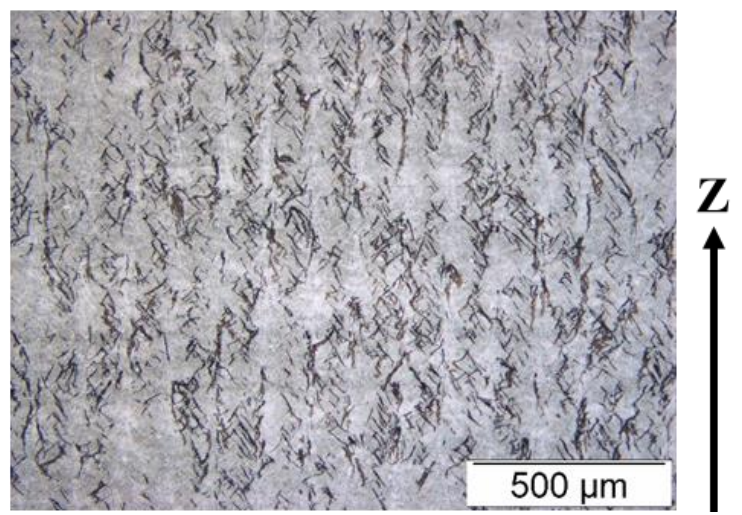

Figure 6.4 Difference in the microstructure of L-PBF 420 stainless steel specimens by varying the nitrogen content of starting powder. 
- This dissertation focused on N-atomized 420 stainless steel powders. In contrast, Aratomized 420 stainless steel powder has a lower $\mathrm{N}$ content in the chemical composition. $\mathrm{N}$ is known to be a strengthening agent for stainless steel. Literature studies focused on MIM also mentioned effects of $\mathrm{N}$ in corrosion behavior of the as-sintered materials. Nitrogen can also lower corrosion properties. Thus, it will an interesting study to observe how the content of $\mathrm{N}$ play a role in properties and microstructure of L-PBF specimens, as seen in Fig. 6.4. Preliminary work is presented in APPENDIX G.

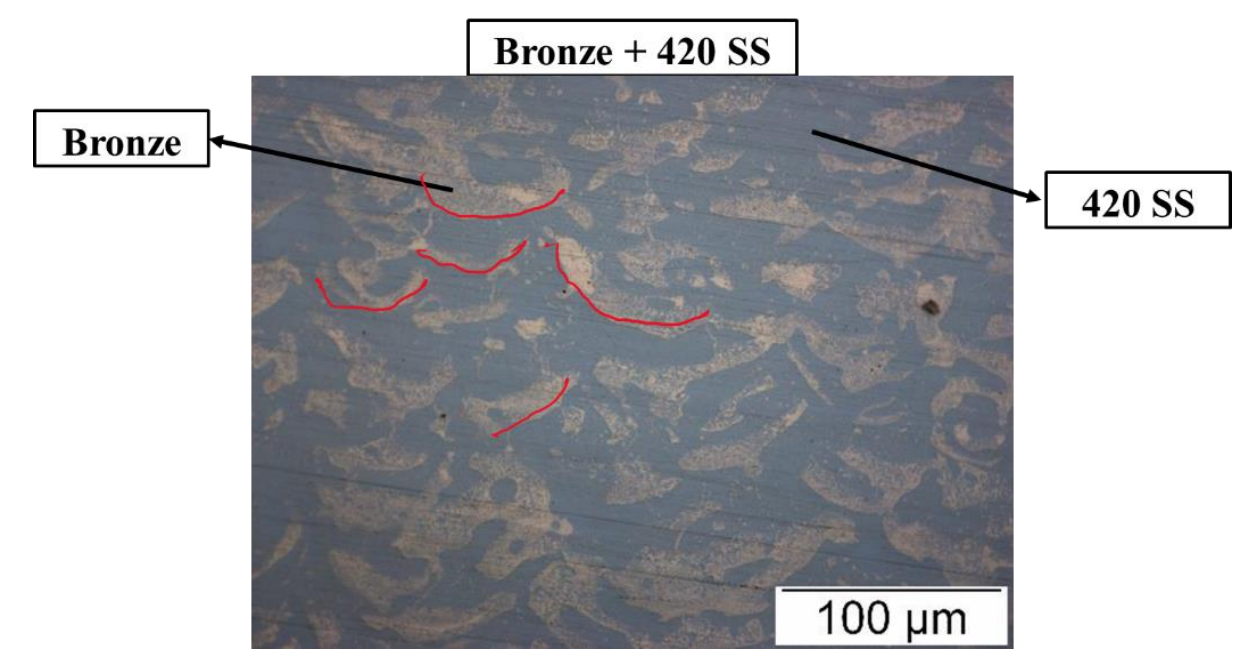

Figure 6.5 Microstructure of L-PBF 420 stainless steel-bronze bimetallic alloy

- Powders with differing alloying chemistries are not easily fabricated by L-PBF. Blending 420 stainless steel with bronze can provide a blend of high mechanical properties and enhanced thermal conductivity. Bronze exhibits liquid phase sintering during the thermal processing. Thus, a bimetallic alloy can be synthesized in a hybrid process combining L-PBF with infiltration as shown in Fig. 6.5. Future work could focus on microstructure-property-processing relationships for this material system. Results from preliminary experiments are presented in APPENDIX H. 


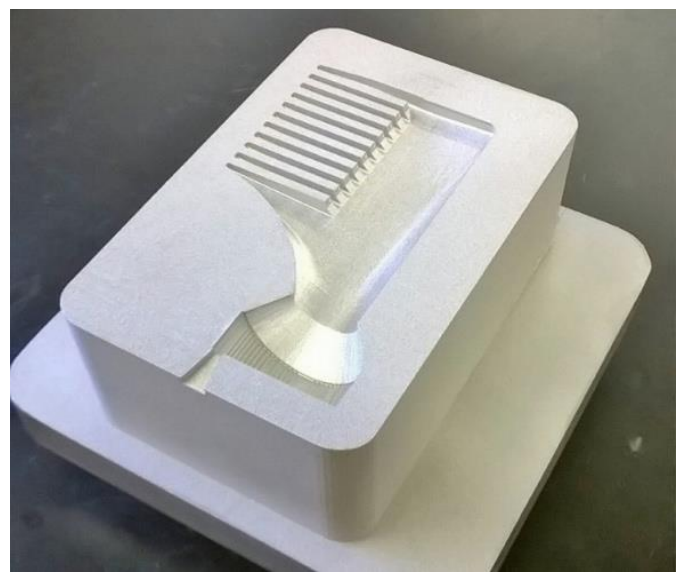

Figure 6.6 Injection mold with conformal cooling channels fabricated by L-PBF using 420 stainless steel powder ( $D_{50}: 12 \mu \mathrm{m}$ ) at a layer thickness of $10 \mu \mathrm{m}$.

- High hardness and strength make AISI 420 stainless steel a suitable choice for tooling applications. In this study, L-PBF 420 stainless steel exhibited mechanical properties surpassing wrought material. L-PBF is an excellent choice to fabricate injection mold with conformal cooling channels. Preliminary work was conducted to fabricate a mold with CCC using L-PBF 420 stainless steel, as shown in Fig. 6.6. In the future, cycle time, cooling time, temperature distribution and sink mark in parts will be characterized through injection molding simulations and experiments. APPENDIX I presents preliminary findings on the feasibility of fabricating tooling for injection molding using L-PBF 420 stainless steel.

- Surgical tools come in a limited number of sizes and designs. However, L-PBF offers a convenient pathway to fabricating surgical tools that are custom-designed to the individual and specific needs of patients as well as doctors. 420 stainless steel is a reasonable choice for fabricating surgical tools owing to the combination of high strength and excellent corrosion properties. The outcomes of this dissertation can be implemented to develop surgical tools as shown in Fig. 6.7. APPENDIX I also presents 
preliminary findings on the feasibility of fabricating laparoscopic surgical tools using L-PBF 420 stainless steel.

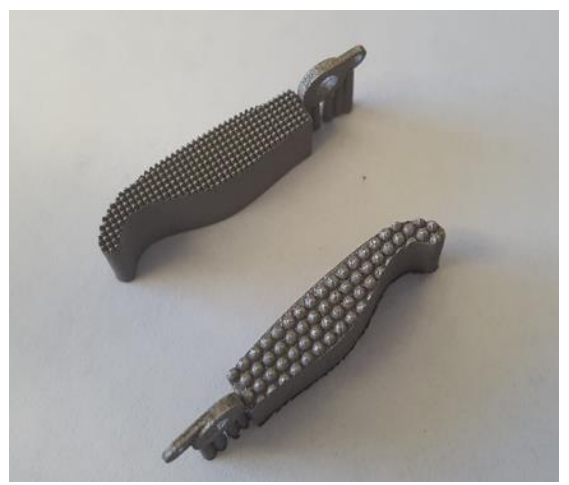

Figure 6.7 Graspers with varying teeth pattern for laparoscopic surgery.

- This dissertation focused on structural properties as well as corrosion properties. Future work could additionally focus on wear properties. In this regard, snake scales possess multiscale textures that enhance their wear resistance and friction during locomotion. Fig. 6.8 shows bio-inspired hexagonal patterns fabricated in 420 stainless steel by LPBF. Besides, the texture of the skin is at micron-level which can also be introduced by L-PBF. Preliminary work on the L-PBF fabrication of bio-inspired surface textures are presented in APPENDIX J.

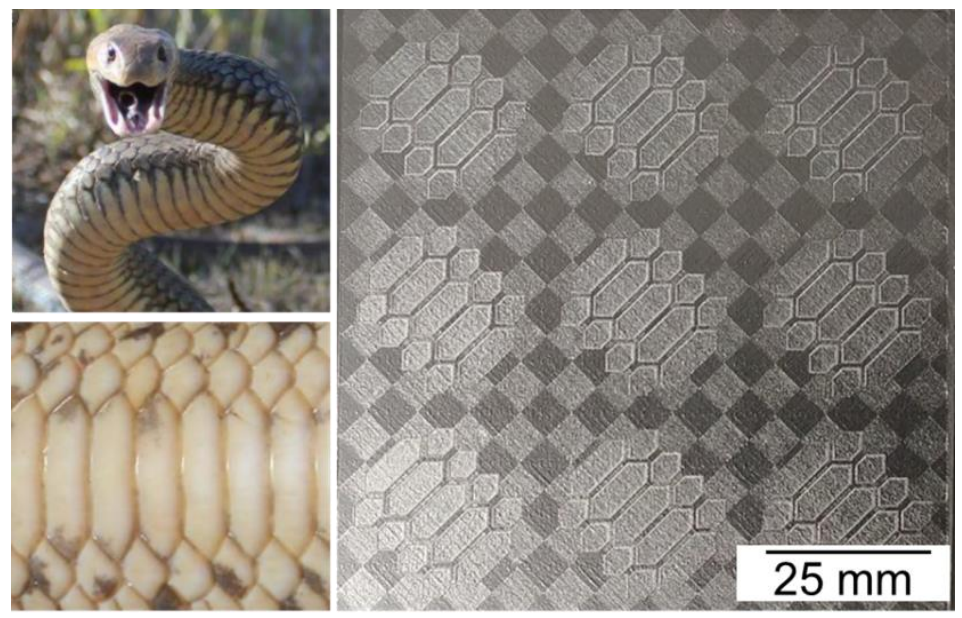

Figure 6.8 Snake skin-inspired patterns in 420 stainless steel fabricated by L-PBF for potential use in wear resistant moving parts. 


\section{REFERENCES}

1. Cotteleer, M., Joyce, J., 3D opportunity: additive manufacturing paths to performance, innovation, and growth. Deloitte Review, 2014. 14: 5-19.

2. Huang, R., Riddle, M.E., Graziano, D., Das, S., Nimbalkar, S., Cresko, J. and Masanet, E., Environmental and economic implications of distributed additive manufacturing: The case of injection mold tooling. Journal of Industrial Ecology, 2017. 21: 130-143.

3. Kalpakjian, S., Sekar, K.V., Schmid, S.R. Manufacturing Engineering and Technology. 2014: Pearson.

4. Frazier, W.E., Metal additive manufacturing: a review. Journal of Materials Engineering and Performance, 2014. 23: 1917-1928.

5. King, W.E., Anderson, A.T., Ferencz, R.M., Hodge, N.E., Kamath, C., Khairallah, S.A. and Rubenchik, A.M., Laser powder bed fusion additive manufacturing of metals; physics, computational, and materials challenges. Applied Physics Reviews, 2015. 2: 041304.

6. Wohlers, T., Campbell, I., Diegel, O., Wohlers Report 2018. Fort Collins: Wohlers Associates, 2018.

7. Sun, P., Fang, Z.Z., Zhang, Y. and Xia, Y., Microstructure and mechanical properties of Ti-6Al-4V fabricated by selective laser melting of powder produced by granulation-sintering-deoxygenation method. JOM, 2017. 69: 2731-2737. 
8. Zhou, Y., Wen, S.F., Song, B., Zhou, X., Teng, Q., Wei, Q.S. and Shi, Y.S., A novel titanium alloy manufactured by selective laser melting: microstructure, high temperature oxidation resistance. Materials \& Design, 2016. 89: 1199-1204.

9. Mahmoudi, M., Elwany, A., Yadollahi, A., Thompson, S.M., Bian, L. and Shamsaei, N., Mechanical properties and microstructural characterization of selective laser melted 17-4 PH stainless steel. Rapid Prototyping Journal, 2017. 23: 280-294.

10. Zhao, X., Wei, Q., Song, B., Liu, Y., Luo, X., Wen, S. and Shi, Y., Fabrication and characterization of AISI 420 stainless steel using selective laser melting. Materials and Manufacturing Processes, 2015. 30: 1283-1289.

11. Krakhmalev, P., Yadroitsava, I., Fredriksson, G. and Yadroitsev, I., In situ heat treatment in selective laser melted martensitic AISI 420 stainless steels. Materials \& Design, 2015. 87: 380-385.

12. El-Tamimi, A., El-Hossainy, T., Investigating the machinability of AISI 420 stainless steel using factorial design. Materials and Manufacturing Processes, 2008. 23: 419-426.

13. Stainless Steel Market Size, Share \& Trend Analysis Report By Grade, By Product, By Application (Construction, Heavy Industry, Transportation, Consumer Goods), By Region, And Segment Forecasts, 2018 - 2025. 2018, Market Research Report.

14. Pierce, R.W., Jolly, N., Kennedy, R.V., Guarded surgical scalpel. 1997, U.S. Patent $5,620,454$.

15. Allen, S. M., Sachs, E. M., Three-dimensional printing of metal parts for tooling and other applications. Metals and Materials, 2000. 6: 589-594. 
16. Cooke, A., Slotwinski, J., Properties of metal powders for additive manufacturing: a review of the state of the art of metal powder property testing. 2012: US Department of Commerce, National Institute of Standards and Technology.

17. Criales, L.E., Arısoy, Y.M., Lane, B., Moylan, S., Donmez, A. and Özel, T., Laser powder bed fusion of nickel alloy 625: experimental investigations of effects of process parameters on melt pool size and shape with spatter analysis. International Journal of Machine Tools and Manufacture, 2017. 121: 22-36.

18. Nachum, S., Fleck, N., The microstructure and mechanical properties of ball-milled stainless steel powder: The effect of hot-pressing vs. laser sintering. Acta Materialia, 2011. 59: 7300-7310.

19. Krakhmalev, P., Yadroitsava, I., Fredriksson, G. and Yadroitsev, I., Microstructure of SLM manufactured 316L and 420 grades stainless steel. RAPDASA 2014.

20. Saeidi, K., Stainless steels fabricated by laser melting. PhD Thesis, 2016, Stockholm University.

21. German, R.M., Powder metallurgy and particulate materials processing: the processes, materials, products, properties, and applications. 2005: Metal powder industries federation Princeton.

22. Irrinki, H., Dexter, M., Barmore, B., Enneti, R., Pasebani, S., Badwe, S., Stitzel, J., Malhotra, R. and Atre, S.V., Effects of powder attributes and laser powder bed fusion (L-PBF) process conditions on the densification and mechanical properties of 17-4 PH stainless steel. JOM, 2016. 68: 860-868.

23. Irrinki, H., Dexter, M., Barmore, B., Enneti, R., Pasebani, S., Badwe, S., Stitzel, J., Malhotra, R. and Atre, S.V., Effects of particle characteristics on the microstructure 
and mechanical properties of 17-4 PH stainless steel fabricated by laser-powder bed fusion. Powder Technology, 2018. 331: 192-203.

24. Nath, S.D., Rajan, A., Yeung, J., Atre, S.V., AM for the OR: Laser-Powder Bed Fusion Delivers Laparoscopic Instruments, in 3D Metal Printing Magazine. 2018. $1-4$.

25. Weaver, T.J., Thomas, J.A., Atre, S.V. and German, R.M., Time compression-rapid steel tooling for an ever-changing world. Materials \& Design, 2000. 21: 409-415.

26. German, R., Atre, S. V., Thomas, J., Large, low-production quantity components via polymer-assisted shaping and sintering technologies. P/M Science \& Technology Briefs, 2002. 4: 9-13.

27. German, R.M., Weaver, T.J., Thomas, J.A., Atre, S.V. and Griffo, A, Powdered material rapid production tooling method and objects produced therefrom. 2002, US Patent 6,399,018.

28. Brnic, J., Turkalj, G., Canadija, M., Lanc, D. and Krscanski, S., Martensitic stainless steel AISI 420 - mechanical properties, creep and fracture toughness. Mechanics of Time-Dependent Materials, 2011. 15: 341-352.

29. Berretta, J.R., de Rossi, W., das Neves, M.D.M., de Almeida, I.A. and Junior, N.D.V., Pulsed Nd: YAG laser welding of AISI 304 to AISI 420 stainless steels. Optics and Lasers in Engineering, 2007. 45: 960-966.

30. Nishiyama, Z., Martensitic Transformation. 2012. Elsevier.

31. Marsden, C., West0, D., Steen, W., Laser surface alloying of stainless steel with carbon, Laser Surface Treatment of Metals. 1986. 461-473. 
32. Nakagawa, H., Miyazaki, T., Effect of retained austenite on the microstructure and mechanical properties of martensitic precipitation hardening stainless steel. Journal of Materials Science, 1999. 34: 3901-3908.

33. Ferguson, J.B., Schultz, B.F., Moghadam, A.D. and Rohatgi, P.K., Semi-empirical model of deposit size and porosity in 420 stainless steel and 4140 steel using laser engineered net shaping. Journal of Manufacturing Processes, 2015. 19: 163-170.

34. Talbot, D.E., Talbot, J.D., Corrosion science and technology. 2018: CRC press.

35. Van Bennekom, A., Robinson, F., The Effect of Martensite Content on the Corrosion and Mechanical Properties of Dual-Phase 12\% Chromium Steels. INFACON 6., 1992. 2: 157-163.

36. Song, Y.Y., Ping, D.H., Yin, F.X., Li, X.Y. and Li, Y.Y., Microstructural evolution and low temperature impact toughness of a $\mathrm{Fe}-13 \% \mathrm{Cr}-4 \% \mathrm{Ni}-\mathrm{Mo}$ martensitic stainless steel. Materials Science and Engineering: A, 2010. 527: 614-618.

37. Corengia, P., Ybarra, G., Moina, C., Cabo, A. and Broitman, E., Microstructure and corrosion behaviour of DC-pulsed plasma nitrided AISI 410 martensitic stainless steel. Surface and Coatings Technology, 2004. 187: 63-69.

38. Candelaria, A., Pinedo, C., Influence of the heat treatment on the corrosion resistance of the martensitic stainless steel type AISI 420. Journal of Materials Science Letters, 2003. 22: 1151-1153.

39. Isfahany, A.N., Saghafian, H, Borhani, G., The effect of heat treatment on mechanical properties and corrosion behavior of AISI420 martensitic stainless steel. Journal of Alloys and Compounds, 2011. 509: 3931-3936. 
40. Oh, J.W., Bollina, R., Lee, W.S. and Park, S.J., Analysis of Nano/Micro Bimodal SUS316L Powder Behavior, Frontiers in Materials Processing, Applications, Research and Technology, 2018. 27-34.

41. Guo, A., J. Beddow, Vetter, A., A simple relationship between particle shape effects and density, flow rate and Hausner ratio. Powder Technology, 1985. 43: 279-284.

42. Cherry, J.A., Davies, H.M., Mehmood, S., Lavery, N.P., Brown, S.G.R. and Sienz, J., Investigation into the effect of process parameters on microstructural and physical properties of $316 \mathrm{~L}$ stainless steel parts by selective laser melting. The International Journal of Advanced Manufacturing Technology, 2015. 76(5-8): 869879.

43. Scheuer, C.J., Cardoso, R.P., Mafra, M. and Brunatto, S.F., AISI 420 martensitic stainless steel low-temperature plasma assisted carburizing kinetics. Surface and Coatings Technology, 2013. 214: 30-37.

44. Gu, H., Gong, H., Pal, D., Rafi, K., Starr, T. and Stucker, B., Influences of energy density on porosity and microstructure of selective laser melted 17-4PH stainless steel. Solid Freeform Fabrication Symposium, 2013.

45. Gong, H., Rafi, K., Gu, H., Ram, G.J., Starr, T. and Stucker, B., Influence of defects on mechanical properties of $\mathrm{Ti}-6 \mathrm{Al}-4 \mathrm{~V}$ components produced by selective laser melting and electron beam melting. Materials \& Design, 2015. 86: 545-554.

46. Khairallah, S.A. Anderson, A., Mesoscopic simulation model of selective laser melting of stainless steel powder. Journal of Materials Processing Technology, 2014. 214: 2627-2636. 
47. Coleman, A.J., Murray, K., Kearns, M., Tingskog, T.A., Sanford, B. and Gonzalez, E., Properties of MIM AISI 420 via pre-alloyed and master alloy routes. International Conference on Powder Metallurgy and Particulate Materials, 2013.

48. Bremen, S., Meiners, W., Diatlov, A., Selective laser melting. Laser Technik Journal, 2012. 9: 33-38.

49. Saeidi, K., Stainless steels fabricated by laser melting: Scaled-down structural hierarchies and microstructural heterogeneities. Stockholm University, 2016.

50. Ali, H., Ghadbeigi, H., Mumtaz, K., Effect of scanning strategies on residual stress and mechanical properties of selective laser melted Ti6Al4V. Materials Science and Engineering: A, 2018. 712: 175-187.

51. Standard, M., 35-Materials Standards for PM in M Structural Parts. Metal Powder Industries Federation, 2016. 32-35.

52. 420 stainless steel properties_AZO. https://www.azom.com/article.aspx?ArticleID=972

53. Young, R.A., The rietveld method. International union of crystallography, 1993.

54. Amato, K.N., Gaytan, S.M., Murr, L.E., Martinez, E., Shindo, P.W., Hernandez, J., Collins, S. and Medina, F., Microstructures and mechanical behavior of Inconel 718 fabricated by selective laser melting. Acta Materialia, 2012. 60: 2229-2239.

55. Riemer, A., Leuders, S., Thöne, M., Richard, H.A., Tröster, T. and Niendorf, T., On the fatigue crack growth behavior in $316 \mathrm{~L}$ stainless steel manufactured by selective laser melting. Engineering Fracture Mechanics, 2014. 120: 15-25.

56. Messler Jr, R., Principle of Eelding. Wiley-Verlag GmbH \& Co., KGaA, 2014. 
57. Irrinki, H., Harper, T., Badwe, S., Stitzel, J., Gulsoy, O., Gupta, G. and Atre, S.V., Effects of powder characteristics and processing conditions on the corrosion performance of 17-4 PH stainless steel fabricated by laser-powder bed fusion. Progress in Additive Manufacturing, 2018: 1-11.

58. Mansouri, K., Ibrik, K., Bensalah, N. and Abdel-Wahab, A., Anodic dissolution of pure Aluminum during electrocoagulation process: Influence of supporting electrolyte, initial $\mathrm{pH}$, and current density. Industrial \& Engineering Chemistry Research, 2011. 50: 13362-13372.

59. Anwar, M.S., Romijarso, T.B. and Mabruri, E., Pitting resistance of the modified $13 \mathrm{Cr}$ martensitic stainless steel in chloride solution. International Journal of Electrochemical Science, 2018. 13: 1515-1526.

60. Abel, J., Virtanen, S., Corrosion of martensitic stainless steel in ethanol-containing gasoline: Influence of contamination by chloride, $\mathrm{H}_{2} \mathrm{O}$ and acetic acid. Corrosion Science, 2015. 98: 318-326.

61. Handoko, W., Pahlevani, F. and Sahajwalla, V., Effect of retained austenite stability in corrosion mechanism of dual phase high carbon steel. World Academy of Science, Engineering and Technology, International Journal of Chemical, Molecular, Nuclear, Materials and Metallurgical Engineering, 2017. 12: 1-5.

62. Vandenbroucke, B., Kruth, J.-P., Selective laser melting of biocompatible metals for rapid manufacturing of medical parts. Rapid Prototyping Journal, 2007. 13: 196203.

63. Shi, X., Ma, S., Liu, C., Chen, C., Wu, Q., Chen, X. and Lu, J., Performance of high layer thickness in selective laser melting of Ti6Al4V. Materials, 2016. 9: 975. 
64. Irrinki, H., Brenton, B., Kate, K., Atre, S. V., Material selection for the production of injection moulding tooling by additive manufacturing. Metal AM, 2016. 2: 7789.

65. Nath, S.D., Dilip, J.J.S, Irrinki, H., Gatsche, M., Kate, K., Ballaro, J., Atre, S.V., Laser-Powder Bed Fusion of 420 Stainless Steel for Mold and Surgical Tool Applications. Additive Manufacturing with Powder Metallurgy Conference Procedings, 2018.

66. Tian, J., Xu, G., Zhou, M. and Hu, H., Refined bainite microstructure and mechanical properties of a high- strength low- carbon bainitic steel treated by austempering below and above Ms. Steel Research International, 2018. 89: 1700469.

67. Sun, S.D., Barr, C., Brandt, M., In situ control of tempered martensite during laser cladding repair of aero-grade 300M steel using AISI 420 stainless steel powder. Journal of Laser Applications, 2018. 30: 032502.

68. Baghjari, S., AkbariMousavi, S., Experimental investigation on dissimilar pulsed Nd: YAG laser welding of AISI 420 stainless steel to kovar alloy. Materials \& Design, 2014. 57: 128-134.

69. Song, B., Dong, S., Zhang, B., Liao, H. and Coddet, C., Effects of processing parameters on microstructure and mechanical property of selective laser melted Ti6Al4V. Materials \& Design, 2012. 35: 120-125.

70. Olakanmi, E., Selective laser sintering/melting (SLS/SLM) of pure Al, Al-Mg, and Al-Si powders: effect of processing conditions and powder properties. Journal of Materials Processing Technology, 2013. 213: 1387-1405. 
71. Ma, M., Wang, Z., Gao, M. and Zeng, X., Layer thickness dependence of performance in high-power selective laser melting of $1 \mathrm{Cr} 18 \mathrm{Ni9Ti}$ stainless steel. Journal of Materials Processing Technology, 2015. 215: 142-150.

72. Song, B., Zhao, X., Li, S., Han, C., Wei, Q., Wen, S., Liu, J. and Shi, Y., Differences in microstructure and properties between selective laser melting and traditional manufacturing for fabrication of metal parts: A review. Frontiers of Mechanical Engineering, 2015. 10: 111-125.

73. Liverani, E., Toschi, S., Ceschini, L. and Fortunato, A., Effect of selective laser melting (SLM) process parameters on microstructure and mechanical properties of 316L austenitic stainless steel. Journal of Materials Processing Technology, 2017. 249: 255-263.

74. Nath, S.D., Irrinki, H., Gautam, G., Gulsoy, O., Kearns, M., Atre, S.V., Microstructure-property relationships of 420 stainless steel fabricated by laserpowder bed fusion. Powder Technology, 2018.

75. Casalino, G., Campanelli, S.L., Contuzzi, N. and Ludovico, A.D., Experimental investigation and statistical optimisation of the selective laser melting process of a maraging steel. Optics \& Laser Technology, 2015. 65: 151-158.

76. Kruth, J.P., Levy, G., Klocke, F. and Childs, T.H.C., Consolidation phenomena in laser and powder-bed based layered manufacturing. CIRP Annals-Manufacturing Technology, 2007. 56: 730-759.

77. Gu, D., Shen, Y., Balling phenomena in direct laser sintering of stainless steel powder: Metallurgical mechanisms and control methods. Materials \& Design, 2009. 30: 2903-2910. 
78. Galarraga, H., Lados, D.A., Dehoff, R.R., Kirka, M.M. and Nandwana, P., Effects of the microstructure and porosity on properties of Ti-6Al-4V ELI alloy fabricated by electron beam melting (EBM). Additive Manufacturing, 2016. 10: 47-57.

79. Brooks, J., Loretto, M., Smallman, R., Direct observations of martensite nuclei in stainless steel. Acta Metallurgica, 1979. 27: 1839-1847.

80. Saritas, S., Doherty, R.D., Lawley, A., Effect of porosity on the hardenability of P/M steels. International Journal of Powder Metallurgy, 2002. 38: 31-40.

81. Xi, Y.T., Liu, D.X. and Han, D., Improvement of corrosion and wear resistances of AISI 420 martensitic stainless steel using plasma nitriding at low temperature. Surface and Coatings Technology, 2008. 202: 2577-2583.

82. Couturier, L., De Geuser, F., Descoins, M. and Deschamps, A., Evolution of the microstructure of a $15-5 \mathrm{PH}$ martensitic stainless steel during precipitation hardening heat treatment. Materials \& Design, 2016. 107: 416-425.

83. Baumers, M., Dickens, P., Tuck, C. and Hague, R., The cost of additive manufacturing: machine productivity, economies of scale and technology-push. Technological forecasting and social change, 2016. 102: 193-201.

84. Herzog, D., Seyda, V., Wycisk, E. and Emmelmann, C., Additive manufacturing of metals. Acta Materialia, 2016. 117: 371-392.

85. Petrovic, V., Vicente Haro Gonzalez, J., Jordá Ferrando, O., Delgado Gordillo, J., Ramón Blasco Puchades, J., Portolés Griñan, L., Additive layered manufacturing: sectors of industrial application shown through case studies. International Journal of Production Research, 2011. 49: 1061-1079. 
86. Liu, B., Wildman, R., Tuck, C., Ashcroft, I. and Hague, R., Investigation the effect of particle size distribution on processing parameters optimisation in selective laser melting process. Additive Manufacturing Research Group, Loughborough University, 2011: 227-238.

87. Kasperovich, G., Haubrich, J., Gussone, J. and Requena, G., Correlation between porosity and processing parameters in TiAl6V4 produced by selective laser melting. Materials \& Design, 2016.105: 160-170.

88. Roberts, I.A., Wang, C.J., Esterlein, R., Stanford, M. and Mynors, D.J., A threedimensional finite element analysis of the temperature field during laser melting of metal powders in additive layer manufacturing. International Journal of Machine Tools and Manufacture, 2009. 49: 916-923.

89. Shan, Y., Luo, X., Hu, X. and Liu, S., Mechanisms of solidification structure improvement of ultra pure $17 \mathrm{wt} \% \mathrm{Cr}$ ferritic stainless steel by $\mathrm{Ti}, \mathrm{Nb}$ addition. Journal of Materials Science \& Technology, 2011. 27: 352-358.

90. Hua, M., Garcia, C., DeArdo, A., Precipitation behavior in ultra-low-carbon steels containing titanium and niobium. Metallurgical and Materials Transactions A, 1997. 28: 1769-1780.

91. Taylor, K., Solubility products for titanium-, vanadium-, and niobium-carbide in ferrite. Scripta metallurgica et materialia, 1995. 32: 7-12.

92. Hamdy, A.S., El-Shenawy, E., El-Bitar, T., Electrochemical impedance spectroscopy study of the corrosion behavior of some niobium bearing stainless steels in 3.5\% NaCl. International Journal of Electrochemical Science, 2006. 1: 171-80. 
93. Rodrigues, C.A.D., Lorenzo, P.L.D., Sokolowski, A., Barbosa, C.A. and Rollo, J.M.D.A., Titanium and molybdenum content in supermartensitic stainless steel. Materials Science and Engineering: A, 2007. 460: 149-152.

94. Moroishi, T., Fujikawa, H., Makiura, H., The effect of carbon, zirconium, niobium, and titanium on the oxidation resistance of chromium stainless steel. Journal of The Electrochemical Society, 1979. 126: 2173-2182.

95. Tian, W., Du, N., Li, S., Chen, S. and Wu, Q., Metastable pitting corrosion of 304 stainless steel in 3.5\% NaCl solution. Corrosion Science, 2014. 85: 372-379.

96. Kimura, M., Miyata, Y., Toyooka, T. and Kitahaba, Y., Effect of retained austenite on corrosion performance for modified 13\% Cr steel pipe. Corrosion, 2001. 57: 433-439.

97. Davis, J.R., Stainless steels. ASM international, 1994.

98. Acharya, R., Sharon, J.A., Staroselsky, A., Prediction of microstructure in laser powder bed fusion process. Acta Materialia, 2017. 124: 360-371.

99. Kolukisa, S., The effect of the welding temperature on the weldability in diffusion welding of martensitic (AISI 420) stainless steel with ductile (spheroidal graphitenodular) cast iron. Journal of Materials Processing Technology, 2007. 186(1-3): 33-36.

100. Lu, S.Y., Yao, K.F., Chen, Y.B., Wang, M.H., Shao, Y. and Ge, X.Y., Effects of austenitizing temperature on the microstructure and electrochemical behavior of a martensitic stainless steel. Journal of Applied Electrochemistry, 2015. 45: 375-383. 
101. Fujita, N., Ohmura, K., Yamamoto, A., Changes of microstructures and high temperature properties during high temperature service of Niobium added ferritic stainless steels. Materials Science and Engineering: A, 2003. 351: 272-281.

102. Maziasz, P.J., McGreevy, T., Pollard, M.J., Siebenaler, C.W. and Swindeman, R.W., Heat and corrosion resistant cast CF8C stainless steel with improved high temperature strength and ductility. U.S. Patent No. 7,153,373., 2006.

103. Yan, H., Bi, H., Li, X. and Xu, Z., Precipitation and mechanical properties of Nbmodified ferritic stainless steel during isothermal aging. Materials Characterization, 2009. 60: 204-209.

104. Ghalambaz, M., Abdollahi, M., Eslami, A. and Bahrami, A., A case study on failure of AISI 347H stabilized stainless steel pipe in a petrochemical plant. Case studies in engineering failure analysis, 2017. 9: 52-62.

105. Murr, L.E., Frontiers of 3D printing/additive manufacturing: from human organs to aircraft fabrication. Journal of Materials Science \& Technology, 2016. 32: 987-995.

106. Kruth, J.P., Dadbakhsh, S., Vrancken, B., Kempen, K., Vleugels, J. and Van Humbeeck, J., Additive manufacturing of metals via Selective Laser Melting: Process aspects and material developments. 2015.

107. Yap, C.Y., Chua, C.K., Dong, Z.L., Liu, Z.H., Zhang, D.Q., Loh, L.E. and Sing, S.L., Review of selective laser melting: Materials and applications. Applied Physics Reviews, 2015. 2: 041101.

108. Simchi, A., Petzoldt, F., and H. Pohl, On the development of direct metal laser sintering for rapid tooling. Journal of Materials Processing Technology, 2003. 141: 319-328. 
109. Spierings, A.B., Levy, G., Comparison of density of stainless steel 316L parts produced with selective laser melting using different powder grades. Proceedings of the Annual International Solid Freeform Fabrication Symposium, 2009.

110. Lee, Y., Zhang, W., Mesoscopic simulation of heat transfer and fluid flow in laser powder bed additive manufacturing. Proceedings of the Annual International Solid Freeform Fabrication Symposium, Austin, 2015.

111. Barlow, L.D., Toit, M., Effect of austenitizing heat treatment on the microstructure and hardness of martensitic stainless steel AISI 420. Journal of Materials Engineering and Performance, 2012. 21: 1327-1336.

112. Whiting, J., Fox. J., Characterization of feedstock in the powder bed fusion process: sources of variation in particle size distribution and the factors that influence them. Solid Freeform Fabrication Symposium Proceedings, 2016.

113. Da Sun, S., Fabijanic, D., Barr, C., Liu, Q., Walker, K., Matthews, N., Orchowski, N., Easton, M. and Brandt, M., In-situ quench and tempering for microstructure control and enhanced mechanical properties of laser cladded AISI 420 stainless steel powder on 300M steel substrates. Surface and Coatings Technology, 2018. 333: $210-219$.

114. Faustin, M., Maciuk, A., Salvin, P., Roos, C. and Lebrini, M., Corrosion inhibition of C38 steel by alkaloids extract of Geissospermum laeve in $1 \mathrm{M}$ hydrochloric acid: electrochemical and phytochemical studies. Corrosion Science, 2015. 92: 287-300.

115. Lowell, S., Shields, J.E., Thomas, M.A., Thommes, M., Characterization of porous solids and powders: surface area, pore size and density. Springer Science \& Business Media, 2012. 
116. Rafi, H.K., Karthik, N.V., Gong, H., Starr, T.L. and Stucker, B.E., Microstructures and mechanical properties of Ti6Al4V parts fabricated by selective laser melting and electron beam melting. Journal of Materials Engineering and Performance, 2013. 22: $3872-3883$.

117. https://www.ptonline.com/articles/why-conformal-cooling-makes-ense 


\section{APPENDIX A}

\section{POWDER CHARACTERISTICS OF 420 STAINLESS STEEL}

Particle size distributions and chemical composition of the used powders in this thesis were provided by the manufacturer. All powders were characterized according to ASTM standards to obtain helium pycnometer, tap and apparent density before using in a L-PBF experiments. The shape of the powders was observed in scanning electron microscopy.

\section{A.1 CHEMICAL COMPOSITION}

\begin{tabular}{|c|c|c|c|c|c|c|c|c|c|c|c|c|c|}
\hline \multicolumn{14}{|c|}{ Chemical analysis- wt. $\%$} \\
\hline Powder & $\begin{array}{c}\text { Median } \\
\text { particle size }\end{array}$ & Atomization & $\mathrm{Fe}$ & $\mathrm{Nb}$ & Mo & $\mathrm{Cr}$ & $\mathrm{Mn}$ & $\mathrm{Si}$ & $\mathrm{P}$ & $\mathrm{C}$ & $\mathrm{S}$ & $\mathrm{O}$ & $\mathrm{N}$ \\
\hline $\begin{array}{c}420 \\
\text { stainless } \\
\text { steel }\end{array}$ & $\mathrm{D}_{50}: 28 \mu \mathrm{m}$ & $\mathrm{N}$ & Bal. & N/A & N/A & 12.8 & 0.72 & 0.79 & 0.012 & 0.3 & 0.008 & 0.04 & 0.09 \\
\hline $\begin{array}{c}420 \\
\text { stainless } \\
\text { with } \mathrm{Nb}\end{array}$ & $\mathrm{D}_{50}: 28 \mu \mathrm{m}$ & $\mathrm{N}$ & Bal. & 1.2 & 0.57 & 12.9 & 0.9 & 1.0 & 0.01 & 0.35 & 0.01 & 0.04 & 0.12 \\
\hline $\begin{array}{c}420 \\
\text { stainless } \\
\text { steel }\end{array}$ & $D_{50}: 12 \mu \mathrm{m}$ & $\mathrm{N}$ & Bal. & N/A & N/A & 12.9 & 0.73 & 0.79 & 0.012 & 0.35 & 0.008 & 0.044 & 0.09 \\
\hline $\begin{array}{c}420 \\
\text { stainless } \\
\text { steel }\end{array}$ & $\mathrm{D}_{50}: 33 \mu \mathrm{m}$ & $\mathrm{Ar}$ & Bal. & N/A & N/A & 13.4 & 0.30 & 0.55 & 0.016 & 0.43 & 0.007 & 0.011 & 0.09 \\
\hline $\begin{array}{c}420 \\
\text { stainless } \\
\text { steel }\end{array}$ & $\mathrm{D}_{50}: 12 \mu \mathrm{m}$ & $\mathrm{Ar}$ & Bal. & N/A & N/A & 13.6 & 0.1 & 0.5 & n.d. & 0.42 & 0.0002 & 0.05 & 0.03 \\
\hline $\begin{array}{c}\text { AISI } \\
\text { standard }\end{array}$ & & - & Bal. & - & - & $\begin{array}{l}12- \\
14\end{array}$ & $\begin{array}{c}< \\
1.0\end{array}$ & $<$ & $\begin{array}{c}< \\
0.04\end{array}$ & $\overrightarrow{0.15}$ & $<0.03$ & - & - \\
\hline
\end{tabular}




\section{A.2. PARTICLE SIZE DISTRIBUTION}

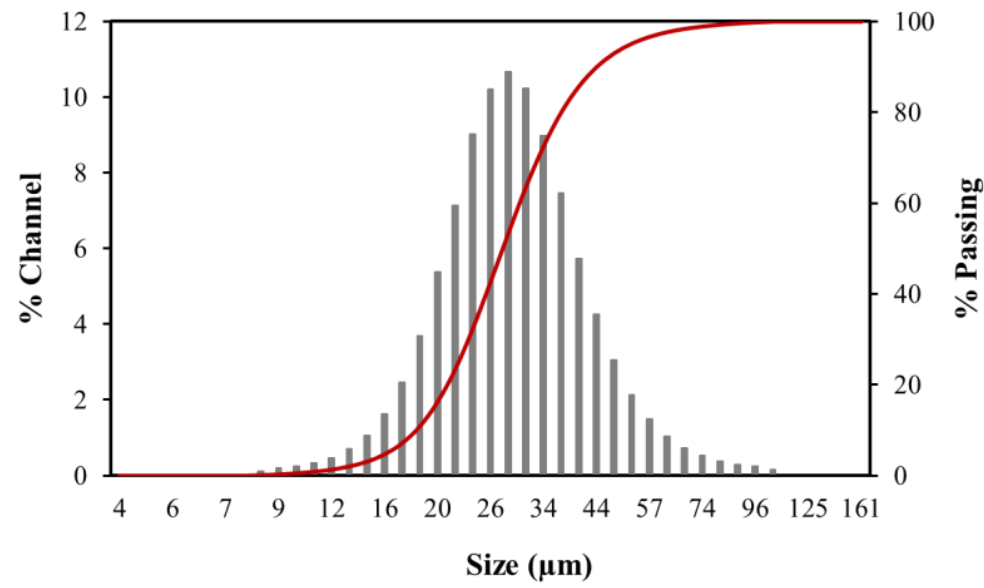

Figure A.1 Particle size distribution of N-atomized coarse AISI 420 stainless steel powder of $\mathrm{D}_{50}: 28 \mu \mathrm{m}$ supplied by Sandvik Osprey Ltd.

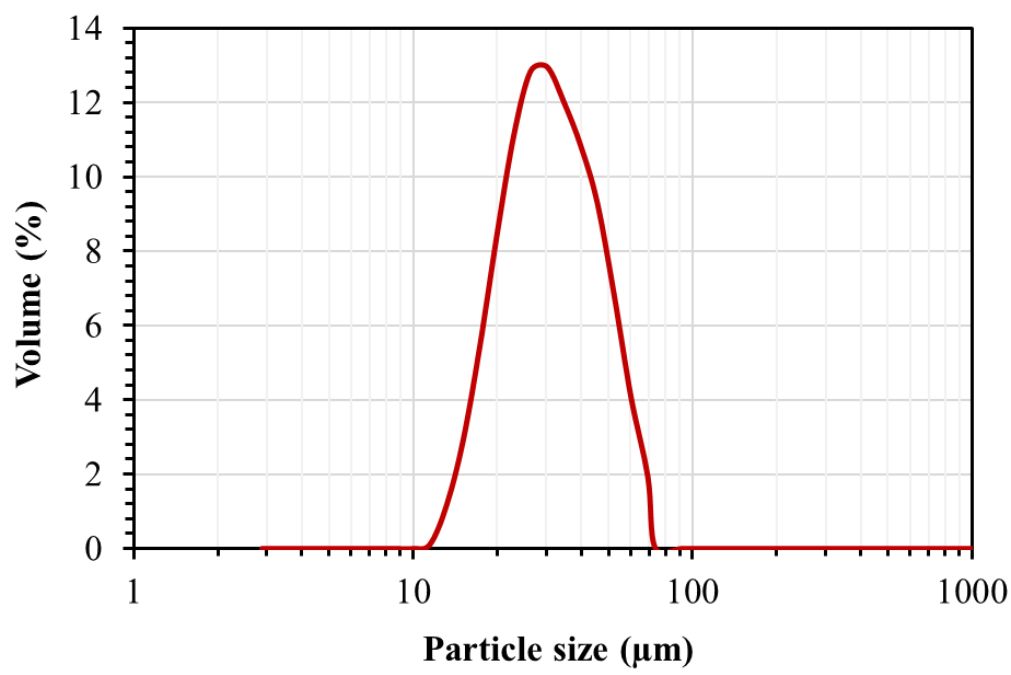

Figure A.2 Particle size distribution of N-atomized AISI 420 stainless steel with $\mathrm{Nb}$ and Mo powder of $\mathrm{D}_{50}: 28 \mu \mathrm{m}$ supplied by Sandvik Osprey Ltd. 


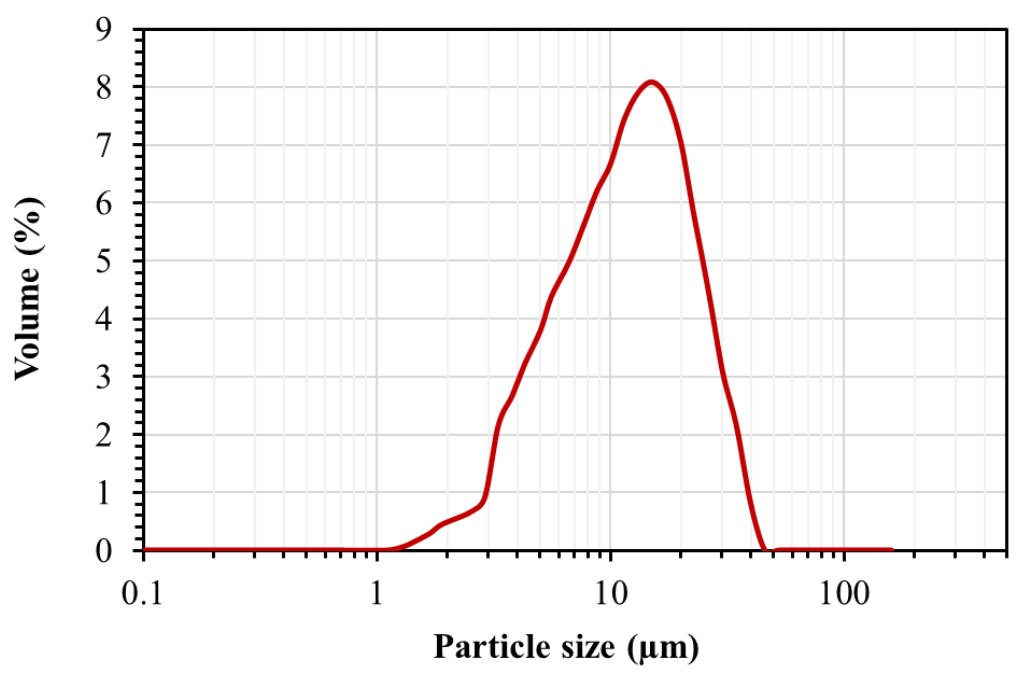

Figure A.3 Particle size distribution of N-atomized fine AISI 420 stainless steel powder of $\mathrm{D}_{50}: 12 \mu \mathrm{m}$ supplied by Sandvik Osprey Ltd.

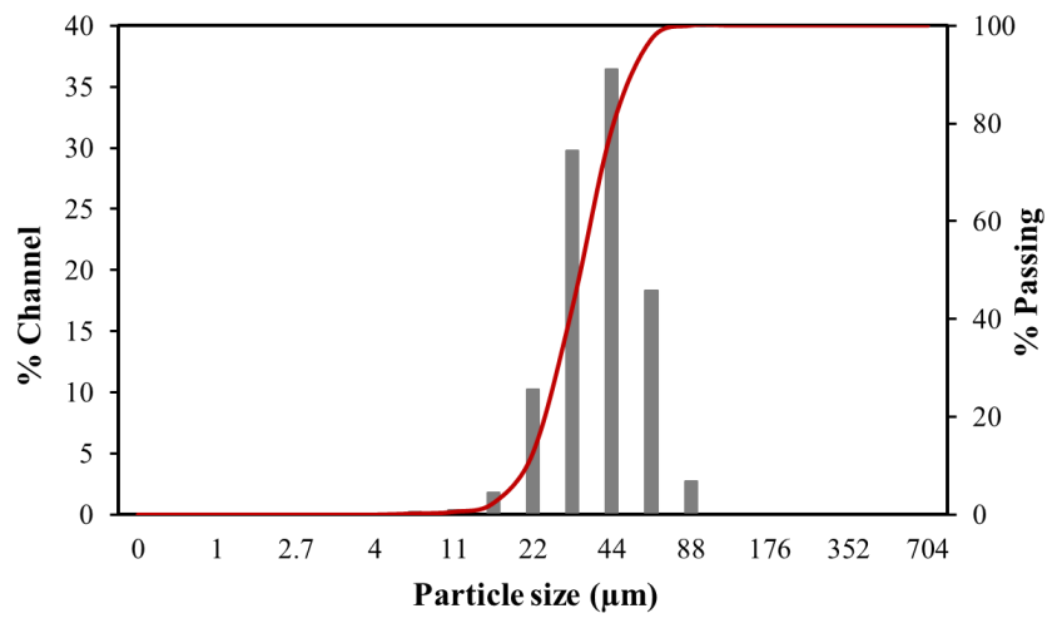

Figure A.4 Particle size distribution of coarse Ar-atomized coarse AISI 420 stainless steel powder of $D_{50}: 33 \mu \mathrm{m}$ supplied by Carpenter Powder Tech. 


\section{A.3 POWDER ATTRIBUTES}

Table A.1 Powder attributes of the as-received N-atomized AISI 420 stainless steel powder of $\mathrm{D}_{50}: 28 \mu \mathrm{m}$ supplied by Sandvik Osprey Ltd.

\begin{tabular}{|c|c|c|c|c|c|}
\hline Density & Test 1 & Test 2 & Test 3 & Test 4 & $\mu \pm \sigma$ \\
\hline Pycnometer & 7.70 & 7.68 & 7.67 & 7.68 & $7.68 \pm 0.01$ \\
\hline Apparent & 4.15 & 3.97 & 4.05 & 3.90 & $4.08 \pm 0.18$ \\
\hline Tap & 4.62 & 4.81 & 4.74 & 4.68 & $4.71 \pm 0.07$ \\
\hline
\end{tabular}

Table A. 2 Powder attributes of the as-received N-atomized AISI 420 stainless steel with $\mathrm{Nb}$ and Mo powder of $\mathrm{D}_{50}: 28 \mu \mathrm{m}$ supplied by Sandvik Osprey Ltd.

\begin{tabular}{|c|c|c|c|c|c|}
\hline Density & Test 1 & Test 2 & Test 3 & Test 4 & $\mu \pm \sigma$ \\
\hline Pycnometer & 7.72 & 7.71 & 7.71 & 7.71 & $7.71 \pm 0.01$ \\
\hline Apparent & 4.15 & 4.31 & 4.22 & 4.25 & $4.23 \pm 0.12$ \\
\hline Tap & 4.95 & 4.91 & 4.77 & 4.86 & $4.87 \pm 0.08$ \\
\hline
\end{tabular}

Table A.3 Powder attributes of the as-received N-atomized AISI 420 stainless steel powder of the as-received $\mathrm{D}_{50}: 12 \mu \mathrm{m}$ supplied by Sandvik Osprey Ltd.

\begin{tabular}{|c|c|c|c|c|c|}
\hline Density & Test 1 & Test 2 & Test 3 & Test 4 & $\mu \pm \sigma$ \\
\hline Pycnometer & 7.68 & 7.67 & 7.68 & 7.7 & $7.68 \pm 0.01$ \\
\hline Apparent & 4.01 & 3.68 & 3.58 & 3.92 & $3.79 \pm 0.26$ \\
\hline Tap & 4.55 & 4.78 & 4.64 & 4.75 & $4.68 \pm 0.09$ \\
\hline
\end{tabular}


Table A.4 Powder attributes of the as-sieved N-atomized AISI 420 stainless steel powder of the as-received $\mathrm{D}_{50}: 12 \mu \mathrm{m}$ supplied by Sandvik Osprey Ltd.

\begin{tabular}{|c|c|c|c|c|c|}
\hline Density & Test 1 & Test 2 & Test 3 & Test 4 & $\mu \pm \sigma$ \\
\hline Pycnometer & 7.68 & 7.67 & 7.69 & 7.7 & $7.68 \pm 0.01$ \\
\hline Apparent & 4.07 & 4.26 & 4.23 & 4.04 & $4.15 \pm 0.13$ \\
\hline Tap & 5.03 & 4.91 & 5.15 & 4.86 & $4.98 \pm 0.11$ \\
\hline
\end{tabular}

Table A.5 Powder attributes of the as-received Ar-atomized AISI 420 stainless steel powder of the as-received $\mathrm{D}_{50}: 33 \mu \mathrm{m}$ supplied by Carpenter Powder Tech.

\begin{tabular}{|c|c|c|c|c|c|}
\hline Density & Test 1 & Test 2 & Test 3 & Test 4 & $\mu \pm \sigma$ \\
\hline Pycnometer & 7.72 & 7.74 & 7.72 & 7.73 & $7.73 \pm 0.01$ \\
\hline Apparent & 4.32 & 4.39 & 4.17 & 4.26 & $4.28 \pm 0.1$ \\
\hline Tap & 4.84 & 4.69 & 4.71 & 4.88 & $4.78 \pm 0.11$ \\
\hline
\end{tabular}

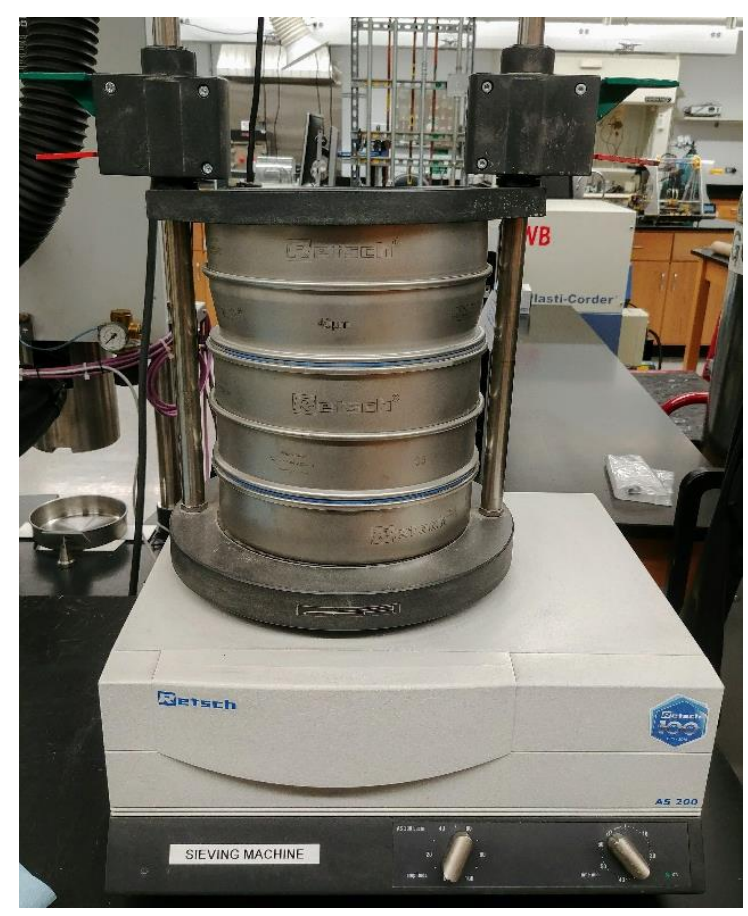

Figure A.5 Retsch AS 200 machine was used for vibratory sieving of the as-received fine 420 stainless steel powder. 


\section{APPENDIX B}

\section{PHYSICAL PROPERTIES OF 420 STAINLESS STEEL FABRICATED BY LASER- POWDER BED FUSION BY VARYING LAYER THICKNESS, CHEMICAL COMPOSITION AND PARTICLE SIZE DISTRIBUTION}

In this study, density of L-PBF specimens was measured using Archimedes principle in the room temperature. Total four measurement were taken to report a density value with the mean $(\mu)$ and standard deviation $(\sigma)$. Similarly, four measurements were taken on the top surface of a L-PBF specimen to report surface roughness $\left(\mathrm{R}_{\mathrm{a}}\right)$.

Table B.1 Physical properties of the L-PBF specimens fabricated with 420 stainless steel powder of $D_{50}: 28 \mu \mathrm{m}$ at a layer thickness of $10 \mu \mathrm{m}$ using an energy flux of $0.125 \mathrm{~J} / \mathrm{mm}^{2}$

\begin{tabular}{|c|c|c|c|c|c|}
\hline Properties & Test 1 & Test 2 & Test 3 & Test 4 & $\mu \pm \sigma$ \\
\hline Density $\left(\mathrm{g} / \mathrm{cm}^{3}\right)$ & 7.72 & 7.67 & 7.69 & 7.71 & $7.69 \pm 0.01$ \\
\hline Surface roughness, $\mathrm{R}_{\mathrm{a}}(\mu \mathrm{m})$ & 3.7 & 2.3 & 2.8 & 3.3 & $3.1 \pm 0.2$ \\
\hline
\end{tabular}

Table B.2 Physical properties of the L-PBF specimens fabricated with 420 stainless steel powder of $D_{50}: 28 \mu \mathrm{m}$ at a layer thickness of $20 \mu \mathrm{m}$ using an energy flux of $0.125 \mathrm{~J} / \mathrm{mm}^{2}$

\begin{tabular}{|c|c|c|c|c|c|}
\hline Properties & Test 1 & Test 2 & Test 3 & Test 4 & $\mu \pm \sigma$ \\
\hline Density $\left(\mathrm{g} / \mathrm{cm}^{3}\right)$ & 7.65 & 7.67 & 7.64 & 7.7 & $7.67 \pm 0.02$ \\
\hline Surface roughness, $\mathrm{R}_{\mathrm{a}}(\mu \mathrm{m})$ & 4.9 & 5.4 & 4.1 & 3.9 & $4.57 \pm 0.45$ \\
\hline
\end{tabular}


Table B.3 Physical properties of the L-PBF specimens fabricated with 420 stainless steel powder of $D_{50}: 28 \mu \mathrm{m}$ at a layer thickness of $30 \mu \mathrm{m}$ using an energy flux of $0.125 \mathrm{~J} / \mathrm{mm}^{2}$

\begin{tabular}{|c|c|c|c|c|c|}
\hline Properties & Test 1 & Test 2 & Test 3 & Test 4 & $\mu \pm \sigma$ \\
\hline Density $\left(\mathrm{g} / \mathrm{cm}^{3}\right)$ & 7.21 & 7.43 & 7.27 & 7.38 & $7.36 \pm 0.05$ \\
\hline Surface roughness, $\mathrm{R}_{\mathrm{a}}(\mu \mathrm{m})$ & 16.1 & 11.8 & 12.5 & 14.2 & $13.6 \pm 1.66$ \\
\hline
\end{tabular}

Table B.4 Physical properties of the L-PBF specimens fabricated with 420 stainless steel with $\mathrm{Nb}$ and Mo powder of $\mathrm{D}_{50}: 28 \mu \mathrm{m}$ at an energy density of $63 \mathrm{~J} / \mathrm{mm}^{3}$

\begin{tabular}{|c|c|c|c|c|c|}
\hline Properties & Test 1 & Test 2 & Test 3 & Test 4 & $\mu \pm \sigma$ \\
\hline Density $\left(\mathrm{g} / \mathrm{cm}^{3}\right)$ & 7.72 & 7.67 & 7.68 & 7.7 & $7.69 \pm 0.01$ \\
\hline Surface roughness, $\mathrm{R}_{\mathrm{a}}(\mu \mathrm{m})$ & 2.2 & 2.9 & 3.8 & 3.5 & $3.1 \pm 0.6$ \\
\hline
\end{tabular}

Table B.5 Physical properties of the L-PBF specimens fabricated with AISI 420 stainless steel powder of $\mathrm{D}_{50}: 12 \mu \mathrm{m}$ at an energy density of $63 \mathrm{~J} / \mathrm{mm}^{3}$

\begin{tabular}{|c|c|c|c|c|c|}
\hline Properties & Test 1 & Test 2 & Test 3 & Test 4 & $\mu \pm \sigma$ \\
\hline Density $\left(\mathrm{g} / \mathrm{cm}^{3}\right)$ & 7.68 & 7.61 & 7.7 & 7.62 & $7.65 \pm 0.03$ \\
\hline Surface roughness, $\mathrm{R}_{\mathrm{a}}(\mu \mathrm{m})$ & 3.2 & 2.8 & 2.9 & 3.2 & $3.05 \pm 0.14$ \\
\hline
\end{tabular}




\section{APPENDIX C}

\section{MECHANICAL PROPERTIES OF 420 STAINLESS STEEL FABRICATED USING L-PBF BY VARYING LAYER THICKNESS, CHEMICAL COMPOSITION AND PARTICLE SIZE DISTRIBUTION}

In this study, each mechanical test was conducted according to ASTM standards. Four measurements were performed to calculate tensile properties and ten measurements were done for hardness for each L-PBF 420 stainless steel system. The experimental data of UTS (ultimate tensile strength), YS (0.2\% yield strength), E (elongation) and Rockwell hardness with the mean $(\mu)$ and standard deviation $(\sigma)$ and provided below.

Table C.1 Mechanical properties of the as-printed L-PBF specimens fabricated with AISI 420 stainless powder of $D_{50}: 28 \mu \mathrm{m}$ at a layer thickness of $20 \mu \mathrm{m}$

\begin{tabular}{|c|c|c|c|c|c|}
\hline Properties & Test 1 & Test 2 & Test 3 & Test 4 & $\mu \pm \sigma$ \\
\hline UTS (MPa) & 1094 & 1025 & 1010 & 1042 & $1047 \pm 31$ \\
\hline YS (MPa) & 880 & 850 & 837 & 865 & $858 \pm 18$ \\
\hline E (\%) & 2.3 & 1.9 & 2.5 & 2.7 & $2.5 \pm 0.3$ \\
\hline
\end{tabular}

Table C.2 Mechanical properties of the heat-treated L-PBF specimens fabricated with AISI 420 stainless powder of $D_{50}: 28 \mu \mathrm{m}$ at a layer thickness of $20 \mu \mathrm{m}$

\begin{tabular}{|c|c|c|c|c|c|}
\hline Properties & Test 1 & Test 2 & Test 3 & Test 4 & $\mu \pm \sigma$ \\
\hline UTS (MPa) & 1525 & 1560 & 1515 & 1555 & $1538 \pm 29$ \\
\hline YS (MPa) & 5.9 & 5.9 & 6.2 & 6.5 & $6.2 \pm 0.25$ \\
\hline E (\%) & 1138 & 1167 & 1115 & 1130 & $1138 \pm 19$ \\
\hline
\end{tabular}


Table C.3 Mechanical properties of the as-printed L-PBF specimens fabricated with AISI 420 stainless powder of $\mathrm{D}_{50}: 28 \mu \mathrm{m}$ at a layer thickness of $10 \mu \mathrm{m}$

\begin{tabular}{|c|c|c|c|c|c|}
\hline Properties & Test 1 & Test 2 & Test 3 & Test 4 & $\mu \pm \sigma$ \\
\hline UTS $(\mathrm{MPa})$ & 1110 & 1092 & 1175 & 1146 & $1130 \pm 33$ \\
\hline YS (MPa) & 1005 & 994 & 1065 & 1020 & $1021 \pm 27$ \\
\hline E $(\%)$ & 2.7 & 3.4 & 2.9 & 2.3 & $2.8 \pm 0.3$ \\
\hline
\end{tabular}

Table C.4 Mechanical properties of the heat-treated L-PBF specimens fabricated with AISI 420 stainless powder of $\mathrm{D}_{50}: 28 \mu \mathrm{m}$ at a layer thickness of $10 \mu \mathrm{m}$

\begin{tabular}{|c|c|c|c|c|c|}
\hline Properties & Test 1 & Test 2 & Test 3 & Test 4 & $\mu \pm \sigma$ \\
\hline UTS (MPa) & 1548 & 1557 & 1510 & 1522 & $1538 \pm 19$ \\
\hline YS (MPa) & 1095 & 1104 & 1055 & 1070 & $1081 \pm 19$ \\
\hline E (\%) & 6 & 6.1 & 6.4 & 6.4 & $6.25 \pm 0.18$ \\
\hline
\end{tabular}

Table C.5 Mechanical properties of the as-printed L-PBF specimens fabricated with AISI 420 stainless powder of $\mathrm{D}_{50}: 28 \mu \mathrm{m}$ at a layer thickness of $30 \mu \mathrm{m}$

\begin{tabular}{|c|c|c|c|c|c|}
\hline Properties & Test 1 & Test 2 & Test 3 & Test 4 & $\mu \pm \sigma$ \\
\hline UTS (MPa) & 750 & 785 & 770 & 740 & $1130 \pm 33$ \\
\hline YS (MPa) & 638 & 680 & 672 & 645 & $668 \pm 18$ \\
\hline E (\%) & 1.6 & 1.7 & 1.2 & 1.3 & $1.45 \pm 0.2$ \\
\hline
\end{tabular}

Table C.6 Mechanical properties of the heat-treated L-PBF specimens fabricated with AISI 420 stainless powder of $\mathrm{D}_{50}: 28 \mu \mathrm{m}$ at a layer thickness of $30 \mu \mathrm{m}$

\begin{tabular}{|c|c|c|c|c|c|}
\hline Properties & Test 1 & Test 2 & Test 3 & Test 4 & $\mu \pm \sigma$ \\
\hline UTS (MPa) & 1015 & 1020 & 985 & 1065 & $1021 \pm 28$ \\
\hline YS (MPa) & 860 & 875 & 832 & 895 & $865 \pm 23$ \\
\hline E (\%) & 3.6 & 3.8 & 2.9 & 4 & $3.5 \pm 0.4$ \\
\hline
\end{tabular}


Table C.7 Mechanical properties of the as-printed L-PBF specimens fabricated with AISI 420 stainless powder with $\mathrm{Nb}$ and Mo of $\mathrm{D}_{50}: 28 \mu \mathrm{m}$ at a layer thickness of $20 \mu \mathrm{m}$

\begin{tabular}{|c|c|c|c|c|c|}
\hline Properties & Test 1 & Test 2 & Test 3 & Test 4 & $\mu \pm \sigma$ \\
\hline UTS $(\mathrm{MPa})$ & 1290 & 1348 & 1335 & 1315 & $1322 \pm 23$ \\
\hline YS (MPa) & 1040 & 1088 & 1065 & 1077 & $3.5 \pm 0.2$ \\
\hline E (\%) & 3.8 & 3.2 & 3.5 & 3.3 & $1067 \pm 18$ \\
\hline
\end{tabular}

Table C.8 Mechanical properties of the heat-treated L-PBF specimens fabricated with AISI 420 stainless powder with $\mathrm{Nb}$ and Mo of $\mathrm{D}_{50}: 28 \mu \mathrm{m}$ at a layer thickness of $20 \mu \mathrm{m}$

\begin{tabular}{|c|c|c|c|c|c|}
\hline Properties & Test 1 & Test 2 & Test 3 & Test 4 & $\mu \pm \sigma$ \\
\hline UTS (MPa) & 1770 & 1720 & 1730 & 1790 & $1755 \pm 32$ \\
\hline YS (MPa) & 1290 & 1250 & 1270 & 1320 & $1282 \pm 28$ \\
\hline E $(\%)$ & 9.1 & 8.6 & 8.7 & 9.5 & $9 \pm 0.3$ \\
\hline
\end{tabular}

Table C.9 Mechanical properties of the as-printed L-PBF specimens fabricated with AISI 420 stainless powder of $\mathrm{D}_{50}: 12 \mu \mathrm{m}$ at a layer thickness of $20 \mu \mathrm{m}$

\begin{tabular}{|c|c|c|c|c|c|}
\hline Properties & Test 1 & Test 2 & Test 3 & Test 4 & $\mu \pm \sigma$ \\
\hline UTS (MPa) & 1066 & 1025 & 1019 & 1045 & $1038 \pm 19$ \\
\hline YS (MPa) & 760 & 725 & 715 & 730 & $732 \pm 17$ \\
\hline E (\%) & 2.2 & 2.4 & 2.6 & 2.4 & $2.4 \pm 0.2$ \\
\hline
\end{tabular}

Table C.10 Mechanical properties of the heat-treated L-PBF specimens fabricated with AISI 420 stainless powder of $D_{50}: 12 \mu \mathrm{m}$ at a layer thickness of $20 \mu \mathrm{m}$

\begin{tabular}{|c|c|c|c|c|c|}
\hline Properties & Test 1 & Test 2 & Test 3 & Test 4 & $\mu \pm \sigma$ \\
\hline UTS (MPa) & 1545 & 1534 & 1502 & 1488 & $1517 \pm 23$ \\
\hline YS (MPa) & 980 & 968 & 940 & 949 & $959 \pm 17$ \\
\hline E $(\%)$ & 6 & 5.8 & 5.7 & 6.4 & $5.9 \pm 0.3$ \\
\hline
\end{tabular}


Table C.11 Rockwell hardness (HRC) of AISI 420 stainless steels fabricated by L-PBF

\begin{tabular}{|c|c|c|c|c|c|c|c|c|c|c|c|}
\hline Test No. & 1 & 2 & 3 & 4 & 5 & 6 & 7 & 8 & 9 & 10 & $\mu \pm \sigma$ \\
\hline $\begin{array}{l}420 \text { SS; } D_{50}: 28 \mu \mathrm{m} \text {; Layer } \\
\text { thickness: } 20 \mu \mathrm{m} \text {; As-printed }\end{array}$ & 55 & 56 & 57 & 56 & 55 & 54 & 54 & 55 & 56 & 55 & $55.3 \pm 0.8$ \\
\hline $\begin{array}{c}420 \mathrm{SS} ; \mathrm{D}_{50}: 28 \mu \mathrm{m} \text {; Layer } \\
\text { thickness: } 20 \mu \mathrm{m} \text {; Heat-treated }\end{array}$ & 53 & 52 & 52 & 54 & 53 & 53 & 53 & 54 & 53 & 53 & $52.9 \pm 0.8$ \\
\hline $\begin{array}{l}420 \mathrm{SS} ; \mathrm{D}_{50}: 28 \mu \mathrm{m} ; \text { Layer } \\
\text { thickness: } 10 \mu \mathrm{m} \text {; As-printed }\end{array}$ & 57 & 58 & 57 & 56 & 58 & 58 & 57 & 57 & 58 & 56 & $57.2 \pm 0.7$ \\
\hline $\begin{array}{c}420 \mathrm{SS} ; \mathrm{D}_{50}: 28 \mu \mathrm{m} ; \text { Layer } \\
\text { thickness: } 10 \mu \mathrm{m} ; \text { Heat-treated }\end{array}$ & 55 & 55 & 55 & 54 & 56 & 56 & 55 & 54 & 55 & 55 & $55 \pm 0.6$ \\
\hline $\begin{array}{l}420 \mathrm{SS} ; \mathrm{D}_{50}: 28 \mu \mathrm{m} ; \text { Layer } \\
\text { thickness: } 30 \mu \mathrm{m} ; \text { As-printed }\end{array}$ & 51 & 52 & 50 & 52 & 49 & 48 & 52 & 50 & 51 & 50 & $50.5 \pm 1.3$ \\
\hline $\begin{array}{c}420 \mathrm{SS} ; \mathrm{D}_{50}: 28 \mu \mathrm{m} \text {; Layer } \\
\text { thickness: } 30 \mu \mathrm{m} \text {; Heat-treated }\end{array}$ & 48 & 47 & 50 & 50 & 48 & 48 & 51 & 48 & 49 & 49 & $48.8 \pm 1.2$ \\
\hline & & & & & & & & & & & \\
\hline $\begin{array}{l}420 \mathrm{SS}+\mathrm{Nb}+\mathrm{Mo} ; \mathrm{D}_{50}: 28 \mu \mathrm{m} \\
\text { Layer thickness: } 20 \mu \mathrm{m} ; \text { As- } \\
\text { printed }\end{array}$ & 52 & 52 & 53 & 52 & 51 & 51 & 52 & 51 & 52 & 53 & $51.9 \pm 0.7$ \\
\hline $\begin{array}{l}420 \mathrm{SS}+\mathrm{Nb}+\mathrm{Mo} ; \mathrm{D}_{50}: 28 \mu \mathrm{m} \\
\text { Layer thickness: } 20 \mu \mathrm{m} ; \text { Heat- } \\
\text { treated }\end{array}$ & 51 & 52 & 51 & 52 & 51 & 50 & 51 & 51 & 50 & 52 & $51.1 \pm 0.7$ \\
\hline $\begin{array}{c}420 \mathrm{SS} ; \mathrm{D}_{50}: 12 \mu \mathrm{m} \text {; Layer } \\
\text { thickness: } 20 \mu \mathrm{m} \text {; As-printed }\end{array}$ & 57 & 56 & 54 & 55 & 56 & 55 & 56 & 57 & 56 & 56 & $55.8 \pm 0.9$ \\
\hline $\begin{array}{c}420 \mathrm{SS} ; \mathrm{D}_{50}: 12 \mu \mathrm{m} \text {; Layer } \\
\text { thickness: } 20 \mu \mathrm{m} ; \text { Heat-treated }\end{array}$ & 54 & 55 & 54 & 53 & 56 & 55 & 53 & 54 & 55 & 53 & $54.2 \pm 1.0$ \\
\hline
\end{tabular}




\section{APPENDIX D}

\section{CORROSION PROPERTIES OF 420 STAINLESS STEEL FABRICATED USING L-PBF BY VARYING LAYER THICKNESS, CHEMICAL COMPOSITION AND PARTICLE SIZE DISTRIBUTION}

In this study, each corrosion test was conducted according to standard electrochemical protocol. Thus, four linear sweep voltammetry (LSV) experiments were performed for each variation of 420 stainless steel fabricated by L-PBF to calculate corrosion current $\left(\mathrm{I}_{\text {corr }}\right)$, corrosion potential $\left(E_{\text {corr }}\right)$, polarization resistance $\left(R_{p}\right)$ and corrosion rate $(C R)$ with the mean $(\mu)$ and standard deviation $(\sigma)$ and provided below.

Table D.1 Corrosion properties of the as-printed L-PBF specimens fabricated with AISI 420 stainless powder of $\mathrm{D}_{50}: 28 \mu \mathrm{m}$ at a layer thickness of $20 \mu \mathrm{m}$

\begin{tabular}{|c|c|c|c|c|c|}
\hline Properties & Test 1 & Test 2 & Test 3 & Test 4 & $\mu \pm \sigma$ \\
\hline $\mathrm{I}_{\text {corr }}\left(\mu \mathrm{A} . \mathrm{cm}^{-2}\right)$ & 2.67 & 2.86 & 3.04 & 2.77 & $2.84 \pm 0.36$ \\
\hline $\mathrm{E}_{\text {corr }}(\mathrm{V})$ & -0.39 & -0.37 & -0.39 & -0.37 & $-0.4 \pm 0.02$ \\
\hline $\mathrm{R}_{\mathrm{p}}\left(\Omega . \mathrm{cm}^{-2}\right)$ & 18015 & 17250 & 16690 & 17090 & $17057 \pm 500$ \\
\hline $\mathrm{CR}(\mu \mathrm{m} /$ year $)$ & 25.8 & 28.3 & 29.8 & 28 & $28 \pm 2$ \\
\hline
\end{tabular}

Table D.2 Corrosion properties of the heat-treated L-PBF specimens fabricated with AISI 420 stainless powder of $\mathrm{D}_{50}: 28 \mu \mathrm{m}$ at a layer thickness of $20 \mu \mathrm{m}$

\begin{tabular}{|c|c|c|c|c|c|}
\hline Properties & Test 1 & Test 2 & Test 3 & Test 4 & $\mu \pm \sigma$ \\
\hline $\mathrm{I}_{\text {corr }}\left(\mu \mathrm{A} . \mathrm{cm}^{-2}\right)$ & 3.95 & 3.26 & 3.33 & 3.67 & $3.56 \pm 0.28$ \\
\hline $\mathrm{E}_{\text {corr }}(\mathrm{V})$ & -0.43 & -0.41 & -0.42 & -0.41 & $-0.42 \pm 0.01$ \\
\hline $\mathrm{R}_{\mathrm{p}}\left(\Omega . \mathrm{cm}^{-2}\right)$ & 16256 & 17060 & 17052 & 16560 & $16730 \pm 730$ \\
\hline $\mathrm{CR}(\mu \mathrm{m} /$ year $)$ & 39 & 32.2 & 33 & 34.8 & $34 \pm 2$ \\
\hline
\end{tabular}


Table D.3 Corrosion properties of the as-printed L-PBF specimens fabricated with AISI 420 stainless powder of $\mathrm{D}_{50}: 28 \mu \mathrm{m}$ at a layer thickness of $10 \mu \mathrm{m}$

\begin{tabular}{|c|c|c|c|c|c|}
\hline Properties & Test 1 & Test 2 & Test 3 & Test 4 & $\mu \pm \sigma$ \\
\hline $\mathrm{I}_{\text {corr }}\left(\mu \mathrm{A} . \mathrm{cm}^{-2}\right)$ & 3.2 & 3.34 & 3.06 & 3.16 & $3.19 \pm 0.2$ \\
\hline $\mathrm{E}_{\text {corr }}(\mathrm{V})$ & -0.38 & -0.36 & -0.38 & -0.37 & $-0.38 \pm 0.01$ \\
\hline $\mathrm{R}_{\mathrm{p}}\left(\Omega . \mathrm{cm}^{-2}\right)$ & 16645 & 16356 & 17005 & 16820 & $16735 \pm 220$ \\
\hline $\mathrm{CR}(\mu \mathrm{m} /$ year $)$ & 32.0 & 33.2 & 30.2 & 31.5 & $32 \pm 2$ \\
\hline
\end{tabular}

Table D.4 Corrosion properties of the heat-treated L-PBF specimens fabricated with AISI 420 stainless powder of $\mathrm{D}_{50}: 28 \mu \mathrm{m}$ at a layer thickness of $10 \mu \mathrm{m}$

\begin{tabular}{|c|c|c|c|c|c|}
\hline Properties & Test 1 & Test 2 & Test 3 & Test 4 & $\mu . \pm \sigma$ \\
\hline $\mathrm{I}_{\text {corr }}\left(\mu \mathrm{A} . \mathrm{cm}^{-2}\right)$ & 3.46 & 3.35 & 3.52 & 3.33 & $3.4 \pm 0.1$ \\
\hline $\mathrm{E}_{\text {corr }}(\mathrm{V})$ & -0.38 & -0.38 & -0.39 & -0.37 & $-0.38 \pm 0.01$ \\
\hline $\mathrm{R}_{\mathrm{p}}\left(\Omega . \mathrm{cm}^{-2}\right)$ & 16254 & 16444 & 16196 & 16465 & $16369 \pm 175$ \\
\hline $\mathrm{CR}(\mu \mathrm{m} /$ year $)$ & 34.5 & 33.6 & 35.0 & 33.2 & $34 \pm 1$ \\
\hline
\end{tabular}

Table D.5 Corrosion properties of the as-printed L-PBF specimens fabricated with AISI 420 stainless powder of $\mathrm{D}_{50}: 28 \mu \mathrm{m}$ at a layer thickness of $30 \mu \mathrm{m}$

\begin{tabular}{|c|c|c|c|c|c|}
\hline Properties & Test 1 & Test 2 & Test 3 & Test 4 & $\mu . \pm \sigma$ \\
\hline $\mathrm{I}_{\text {corr }}\left(\mu \mathrm{A} . \mathrm{cm}^{-2}\right)$ & 4.12 & 3.87 & 4.05 & 4.25 & $4.04 \pm 0.26$ \\
\hline $\mathrm{E}_{\mathrm{corr}}(\mathrm{V})$ & -0.4 & -0.42 & -0.41 & -0.43 & $-0.41 \pm 0.02$ \\
\hline $\mathrm{R}_{\mathrm{p}}\left(\Omega . \mathrm{cm}^{-2}\right)$ & 15935 & 16313 & 16146 & 15864 & $16089 \pm 275$ \\
\hline $\mathrm{CR}(\mu \mathrm{m} /$ year $)$ & 41.5 & 40.1 & 41.0 & 43.8 & $41.6 \pm 2.5$ \\
\hline
\end{tabular}

Table D.6 Corrosion properties of the heat-treated L-PBF specimens fabricated with AISI 420 stainless powder of $\mathrm{D}_{50}: 28 \mu \mathrm{m}$ at a layer thickness of $30 \mu \mathrm{m}$

\begin{tabular}{|c|c|c|c|c|c|}
\hline Properties & Test 1 & Test 2 & Test 3 & Test 4 & $\mu . \pm \sigma$ \\
\hline $\mathrm{I}_{\text {corr }}\left(\mu \mathrm{A} . \mathrm{cm}^{-2}\right)$ & 4.25 & 4.68 & 4.74 & 4.37 & $4.5 \pm 0.25$ \\
\hline $\mathrm{E}_{\text {corr }}(\mathrm{V})$ & -0.4 & -0.39 & -0.42 & -0.38 & $-0.40 \pm 0.02$ \\
\hline $\mathrm{R}_{\mathrm{p}}\left(\Omega . \mathrm{cm}^{-2}\right)$ & 16290 & 16050 & 15940 & 16275 & $16167 \pm 275$ \\
\hline $\mathrm{CR}(\mu \mathrm{m} /$ year $)$ & 39.6 & 44.5 & 44.8 & 40.1 & $42.2 \pm 2.24$ \\
\hline
\end{tabular}


Table D.7 Corrosion properties of the as-printed L-PBF specimens fabricated with AISI 420 stainless powder with $\mathrm{Nb}$ and Mo of $\mathrm{D}_{50}: 28 \mu \mathrm{m}$ at a layer thickness of $20 \mu \mathrm{m}$

\begin{tabular}{|c|c|c|c|c|c|}
\hline Properties & Test 1 & Test 2 & Test 3 & Test 4 & $\mu . \pm \sigma$ \\
\hline $\mathrm{I}_{\text {corr }}\left(\mu \mathrm{A} . \mathrm{cm}^{-2}\right)$ & 1.23 & 1.68 & 1.56 & 1.4 & $1.46 \pm 0.17$ \\
\hline $\mathrm{E}_{\text {corr }}(\mathrm{V})$ & -0.4 & -0.43 & -0.45 & -0.42 & $-0.43 \pm 0.03$ \\
\hline $\mathrm{R}_{\mathrm{p}}\left(\Omega . \mathrm{cm}^{-2}\right)$ & 26418 & 22795 & 23460 & 25014 & $24193 \pm 572$ \\
\hline $\mathrm{CR}(\mu \mathrm{m} /$ year $)$ & 12.9 & 17.8 & 16.4 & 14.6 & $15.7 \pm 1.8$ \\
\hline
\end{tabular}

Table D.8 Corrosion properties of the heat-treated L-PBF specimens fabricated with AISI 420 stainless powder with $\mathrm{Nb}$ and Mo of $\mathrm{D}_{50}: 28 \mu \mathrm{m}$ at a layer thickness of $20 \mu \mathrm{m}$

\begin{tabular}{|c|c|c|c|c|c|}
\hline Properties & Test 1 & Test 2 & Test 3 & Test 4 & $\mu . \pm \sigma$ \\
\hline $\mathrm{I}_{\text {corr }}\left(\mu \mathrm{A} . \mathrm{cm}^{-2}\right)$ & 1.72 & 1.52 & 1.57 & 1.75 & $1.64 \pm 0.09$ \\
\hline $\mathrm{E}_{\text {corr }}(\mathrm{V})$ & -0.35 & -0.32 & -0.3 & -0.32 & $-0.32 \pm 0.02$ \\
\hline $\mathrm{R}_{\mathrm{p}}\left(\Omega . \mathrm{cm}^{-2}\right)$ & 23042 & 23996 & 24020 & 22745 & $23745 \pm 467$ \\
\hline $\mathrm{CR}(\mu \mathrm{m} /$ year $)$ & 18.5 & 16.8 & 17.1 & 18.8 & $18.4 \pm 0.8$ \\
\hline
\end{tabular}

Table D.9 Corrosion properties of the as-printed L-PBF specimens fabricated with AISI 420 stainless powder with $\mathrm{Nb}$ and Mo of $\mathrm{D}_{50}: 12 \mu \mathrm{m}$ at a layer thickness of $20 \mu \mathrm{m}$

\begin{tabular}{|c|c|c|c|c|c|}
\hline Properties & Test 1 & Test 2 & Test 3 & Test 4 & $\mu \pm \sigma$ \\
\hline $\mathrm{I}_{\text {corr }}\left(\mu \mathrm{A} . \mathrm{cm}^{-2}\right)$ & 2.75 & 2.9 & 2.87 & 2.7 & $2.8 \pm 0.08$ \\
\hline $\mathrm{E}_{\text {corr }}(\mathrm{V})$ & -0.38 & -0.39 & -0.38 & -0.38 & $-0.38 \pm 0.01$ \\
\hline $\mathrm{R}_{\mathrm{p}}\left(\Omega . \mathrm{cm}^{-2}\right)$ & 17685 & 17102 & 17154 & 17733 & $17418 \pm 292$ \\
\hline $\mathrm{CR}(\mu \mathrm{m} /$ year $)$ & 24.8 & 27.8 & 27.6 & 24.8 & $26.2 \pm 1.45$ \\
\hline
\end{tabular}

Table D.10 Corrosion properties of the heat-treated L-PBF specimens fabricated with AISI 420 stainless powder with $\mathrm{Nb}$ and Mo of $\mathrm{D}_{50}: 12 \mu \mathrm{m}$ at a layer thickness of $20 \mu \mathrm{m}$

\begin{tabular}{|c|c|c|c|c|c|}
\hline Properties & Test 1 & Test 2 & Test 3 & Test 4 & $\mu \pm \sigma$ \\
\hline $\mathrm{I}_{\text {corr }}\left(\mu \mathrm{A} . \mathrm{cm}^{-2}\right)$ & 3.18 & 3.29 & 3.4 & 3.34 & $3.3 \pm 0.08$ \\
\hline $\mathrm{E}_{\mathrm{corr}}(\mathrm{V})$ & -0.36 & -0.34 & -0.35 & -0.34 & $-0.35 \pm 0.01$ \\
\hline $\mathrm{R}_{\mathrm{p}}\left(\Omega . \mathrm{cm}^{-2}\right)$ & 17587 & 16970 & 16717 & 17008 & $17070 \pm 318$ \\
\hline $\mathrm{CR}(\mu \mathrm{m} /$ year $)$ & 30.8 & 31.9 & 33.2 & 32.7 & $32.1 \pm 0.9$ \\
\hline
\end{tabular}


APPENDIX E

\section{MICROSTRUCTURE OF 420 STAINLESS STEEL FABRICATED BY LASER- POWDER BED FUSION VARYING LAYER THICKNESS, CHEMICAL COMPOSITION AND PARTICLE SIZE DISTRIBUTION}

\section{E.1 XRD}

Several XRD and optical and scanning electron microscopic images were collected for each 420 stainless steel fabricated by L-PBF. Three or more XRD images were collected and retained austenite (\%RA) was calculated using Rietvield Analysis. OM and SEM images were obtained at multiple locations at various magnifications. These additional data are provided below-

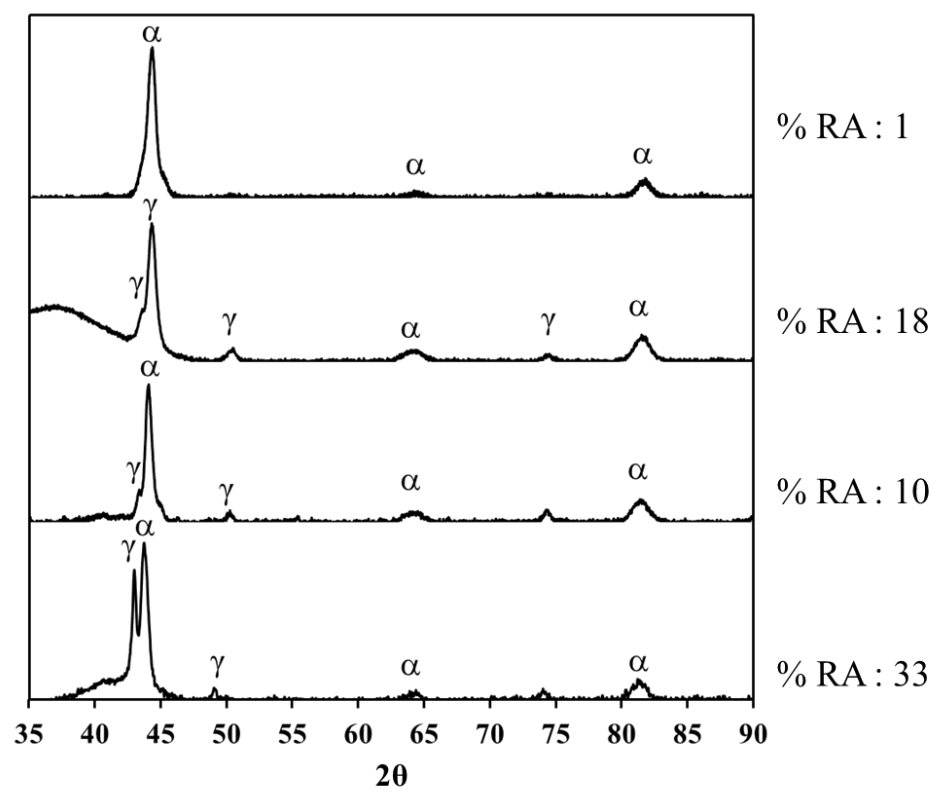

Figure E.1 XRDs collected on the as-printed 420 stainless steel fabricated by L-PBF at a layer thickness of $20 \mu \mathrm{m}$ using $\mathrm{D}_{50}: 28 \mu \mathrm{m}$ powder. 


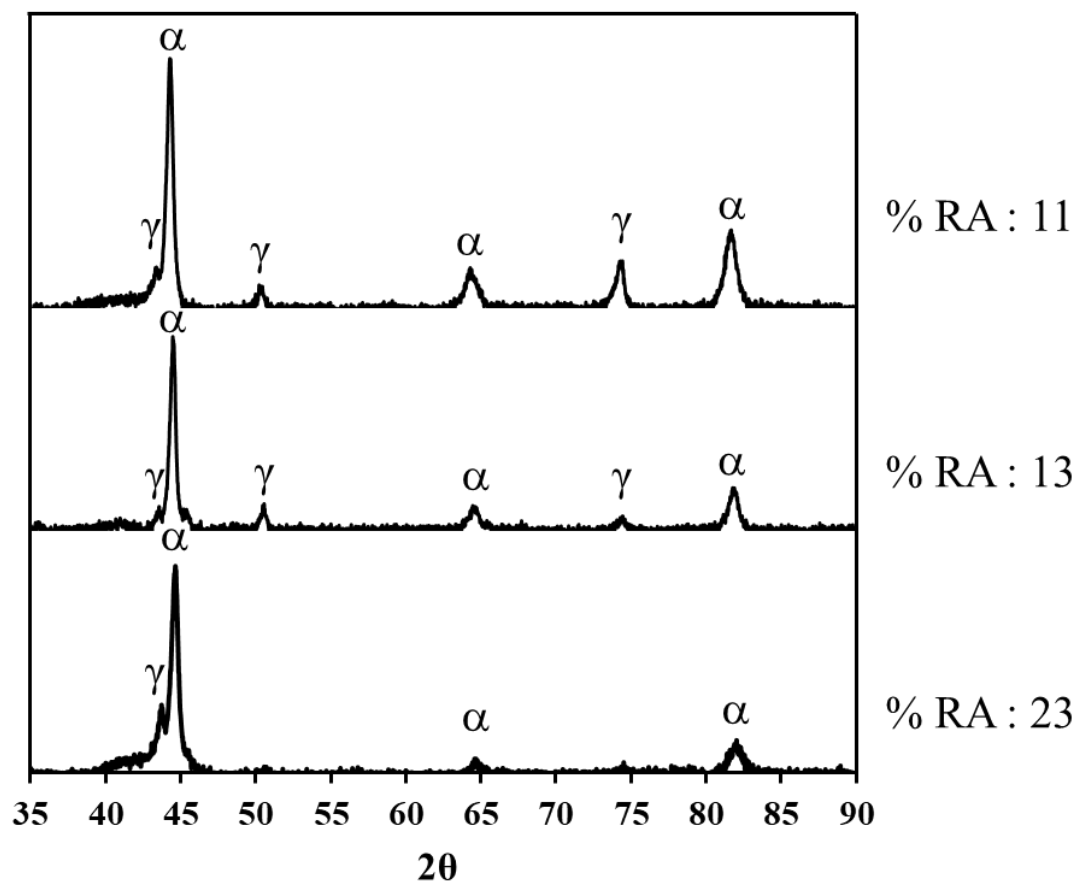

Figure E.2 XRDs collected on the heat-treated 420 stainless steel fabricated by L$\mathrm{PBF}$ at a layer thickness of $20 \mu \mathrm{m}$ using $\mathrm{D}_{50}: 28 \mu \mathrm{m}$ powder.

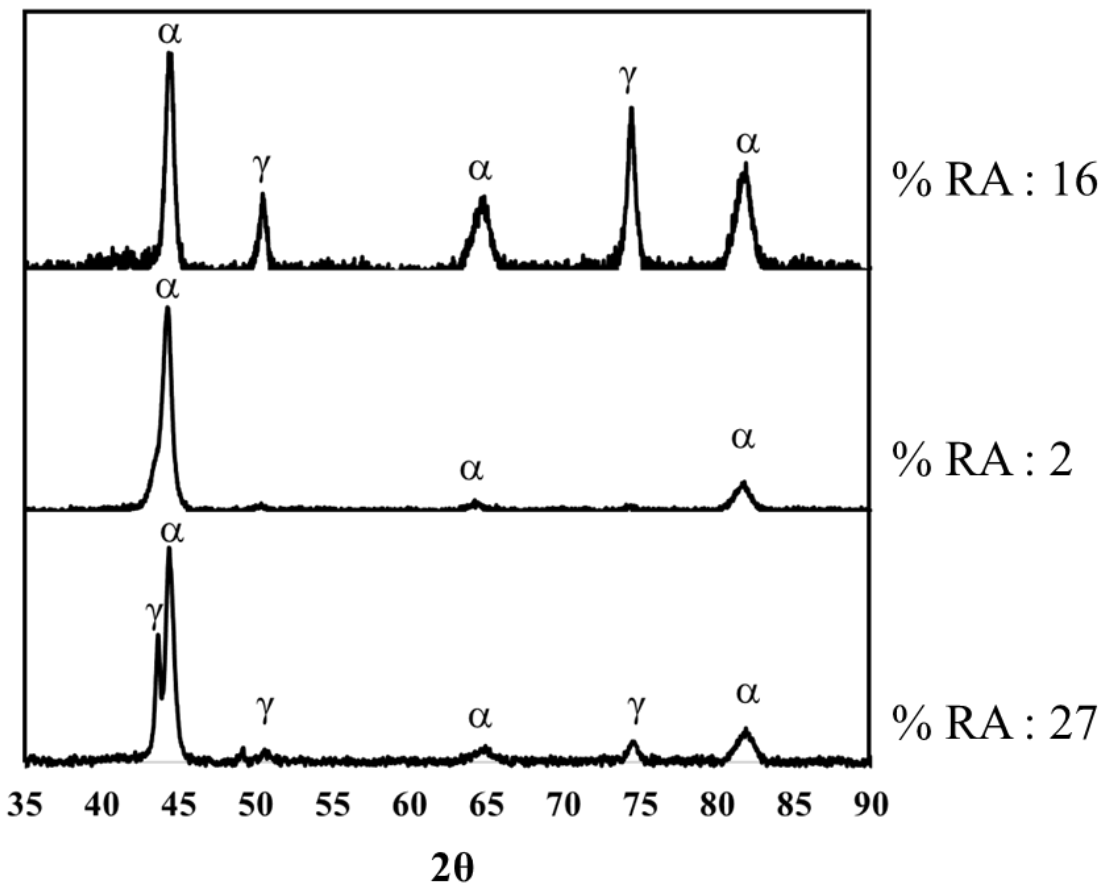

Figure E.3 XRDs collected on the as-printed 420 stainless steel fabricated by L$\mathrm{PBF}$ at a layer thickness of $10 \mu \mathrm{m}$ using $\mathrm{D}_{50}: 28 \mu \mathrm{m}$ powder. 


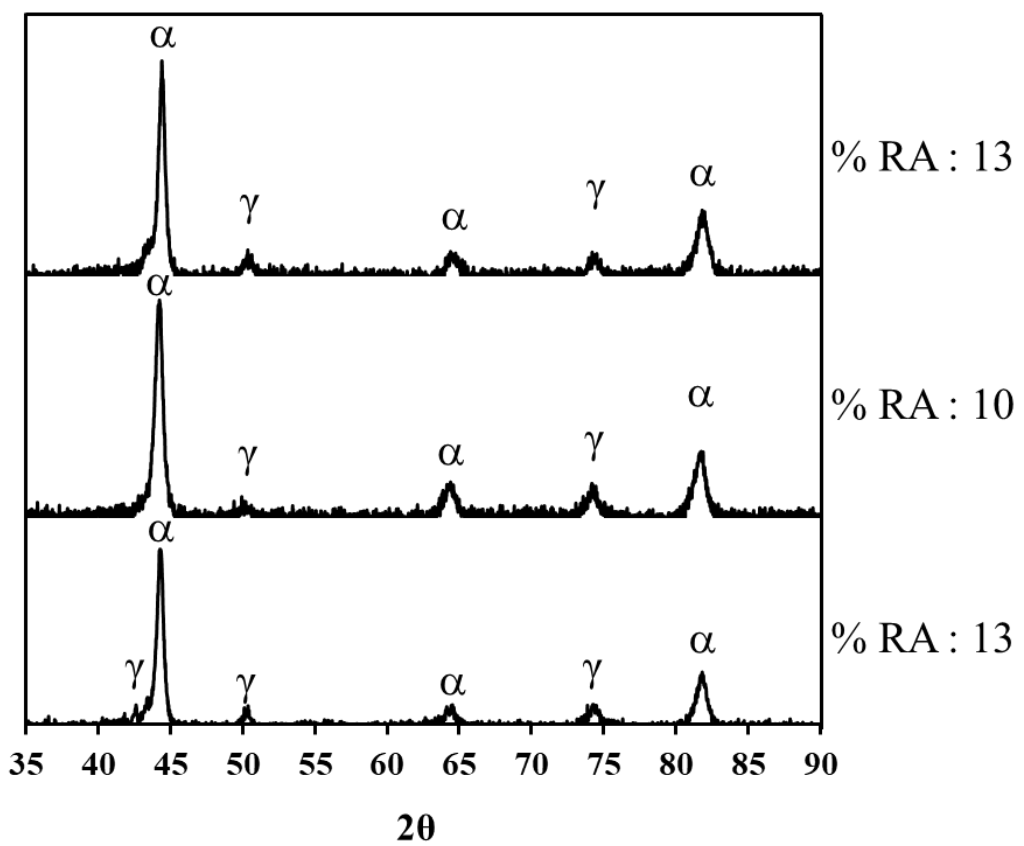

Figure E. 4 XRDs collected on the heat-treated 420 stainless steel fabricated by LPBF at a layer thickness of $10 \mu \mathrm{m}$ using D50:28 $\mu \mathrm{m}$ powder.

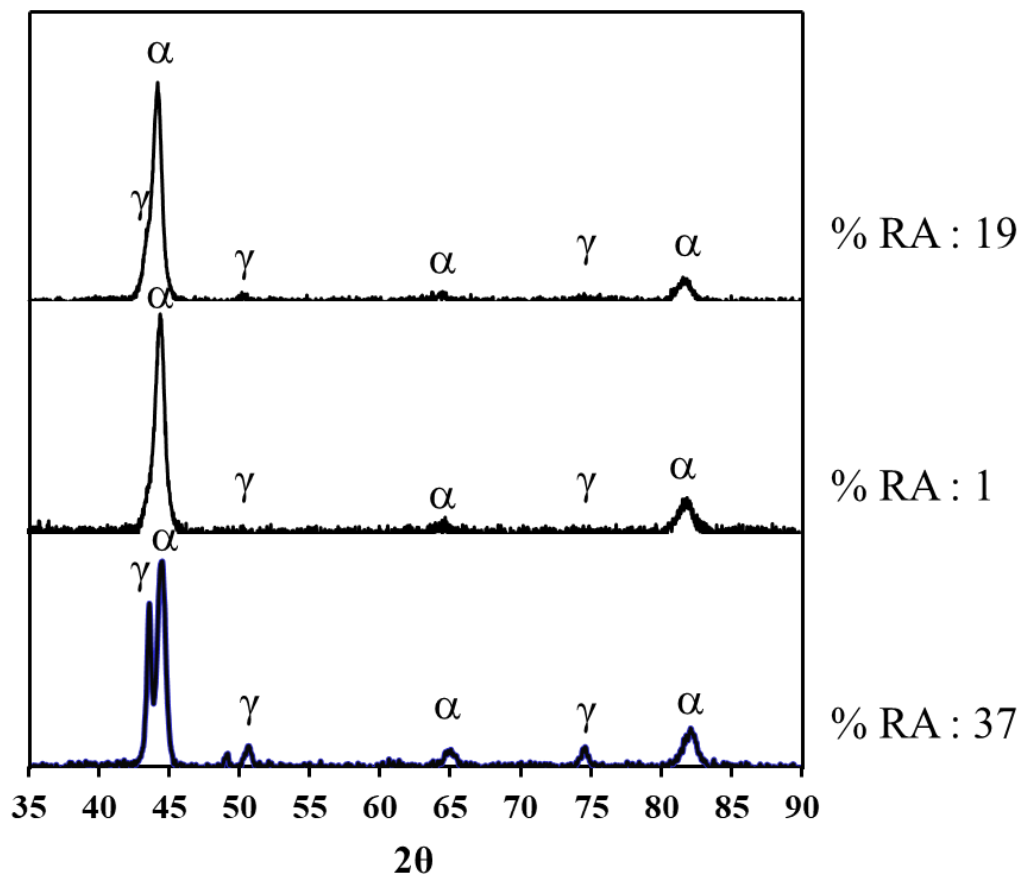

Figure E.5 XRDs collected on the as-printed 420 stainless steel fabricated by L-PBF at a layer thickness of $30 \mu \mathrm{m}$ using $\mathrm{D}_{50}: 28 \mu \mathrm{m}$ powder. 


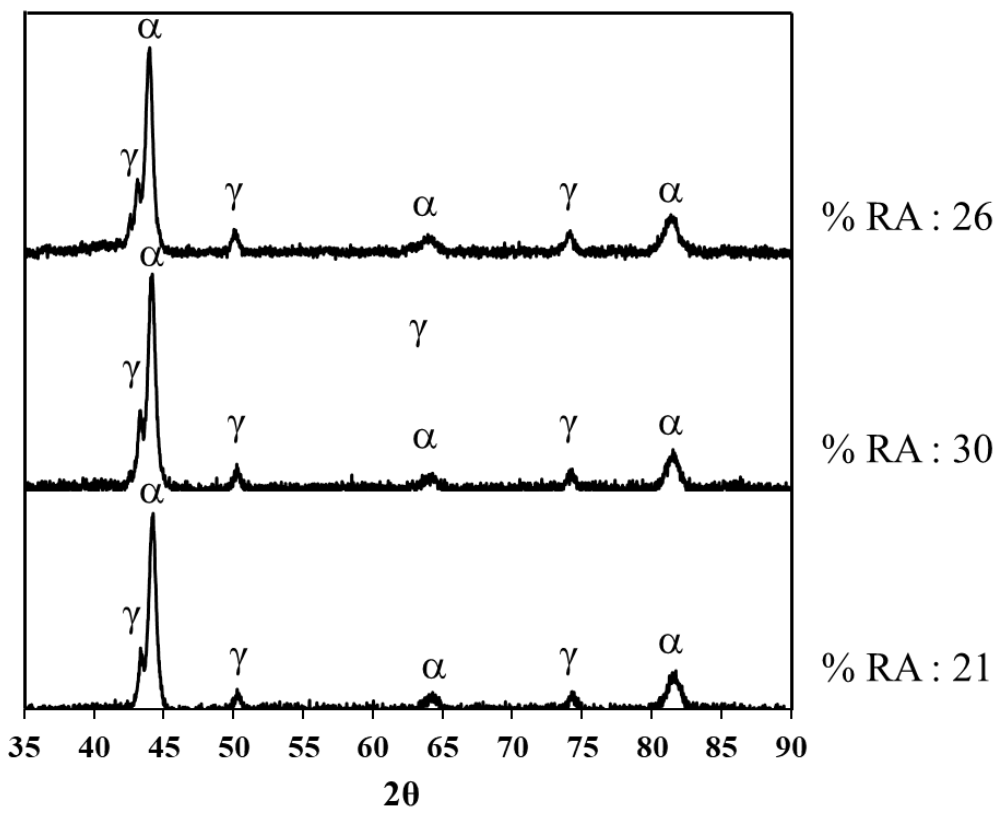

Figure E.6 XRDs collected on the heat-treated 420 stainless steel fabricated by L$\mathrm{PBF}$ at a layer thickness of $30 \mu \mathrm{m}$ using $\mathrm{D}_{50}: 28 \mu \mathrm{m}$ powder.

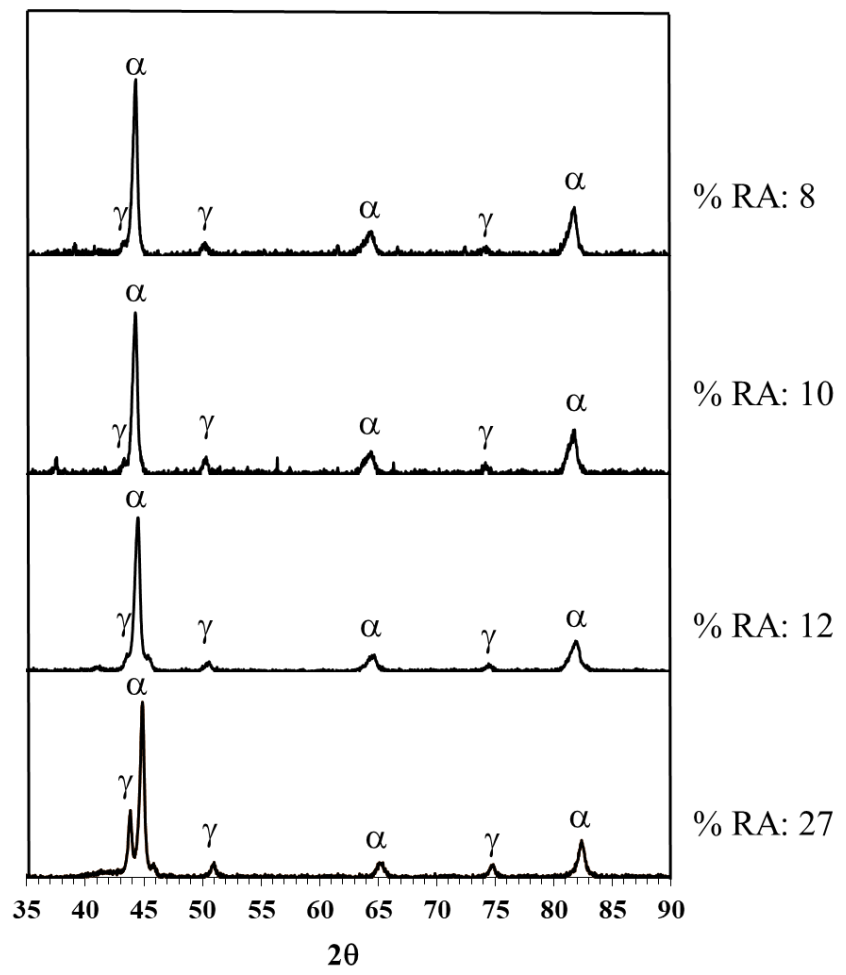

Figure E.7 XRDs collected on the as-printed 420 stainless steel with $\mathrm{Nb}$ and Mo fabricated by L-PBF at a layer thickness of $20 \mu \mathrm{m}$ using $\mathrm{D}_{50}: 28 \mu \mathrm{m}$ powder. 


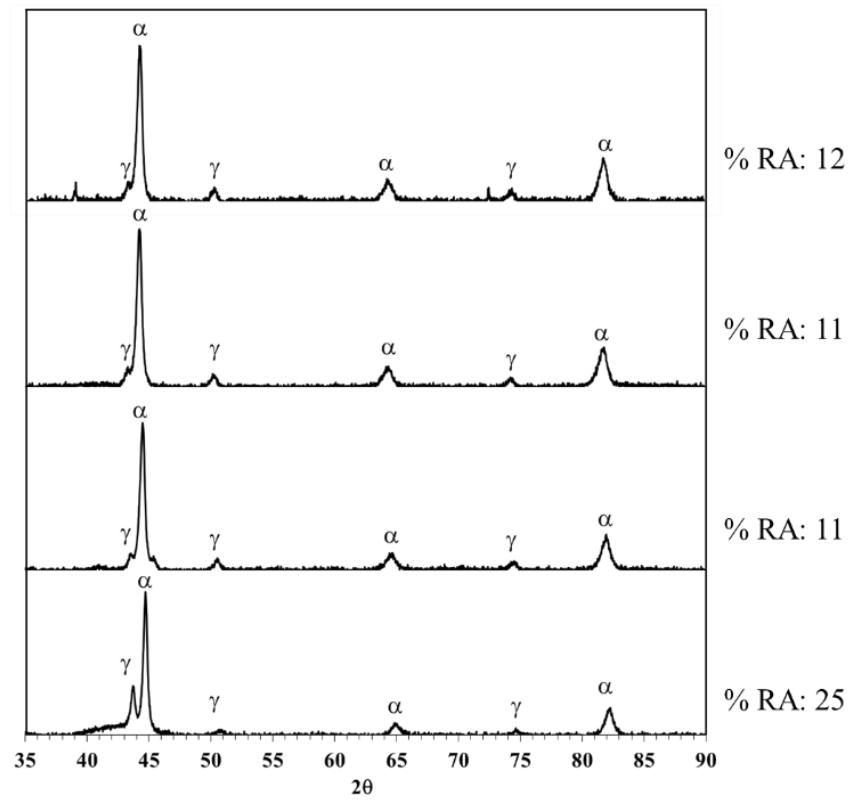

Figure E. 8 XRDs collected on the heat-treated 420 stainless steel with $\mathrm{Nb}$ and Mo fabricated by L-PBF at a layer thickness of $20 \mu \mathrm{m}$ using $\mathrm{D}_{50}: 28 \mu \mathrm{m}$ powder. 
Layer thickness: $10 \mu \mathrm{m} \quad$ Layer thickness: $20 \mu \mathrm{m}$

Layer thickness: $\mathbf{3 0} \mu \mathrm{m}$
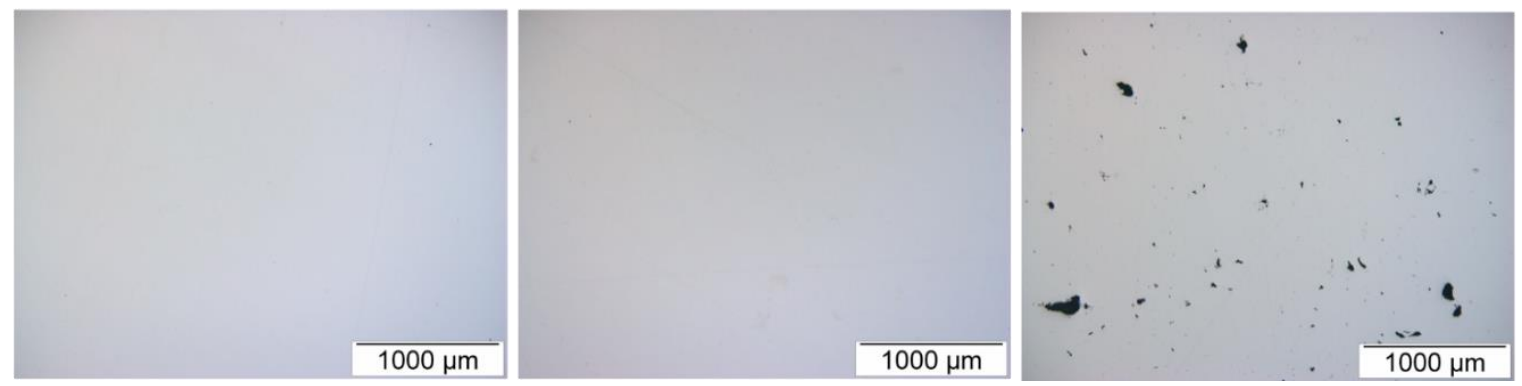

Figure E.9 Optical images of the as-polished surface (inland) of 420 stainless steel fabricated by L-PBF using powder of $\mathrm{D}_{50}: 28 \mu \mathrm{m}$ varying layer thickness at an energy flux of $1.25 \mathrm{~J} / \mathrm{mm}^{2}$.

Wrought

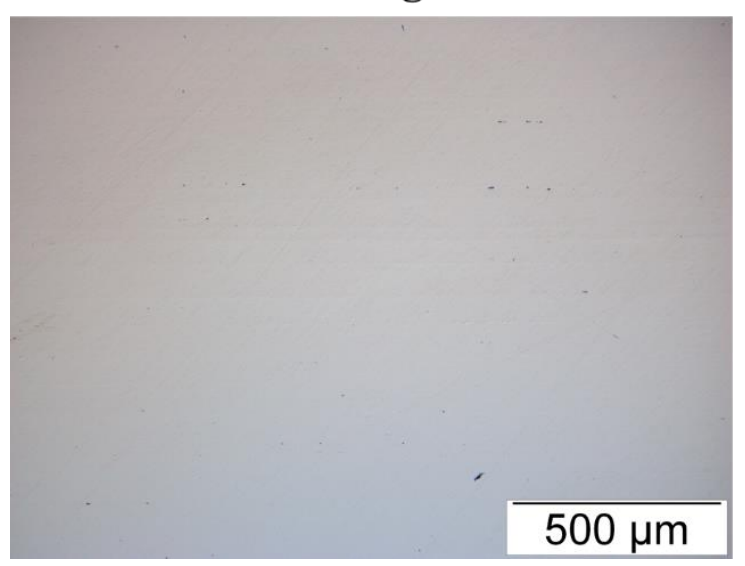

MIM

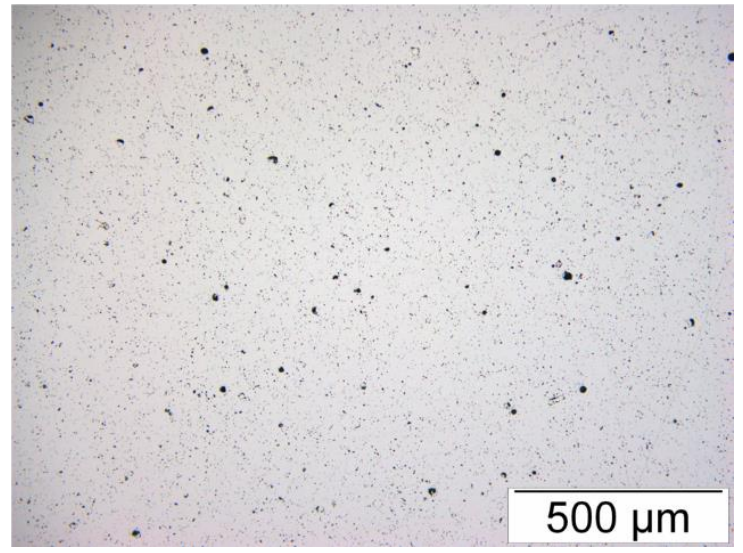

Figure 2.10 Optical images of cross-sections of the as-hardened wrought and assintered-heat-treated MIM 420 stainless steel. The samples were obtained from McMaster-Carr and NetShape Technologies restively. 

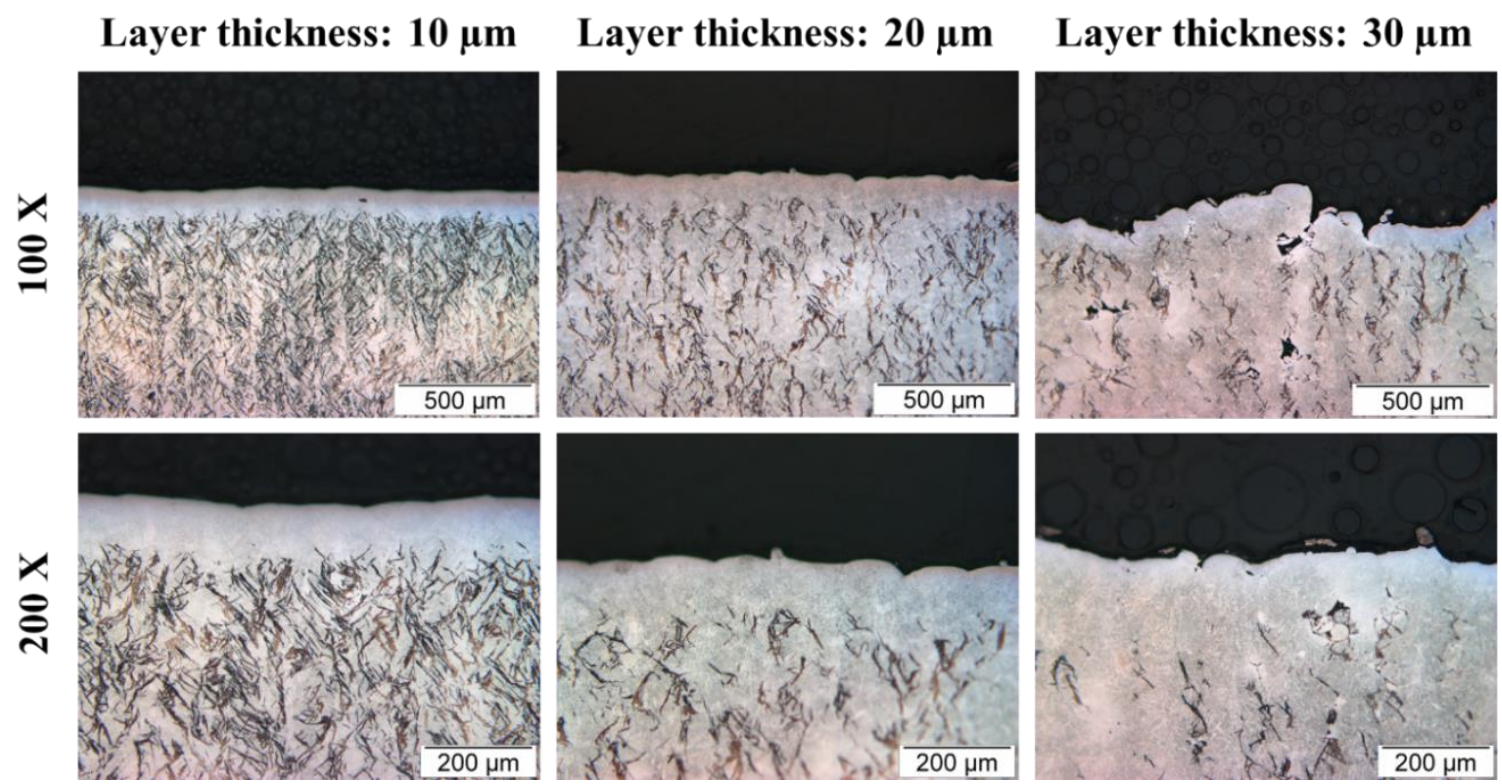

Figure E.11 Optical images of the as-etched surfaces of the as-printed 420 stainless steel fabricated by L-PBF using powder of $\mathrm{D}_{50}: 28 \mu \mathrm{m}$ varying layer thickness at an energy flux of $1.25 \mathrm{~J} / \mathrm{mm}^{2}$. The cross-sections were taken parallel to the build direction. The images were collected from the top region (in the Z-direction) of L-PBF specimens. The samples were etched with Kalling II reagent.

Layer thickness: $10 \mu \mathrm{m}$
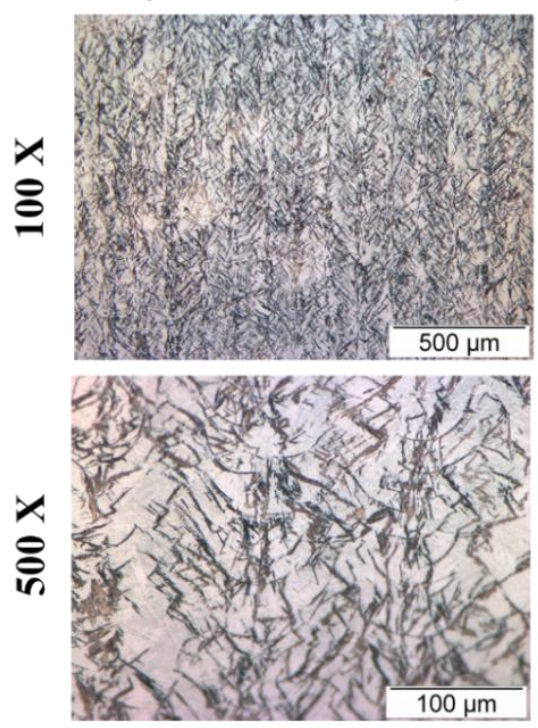

Layer thickness: $20 \mu \mathrm{m}$
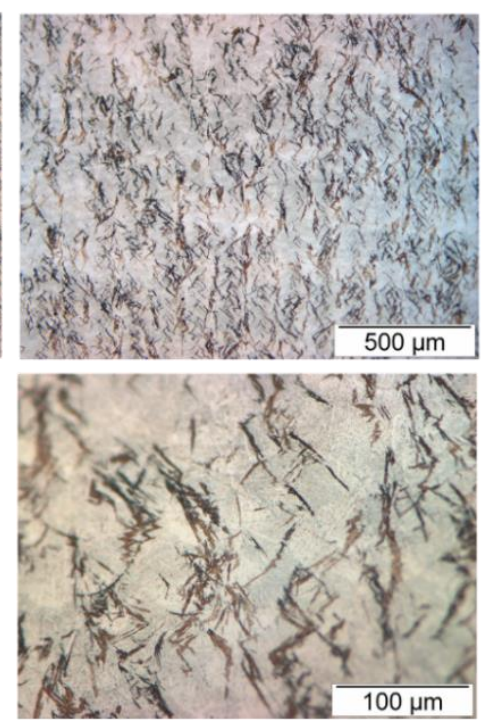

Layer thickness: $\mathbf{3 0} \boldsymbol{\mu m}$
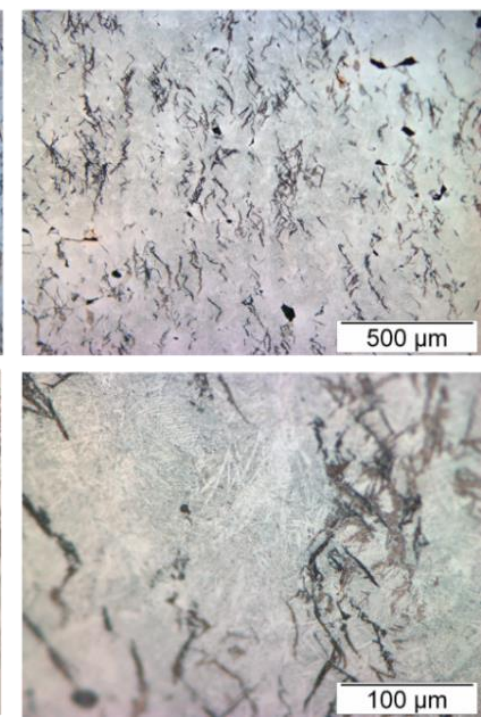

Figure E.12. Optical images of the as-etched surfaces of the as-printed 420 stainless steel fabricated by L-PBF using powder of $\mathrm{D}_{50}: 28 \mu \mathrm{m}$ varying layer thickness at an energy flux of $1.25 \mathrm{~J} / \mathrm{mm}^{2}$. The cross-sections were taken parallel to the build direction.

The images were collected from the inland region of L-PBF specimens. The samples were etched with Kalling II reagent. 

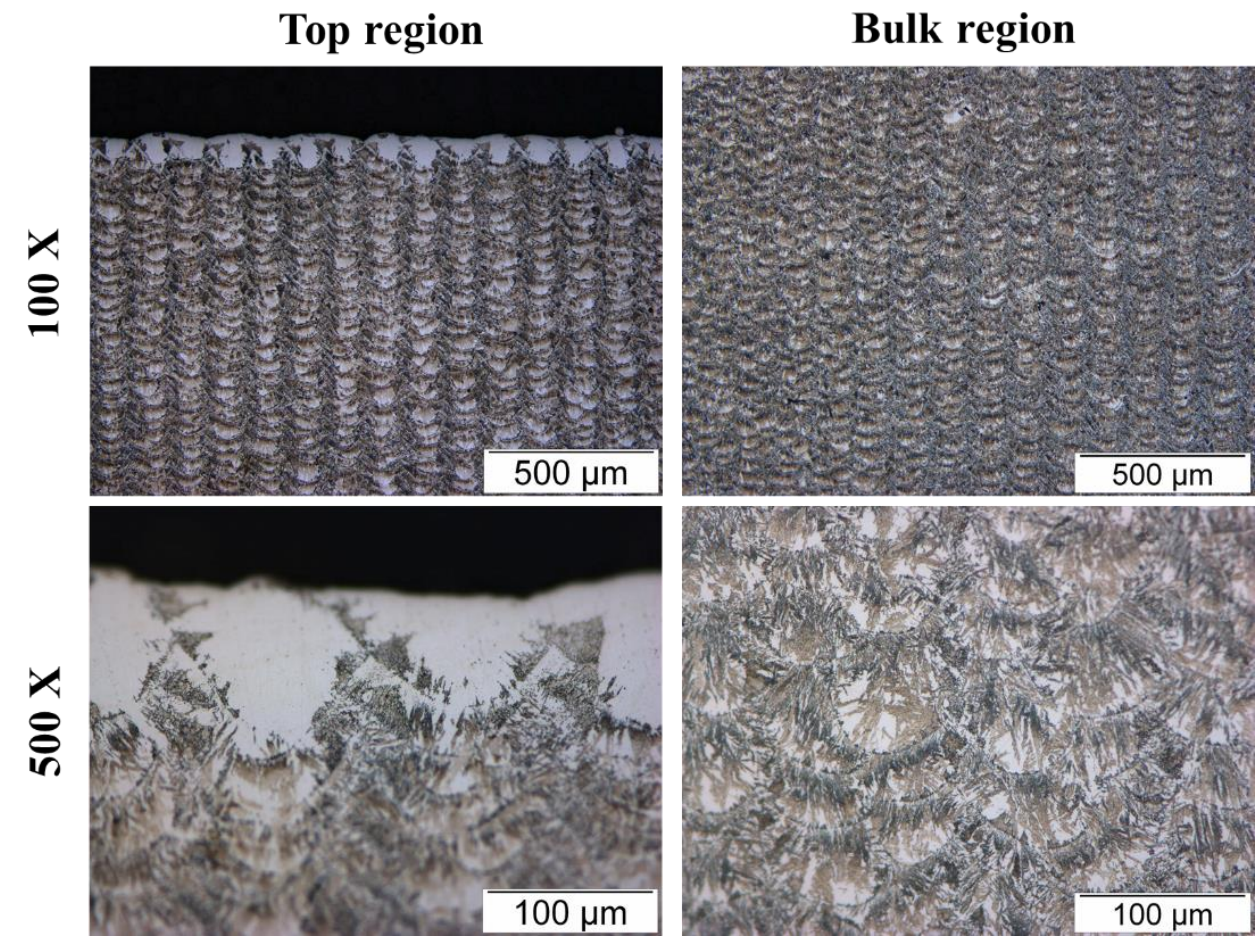

Figure E.13 Optical images of the as-etched surfaces of the as-printed 420 stainless steel with $\mathrm{Nb}$ and Mo fabricated by L-PBF using powder of $\mathrm{D}_{50}: 28$ $\mu \mathrm{m}$ at an energy density of $63 \mathrm{~J} / \mathrm{mm}^{3}$. The cross-sections were taken parallel to the build direction. The samples were etched with Kalling II reagent.

$100 \mathrm{X}$

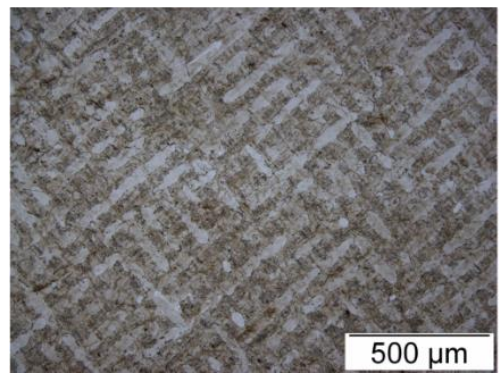

$500 \times$

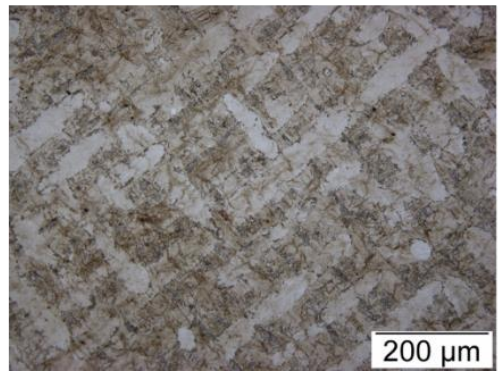

$1000 \mathrm{X}$

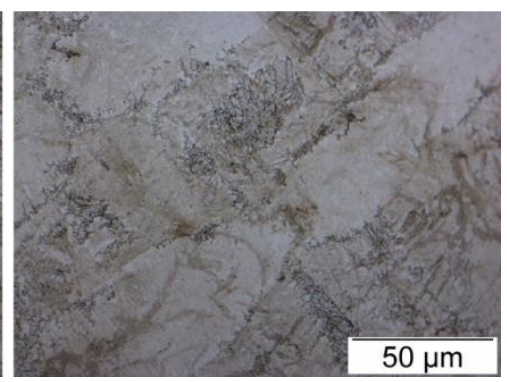

Figure E.14 Optical images of the as-etched surfaces of the as-printed 420 stainless steel with $\mathrm{Nb}$ and Mo fabricated by L-PBF using powder of $\mathrm{D}_{50}: 28 \mu \mathrm{m}$ at an energy density of $63 \mathrm{~J} / \mathrm{mm}^{3}$. The cross-sections were taken parallel to the scan direction. The images were collected from the top region (in the Z-direction) of L-PBF specimens. The samples were etched with Kalling II reagent. 


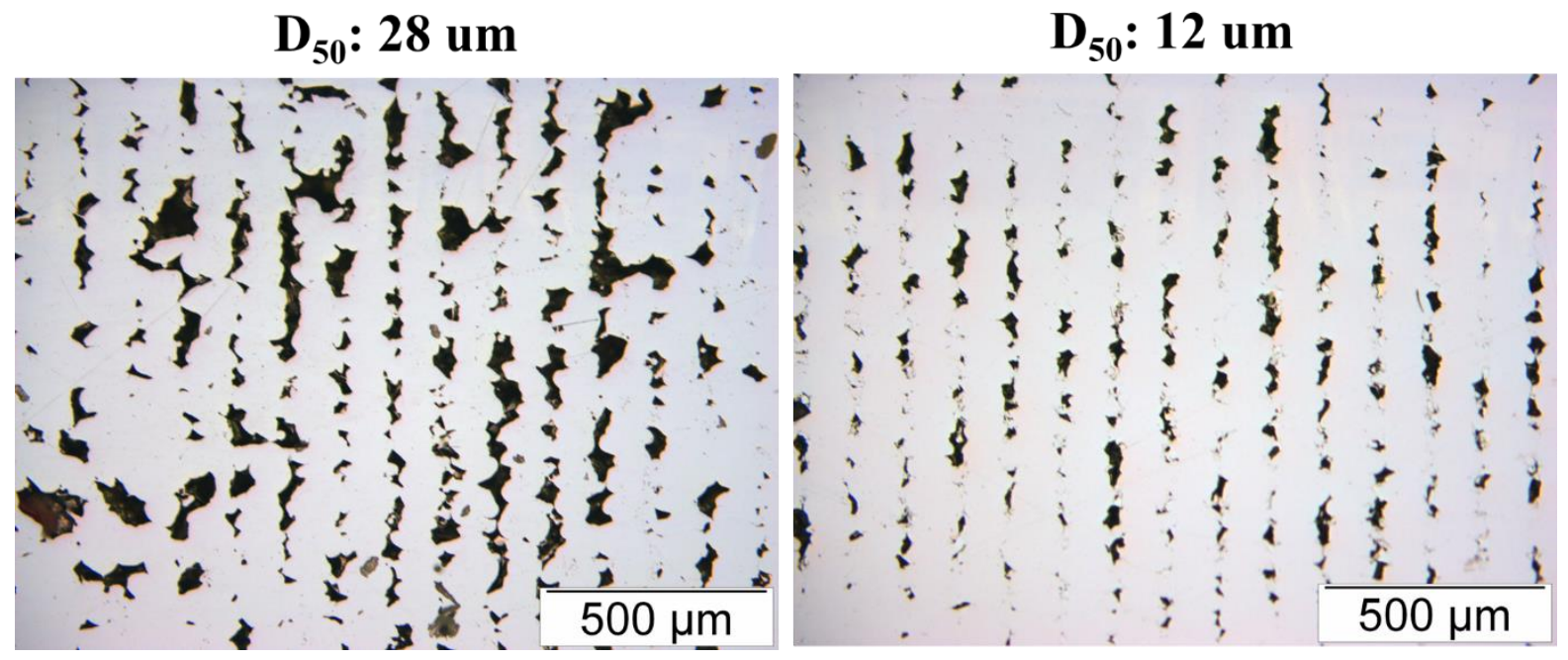

Figure E.16 Optical images of the as-polished surface (bulk region) of 420 stainless steel fabricated by L-PBF using coarse ( $\left.\mathrm{D}_{50}: 28 \mu \mathrm{m}\right)$ and fine ( $\left.\mathrm{D}_{50}: 12 \mu \mathrm{m}\right)$ powders at an energy density of $29 \mathrm{~J} / \mathrm{mm}^{3}$.

Layer thickness: $10 \mu \mathrm{m} \quad$ Layer thickness: $20 \mu \mathrm{m} \quad$ Layer thickness: $30 \mu \mathrm{m}$

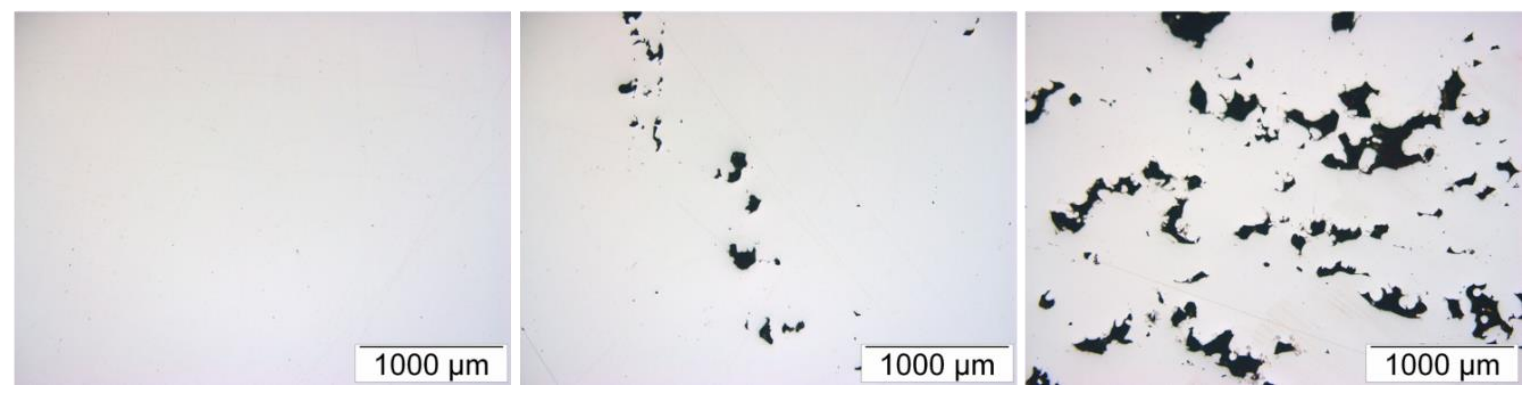

Figure E.15 Optical images of the as-polished surface (bulk region) of 420 stainless steel fabricated by L-PBF using powder of $\mathrm{D}_{50}: 28 \mu \mathrm{m}$ varying layer thickness at an energy flux of $0.8 \mathrm{~J} / \mathrm{mm}^{2}$. 

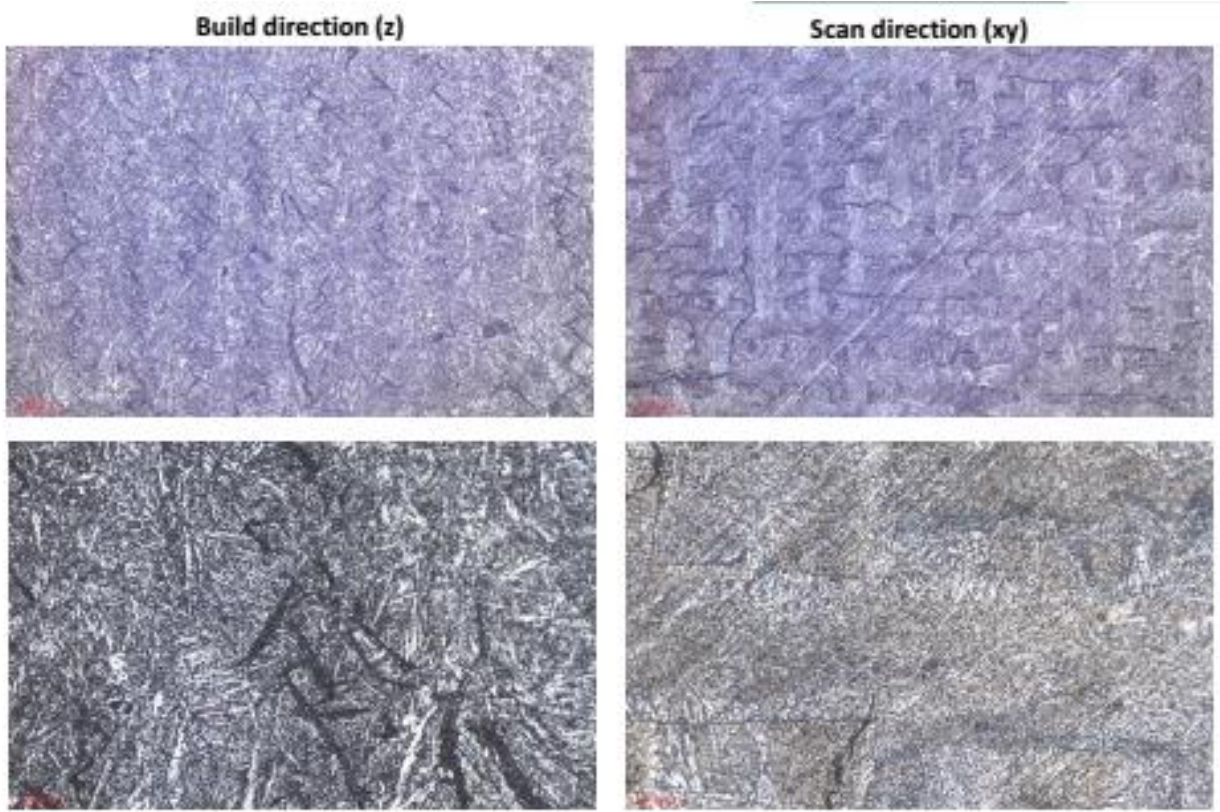

Figure E.17 As-etched microstructure of the as-printed 420 stainless steel in the build and scan directions fabricated by L-PBF. The finely polished surfaces were etched with Fry's reagent.
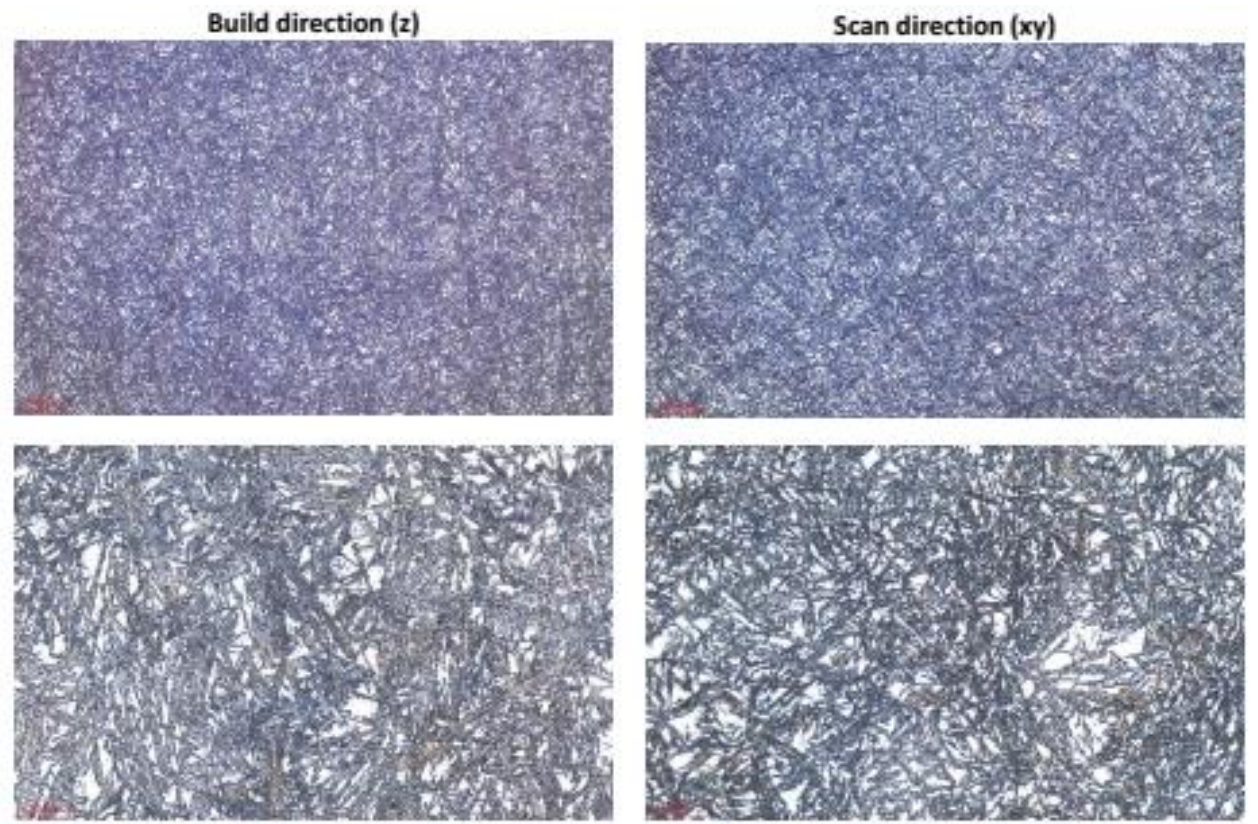

Figure E.18 As-etched microstructure of the heat-treated 420 stainless steel in the build and scan directions fabricated by L-PBF. The finely polished surfaces were etched with Fry's reagent. 

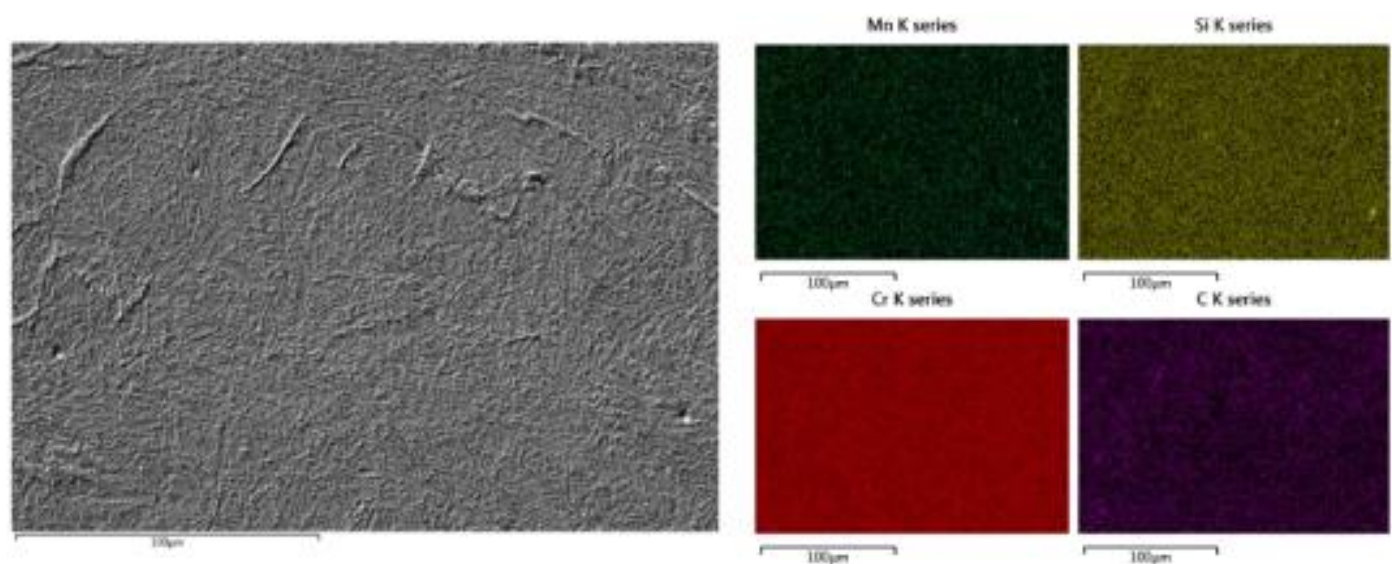

Figure E.19 EDS analysis on the etched surface of the as-printed 420 stainless steel to show the distribution of $\mathrm{Cr}, \mathrm{C}, \mathrm{Mn}$ and $\mathrm{Si}$ in the microstructure.
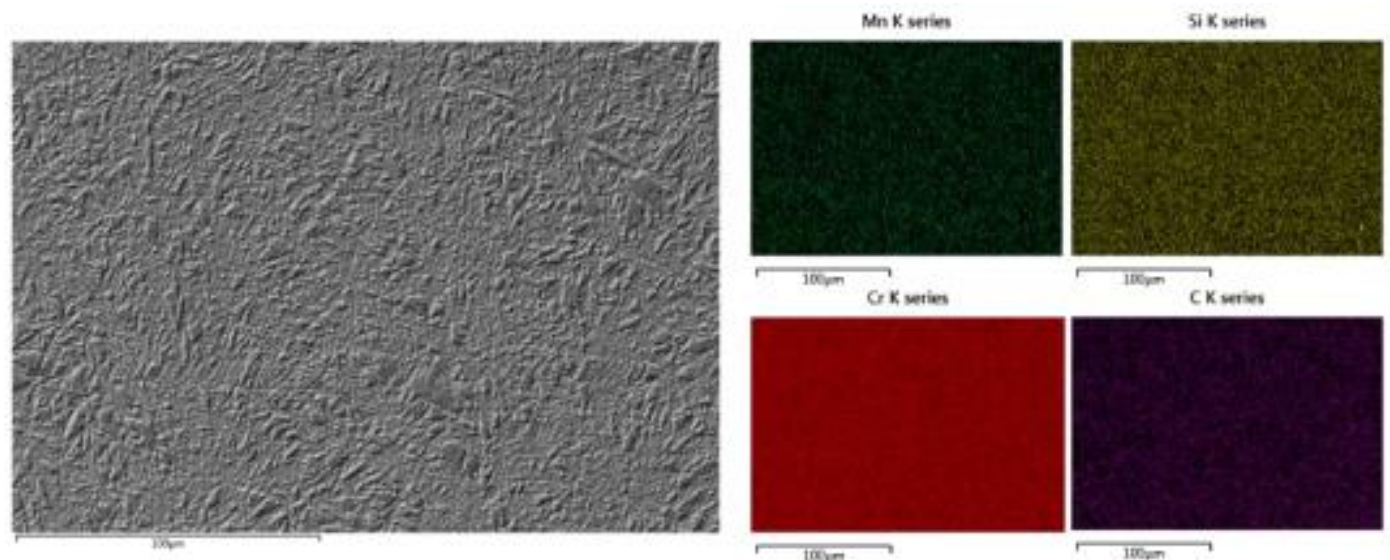

Figure E.20 EDS analysis on the etched surface of the heat-treated 420 stainless steel to show the distribution of $\mathrm{Cr}, \mathrm{C}, \mathrm{Mn}$ and $\mathrm{Si}$ in the microstructure. 


\section{APPENDIX F}

FEASIBILITY STUDIES OF 420 STAINLESS STEEL FABRICATED BY L-PBF

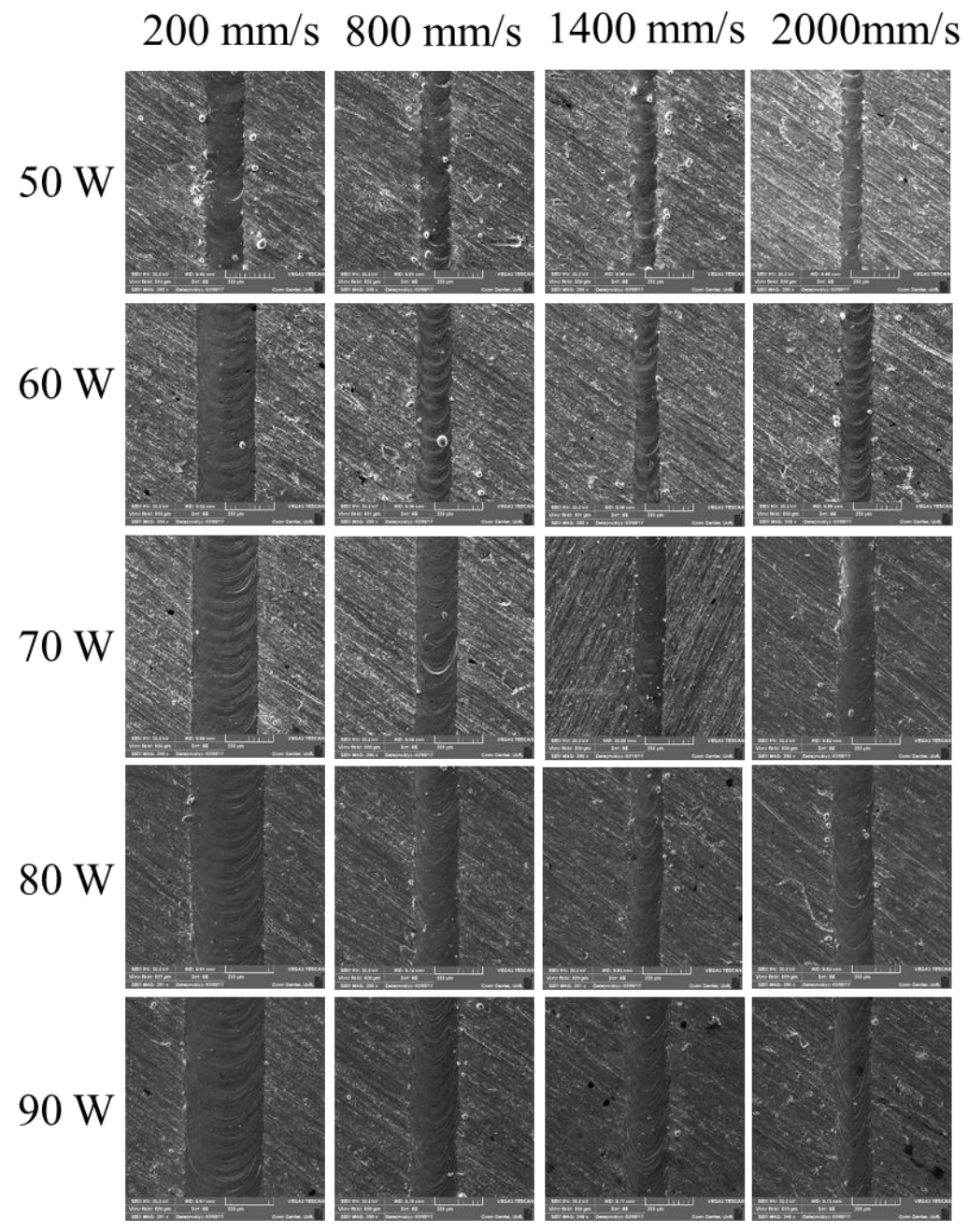

Figure F.1 Scanning electron microscopic images of the single tracks of 420 stainless steel powder of $\mathrm{D}_{50}: 28 \mu \mathrm{m}$ at a layer thickness of $30 \mu \mathrm{m}$ on a steel build plate varying laser powder from 50 to $90 \mathrm{~W}$ and scan speed from 200 to 2000 $\mathrm{mm} / \mathrm{s}$. 

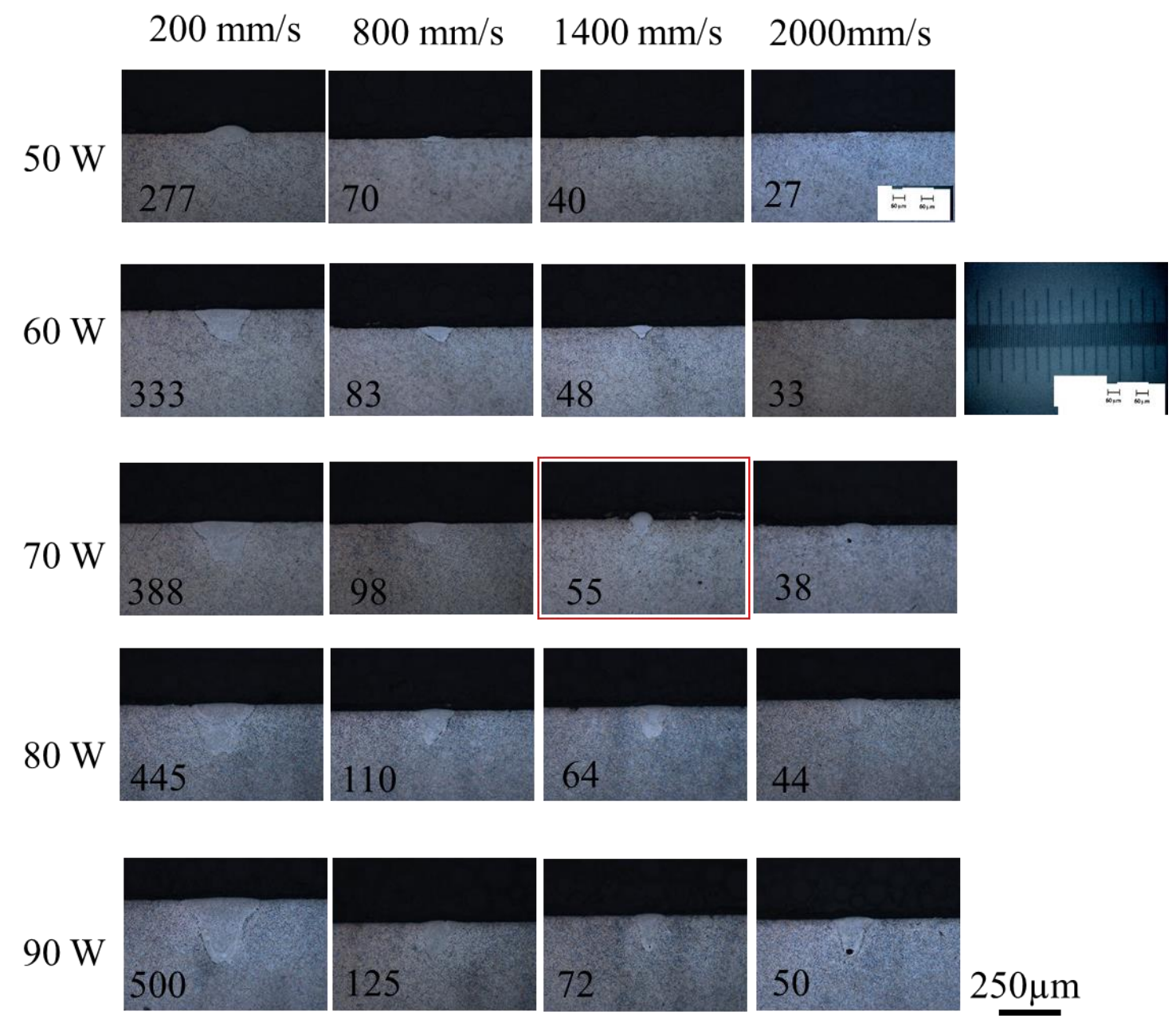

Figure F.2 Optical microscopy images of the cross-sections of single tracks of 420 stainless steel obtained from single track experiment at a layer thickness of $30 \mu \mathrm{m}$. 

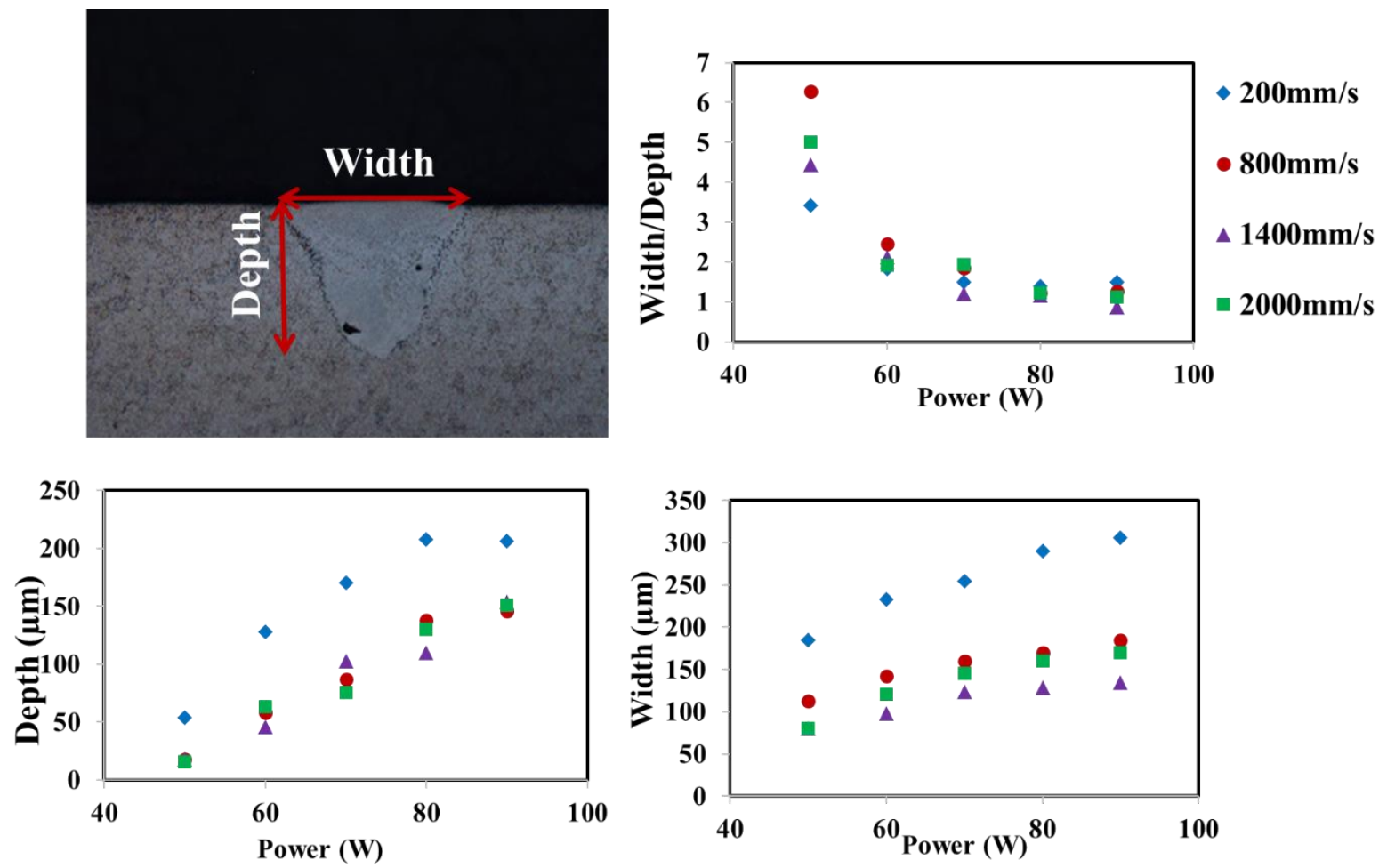

Figure F.3 Width and depth obtained from single track experiment with a layer of $30 \mu \mathrm{m}$ stainless steel powder were plotted against laser power varying scan speed 
Table F.1 Processing parameters used in L-PBF experiments using Ar-atomized 420 stainless steel powder of $\mathrm{D}_{50}: 12 \mu \mathrm{m}$

\begin{tabular}{|c|c|}
\hline Laser power $(\mathrm{W})$ & $50 / 60 / 70 / 80 / 90$ \\
\hline Scan speed $(\mathrm{mm} / \mathrm{s})$ & $200 / 800 / 1400 / 2000$ \\
\hline \multicolumn{2}{|c|}{ Layer thickness $(\mu \mathrm{m}): 30$ and Trace width $(\mu \mathrm{m}): 30$} \\
\hline
\end{tabular}
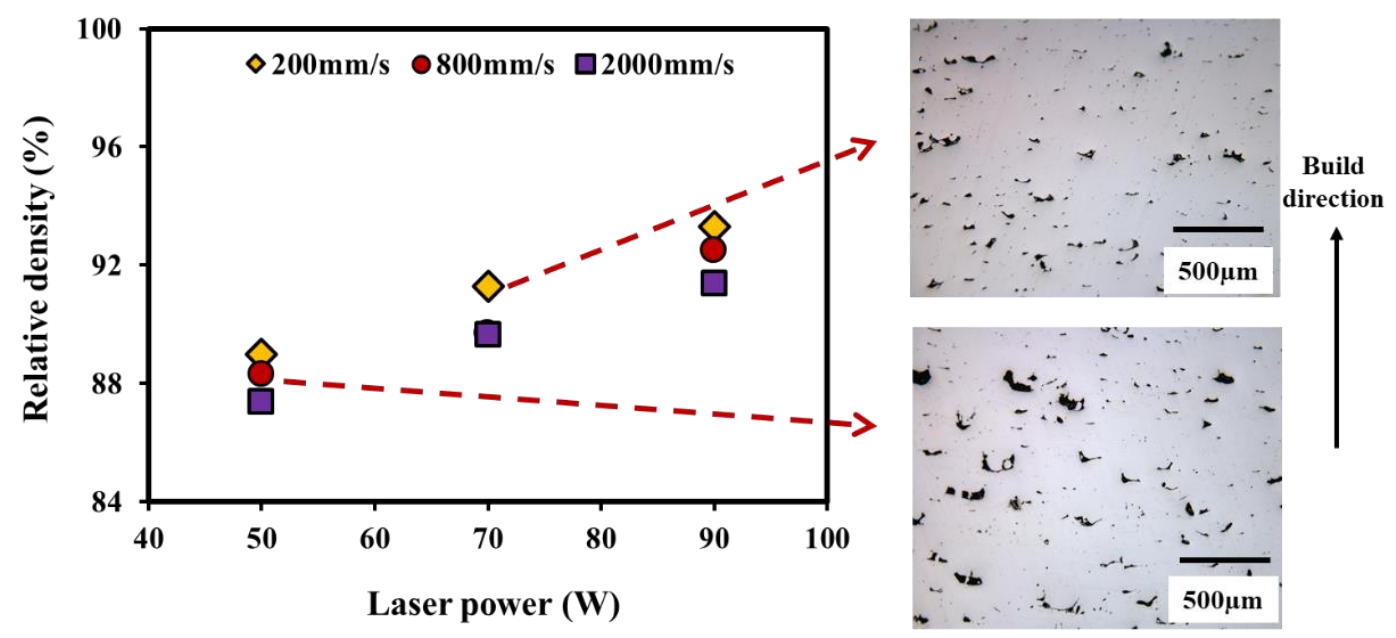

$90 \pm 3 \%$ densities were achieved.

Figure F.4 Relative density vs laser power graph at different scan speed obtained from L-PBF experiments using 420 stainless steel powder. Corresponding optical images of the cross-sections are also provided. 


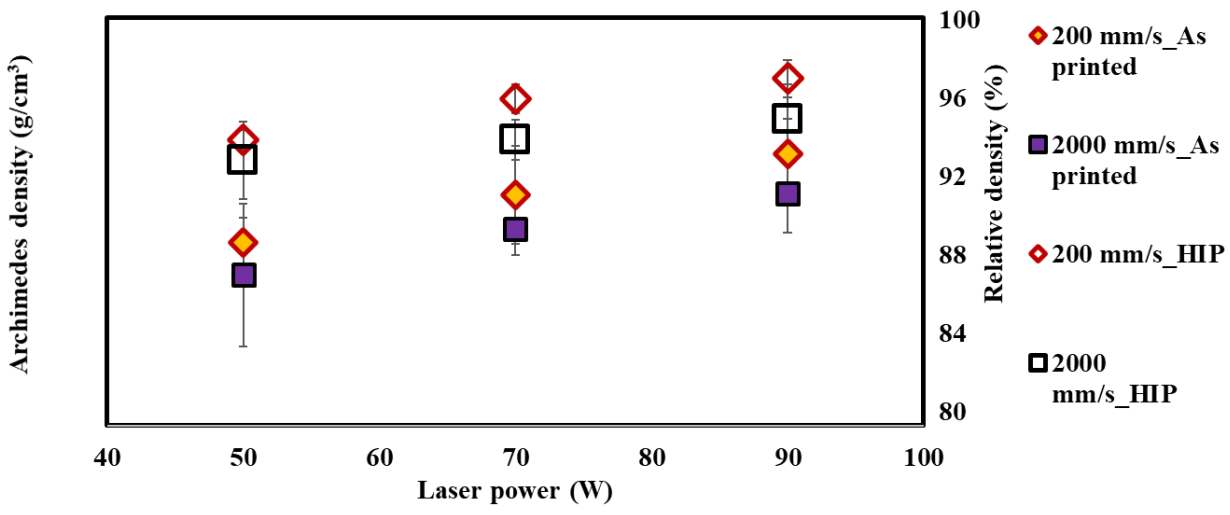

Figure F.5 Relative density vs laser power graph at different scan speed obtained from L-PBF experiments followed by hot isostatic pressing (HIP) using 420 stainless steel powder.

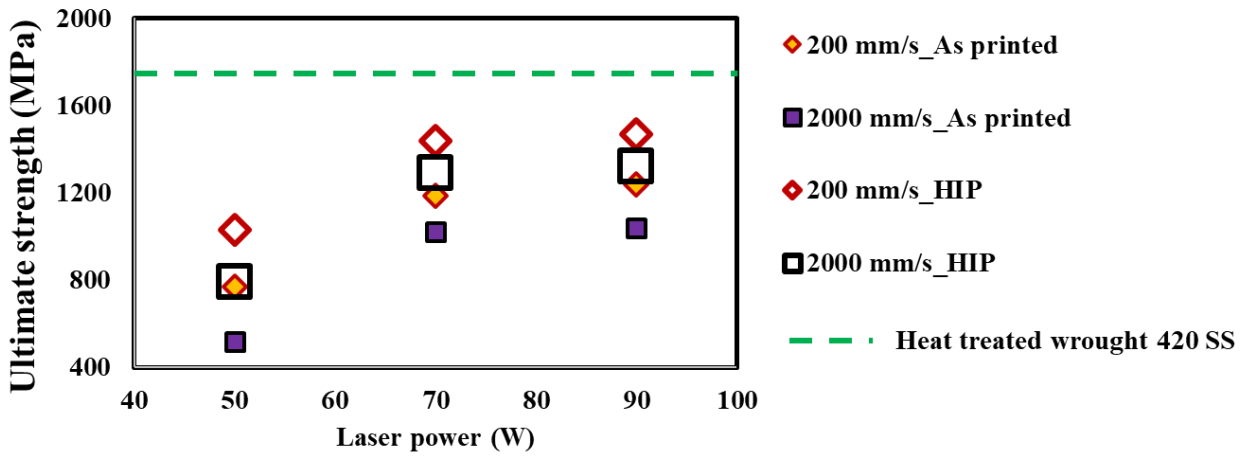

Figure F.6 Ultimate tensile strength vs laser power graph at different scan speed obtained from L-PBF experiments followed by hot isostatic pressing (HIP) using 420 stainless steel powder. 


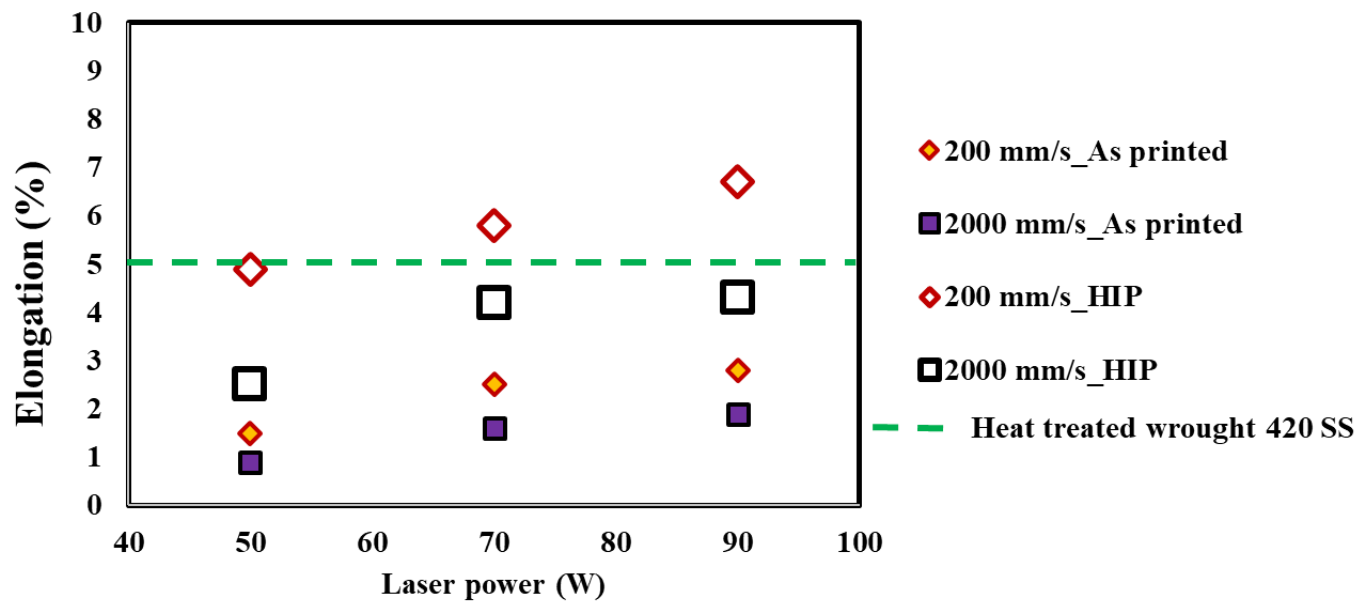

Figure F.7 Elongation vs laser power graph at different scan speed obtained from L-PBF experiments followed by hot isostatic pressing (HIP) using 420 stainless steel powder.
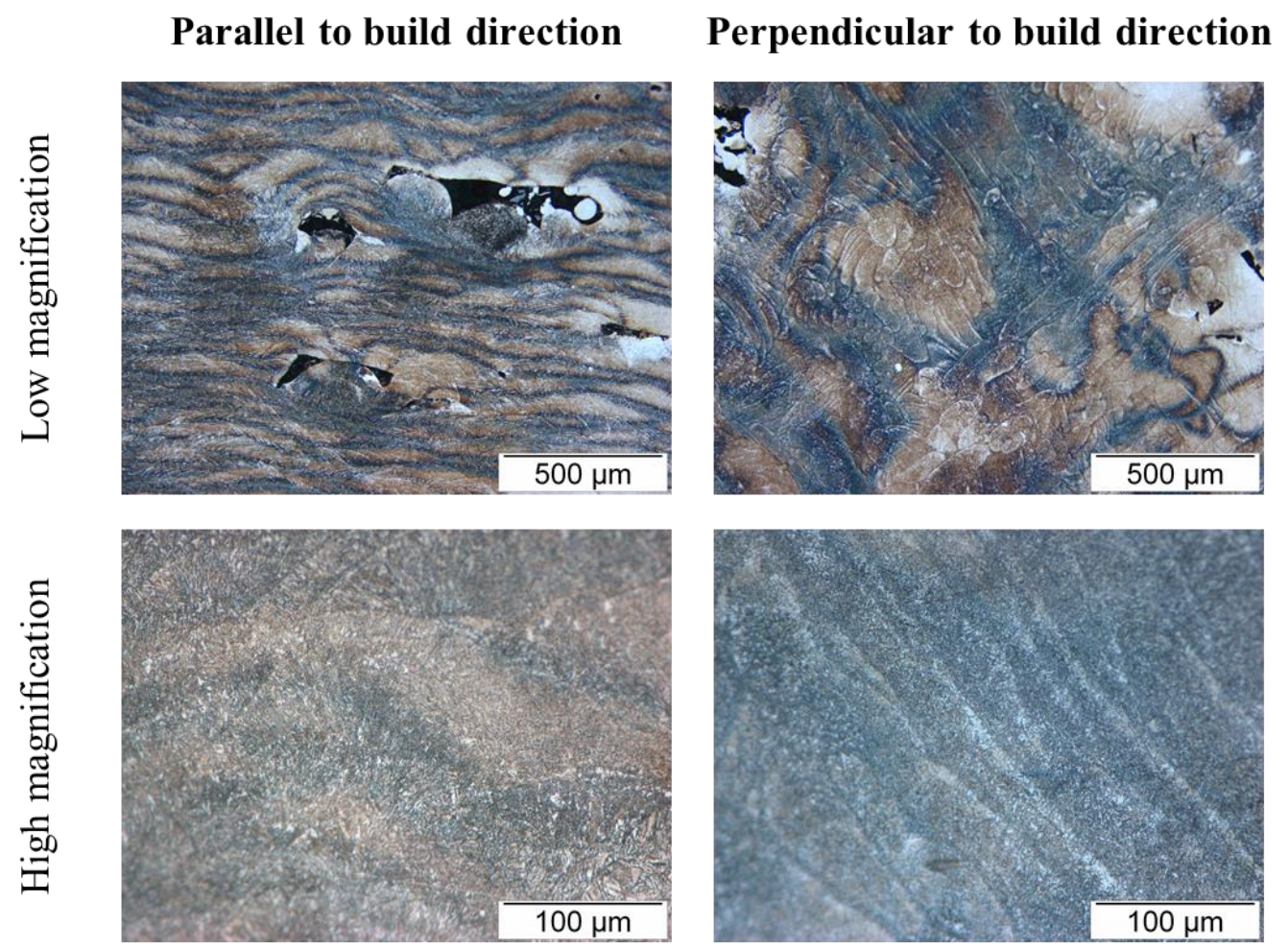

Figure F.8 As-etched microstructure of L-PBF specimens of 420 stainless steel fabricated at a laser power of $90 \mathrm{~W}$, a scan speed of $200 \mathrm{~mm} / \mathrm{s}$, a trace width of 30 $\mu \mathrm{m}$ and a layer thickness of $30 \mu \mathrm{m}$. 


\section{APPENDIX G}

\section{EFFECTS OF ATOMIZATION ATMOSPHERE ON PROPERTIES AND}

MICROSTRCTURE OF 420 STAINLESS STEEL PROCESSED BY L-PBF

Table G.1 Chemical composition of Ar-atomized AISI 420 stainless steel powder

\begin{tabular}{|c|c|c|c|c|c|c|c|c|c|c|}
\hline \multicolumn{10}{|c|}{ Chemical analysis- wt. \% } \\
\hline Element & $\mathrm{Fe}$ & $\mathrm{Cr}$ & $\mathrm{Ni}$ & $\mathrm{Mn}$ & $\mathrm{Si}$ & $\mathrm{P}$ & $\mathrm{C}$ & $\mathrm{S}$ & $\mathrm{O}$ & $\mathrm{N}$ \\
\hline $\begin{array}{c}420 \\
\text { stainless } \\
\text { steel }\end{array}$ & Bal. & 13.4 & 0.4 & 0.3 & 0.5 & 0.02 & 0.43 & 0.01 & 0.01 & 0.09 \\
\hline
\end{tabular}

Table G.2 Powder characteristics of Ar atomized AISI 420 stainless steel powder

\begin{tabular}{|c|c|c|c|c|c|c|}
\hline $\begin{array}{l}\mathrm{D}_{10} \\
\mu \mathrm{m}\end{array}$ & $\begin{array}{l}\mathrm{D}_{50} \\
\mu \mathrm{m}\end{array}$ & $\begin{array}{l}\mathrm{D}_{90} \\
\mu \mathrm{m}\end{array}$ & $\begin{array}{c}\text { Gas } \\
\text { pycnometer } \\
\text { density } \\
\mathrm{g} / \mathrm{cm}^{3}\end{array}$ & $\begin{array}{c}\text { Apparent } \\
\text { density } \rho A \\
\mathrm{~g} / \mathrm{cm}^{3}\end{array}$ & $\begin{array}{c}\text { Tap } \\
\text { density } \rho T \\
\mathrm{~g} / \mathrm{cm}^{3}\end{array}$ & $\begin{array}{l}\text { Hausner } \\
\text { ratio } \\
=\rho T / \rho A\end{array}$ \\
\hline 19 & 33 & 52 & $7.73 \pm 0.01$ & $4.3 \pm 0.1$ & $4.8 \pm 0.1$ & $1.14 \pm 0.01$ \\
\hline
\end{tabular}




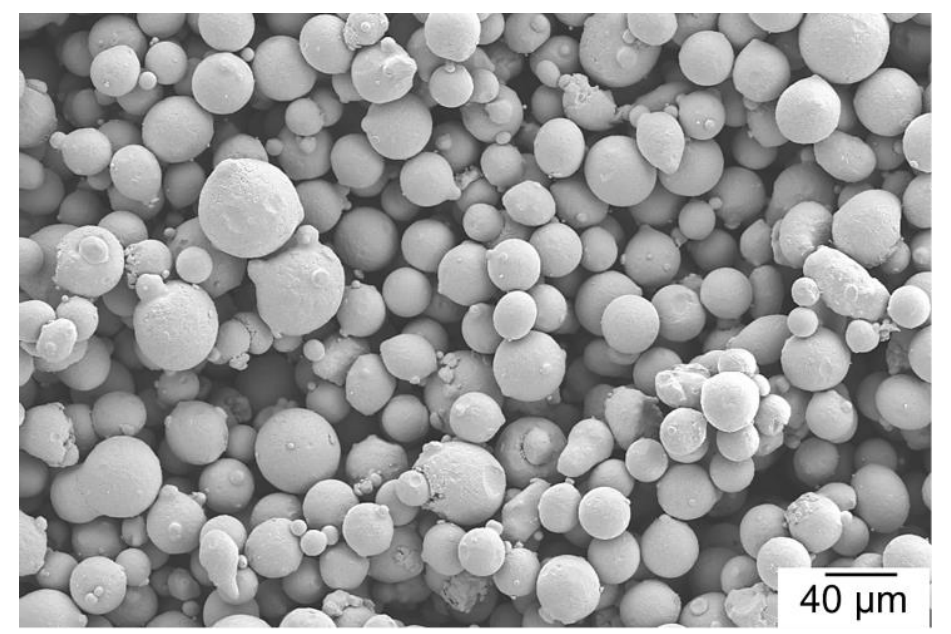

Figure G.1 Scanning electron microscopic image of the Ar-atomized 420 stainless steel powder used in L-PBF experiments.

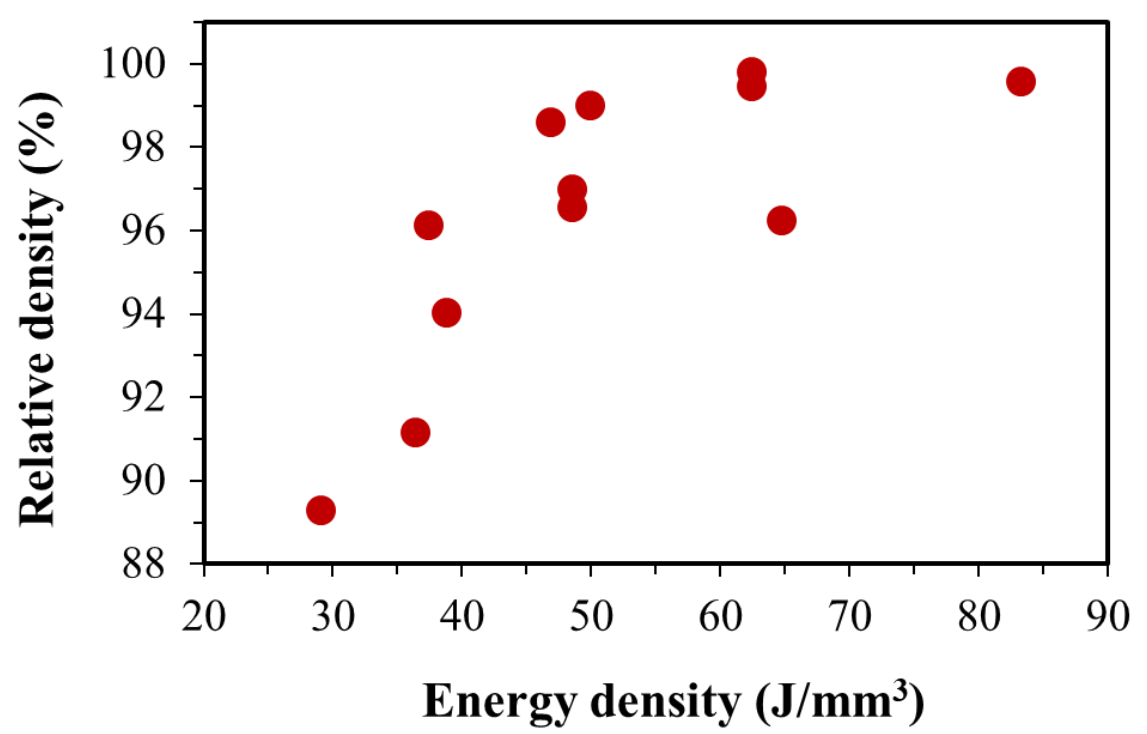

Figure G.2 Relative density of the L-PBF specimens fabricated using Aratomized 420 stainless powder of $\mathrm{D}_{50}: 33 \mu \mathrm{m}$ were plotted against energy density. All specimens were printed with a layer thickness of $20 \mu \mathrm{m}$. 

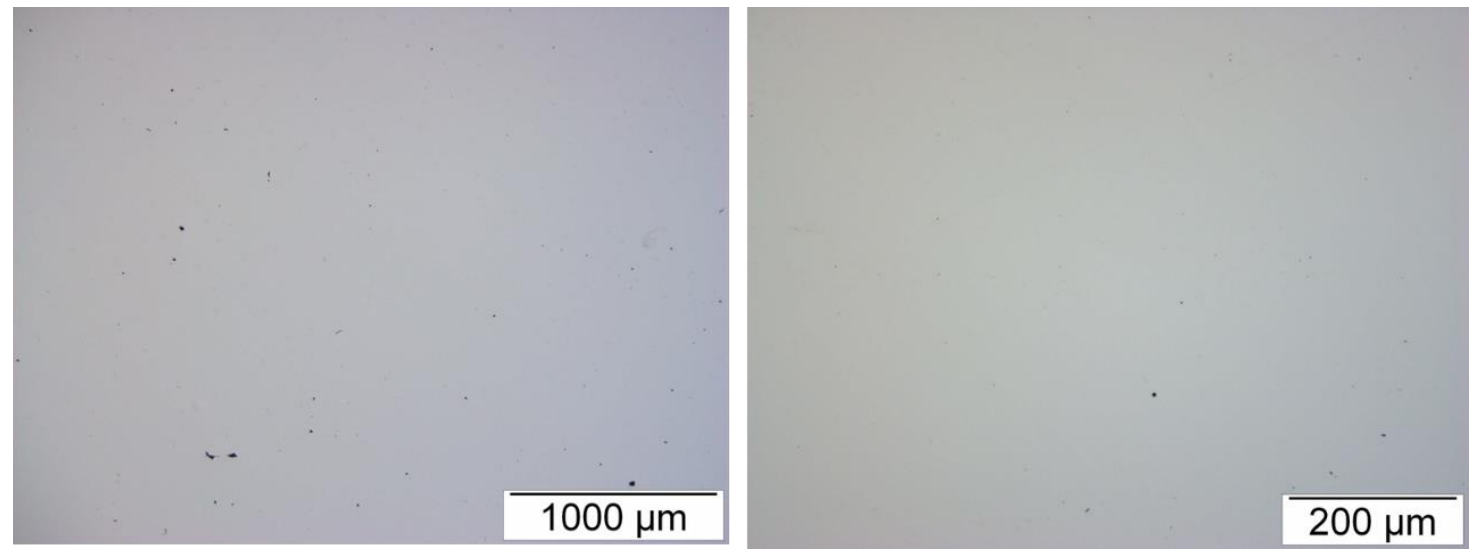

Figure G.3 As-polished cross-sectional images at low and high magnifications of the as-printed L-PBF tensile specimens fabricated using Ar-atomized powder of $\mathrm{D}_{50}: 33$ $\mu \mathrm{m}$ at an energy density of $63 \mathrm{~J} / \mathrm{mm}^{3}$.

Table G.3 Mechanical properties of L-PBF specimens of 420 stainless steel fabricated at an energy density of $63 \mathrm{~J} / \mathrm{mm}^{3}$

\begin{tabular}{|c|c|c|c|c|c|c|}
\hline Powder & Condition & $\begin{array}{c}\text { Density } \\
\mathrm{g} / \mathrm{cc}\end{array}$ & $\begin{array}{c}\text { Ultimate } \\
\text { tensile } \\
\text { strength } \\
\mathrm{MPa}\end{array}$ & $\begin{array}{c}\text { 0.2\% Yield } \\
\text { Strength } \\
\mathrm{MPa}\end{array}$ & $\begin{array}{c}\text { Elongation } \\
\%\end{array}$ & $\begin{array}{c}\text { Hardness } \\
\text { HRC }\end{array}$ \\
\hline $\begin{array}{c}\text { Ar- } \\
\text { atomized } \\
\mathrm{D}_{50}: 33 \\
\mu \mathrm{m}\end{array}$ & $\begin{array}{c}\text { As- } \\
\text { printed }\end{array}$ & $\begin{array}{c}7.70 \pm \\
0.02\end{array}$ & $760 \pm 16$ & $650 \pm 12$ & $1.5 \pm 0.1$ & $49 \pm 1$ \\
\cline { 2 - 7 } & $\begin{array}{c}\text { Heat- } \\
\text { treated }\end{array}$ & $\begin{array}{c}7.70 \pm \\
0.02\end{array}$ & $1080 \pm 20$ & $890 \pm 15$ & $3.1 \pm 0.1$ & $48 \pm 1$ \\
\hline
\end{tabular}




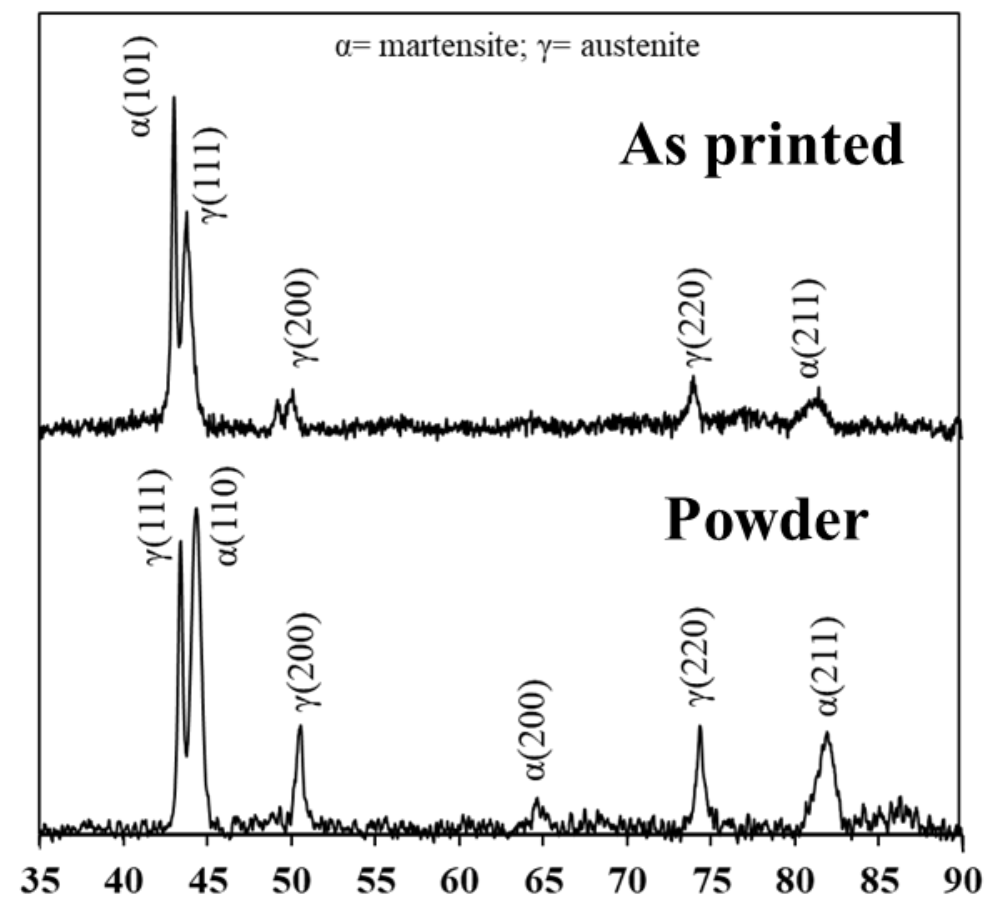

Figure G.4 Representative XRDs of the Ar-atomized 420 stainless steel powder and as-printed L-PBF specimen.
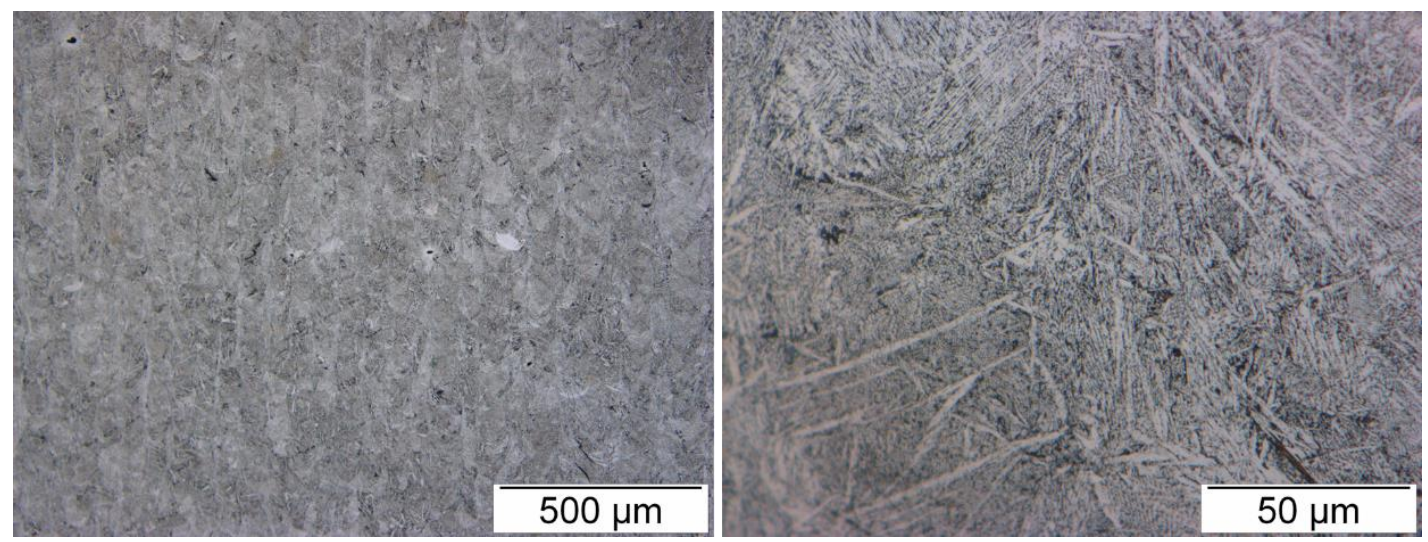

Figure G.5 As-etched cross-sectional images at low and high magnifications of LPBF tensile bars fabricated using Ar-atomized powder of $\mathrm{D}_{50}: 33 \mu \mathrm{m}$ at an energy density of $63 \mathrm{~J} / \mathrm{mm}^{3}$. Kalling II reagent was used to etch the surface after polishing with $1 \mu \mathrm{m}$ diamond paste. 


\section{APPENDIX H}

\section{L-PBF OF 420 STAINLESS STEEL INFILTRATED WITH BRONZE}
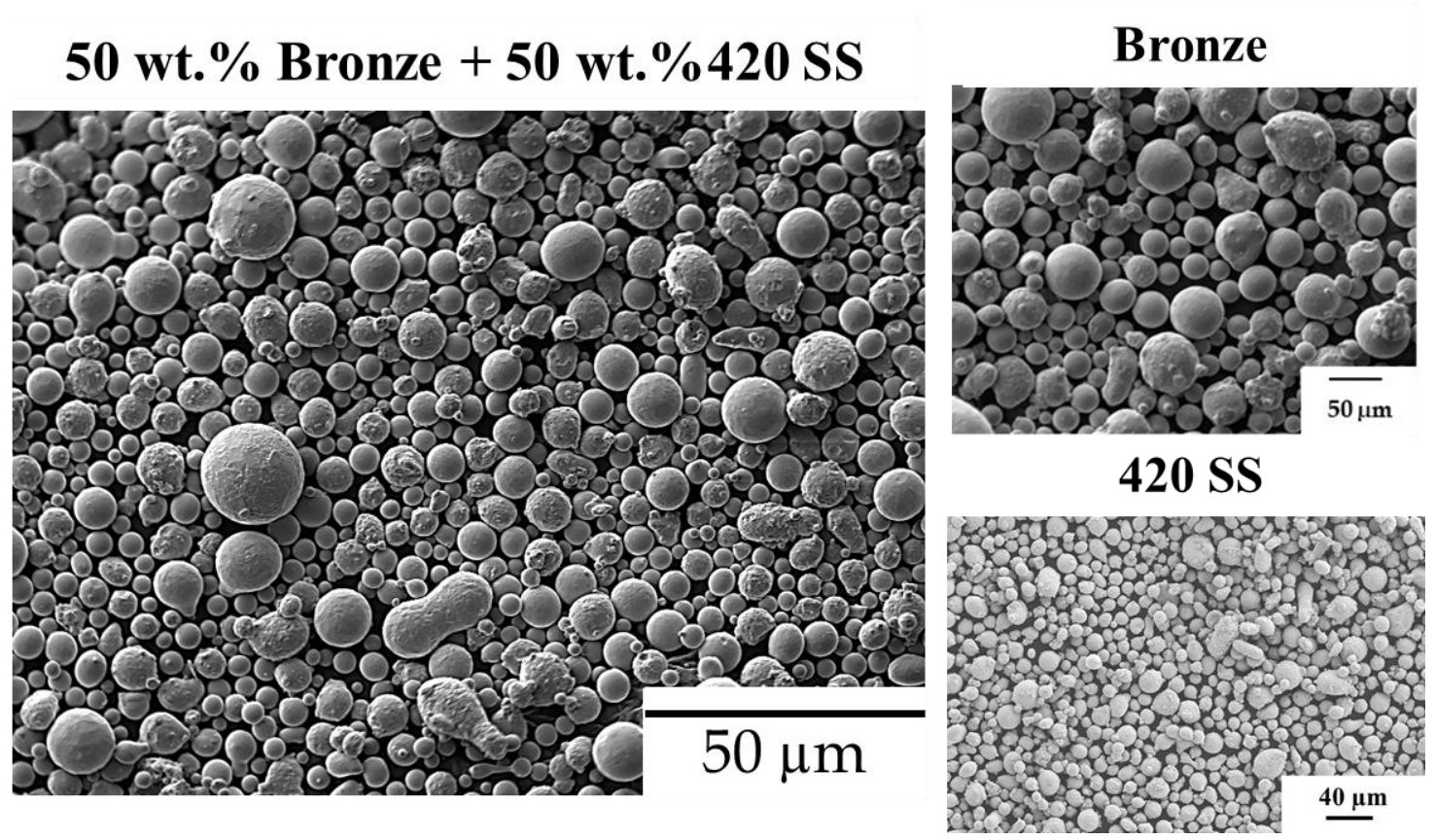

Figure H.1 Scanning electron microscopy images of 420 stainless steel ( $\left.\mathrm{D}_{50}: 28 \mu \mathrm{m}\right)$, bronze ( $\left.\mathrm{D}_{50}: 34 \mu \mathrm{m}\right)$ and mixed powder at 50-50 wt $\%$.

Table H.1 Physical and mechanical properties achieved by processing of bronze and 420 stainless steel together using L-PBF

\begin{tabular}{|c|c|c|c|c|c|}
\hline Material & $\begin{array}{c}\text { Scanning } \\
\text { pattern }\end{array}$ & $\begin{array}{c}\text { Relative density } \\
(\%)\end{array}$ & $\begin{array}{c}\text { Ultimate tensile } \\
\text { strength (MPa) }\end{array}$ & $\begin{array}{c}\text { Elongation } \\
(\%)\end{array}$ & Hardness \\
\hline Bronze & Line & $94 \pm 0.5$ & $500 \pm 50$ & $10 \pm 2$ & $68 \pm 3$ (HRB) \\
\hline $\begin{array}{c}420 \mathrm{SS} \\
\text { (Nath et al) }\end{array}$ & Line & $97 \pm 0.5$ & $1050 \pm 40$ & $3 \pm 0.5$ & $54 \pm 3$ (HRC) \\
\hline $\begin{array}{c}\text { Bronze }+ \\
\text { 420SS }\end{array}$ & Line & $99 \pm 0.5$ & $950 \pm 50$ & $3 \pm 2$ & $27 \pm 3$ (HRC) \\
\hline
\end{tabular}



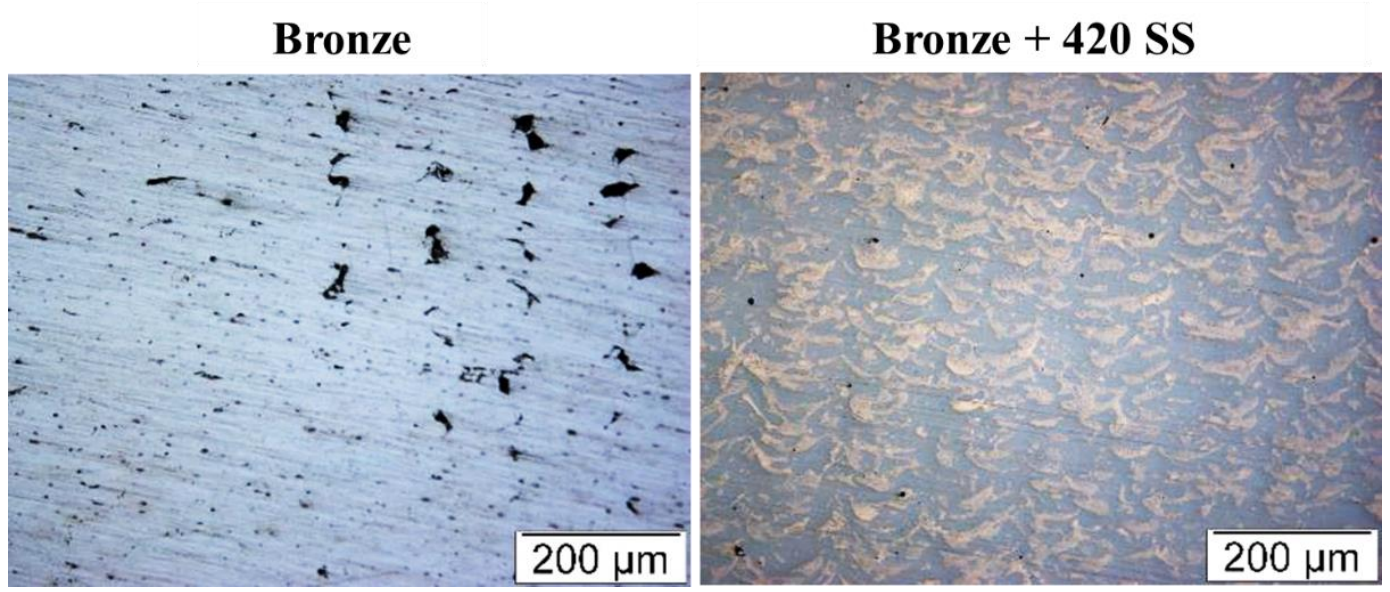

Figure H.2 As-polished microstructure of bronze and 420 stainless with bronze processed by L-PBF at an energy density of $63 \mathrm{~J} / \mathrm{mm}^{3}$.

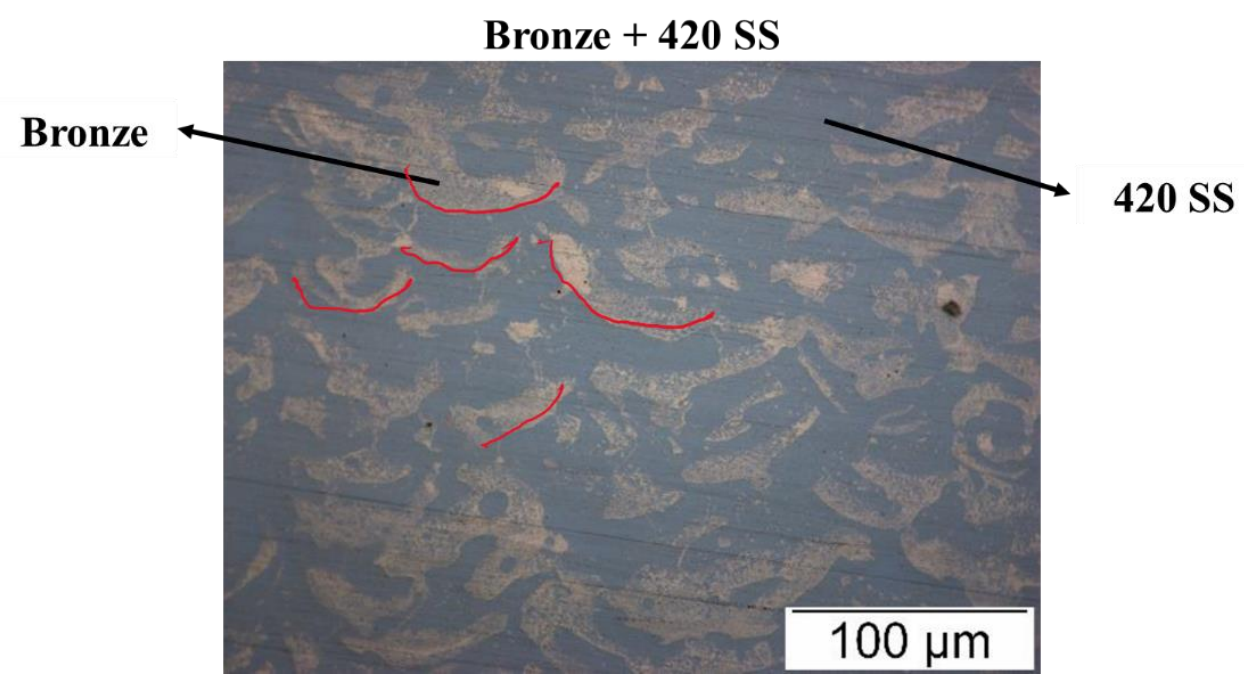

Figure H.3 As-polished microstructure at the high resolution to show bronze and 420 stainless steel in L-PBF specimen. 
APPENDIX I

CONFERENCE PAPER ON APPLICATIONS OF L-PBF 420 STAINLESS STEEL PRESENTED AT AMPM 2017 IN LAS VEGAS, NV

\title{
LASER-POWDER BED FUSION OF 420 STAINLESS STEEL FOR
}

MOLD AND SURGICAL TOOL APPLICATIONS

\author{
Subrata Deb Nath ${ }^{1}$, Samuel Dilip ${ }^{1}$, Harish Irrinki ${ }^{1}$, Max Gatsche ${ }^{2}$, Kunal Kate ${ }^{1}$, John \\ Ballaro $^{2}$ and Sundar Atre ${ }^{1, *}$ \\ ${ }^{1}$ Department of Mechanical Engineering, University of Louisville, Louisville KY 40208 \\ ${ }^{2}$ Amaray Plastics, Elizabethtown KY 42701
}

\section{$\underline{\text { ABSTRACT }}$}

420 stainless steel has high hardness and wear resistance with good corrosion resistance which makes it well suited material for injection mold and surgical tools. In the current work, laser powder bed fusion (L-PBF) using 420 stainless steel was conducted to study the physical properties of test cube specimens and determine best process parameters to print functional injection molding mold and surgical tools. Towards this end, using different combinations of laser power (50W and 90W) and scan speeds $(200 \mathrm{~mm} / \mathrm{s}$ and 800 $\mathrm{mm} / \mathrm{s}$ ) test specimen cube coupons were fabricated. Cut cross-sections of the printed cube 
were analyzed for surface porosity and density measurements. To evaluate the potential of manufacturing of industrial products by L-PBF, an injection mold with conformal cooling channel was designed and the mold filling behavior was simulated using Moldex3D software. It was estimated that about $15 \%$ reduction in production cycle time could be achieved with the use of 3D printed molds with conformal cooling channels compared to traditional molds. Furthermore, surgical tool graspers with various teeth pattern for laparoscopic instrument model was also created and tested in simulated environment. The results showed no presence of stress concentration regions in the surgical tool design. Following design simulation evaluations for the mold and surgical tools, they were L-PBF printed using the developed process parameters.

\section{INTRODUCTION}

Laser-powder bed fusion (L-PBF) is an additive manufacturing (AM) technique that has been successfully used to fabricate injection-molding tools [1-2]. In recent years, L-PBF process gained noticeable attention due to its capability of fabrication parts with various engineering alloys along with geometrical design freedom it offers. L-PBF process involves layer-by-layer fabrication of metallic parts directly using a concentrated laser heat source. 420 stainless steel has excellent tensile strength, hardness and wear resistance along with good corrosion properties which makes it suitable for tooling applications. [5] However, very few studies have been conducted on L-PBF with 420 stainless steel and implement the findings to fabricate industry scaled products. In the present work, as a case study two application of L-PBF printed 420 stainless steel mold tool and surgical tools 
Injection molding is a widely-used manufacturing process which can produce 100 or more parts per hour compared to conventional machining which may produce half a dozen parts per hour. Currently, the mold manufacturing market in the injection molding industry composes of $\$ 33.5$ billion with a $3.3 \%$ annual growth. One of the crucial factors contributing to the efficiency of the injection molding process is the time required to cool the parts. The presence of cooling channels inside molds cause to reduce process cycle times and minimize thermal defect. [3] Of the distinct types of cooling channel designs, conformal cooling channels provide the most significant benefit in reducing cycle times. Conformal cooling channels typically curve and follow closely besides the cavity walls and efficiently cool the molded part. [4] However, using conventional manufacturing processes it is difficult to make conformal cooling channels and therefore 3D printing such geometries can be most suited. Furthermore, to design conformal cooling channels various injection molding simulation platforms such as MoldeX3D, Moldflow, Sigma Soft are available but integration of such types of software with 3D printing technology to reduce lead times in implementing new designs and prototypes are not very studied [117].

Another important and life-saving tool industry is surgical tool manufacturing which traditionally offers very few scopes of innovation and customization. Scaling up or down of the size and shape of the surgical tools has not been previously looked at in the medical device industry even though there were reports on complications in surgery due to limited surgical tool designs [6]. Necessity of such custom surgical tools with different sizes and shapes are increasing because of an increase in obesity among people in the last decade [7]. L-PBF 3D printing of custom surgical tools has a potential reduce chances of complications in surgery [8-9]. 
Therefore, to L-PBF print products such as mold tool and surgical tools it is imperative for it to have better quality and good dimensional accuracy. The quality and the properties of L-PBF printed parts typically depend on the applied processing parameters. Change of process parameters typically affect the bonding between the layers and tracks of material being deposited, and therefore density. It is essential to study and understand the effect of the processing parameters such as scanning speed, laser power, and powder layer thickness before products such as mold tool and surgical tool are fabricated. In the present work, we attempt to study the influence of process parameters on the part density and properties. After identifying a good parameter combination, our study focuses on fabrication of injection mold and surgical tool using 420 stainless steel to explore.

\section{METHODOLOGY}

In the current study a gas atomized pre-alloyed 420 stainless steel powder was used as a starting material to fabricate test specimen cubes, an injection molding tool and surgical tools using the L-BPF process. AISI 420 stainless steel powder, manufactured by Carpenter Technology Corporation, was supplied by Netshape Technologies, Inc. The powder was characterized for its particle size distribution by laser diffraction method using Microtrac S3000. Furthermore, true density measurements were done using a gas pycnometer while scanning electron microscopy (SEM) was performed to examine the powder morphology. The Concept laser Mlab Cusing R machine was used to perform L-PBF experiments. To setup L-PBF experiments initially the build plate was sand blasted and washed with ethyl alcohol. The sandblasting was performed to enhance the friction between powder and build plate to allow powder to spread uniformly on the build plate. The coater blade speed was set at $60 \mathrm{~mm} / \mathrm{s}$ during the powder spreading and $120 \mathrm{~mm} / \mathrm{s}$ in the return stroke to allow 
uniform spreading of the powder. L-PBF experiments were conducted under argon gas to create inert atmosphere and prevent oxidation of the 420 stainless steel powder. Initial LPBF experiments were carried out to fabricate test specimen cubes for identifying appropriate process conditions that results in low porous cubes and the identified condition was used to further print injection molding tool and surgical tools. The test specimen cubes have dimensions of $10 \mathrm{~mm} \times 10 \mathrm{~mm} \times 10 \mathrm{~mm}$ and were printed using process parameters listed in Table 1. To perform L-PBF experiment, laser power was varied between 50 and $90(\mathrm{~W})$ and scan speed was varied between 200 and $800(\mathrm{~mm} / \mathrm{s})$. Furthermore, both layer thickness and trace widths were kept constant at $30 \mu \mathrm{m}$. After the test cubes were 3D printed they sectioned with a low-speed cutting machine and the cutting direction was kept perpendicular to the build direction. Cube density was measured according to the Archimedes principle by weighing the samples in air and subsequently in water to measure the volume. The cut test cubes were further prepared for optical microscopy characterization to check for surface porosity. To prepare samples for optical image analysis, the cut samples were first polished using 120, 400, 600 and 800 grit papers on a Nano 2000T machine manufactured by Pace Technologies. Then, the samples were fine polished with $9 \mu \mathrm{m}$ and $1 \mu \mathrm{m}$ diamond particle solution and then etched with Kalling agent to reduce reflectivity and clearly observe the microstructure. Additionally, true density measurements of the 3D printed test cubes were performed using Archimedes method and martensite content was measured with Feritscope FMP 30 manufactured by Fisher Technology Inc.

The best process setting identified from Table 1 was used to $3 \mathrm{D}$ print mold tool and surgical tools with 420 stainless steel but before 3D printing design optimization was done 
using computer aided design (CAD) based simulation platforms. To design the mold cavity for injection molding tool, SolidWorks software was used. Injection molding simulations and conformal cooling channel design for the designed 3D mold cavity was performed using Moldex 3D simulations to eliminate injection molding defects and change cavity design based on mold filling simulation results. To design surgical tools and conduct stress analysis on the designed geometries, SolidWorks software used. The optimized designs of both mold tool and surgical tool were then 3D printed. After 3D printing, both tools the support structures that were close to the build plate was removed using lathe and low speed cutting machines. Surfaces of both the cut tools were post-processed using emery paper and dermal tool to improve their aesthetic appearance. Additionally, density and dimensional tolerance measurements of both the tools were performed.

\section{RESULTS AND DISCUSSION}

\section{Powder morphology}

(a)

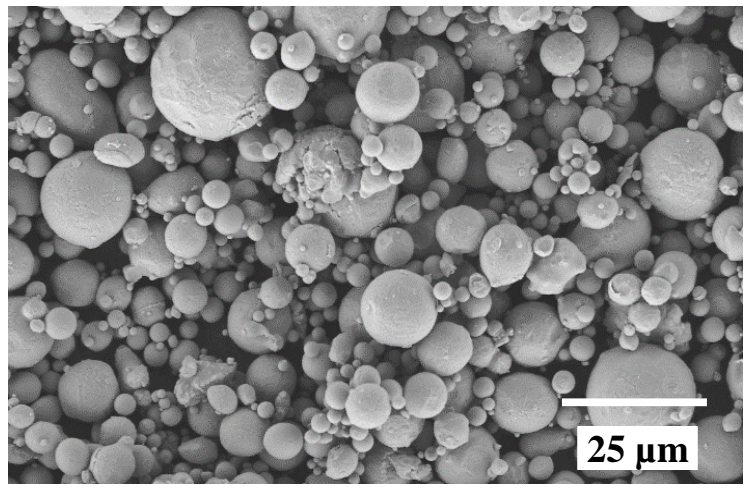

(b)

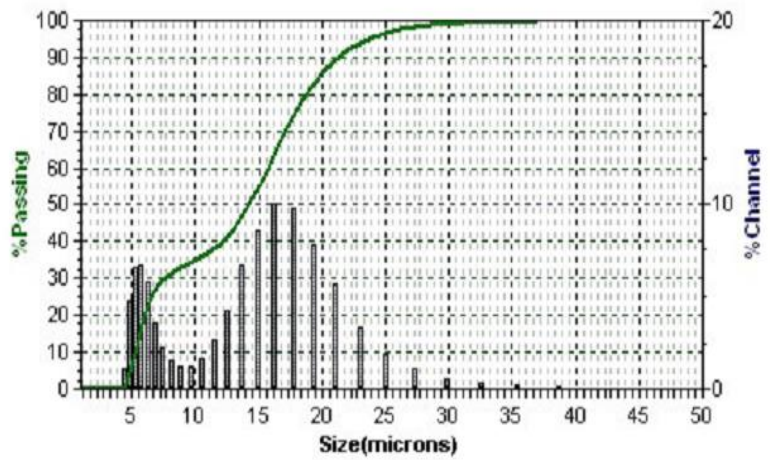

Figure 1. a) A low magnification SEM micrograph of 420 stainless steel powder. b) The particle size distribution curve of the powder obtained from Microtrac S3000. 
Table I. Characteristics of the AISI 420 stainless steel powder.

\begin{tabular}{|c|c|c|c|c|c|}
\hline $\begin{array}{c}\mathrm{D}_{10} \\
\mu \mathrm{m}\end{array}$ & $\begin{array}{c}\mathrm{D}_{50} \\
\mu \mathrm{m}\end{array}$ & $\begin{array}{c}\mathrm{D}_{90} \\
\mu \mathrm{m}\end{array}$ & $\begin{array}{c}\text { True density } \\
\mathrm{g} / \mathrm{cm}^{3}\end{array}$ & $\begin{array}{c}\text { Apparent density } \\
\mathrm{g} / \mathrm{cm}^{3}\end{array}$ & Shape \\
\hline 4 & 11 & 22 & 7.7 & 3.4 & Spherical \\
\hline
\end{tabular}

The particle size distribution and density measurements of 420 stainless steel are shown in Table II. The powder showed a size distribution of $4 \mu \mathrm{m}$ to $20 \mu \mathrm{m}$ for $80 \%$ of the powder. The true and apparent density of this 420 stainless steel powder as 7.7 and $3.4 \mathrm{~g} / \mathrm{cm}^{3}$ respectively. Figure 1 shows the scanning electron microscopy (SEM) of the 420 stainless steel powder and it can be observed that the powders were mostly spherical in shape. The powder particle distribution plays an important role to choose the processing condition layer thickness. Very high layer thickness may make obstacle to obtain even powder spreading in every layer whereas very low layer thickness will end up with blank space in some place.

\section{Material properties}

L-PBF printed test specimen cubes of dimensions $10 \mathrm{~mm}$ X $10 \mathrm{~mm}$ X $10 \mathrm{~mm}$ were built using process parameters listed in Table II and their physical properties are listed in Table III. All the L-PBF printed test cubes had a density of $90 \pm 2 \%$ and martensite content in it varied from $32 \%$ to $64 \%$. However, higher martensite content (64\%) was observed with lower scan speed $(200 \mathrm{~mm} / \mathrm{s})$. The polished cross-section surfaces of the test cubes L-PBF printed at $50 \mathrm{~W}$ laser power and $800 \mathrm{~mm} / \mathrm{s}$ scan speed process conditions is Fig.2a and an etched micrograph of this sample is shown in Fig.2b. The black needle like formation in Fig. $2 \mathrm{~b}$ represents the martensite while the light gray contrasts regions represent austenite region. The mastensite needles formed are characteristics to high cooling rates observed in the L-PBF process and pertain to a typical 420 stainless steel microstructure [10]. 
Therefore, process parameters of $50 \mathrm{~W}$ laser power and $800 \mathrm{~mm} / \mathrm{s}$ scan speed that had high relative density and low porosity were chosen to fabricate the mold and surgical tool parts.

Table II. Physical properties of the L-PBF printed coupons according to processing conditions.

\begin{tabular}{|c|c|c|c|c|c|}
\hline \multicolumn{4}{|c|}{ Processing conditions } & \multicolumn{2}{c|}{ Physical properties } \\
\hline $\begin{array}{c}\text { Layer } \\
\text { thickness } \\
(\mu \mathrm{m})\end{array}$ & $\begin{array}{c}\text { Laser power } \\
(\mathrm{W})\end{array}$ & $\begin{array}{c}\text { Scan speed } \\
(\mathrm{mm} / \mathrm{s})\end{array}$ & $\begin{array}{c}\text { Trace width } \\
(\mathrm{mm} / \mathrm{s})\end{array}$ & $\begin{array}{c}\text { Relative } \\
\text { density } \\
(\%)\end{array}$ & $\begin{array}{c}\text { Surface } \\
\text { roughness } \\
\mu \mathrm{m}\end{array}$ \\
\hline 10 & 600 & 600 & 10 & 99.3 & $2.9 \pm 0.04$ \\
\hline
\end{tabular}

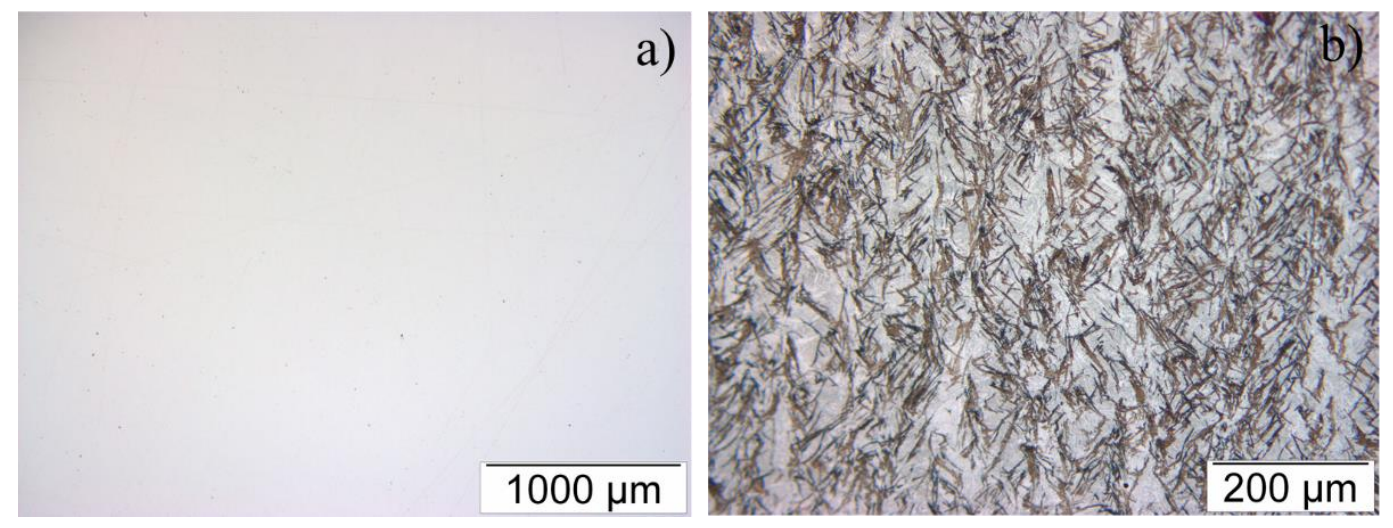

Figure 2. Cross-sectional microstructure of L-PBF specimen of 420 stainless steel using a layer thickness of $10 \mu \mathrm{m}$ in the (a) as-polished and (b) as-etched condition. 


\section{L-PBF of injection mold tool with conformal cooling channel}

Solidworks was used to design the mold tool cavity of a half section of a hairbrush as shown in Fig. 3a. A draft angle of 3 degree was included on the cavity for smoother ejection of molded parts [11]. Cavity design was received from our industry partners Amaray Plasitics, Elizabethtown, KY. The half cross section of hairbrush was imported from

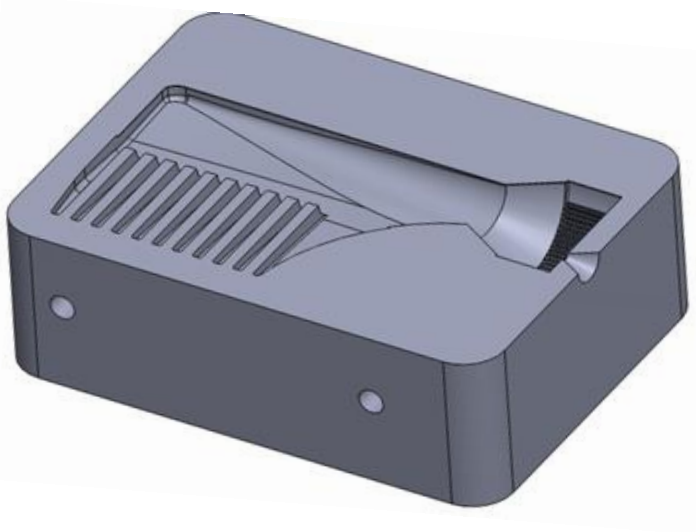

(a)

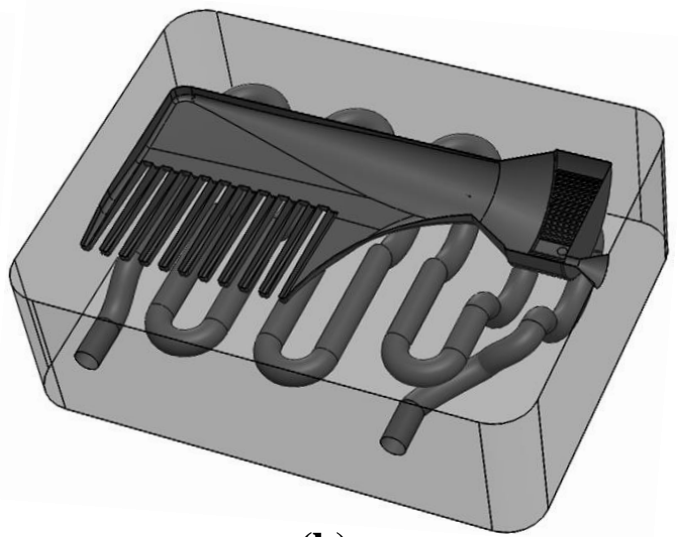

(b)

Figure 3. CAD model of the (a) mold cavity where inlet and outlet of the conformal cooling channel are faced at front face. The gate is located at the right face. The conformal cooling channel underneath of the cavity has been shown in image (b).

SolidWorks to Moldex3D designer software where conformal cooling channels.

were designed (Fig.3b). The entire injection mold tool that contained the hairbrush cavity and conformal cooling channels had a size of $86 \mathrm{~mm}$ x $67 \mathrm{~mm}$ x $28 \mathrm{~mm}$.

After designing the mold tool with conformal cooling channels injection molding simulation were performed to study the effect of conformal cooling channel in the mold cavity in terms of cycle time and warpage, and results were compared with a mold without conformal channels. To setup injection molding simulations, machine parameters were provided by Amaray Plastics, Elizabethtown, KY for Sumitomo SG180M-C450M injection molding machine and were inputted into the Moldex3D software, material data file of polypropylene (homopolymer) was imported from the software database, mold 
material was chosen as 420 stainless steel as a basis to perform simulations and process settings of $212 \mathrm{MPa}$ injection pressure, $473 \mathrm{~K}$ melt temperature, $323 \mathrm{~K}$ mold temperature and an injection velocity of $90 \mathrm{~mm} / \mathrm{s}$. Injection molding simulations analysis was performed for filling, packing, cooling and warpage stages and conducted for mold tools designed with and without conformal cooling channels and with regular cooling lines. Parts were filled completely for both types of molds and no warpage was observed for the set process condition. A typical molding filing behavior is shown in Fig. 4. However, addition of conformal cooling channel in the mold tool reduced $15 \%$ of the cycle time (Table IV).

Table III. Comparison of cycle time with different cooling systems in Moldex3D simulated condition

\begin{tabular}{|c|c|}
\hline Type of cooling channel & Cycle time (s) \\
\hline Mold with no cooling channel & 14.3 \\
\hline Mold with regular cooling channel & 13.5 \\
\hline Mold with conformal cooling channel & 12.4 \\
\hline
\end{tabular}
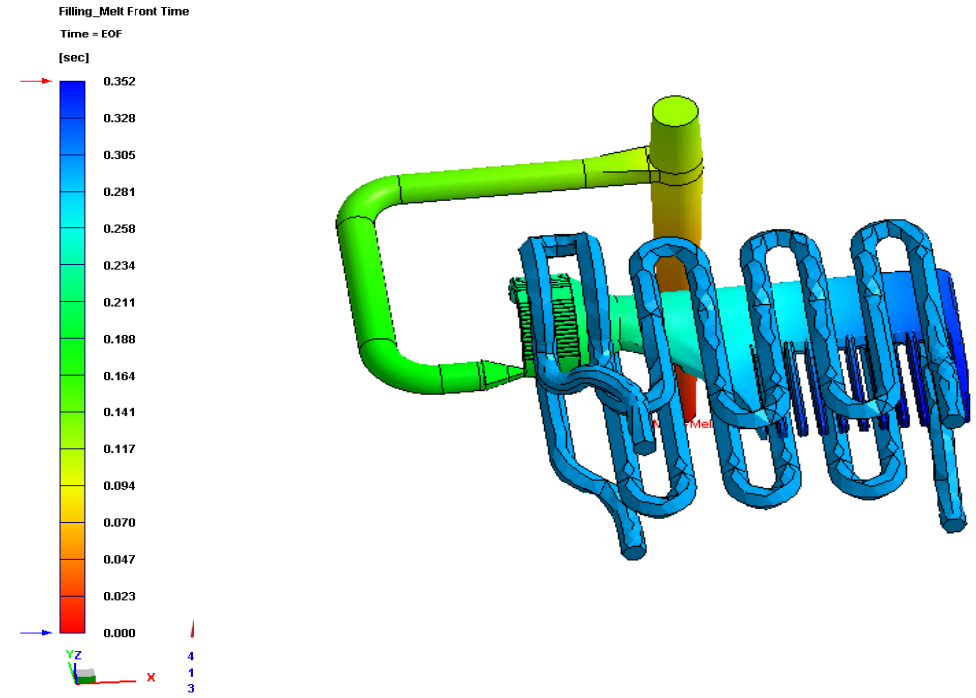

Figure 4. Mold flow behavior simulations with Moldex3D for PP surrounding with conformal cooling channels 

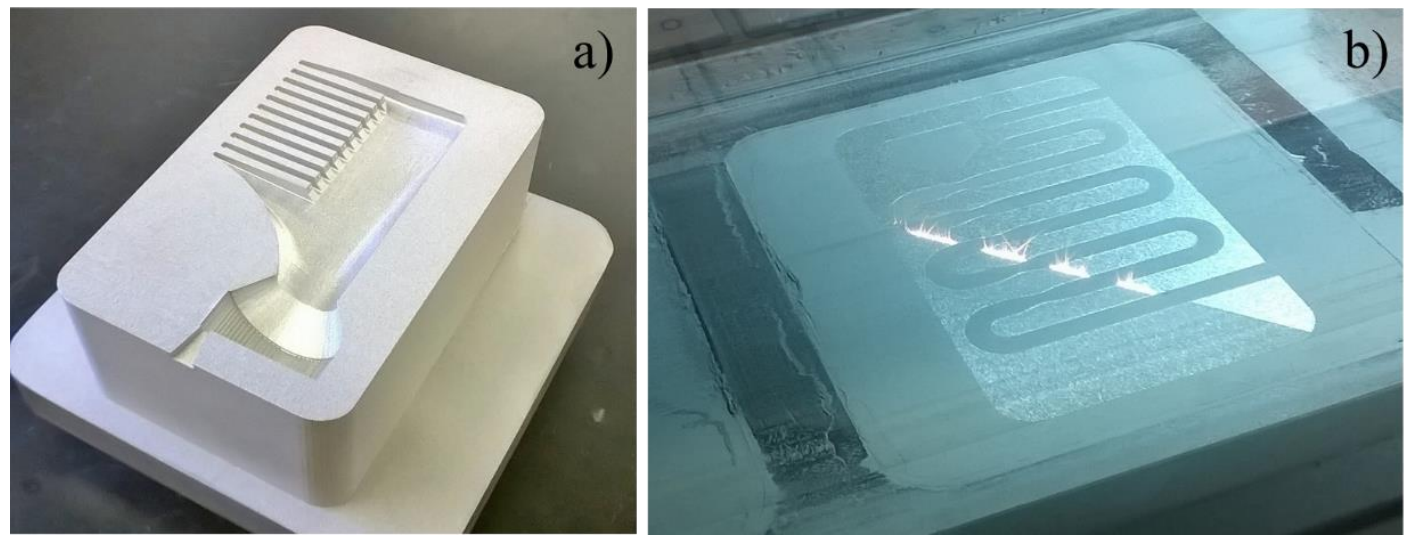

Figure 5. (a) Injection mold with conformal cooling channel of AISI 420 stainless steel fabricated by L-PBF. (b) Printing of cooling channel on the build chamber with a focused laser beam at a scan speed of $600 \mathrm{~mm} / \mathrm{s}$.

As observed in Table IV that by adding conformal cooling channels around 2 seconds per part in cycle time can be saved, which can result in 40,000 more parts produced with mold using conformal cooling channels than with mold with any cooling channels by taking 100,000 parts/day as a basis. With the above analysis, the mold with conformal cooling channel was L-PBF printed with the parameter $50 \mathrm{~W}, 800 \mathrm{~mm} / \mathrm{s}, 30 \mu \mathrm{m}$ trace width. The print time was about 54 hours where as a typical traditional manufacturing of a similar mold will take more than a week to get fine features. The dimensional accuracy was within one tenth of a millimeter in each $\mathrm{x}, \mathrm{y}$ and $\mathrm{z}$ direction for the L-PBF printed mold tool. Fig. 5a shows the L-PBF printed mold tool cavity and Fig. 5b shows the in-process printing layout of the conformal cooling channels. After the mold tool was L-PBF printed highpressured air was used to clear trapped metal powder within the cooling channel lines. Future testing studies using the L-PBF printed mold tool will be performed at our industry partners Amaray Plastics molding facility

\section{L-PBF 3D printed of Surgical tools}

Graspers for laparoscopic instrument were design and simulated with three different teeth pattern. The primary function of them was to grip tissue, vessel and fat during the 
laparoscopic surgery. Surgical graspers with three different teeth patterns- lofted, cubic and hemispherical, were designed for laparoscopic instruments (Fig. 6a) and the assembly CAD design is shown in Fig. 6b. The length and width of the grasper was $26.23 \mathrm{~mm}$ and 4.38 $\mathrm{mm}$ respectively. The teeth were in microscopic size varied from $150 \mu \mathrm{m}$ to $300 \mu \mathrm{m}$. The smallest one was the cubic and this grasper contains 400 teeth in each side. The grasper was designed to facilitate multi planer gripping to reduce the stress on the tissue. It also had chamfered grip yielding which meant after a certain force, no force would be applied.

A simulation study was undertaken to observe the stress distribution and strain among the teeth by applying static force and is shown in Fig 7. In the simulated condition the cubic pattern produced most evenly distributed force.

(a)

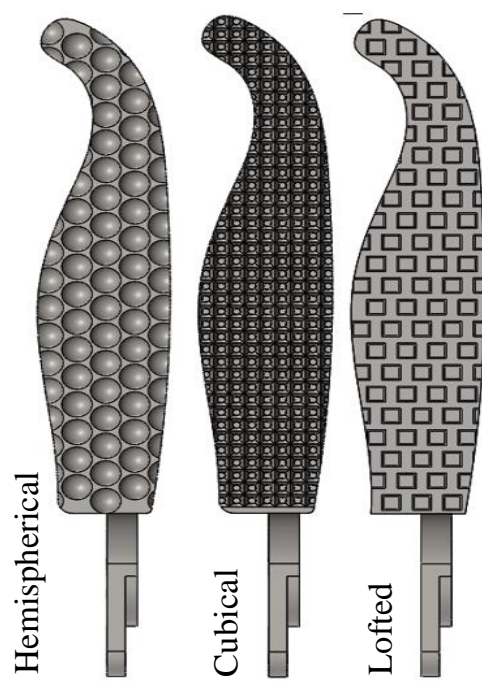

(b)

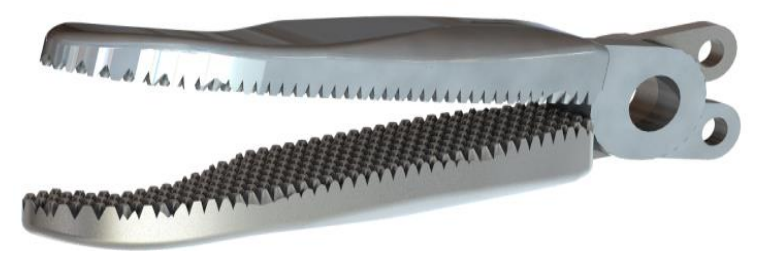

(c)

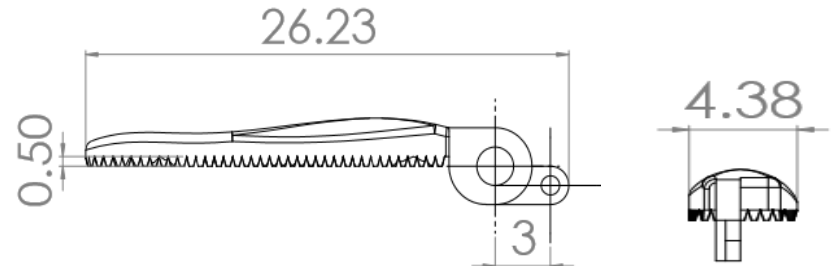

Figure 6. CAD model of the surgical tools: (a) Three different teeth patterns of the grasper; (b) assembly of the grasper; (c) dimension of a single part. 
a)
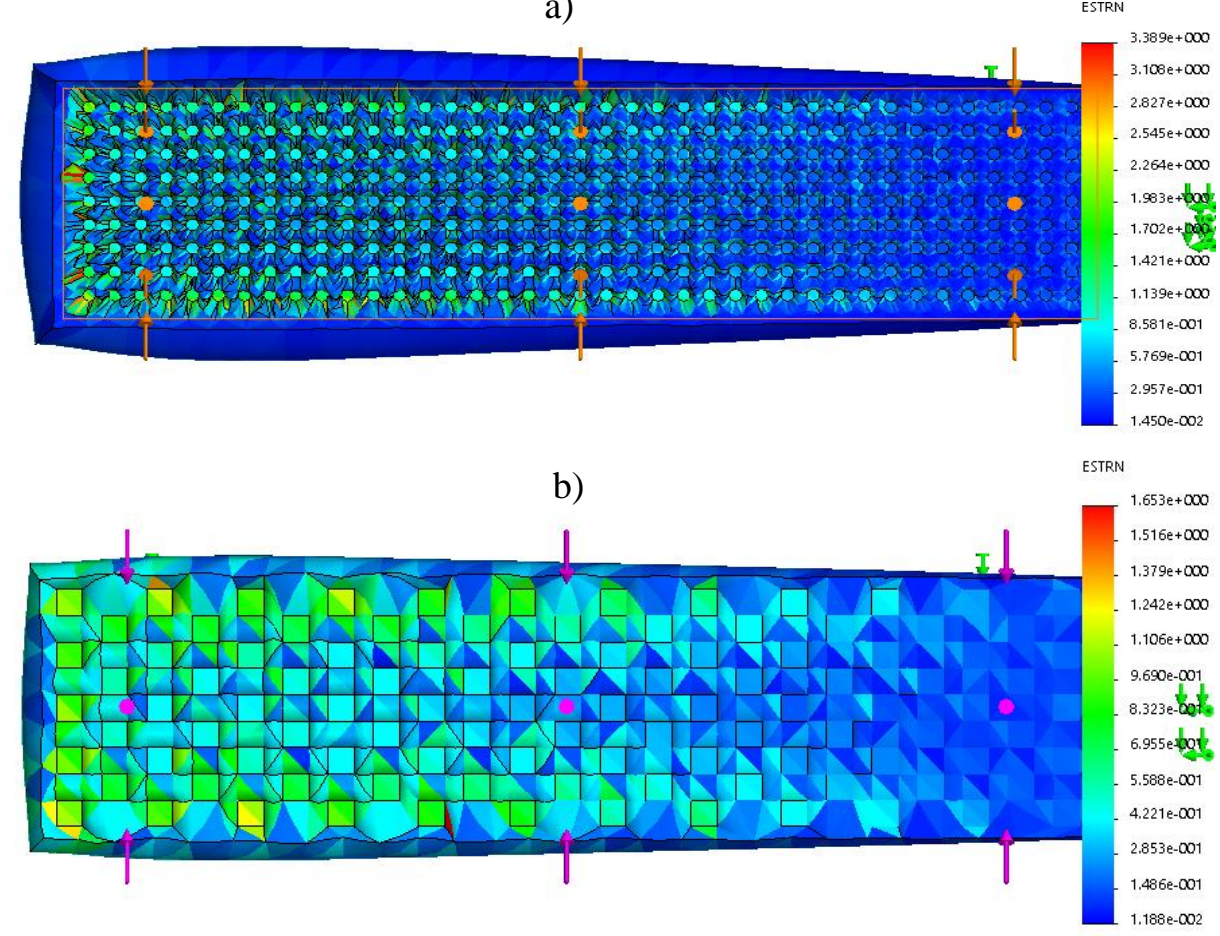

Figure 7. Stress and stain distribution on the teeth of (a) cubical pattern and (b) lofted pattern of surgical graspers by Solidworks simulation.

The surgical tools were printed using the same processing condition that was used to print the mold (Fig. 8). The density of all the tools were more around 90\%. The tolerance of the tools was within a tenth of a millimeter. Herein, the supports were built using the slicing software Autofab which were removed with low speed cutting machine. Under the electron microscopy the teeth of the tools were observed. It was evident that the microscopic teeth were printed in proper shape and size. The teeth of each sides mated each other without slippage. There was no defect or damage observed on the surface. The spacing between the teeth was visible in microscopy. However, there were some partially melted powder on the periphery which should be removed by fine or ultrasonic polishing. 

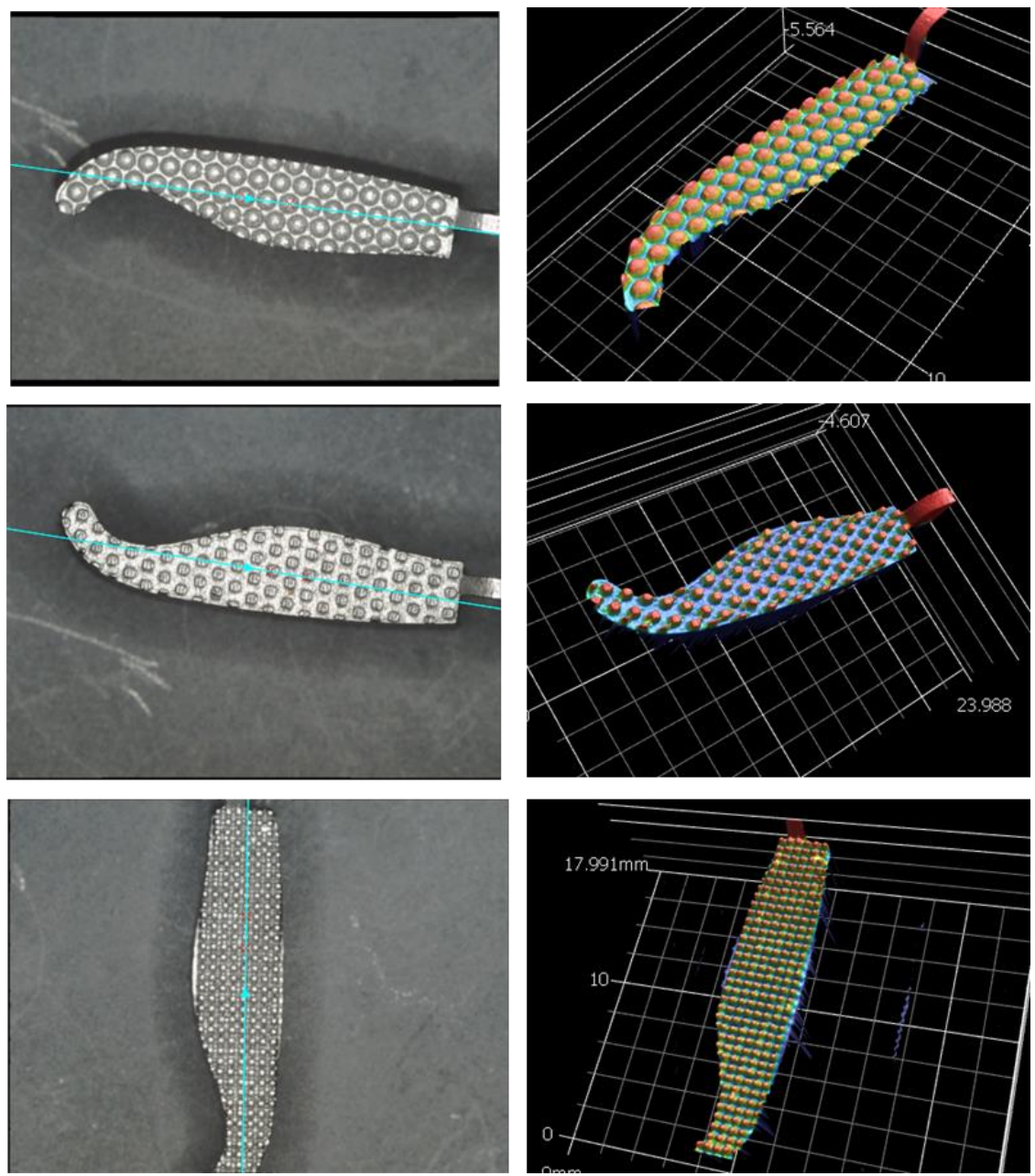

Figure 8. Customized surgical graspers for laparoscopic instrument fabricated by L-PBF using AISI 420 stainless steel.

\section{CONCLUSIONS}

L-PBF brings the opportunity to fabricate complex parts with a shorter lead time to save cost and enhance productivity. The main goal of this study was to develop the optimum processing condition for L-PBF of 420 stainless and use the parameters to fabricate mold with internal cooling channel and surgical graspers with microscopic teeth to demonstrate the potential of $3 \mathrm{D}$ printing in the industry. The process parameters of $50 \mathrm{~W}$ laser power and $800 \mathrm{~mm} / \mathrm{s}$ scan speed showed that $90 \%+$ of density can be achieved with one tenth of a millimeter dimensional tolerance in printed parts and was used to fabricate injection molding tool and surgical tools. CAE software platforms such as Moldex3D and 
SolidWorks were used to conduct design simulations and optimize part files for L-PBF printing. Injection molding simulation with Moldex3D and use of conformal cooling channels inside the designed mold geometry indicates a reduction in cycle time by $15 \%$ compared to mold with no cooling channels. Furthermore, simulation study on surgical grasper varying teeth pattern was performed to reduce stress distribution in the designed geometry. The L-PBF printing of mold with cooling channel and surgical tool shows successful implementation developed process parameters in this study to make industrial products.

\section{ACKNOWLEDGEMENT: UOFL 3D PRINTING BUSINESS INCUBATOR}

The authors would like to thank Walmart Foundation for supporting this project. The mold design and simulation of mold flow behavior were conducted by the team of Riley Cusick, Jake Groneck, Andrew Wilson, Shrirang Patel, David Campbell, Aaron Hartpence and Nathan Westurn as a part of Capstone Design: UofL 3D Printing Business Incubator
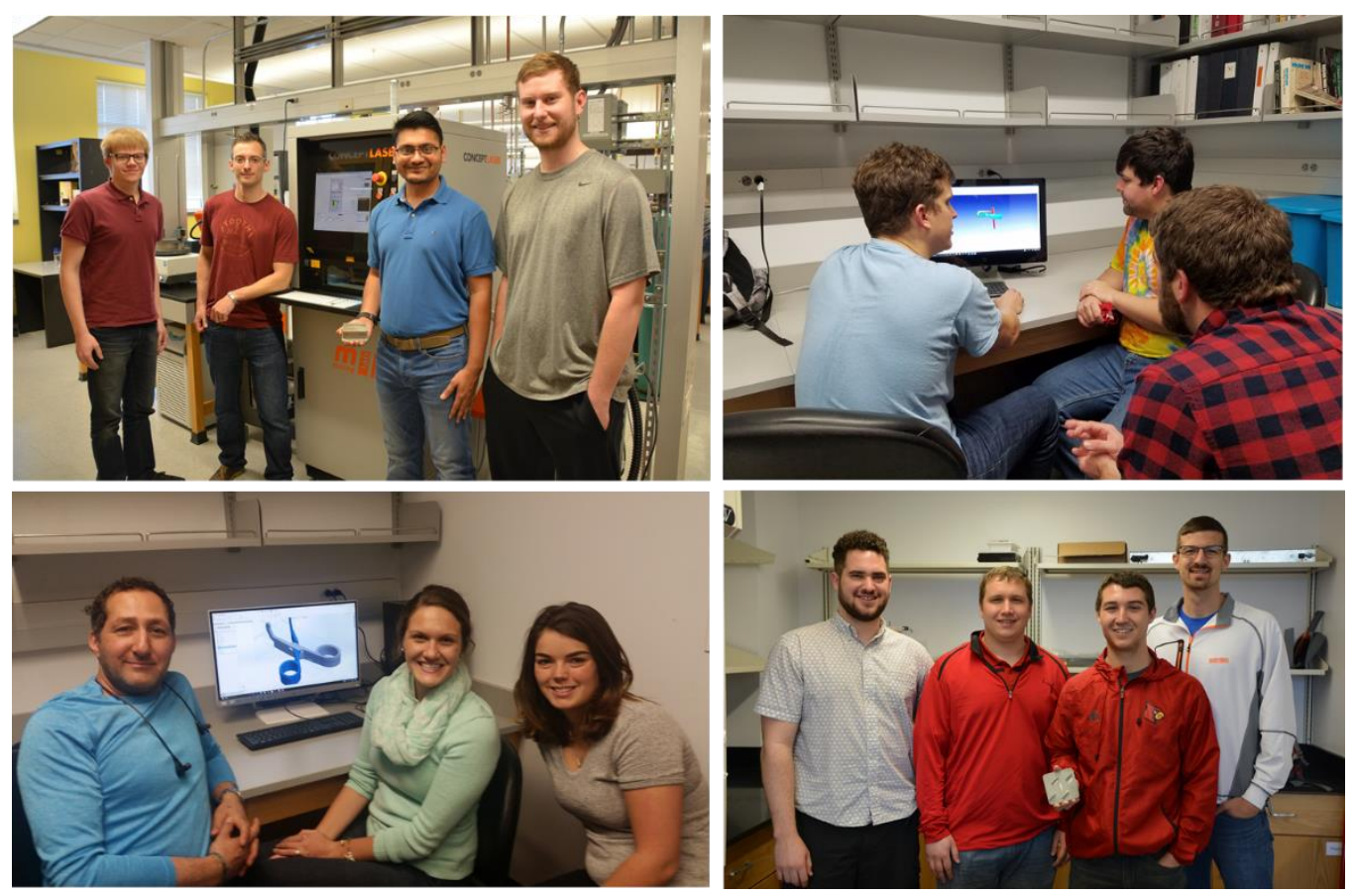
course. The surgical tool team included Alex Conradi, Jacob Groeschen, Josh Graff, Ryan Stoller, Abbas Abbas, Daniale Thomas and Olivia Naber.

\section{REFERENCES}

1. Petrovic, Vojislav, Juan Vicente Haro Gonzalez, Olga Jorda Ferrando, Javier Delgado Gordillo, Jose Ramon Blasco Puchades, and Luis Portoles Grinan. "Additive layered manufacturing: sectors of industrial application shown through case studies." International Journal of Production Research 49, no. 4 (2011): 1061-1079.

2. Mellor, Stephen, Liang Hao, and David Zhang. "Additive manufacturing: A framework for implementation." International Journal of Production Economics 149 (2014): 194201.

3. King, W. E., A. T. Anderson, R. M. Ferencz, N. E. Hodge, C. Kamath, S. A. Khairallah, and A. M. Rubenchik. "Laser powder bed fusion additive manufacturing of metals; physics, computational, and materials challenges." Applied Physics Reviews 2, no. 4 (2015): 041304.

4. Xu, Xiaorong, Emanuel Sachs, and Samuel Allen. "The design of conformal cooling channels in injection molding tooling." Polymer Engineering \& Science 41, no. 7 (2001): 1265-1279.

5. http://www.ptonline.com/articles/why-conformal-cooling-makes-ense

6. Bram, Martin, Cornelia Stiller, Hans Peter Buchkremer, Detlev Stöver, and Hartmut Baur. "High- Porosity Titanium, Stainless Steel, and Superalloy Parts." Advanced Engineering Materials 2, no. 4 (2000): 196-199.

7. Makino, T., Shukla, P. J., Samuels, J. D., Rubino, F., \& Milsom, J. W. (2012). Identifying specific surgical tools and methods for laparoscopic colorectal operations in obese patients. Journal of Gastrointestinal Surgery, 16(12), 2304-2311.

8. Kondor, S., Grant, C. G., Liacouras, P., Schmid, M. J. R., Parsons, L. M., Rastogi, V. K., ... \& Macedonia, C. (2013). On demand additive manufacturing of a basic surgical kit. Journal of Medical Devices, 7(3), 030916.

9. http://www.fda.gov/MedicalDevices/DeviceRegulationandGuidance/PostmarketRequ irements/ReportingAdverseEvents/EventProblemCodes/ucm134761.htm 
10. Isfahany, A. Nasery, H. Saghafian, and Gh Borhani. "The effect of heat treatment on mechanical properties and corrosion behavior of 420 martensitic stainless steel." Journal of Alloys and Compounds 509, no. 9 (2011): 3931-3936.

11. Rosato, Dominick V., and Marlene G. Rosato. Injection molding handbook. Springer Science \& Business Media, 2012. 
APPENDIX J

\title{
EXLORING SNAKE-SKIN-INSPIRED TEXTURE DESIGNS FOR 3-D PRINTING
}

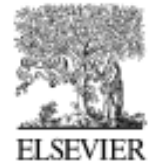

\author{
Available online at www.sciencedirect.com \\ ScienceDirect \\ Procedia Manufacturing 00 (2019) 000-000
}

Procedia

MANUFACTURING

www.elsevier.com//ocate/procedia

$47^{\text {th }}$ SME North American Manufacturing Research Conference, NAMRC 47, Pennsylvania, USA

\section{Exploring Snake-Skin-Inspired Texture Designs for 3D Printing}

\author{
Catherine Tiner ${ }^{a}$, Salil Bapat ${ }^{b}$, Subrata Deb Nath ${ }^{\mathrm{c}}$, Sundar V. Atre ${ }^{\mathrm{c}}$, and Ajay Malshe $\mathrm{e}^{\mathrm{a}, \mathrm{b} *}$ \\ Microelectronicsa Phatanics Gmadnate Prognum, University of Arkansas, Fayetteville, AR 7270I, USA \\ 'Depariment of Mechanical Engineering, University of Arkansas, Fayetteville, AR 72701, USA \\ "Materials Innowation Guild, University of Lowisville, Louisville, KY 40208, USA \\ * Corresponding author E-mail address: apm2 2 a mank ech
}

\begin{abstract}
This research presents an exploration of the application of a 3D printing process to create snake-skin-inspired textures. The design attributes of snakeskin seales were studied via the shed skin of species Python Regius. Snakeskin design, especially on ventricular side, consists of hexagonal scale patterns with denticulations and fibrils as sub-features of the design. The snake-skin-inspired design was then explored for printing using the laser-powder bed fusion (L-PBF) manufacturing technique on 420 stainless steel. It was discovered that the surface roughness generated by the laser scanning path during the 3D printing technique closely mimics the hierarchical micro-texture of snakeskin scales. The texture of the 3D printed part surface was measured using the JIS B 06061-2001 standard by a laser scanning microscope and this manuscript presents a comparison of the 3D printed texture with the shed snake skin surface.
\end{abstract}

O 2019 The Authors. Published by Elsevier B.V.

This is an open access article under the CC BY-NC-ND license (http://creativecommons.org/licenses/by-nc-nd/3.00)

Peer-review under responsibility of the Scientific Committee of NAMRI/SME.

Keywords:Blio-inspired Design; 3D Printing; Surface Texture

\section{Introduction}

Robust designs are crucial in the field of mechanical engineering and manufacturing for improving the efficiency, operation costs, and reliability of products. These designs include form (overall shape) and features (such as surface and subsurface architectures) as key aspects that are responsible for the desired functional property. Nature, in the form of plants and animals, offers a vast database of robust designs (both forms and features). These designs have survived the harshest environmental conditions and thrived over a long period of time. Over last few decades, scientists and engineers have drawn inspiration from Nature for developing innovative engineering solutions and products [1,2]. Animals in different habitats have evolved in different ways to increase their ease of movement in various environments including land (managing friction while walking), water (reducing hydrodynamic drag while swimming) and air (reducing aerodynamic drag while flying). Reptiles such as snakes are of particular interest for studying efficient locomotion, as they navigate effectively in harsh surroundings without legs, arms, ears or other appendages. The efficient locomotion of snakes across multiple terrains is attributed to the unique hierarchical arrangement of features on their scales [3-5]. The focus of this paper is on understanding the design attributes of snake skin and the development and fabrication of snake-skininspired texture designs. The replication of snake skin design patterns was explored by using a near net-shape process of 3D printing due to its versatility in producing parts with complex designs in a layer-by-layer method. In 3D printing, the part designs can typically be customized from a CAD drawing, making the process an attractive option to replicate existing patterns and designs morphologies. This approach and the discussed findings can potentially be useful for several industrial applications for effective friction control and friction management.

The following sections discuss the locomotion and design attributes of snake skin, the experimental approach used to fabricate the snake -skin- inspired 3D printed structures, and the characterization of the printed structures. 


\section{Design analysis of snake skin}

\section{I Functionalities and design attributes of snake skin}

A typical snake has an elongated body and tail, a large gaping mouth, and no appendages. In most snakes, the body is sharper at the head and the tail ends and rounder at the middle portion of the snake. Snake skin is separated into two main central layers, the dermis and epidermis. The epidermis is the inner generational layer and consists of the organs and lipids of the snake [6]. The dermis is the outer generational layer and contains the scales that snakes are known for. These scales are arranged in rows along the body in a layered fashion. Snakes have two different types of scales on their bodies. Along the top and side of their bodies, they have smooth dorsal or keeled dorsal scales while the bottom side, which is in contact with the ground, has ventral scales as shown in Figure 1. The dorsal scales of snakes create the visual appearance needed for their survival and/or hunting for prey. The dorsal scales in some snakes contain apical pits. These pits contain micro-fibrils, or small little hooks, that allow the snakes to grip onto trees or other objects. The bottom scales or ventral scales on the other hand are shaped in the form of long elongated hexagons (Figure 1). Ventral scales are primarily responsible for manipulating locomotive abilities and are of primary interest in this research [6-8].

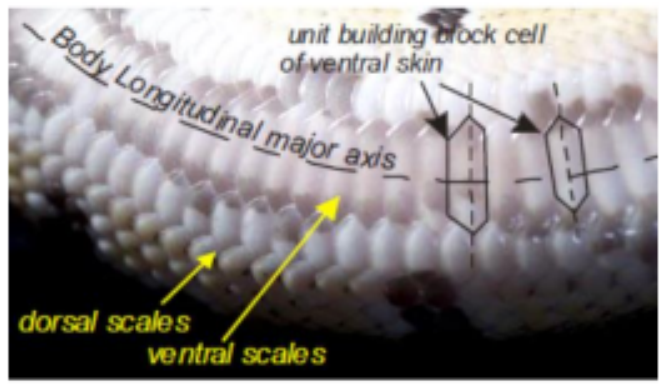

Figure 1: Photograph of a python snake indicating the ventral and dorsal scales [8]

\subsection{Modes of locomotion}

Snakes follow different modes of locomotion that are classified by the type of movement and the surrounding environment. During locomotion, as the ventral scales of the snake are always in contact with a surface, the way a snake moves plays an important role in the generation of frictional forces. Thus, different modes of locomotion in snakes have important consequences on the design and tribological properties of snake skin. Snakes have four main types of terrestrial movement as depicted in Figure 2. The types are categorized as serpentine, concertina, crotaline (also known as sidewinding), and rectilinear and are briefly discussed below.

In serpentine locomotion, the snake moves in curves where the body follows the previous position of the head. This type of motion is typically observed when a snake is moving through tall grasses and irregular surfaces. During this locomotion, the whole body of the snake moves simultaneously, facilitating its movement over most surfaces. Concertina locomotion typically occurs when a snake is in a narrow channel. Concertina movement uses a gripping and pushing motion. In this type of locomotion, the snake relies on its muscles to physically lift itself up and push itself forward while dropping down. Crotaline locomotion is a very irregular form of serpentine locomotion. This type of locomotion typically occurs when the snake travels over a smooth or uniform surface. Since the snake is unable to secure a strong grip to the smooth surface, the snake moves in a random curved pattern $[6,7,9-12]$.

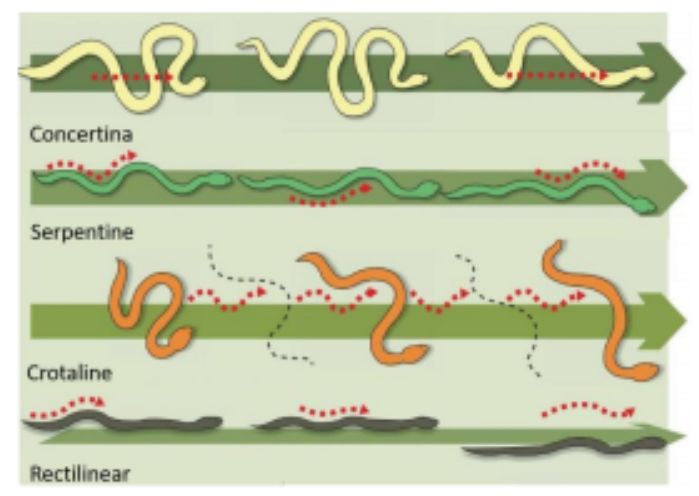

Figure 2: Illustration of different types of snake locomotion [12].

Rectilinear locomotion is most commonly associated with larger snakes such as boas or pythons. In this movement, the snake creates a "walking" pattern. Snakes that use rectilinear locomotion rely on two opposing muscles in their ribs and skin to propel themselves forwards. The two muscles cause a lifting and placing movement to occur which propels the snake in the forward direction. This results in the ventral surface moving in discrete sections or steps as the rest of the body moves forward at a constant speed. During this type of movement, the snake's body is always in contact with the ground. This type of movement is generally slow but allows the snake to move silently and occurs when the snake chooses to climb trees or other surfaces $[7,11,12]$.

The locomotion of a snake depends on a few factors. Apart from the active muscles responsible for the physical movement and propelling motion, the surface structure and frictional attributes of the snake scales also play a crucial role. The snake scales and their morphologies have evolved to adapt to their changing environment. Each scale on a snake is shaped to facilitate its movement on variety of surfaces. Snakes can be found in many terrains and all have adapted to use a specific movement needed to survive. One of the important functional attributes of snake skin is the ability to manage friction during locomotion through the dynamic interaction between the ventral scale texture and the mating surface of the terrain. Since the ventral scales of a snake are in constant contact with surfaces and are used in manipulation of locomotion, it was decided to study and recreate the ventral 
scales rather than the smooth scales found over the rest of the body.

The movement of snakes is characterized by the anisotropic frictional properties of snake skin. Due to the directional texture observed on the scales of a snake, the friction is lower in the forward direction and higher in the backward direction, resisting backward movement [13-15]. Figure 3 shows the anisotropic micro-texture observed on a snake scale. As seen from the figure, each individual scale consists of periodically arranged directional micro-fibrils and denticulations [13]. The shape, pattern, distribution, and positioning of the fibrils on the scales is important to manipulate the contact points on the counter-surface during locomotion. Each species of snake has a unique profile in which these patterns and their arrangement are changed. The study of these patterns of snake skin is particularly relevant for advancing the designs of textured surfaces for tribological applications $[6,8,15-17]$

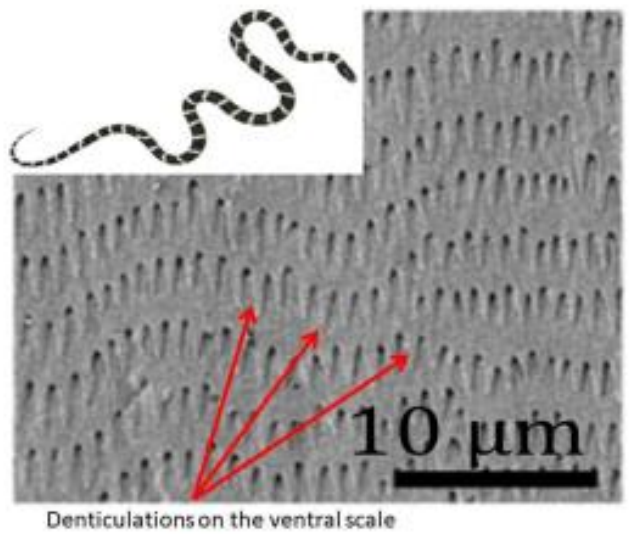

Figure 3: Detailed SEM image of microstexture on snake skin [13] .

\subsection{Snake skin measurements and proposed design}

For this study, the snake species Python Regius was chosen. These pythons are native to West and Central Africa. Living in these areas the snakes' scales are constantly rubbed by different landscapes including sandy plains and rolling hills. Therefore, due to the harsh environments the skin would be subjected to severe wear and is ideal for studying the texture design and frictional properties discussed in this research. Ventral scales from the middle body of the snake were chosen for the design study rather than the ventral scales from the head or tail region. This choice was made because the larger size of these scales and due to fact that the middle body of the snake carries most of the load during locomotion.

Figure 4 shows a photograph of the shed skin of the species Python Regius that was commercially purchased for the purpose of experiments. As highlighted in the figure, hexagonal shaped building blocks were observed. To accurately replicate the skin of the Python Regius, dimensions (as specified in Figure 4) of 5 center ventral scales and 8 side ventral scales of the shed snake skin specimen were measured. The average values of the measurements are listed in Table 1. In addition to the size of the hexagonal scales, the separation between the two adjoining hexagonal scales was measured to be $0.47 \mathrm{~mm}$.
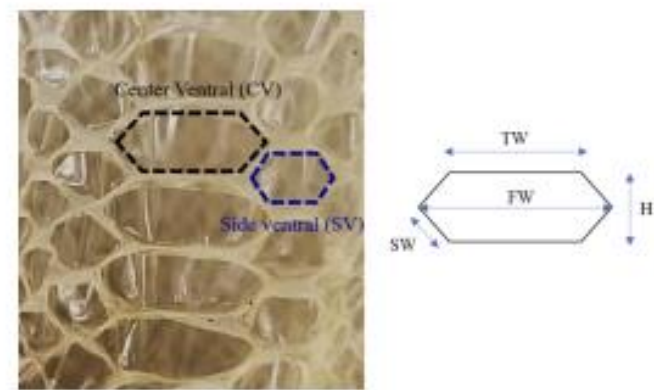

Figure 4: Photograph of shed skin of Python Reguis showing the bexagonal shape as design feature of ventral scales and different dimensions of interest.

Table I: Dimensions of hexagonal features measured on the shed snake_skin

\begin{tabular}{lll}
\hline & CV & SV \\
\hline H $(\mathrm{mm})$ & $4.2 \pm 0.8$ & $3.1 \pm 0.3$ \\
FW $(\mathrm{mm})$ & $10 \pm 0.1$ & $4.375+-0.7$ \\
SW $(\mathrm{mm})$ & $2.15 \pm 0.23$ & $2 \pm 0.4$ \\
TW $(\mathrm{mm})$ & $7 \pm 0.1$ & $2.2 \pm 0.4$ \\
\hline
\end{tabular}

The ventral scale design was then created using SolidWorks with the above measurements as design parameters; the design was then utilized for 3D printing as described in Section 3.

\section{3D printing of snake skin design}

A laser-powder bed fusion (L-PBF) process was utilized to fabricate the above snake skin texture design; the details are discussed below.

\subsection{Description of the L-PBF process}

In L-PBF, four primary parameters are used to define the applied energy $\left(\mathrm{J} / \mathrm{mm}^{3}\right)$ to powders: layer thickness $(\mu \mathrm{m})$, laser power $(\mathrm{W})$, scan speed $(\mathrm{mm} / \mathrm{s})$ and trace width $(\mu \mathrm{m})$. The minimum resolution in the build direction is $10 \mu \mathrm{m}$ in this process [18]. During the printing process, the laser is scanned in the specified direction and solidification follows the direction of the laser scanning. As a result of this movement of the laser path, it was observed that L-PBF intrinsically produces micro-scale directional textures on the surface of the printed parts as discussed further in Section 4. 
AISI 420 stainless steel was chosen for this experiment as it is a material with high hardness and strength and is a suitable choice for surgical and tooling industries. The details of the work on 420 stainless steel using L-PBF for studying chemical composition, powder attributes and process parameters for mechanical and physical properties can be found in previously published reports [18-20].

\section{$3.2 L-P B F$ process parameters}

The proposed snake-skin-inspired design is shown in Figure 5. The arrangement of hexagons is similar to the arrangement of hexagonal features observed on the shed snake skin with the center ventral and side ventral scales representing a similar pattern. For simplicity, the design consisted of 5 centrally located hexagons (replicating the center ventral scales) and 4 smaller hexagons on each side (replicating the side ventral scales). This geometric arrangement aimed to replicate the directional orientation of the scales found on the snake skin along the central body axis of the snake. Dimensionally, each central hexagon was $10 \mathrm{~mm}$ long (FW) with a height $(\mathrm{H})$ of $4 \mathrm{~mm}$. The side ventral width (SW) of all hexagons was kept at 2 $\mathrm{mm}$. The spacing between two hexagons was kept around $0.47 \mathrm{~mm}$. This matches the membrane size found on the snake skin and allows for the symmetrical arrangement of the hexagonal scales with a consistent spacing between the features that closely match the snake skin.

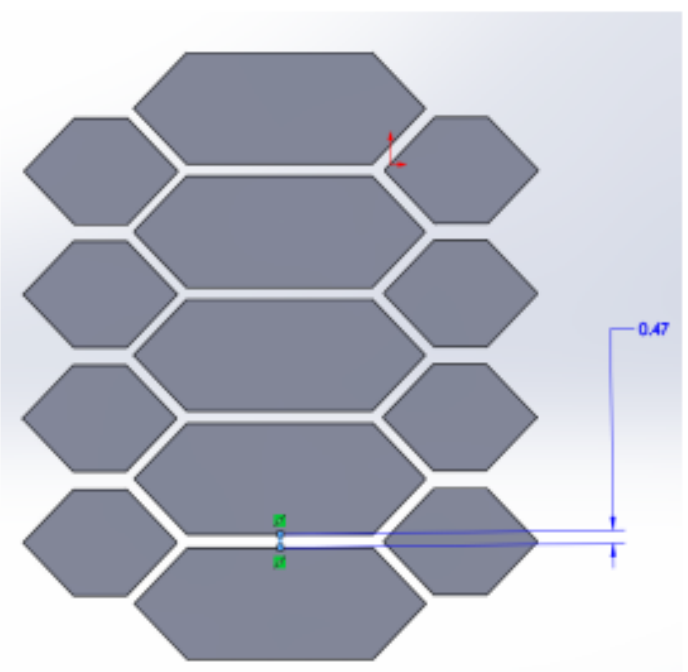

Figure 5: CAD model of a hexagon pattern including dimensions to mimic snake skin.

Overall, the combined dimensions of the pattern were 25 $\mathrm{mm}$ long and $20 \mathrm{~mm}$ wide. The height of the hexagonal features was chosen to be $100 \mu \mathrm{m}$. As shown in Figure 6(a), a total of six patterns were put together to print at a time. A minimum spacing of $10 \mathrm{~mm}$ was kept between two patterns for the easiness of sectioning after printing for further characterization.

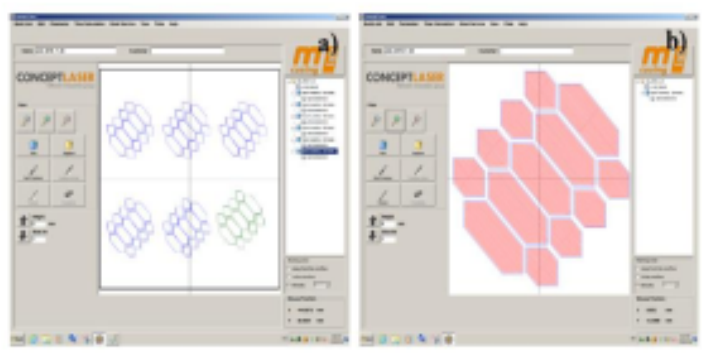

Figure 6: a) Total six hexagons pattems were printed together. The clearance was maintained for the convenience of sectioning for characterization; b) the directionality of the laserescan was parallel to the width of the hexagons

The design was created using a CAD softwareSolidWorks, Dassault Systems. AutoFab software (Materialise) was used to slice the STL file into layers to be used in the L-PBF machine. A line scan pattern of $-45 /+45$ degrees at alternate layers was chosen to fabricate the specimen. The scan direction of the laser was set parallel along the width of the hexagons as shown in Figure 6(b).

Table 2: Powder properties of nitrogeneatomized AISI 420 stainless steel powder

\begin{tabular}{|c|c|c|c|}
\hline Powder & $\begin{array}{l}\text { Particle size } \\
\text { distribution } \\
(\mu \mathrm{m})\end{array}$ & Density $\left(g / \mathrm{cm}^{3}\right)$ & $\begin{array}{l}\text { Notable } \\
\text { chemical } \\
\text { composition } \\
(\%)\end{array}$ \\
\hline $\begin{array}{l}420 \\
\text { stainless } \\
\text { steel }\end{array}$ & $\begin{array}{l}\mathrm{D}_{10}: 17 \\
\mathrm{D}_{96}: 28 \\
\mathrm{D}_{\mathrm{si}}: 47\end{array}$ & $\begin{array}{l}\text { Pyenometer density: } \\
7.68 \pm 0.01 \\
\text { Apparent density: } 4.0 \pm \\
0.2 \\
\text { Tap density: } 4.7 \pm 0.1\end{array}$ & $\begin{array}{l}\text { Cr: } 12.8 \\
C: 0.3 \\
M n: 0.7\end{array}$ \\
\hline
\end{tabular}

\subsection{Materials and manufacturing details}

Nitrogen gas atomized and pre-alloyed 420 stainless steel powder was used to conduct the L-PBF experiment to fabricate the snake-skin-inspired pattern. The powder was manufactured and supplied by Sandvik Osprey Ltd., U.K. The powder attributes are discussed in the Table 2. The AISI 420 stainless steel powder had a median particle size (Dso) of 28 $\mu \mathrm{m}$ and $90 \%$ of the particles ( $\mathrm{D}_{90}$ ) were below $47 \mu \mathrm{m}$. The pycnometer density of the powder was found to be $7.68 \pm$ $0.01 \mathrm{~g} / \mathrm{cm}^{3}$. The powder had an apparent density of $4.0 \pm 0.1$ $\mathrm{g} / \mathrm{oc}$ and tap density of $4.7 \pm 0.1 \mathrm{~g} / \mathrm{cc}$. Besides the very low amount of $\mathrm{Si}, \mathrm{N}$ and $\mathrm{O}$ in the chemical composition, $\mathrm{Cr}, \mathrm{C}$ and $\mathrm{Mn}$ content in the powder were found to be $12.8 \%, 0.3 \%$ and $0.7 \%$, respectively. A Concept Laser Mlab cusing R machine equipped with an $\mathrm{Yb}$-fiber laser was used to $3 \mathrm{D}$-print the above discussed design. The machine had a maximum power of $100 \mathrm{~W}$ and a laser beam diameter of $50 \mu \mathrm{m}$. The largest size that the machine can print is $90 \mathrm{~mm} \times 90 \mathrm{~mm}$. A Yshaped rubber coater blade was used for spreading the powder on the baseplate. In the experiment, a baseplate of 420 
stainless steel was used to avoid any contamination. Argon gas with a setting of 20 percent of maximum ventilation capability was used to create an inert atmosphere during printing to avoid oxidation. The sliced design file from Autofab was loaded in the machine. An energy density of 63 $\mathrm{J} / \mathrm{mm}^{3}$ (layer thickness of $20 \mu \mathrm{m}$, laser power of $90 \mathrm{~W}$, scan speed of $600 \mathrm{~mm} / \mathrm{s}$ and trace width of $120 \mu \mathrm{m}$ ) was used as the process parameter. The optimization of the process parameter has been discussed previously [21]. The density of L-PBF specimens printed at an energy density of $63 \mathrm{~J} / \mathrm{mm}^{3}$ was reported to be $7.67 \pm 0.03 \mathrm{~g} / \mathrm{cm}^{3}$. Figure 7 shows the printed hexagon patterns on a 420 stainless steel build plate. The build was removed from the machine and washed with ethyl alcohol.

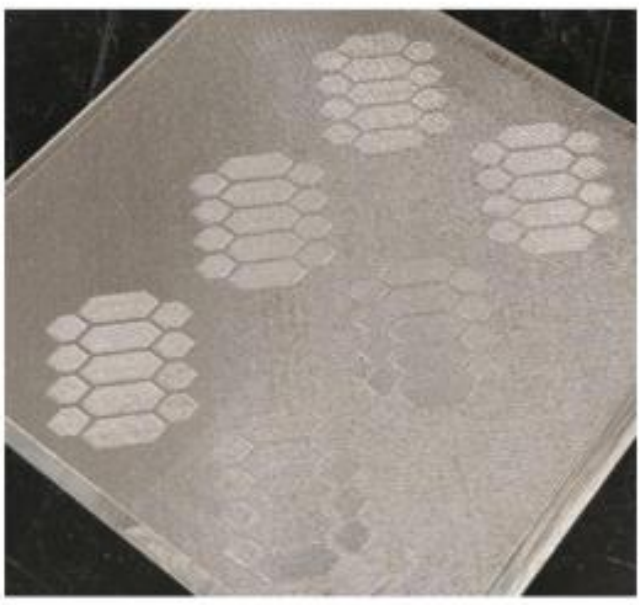

Figure 7: Top view of the 3D printed snake-skipeinspired design on 420 stainless steel.

\section{Measurement results}

Figure 8 shows an optical micrograph of the printed pattern. It can be observed from Figure 8 that there are clear u-shaped denticulation markings on the surface much like those observed on the snake skin sample as shown in Figure 3.

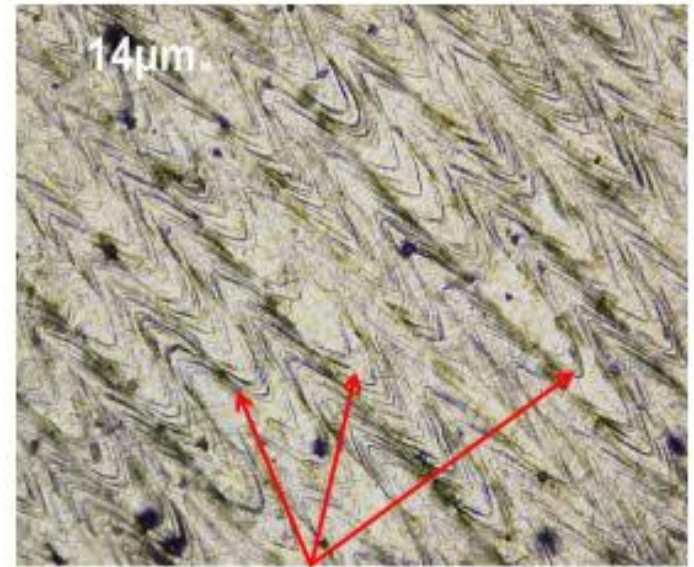

As printed micro-texture on the 3D printed sample

Figure 8: Detailed profilometer image showing the microtexture on 3D printed stainlessesteel sample.

The two most important criteria to evaluate the feasibility of 3D printing to manufacture bio-inspired textured design are: 1) quality of frictional performance on the printed samples in comparison with the snake skin; and 2) the comparison of surface roughness parameters. In this paper, the focus is on the measurement of surface texture parameters on the printed samples in comparison to texture of snake skin. Experiments to test the frictional response of the printed surfaces are currently ongoing.

The texture on the snake skin and the 3D printed sample

Table 3: Comparison of selected profile roughness values measured on snakeskin and 3D printed sted sample

\begin{tabular}{llll}
\hline & $\mathrm{R}_{2}(\mu \mathrm{m})$ & $\mathrm{R}_{\mathrm{mam}}(\mu \mathrm{m})$ & $\mathrm{R}_{4}(\mu \mathrm{m})$ \\
\hline Snakeskin & $7.32 \pm 2.7$ & $87.6 \pm 53.3$ & $8.82 \pm 3.1$ \\
Steel sample & $3.8 \pm 0.78$ & $142.22 \pm 64.7$ & $4.75 \pm 0.7$ \\
\hline
\end{tabular}

were measured using a Keyence VK-250 laser scanning microscope. The sample surfaces were measured at $10 \mathrm{X}$ magnification and the measurement data was analyzed using the Keyence multi-file analyzer software. For better accuracy in the profile measurements, line scan analysis was performed at 5 locations perpendicular to the texture orientation as shown in Figure 9; the average values are reported. Profile roughness comparisons were made according to the ASTM surface roughness standards (JIS B 06061-2001). These measurements are summarized in Table 3. 


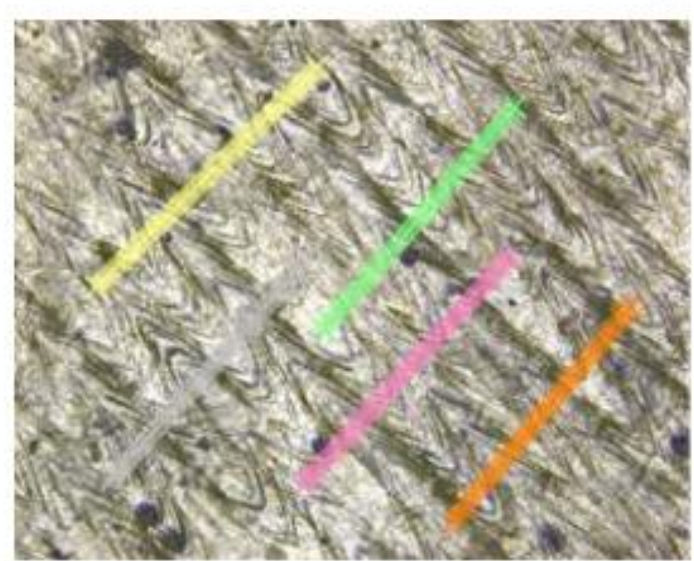

Figure 9: Ulustration of profile roughness measurement scans performed perpendicular to the texture dinection

Here, $R_{a}$ represents the arithmetical mean height, $R_{s m}$ the mean width of the profile elements, and $R_{4}$ the root mean square height. The $R_{k}$ and $R_{4}$ parameters are commonly used for analyzing surface finish and comparing surface roughness values as they characterize the overall deviation in height with respect to the mean height. $\mathbf{R}_{\mathrm{sm}}$ values indicate the mean distance between the repeating features and thus are useful to characterize the periodicity of features along a given direction. More detailed information (geometric interpretation and mathematical representation) about these parameters can be found elsewhere $[22,23]$. The surface roughness $\left(R_{a}\right.$ and $R_{4}$ ) values on the $3 D$ printed sample are slightly larger but comparable to the roughness measured on the snake skin. Additionally, the standard deviation in roughness values for the steel sample is low in comparison to the snake skin, indicating the repeatability and control allowed with the 3D printing process. Similarly, the mean width of the profile elements is larger for the steel sample yet remains comparable to the shed snake skin. It should be noted that the periodicity of the profile elements is closely related to the pitch between the two consecutive laser scan lines, indicating it was controlled by the choice of processing parameters.

In addition to the profile measurements, areal surface texture parameters were also calculated on the measured steel sample and the snake skin surfaces according to the ISO 25178 standard. A detailed description of the areal texture parameters can be found elsewhere in published texts [24]. Since the areal texture parameters are calculated on an overall specified area rather than a linear profile, they are more suitable for correlating the functional properties of a textured surface [25]. Figure 10 shows a comparison of selected areal texture parameters calculated on the snake skin and the steel surface. As seen, areal surface roughness $\left(\mathrm{S}_{4}\right)$ remains comparable on both the surfaces much like the profile roughness values discussed above. Texture aspect ratio $\left(\mathrm{S}_{\mathrm{e}}\right)$ is indicative of the isotropic/anisotropic characteristics of the surface. A perfectly isotropic surface has a $S_{t x}$ value of 1 . Since the $S_{x x}$ is less than 0.5 for both the steel surface and the snake skin, it can be concluded that both of the surfaces have directional texture present, as desired. The last parameter, $\mathrm{S}_{\mathrm{ph}}$ calculates the density of peaks per unit area. This parameter also remains comparable for both the tested surfaces. Since the peaks can be viewed as contacting points with the countersurface, $\mathrm{S}_{\mathrm{pd}}$ values are important for characterizing the tribological (locomotive) properties of the surface. The comparable areal surface roughness values measured on the printed steel surface thus confirm the feasibility of the 3D printing method to fabricate snake-skin-inspired texture designs.

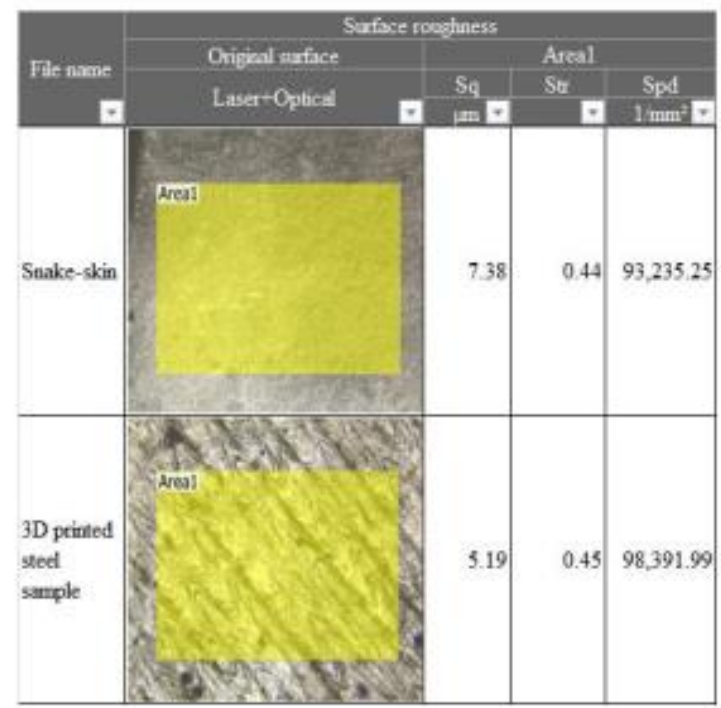

Figure 10: Areal texture comparison between snake skin and the 3D printed steel surface. The shaded porticn indicated the area on which the areal texture parameters are calculated.

It should also be noted that no post-processing was performed on the 3D printed part before measurement. The snake-skin-like micro-texture (as indicated by arrows in Figure 3 and Figure 8) with comparable surface roughness values was generated on the surface by virtue of the laser scanning movement during the printing process. This is noteworthy and distinguishing, as the majority of the reported research on metallic $3 \mathrm{D}$ printing requires reducing the surface roughness on the printed parts.

\section{Conclusions and future work}

The micro-texture design of the snake skin was studied and analyzed in correlation with the friction enabled locomotion properties of the snake skin. From the analysis of the shed snake skin of Python Regius, a simplified snake-skininspired texture pattern was created and replicated using LPBF on 420 stainless steel. The 3D printed sample shows clear denticulation areas similar to those found on snake skin. The roughness results between the steel sample and the snake skin are also comparable. Thus, the 3D printing approach to fabricate snake-skin-inspired surfaces was shown to be effective for the fabrication of micro-textured surface. 
The frictional anisotropic behavior of 3D printed stainless steel surfaces is currently under investigation. The expected outcome of these tests is proving that the denticulation pattern on a steel sample will maintain anisotropic frictional parameters, justifying the 3D printed manufacturing approach to fabricate bioinspired texture designs. Further optimization of the process control variables (to control the above discussed surface roughness parameters) and/or post-printing texturing options will be evaluated in the future.

\section{Acknowledgements:}

One of the authors (CT) acknowledges funding support by the National Science Foundation Grant and the Arkansas EPSCoR Program, ASSET III. Two authors (SB and APM) acknowledge the support from the $21^{\text {st }}$ Century Endowed Chair Professorship fund.

\section{References}

[1] Malshe, A. P., Bapat, S, Rajurkar, K. P., and Haitjema, H, 2018, "Bio-Inspired Textures for Functional Applications," CIRP Ann., 67(2), pp. 627-650.

[2] Malshe, A., Rajurkar, K., Samant, A., Hansen, H. N., Bapat, S., and Jiang, W., 2013, "Bio-Inspired Functional Surfaces for Advanced Applications," CIRP Ann. - Manuf. Technol., 62(2), pp. 607-628.

[3] Abdel*Aal, H. A., 2016, Tunctional Surfaces for Tribological Applications: Inspiration and Design," Surf. Topogr. Metrol. Prop., 4(4), p. 043001 .

[4] Abdel-Aal, H. a, and El Mansori, M., 2013, "Tribological Analysis of the Ventral Scale Structure in a Python Regius in Relation to Laser Textured Surfaces," Surf. Topogr. Metrol. Prop., 1, p. 015001

[5] Baum, M. J., Kovalev, A. E., Michels, J., and Gorb, S. N., 2014, "Anisotropic Friction of the Ventral Scales in the Snake Lampropeltis Getula Californiae," Tribol. Lett., 54(2), pp. 139-150.

[6] Abdel-Aal, H. A., "The Structure of Ventral Scale Textures in Snakes in Comparison to Texturing of Deterministic Tribological Surfaces," pp. 268-315.

[7] Peters, J. A., and Wallach, V., 2018, "Snake," Encycl. Br.

[8] Abdel-Aal, H. A., El Mansori, M., and Merghani, S., 2010, "MultiScale Investigation of Surface Topography of Ball Python (Python Regius) Shed Skin in Comparison to Human Skin," Tribol. Lett., 37(3), pp. 517-527.

[9] Giray, B. Y. J., 1946, "The Mechanism of Locomotion in Snakes," 23(2).

[10] Hu, D. L, Nirody, J., Scott, T, and Shelley, M. J., 2009, "The Mechanics of Slithering Locomotion," Proc. Natl. Acad. Sci., 106(25), pp. 10081-10085.

[11] "Snake Locomotion" [Online]. Available: https://www.ucs.louisiana.edu/-brm2286/locomotn.htm. [Accessed: 01-Nov=2018].

[12] Micu, A., "Research of Snakes' Straight-Line Movement Could Power the Rescue Bots of the Future- [Online]. Available: https://www.zmescience.com/science/snake-movementestraight* linel. [Accessed: 15:Nov-2018]

[13] Baum, M. J., Hecpe, L, Fadeeva, E., and Gorb, S. N_, 2014, "Dry Friction of Microstructured Polymer Surfaces Inspired by Snake Skin," Beilstein J. Nanotechnol., 5(1), pp. 1091-1103.

[14] Filippov, A. E., and Gorb, S. N., 2016, "Modelling of the Frictional Behaviour of the Snake Skin Covered by Anisotropic Surface Nanostructures," Sci. Rep., 6(August 2015), pp. 1-6.

[15] Hazel, J., Stone, M., Grace, M. ., and Tsukruk, V. ., 1999, "Nanoscale Design of Snake Skin for Reptation Locomotions via Friction Anisotropy," J. Biomech., 32(5), pp. 477-484.

[16] Abdel-Aal, H. A., 2013, "On Surface Structure and Friction Regulation in Reptilian Limbless Locomotion," J. Mech. Behav. Biomed. Mater., 22, pp. 115-135.

[17] Abdel*Aal, H. A., and E Mansori, M., 2014, "Characterization of Load Bearing Metrological Parameters in Reptilian Exuviae in Comparison to Precision•Finished Cylinder Liner Surfaces," Surf. Topogr. Metrol. Prop., 2(4), p. 045002.

[18] Nath, S. D., Irrinki, H., Gupta, G., Kearns, M., and Atre, S. V., 2019, "Effects of Layer Thickness in Laser-Powder Bed Fusion of 420 Stainless Steel," J. Miner. Met. Eamp; Mater. Soc.

[19] Nath, S. D., Rajan, A., Yeung, J., and Atre, S. V., 2018, -AM for the OR: Laser-Powder Bed Fusion Delivers Laparoscopic Instruments," 3D Met. Print. Mag.

[20] Irrinki, H., Dexter, M., Barmore, B., Enneti, R., Pasebani, S., Badwe, S., Stitzel, J., Malhotra, R., and Atre, S. V., 2016, "Effects of Powder Attributes and Laser Powder Bed Fusion (L-PBF) Process Conditions on the Densification and Mechanical Properties of 17-4 PH Stainless Steel," JOM, 68(3), pp. 860-868.

[21] Nath, S. D., Irrinki, H., Gupta, G., Kearns, M., Gulsoy, O., and Atre, S. V., 2018, "Microstructure-Property Relationships of 420 Stainless Steel Fabricated by Laser-Powder Bed Fusion," Powder Technol.

[22] Gadelmawla, E. S., Koura, M. M., Maksoud, T. M. A., Elewa, L. M., and Soliman, H. H., 2002, "Roughness Parameters," J. Mater. Process. Technol., 123(1), pp. 133-145.

[23] "Line Roughness Parameters" [Online]. Available: https://www.keyence.ew/ss/products/microscope/roughness/line/par ameters.jpp. [Accessed: 22-Mar*2018].

[24] Blateyron, F., 2013, "The Areal Field Parameters," Characterisation of Areal Surface Texture, R. Leach, ed., Springer Berlin Heidelberg, pp. 15-43.

[25] Leach, R. K., 2010, "Surface Topography Measurement Instrumentation," Fundamental Principles of Engineering Nanometrology, Elsevier, Oxford; Amsterdam, pp. 115-175. 


\title{
CURRICULUM VITAE
}

\author{
Subrata Deb Nath
}

$\begin{array}{lll}\text { CONTACT } & 1800 \mathrm{~S} 2^{\text {nd }} \text { St., A-40, } & \text { Phone: }+1 \text { (864) 633-9893 } \\ \text { INFORMATION } & \text { Louisville, KY USA 40208 } & \text { Email: subrata.nath@louisville.edu }\end{array}$

RESEARCH Additive Manufacturing: Materials development and characterization for INTEREST laser-powder bed fusion, fused deposition modeling and digital light processing; Process-Property-Microstructure relationships; Process selection, optimization and modelling; Heat treatment and hot isostatic pressing (HIP); Corrosion behavior.

Mechanical and Materials: Materials selection for mechanical design; Mechanical behavior of materials; Fractography and microstructure.

Industrial: Powder manufacturing and attributes; Industrial and surgical tooling; Powder metallurgy; Injection molding; Casting-debindingsintering.

Bioengineering: Biomaterials and tissue engineering; In-vitro and in-vivo characterization; Design and fabrication of bio-inspired design and pattern.

EDUCATION Ph.D. in Mechanical Engineering, December 2018

University of Louisville, Kentucky, USA

Thesis: Process-Property-Microstructure Relationships in Laser- Powder Bed Fusion (L-PBF) of 420 Stainless Steel

Advisor: Prof. Sundar V. Atre

M.Sc. in Medical Science and Biomaterials, March 2013

Soonchunhyang University, Cheonan, South Korea

Thesis: Fabrication and Characterization of PLGA Microspheres Incorporated Hydroxyapatite Scaffolds for Controlled Drug Delivery and Bone Regeneration

Advisor: Prof. Byong Taek Lee

B.Sc. in Mechanical Engineering, May 2009

Bangladesh University of Engineering and Technology, Dhaka, Bangladesh

Thesis: Design and Fabrication of Mechanisms and Control Systems of Robots

Advisor: Prof. Zuhurul Haque 


\section{RESEARCH Process-Property-Microstructure Relationships in Additive EXPERIENCE Manufacturing}

- Developed high strength and corrosion resistant alloy using laserpowder bed fusion and analyzed microstructure.

- Investigated stainless steels, Ti-6Al-4V, tungsten and bronze for laser-powder-bed fusion.

- Characterized effects of chemical composition, particle size distribution and process parameters on microstructure and properties of L-PBF alloys.

- Analyzed corrosion properties of as-printed, HIPed and heat-treated alloys using electrochemical protocols.

- Developed and characterized vibratory sieving method to improve flowability of fine powder to be used in laser-powder bed fusion.

- Contributed in digital image correlation (DIC) study to characterize residual strain and stress in as-printed and heat-treated steels to predict defects and failure.

- Supported development of metal fused filament fabrication of Ti6Al-4V.

\section{Biomimicry and Biomaterials}

- Modeled and fabricated biomimetic structures of snake scale of martensitic stainless steel to characterize tribological properties.

- Mathematically modeled and 3D printed tree-root mimetic structures to study geometry-property relationships for multi-material joining applications.

- Investigated material properties and in-vitro behavior of electrosprayed microspheres for drug delivery applications.

- Developed and evaluated mechanical, in-vitro and in-vivo performances of porous ceramic-polymer scaffolds for bone-tissue engineering.

AWARD

- National Science Foundation Innovation Corps (I-Corps ${ }^{\mathrm{TM}}$ ) Grant 2017

- National Science Foundation-Metal Powder Industry Federation Award 2017-18

- Metal Injection Molding Conference Grant 2017-18

- Six Sigma Green Belt, Institute of Industrial and Systems Engineers 2017

- Outstanding Paper Award, Korean Ceramic Society Conference 2012

- BUET Blazer- an award for participating in ABU Robot competition, India 2008 
JOURNAL PUBLICATION
1. Nath, S.D., Irrinki, H., Gupta, G., Gulsoy, O., Kearns, M., Atre, S.V., 2018, Microstructure-Property Relationships of 420 Stainless Steel Fabricated by Laser-Powder Bed Fusion, Powder Technology.

2. Nath, S.D., Irrinki, H., Gupta, G., Kearns, M., Atre, S.V., 2018, Effects of Layer Thickness on Mechanical, Physical and Corrosion Properties of 420 Stainless Steel Processed by Laser-Powder Bed Fusion, International Journal of Powder Metallurgy. (invited paper)

3. Nath, S.D., Vincent, W-P., L'Espérance, G., Gupta, G., Kearns, M., Atre, S.V., 2018, Roles of Niobium and Molybdenum on Properties and Microstructure of 420 Stainless Steel Processed by LaserPowder Bed Fusion, Journal of Materials Processing Technologies. (under review)

4. Tiner C, Bapat, S., Malshe, A., Nath, S.D., Atre, S.V., Exploring Snake-Skin-Inspired Texture Designs for 3-D Printing, Procedia Manufacturing. (under review)

5. Deshpande, A., Nath, S.D., Atre, S.V., Hsu, K., 2018, Examination of Process-Structure-Property Correlation in Haynes-282 Fabricated Using Selective Laser Melting (SLM), Metallurgical and Materials Transactions A. (under review)

6. Irrinki, H., Nath, S.D., Ahlfors, M., Stitzel, J., Gulsoy, O., Atre, S.V., 2018, Microstructure, Properties and Applications of LaserSintered Metal Powders, American Ceramic Society. (accepted)

7. Ramesh, B., Corinne, W., Nath, S.D., Barlaw, B., Keynton, R., Kate, K.; 3-D Printing of Polymeric Scaffolds with Modified PLAPEG Copolymers for Bioengineering Applications, Journal of Biomaterials Applications. (under review)

8. Atul A.C., D'andrea A., Nath, S.D., Kate, K., Vida, D., Shree, R.S., Don R., Pillai, S.K., 2016, A Novel Covalent Approach to Bioconjugate Silver Coated Single Walled Carbon Nanotubes with Antimicrobial Peptide, Journal of Nanobiotechnology. 14.

9. Nath, S.D., Abueva, C., Kim, B., Lee, B.T., 2014, ChitosanHyaluronic Acid Polyelectrolyte Complex Scaffold Crosslinked with Genipin for Controlled Release of BMP-2, Carbohydrate Polymer. 115, 160-169.

10. Nath, S.D., Son, S., Sadiasa, A., Min, Y.K., Lee, B.T., 2014, Encapsulation of Simvastatin in PLGA Microspheres Loaded into Hydrogel Loaded BCP Porous Spongy Scaffold as a Controlled Drug Delivery System for Bone Tissue Regeneration, Journal of Biomaterials Applications. 28, 1151-63.

11. Nath, S.D., Linh, N.T., Sadiasa, A., Lee, B.T., 2013, Preparation and Characterization of PLGA Microspheres by the electrospraying Method for Delivering Simvastatin for Bone Regeneration, International Journal of Pharmaceutics. 443, 87-94. 
MANUSCRIPT

IN

SUBMISSION/

PREPARATION
1. Nath, S.D., Clinnings, E.R., Gupta, G., Kelkar, R., Kearns, M., Atre, S.V., Powder Attributes in Laser-Powder Bed Fusion of 420 Stainless Steel.

2. Nath, S.D., Clinnings, E. R., Lesparance, G., Kearns, M., Atre, S. V., Effects of Atomization of the Powder in Laser-Powder Bed Fusion of 420 Stainless Steel.

3. Gal, C.W., Nath, S.D., Irrinki. H., Stanley, J., Clinning, E.R., Gupta, G., Park, S.J., Atre, S. V., Microstructure, mechanical properties and corrosion resistance of L-PBF duplex stainless steel.

4. Irrinki, H., Nath, S.D., Gulsoy, O., Ahlfors, M., Beaumier, C., Atre, S.V., Hot Isostatic Pressing of Laser-Powder Bed Fusion Processed 17-4 PH Stainless Steel to Improve Mechanical and Corrosion Properties.

5. Nath, S.D., Irrinki, H., Atre, S.V., Development of Bi-Metallic Alloys by Laser-Powder Fusion of 420 Stainless Steel Infiltrated with Bronze.

6. Singh, P., Nath, S.D., Kate, K., Atre, S.V., Mechanical Properties and Microstructure of Ti-6Al-4V Processed by Metal Fused Filament Fabrication.

PEER-

REVIEWED PROCCEDING/ MAGAZINE
1. Nath, S.D., Gupta, G., Gulsoy, O., Kearns, M., Atre, S.V., 2018, Investigation of Corrosion Behavior of 420 Stainless Steel Processed by Laser-Powder Bed Fusion, Metal Additive Manufacturing.

2. Warrier, N., Nath, S. D., Atre, S.V., Kate, K., 2018, Fused Filament Fabrication 3D Printing and Casting with Low-Melt Alloys, POWDERMET.

3. Nath, S.D., Dilip, S., Irrinki, H., Gatsche, M., Kate, K., Atre, S.V., 2017, Laser- Powder Bed Fusion of 420 Stainless Steel for Mold and Surgical Tool Applications, Additive Manufacturing with Powder Metallurgy Conference.

4. Nath, S.D., Rajan, A., Yeung, J., Atre, S.V., 2018, AM for the OR: Laser-Powder Bed Fusion Delivers Laparoscopic Instrument, Metal Forming Magazine.

5. Sadiasa, A., Jang, D.W., Nath, S.D., Seo, H.S., Yang, H.M., Lee, B.T., 2013, Addition of hydroxyapatite to toothpaste and its effect to dentin remineralization. Korean Journal of Materials Research. $23,168-176$

6. Kim, WS.S., Nath, S.D., Bae, J.S., Padalhin, A., Kim, B., Song, M.J., Min, Y.K., 2014, In Vitro and In Vivo Evaluation of Composite Scaffold of BCP, Bioglass and Gelatin for Bone Tissue Engineering, Korean Journal of Materials Research. 24, 310-318 
7. Nath. S.D., Abueva, C., Sarkar, S.K., Lee, B.T., 2014, BMP-2 Immobilized in BCP-Chitosan-Hyaluronic Acid Hybrid Scaffold for Bone Tissue Engineering, Korean Journal of Materials Research. 24, 704-709

CONFERENCE/ - Role of Powder Attributes in Laser-Powder Bed Fusion of 420 INVITED

TALK Stainless Steel, Additive Manufacturing with Powder Metallurgy, 2018, San Antonio, TX, USA.

- Investigation of Corrosion Behavior of 420 Stainless Steel Processed by Laser-Powder Bed Fusion, Additive Manufacturing with Powder Metallurgy, 2018, San Antonio, TX, USA.

- Effects of $\mathrm{Nb}$ and Mo on Mechanical Properties and Microstructure of Laser-Powder Bed Fusion 420 Stainless Steel, Metal Injection Molding Conference, 2018, Irvine, CA, USA.

- Laser- Powder Bed Fusion of 420 Stainless Steel for Mold and Surgical Tools Applications, Additive Manufacturing of Powder Metallurgy, 2017, Las Vegas, NV, USA.

- Biomimicry and Structural Analysis of Rooted Structures in Nature, Graduate Students Conference, 2015, Clemson, SC, USA.

- BMP-2 Conjugated Chitosan-Hyaluronic Acid Polymer Complex as a Controlled Delivery System for Bone Tissue Regeneration, Korean Materials Research Society Conference, 2013, Jeju, South Korea.

- In-Vivo Analysis of Bone Regeneration Using PLGA-Bioglass Scaffold, Korean Ceramic Society Conference, 2012, Kwangju, South Korea.

- Fabrication and Characterization PLGA Microspheres for Drug Delivery Applications, Asian Conference on Biomaterials, 2011, Busan, South Korea.

COLLABORATOR Prof. Gautam Gupta, University of Louisville- Corrosion properties of 3D-printed alloys

Prof. Ajay P. Malshe, University of Arkansas- Bio-inspired design using 3-D printing

Dr. Martin Kearns, Sandvik Osprey Ltd.- Materials development for powder-bed fusion

Rajendra Kelkar, GE Additive- Powder characterization for additive manufacturing 
EXPERTISE Materials Stainless Steels; Titanium; Super Alloys; Bronze;

Biopolymers; Bioceramics

Design Solid Works; NetFabb; MATLAB; Ansys; Minitab; OriginPro

Methodology 3D Printing; Casting and Molding; Heat Treatment;

Metallography; Electrochemical Corrosion; Electrospraying; In-Vitro

Characterization Universal Testing System; Hardness Test; Dynamic and Fatigue Test; SEM; AFM; XRD; FTIR; TGA \& DSC

MENTORSHIP - Supervise and mentor students group in UofL 3D Printing Business Incubator Program-

- Led two teams to design, simulate and fabricate customized surgical graspers and scissors collaborating with UofL Medical School and GE Concept Laser.

- Mentored two student teams to design and fabricate injection mold with conformal cooling channel for higher productivity collaborating with Amaray Plastics.

- Supported prototyping and simulation of automotive gears in a collaboration with Cummins Inc.

- Guided research students to use lab facilities and experimental protocols-

- Abdullah Abdulmogith, undergraduate student, physical characterization.

- Victor Papyshev, undergraduate student, digital light processing of Ecopoxy.

- Akul Rajan, undergraduate student, optical microscopy of surgical tools.

ACADEMIC 1. Undergraduate course at Department of Mechanical Engineering, EXPERIENCE University of Louisville

-ME 497: Capstone Design. (Fall and Spring 2016-17)

2. Researcher at Asiatic Society of Bangladesh -Science Volume of Junior Banglapedia. (2010-11)

3. Academic Co-Ordinator at Bangladesh Mathematical Olympiad Committee

- Regional and National Olympiads in Bangladesh (2006-10)

- National Math Camp in Bangladesh (2007-10)

REFERENCE Available upon request 